\title{
Comprehensive Report For Proposed Elevated Temperature Elastic Perfectly Plastic (EPP) Code Cases Representative Example Problems
}

Greg L. Hollinger

June 2014

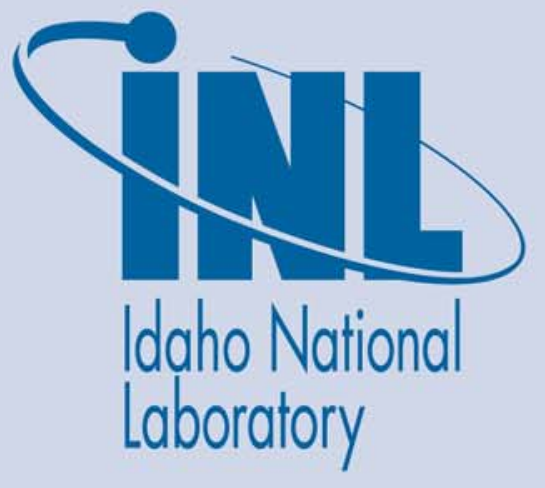

The INL is a U.S. Department of Energy National Laboratory operated by Battelle Energy Alliance 
INL/EXT-14-32908

\title{
Comprehensive ReportFor ProposedElevated Temperature Elastic Perfectly Plastic (EPP) Code Cases Representative Example Problems
}

\author{
Greg L. Hollinger
}

June 2014

\begin{abstract}
Idaho National Laboratory
Idaho Falls, Idaho 83415
\end{abstract}

http://www.inl.gov

Prepared for the

U.S. Department of Energy

Office of Nuclear Energy

Under DOE Idaho Operations Office

Contract DE-AC07-05ID14517 
Comprehensive Report

For Proposed

\section{Elevated Temperature Elastic Perfectly Plastic (EPP) Code Cases} Representative Example Problems

June 26, 2014

This Comprehensive Report is an assembly of two related documents, which -- in combination -- provide a comprehensive report on the implementation of two proposed Subsection NH Code Cases for strain limits and creepfatigue using elastic-perfectly plastic (EPP) methodology defined in the Code Cases:

Report 20362-R-001: Limited Scope Design Specification Report 20362-R-002: Design Report

The Limited Scope Design Specification provides the two proposed EPP Code Cases and description of the example problems used to demonstrate implementation of the two Code Cases. Dimensions, material properties and loads are defined in the Design Specification.

The Design Report provides the results of implementing the two proposed EPP Code Cases using the Representative Example Problems (REP-B and REP-W). The two Representative Example Problems are based on the same nozzlehead-juncture: with base metal only termed, "REP-B" and with a full-penetration butt weld, "REP-W". 
Becht Engineering Co., Inc., Nuclear Services Division

\title{
Elevated Temperature Code Case Representative Example Problem Specifications Report
}

\section{2-R-001 Rev. 3}

\author{
June 25, 2014
}

Prepared By: $\quad$ Greg L. Hollinger, PE, Senior Engineering Advisor

Derrick J. Pease, Senior Engineering Advisor

\section{Contents}

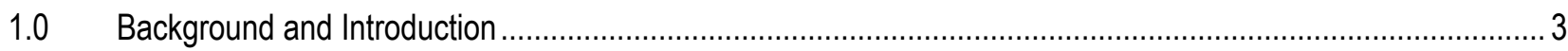

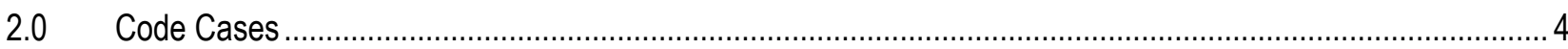

3.0 The Limited Scope Design Specification for the Representative Example Problem ..................................... 13

3.1 Component Classification and Basis for Selecting the Representative Example Problem Geometry...... 13

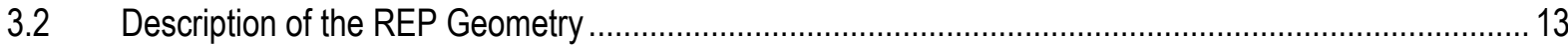

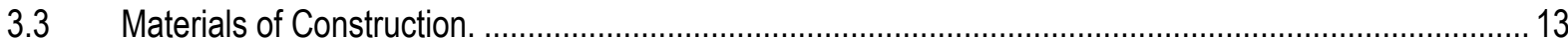

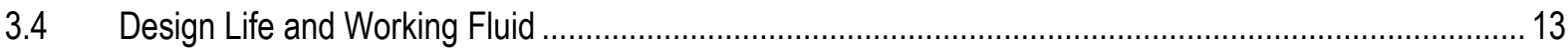

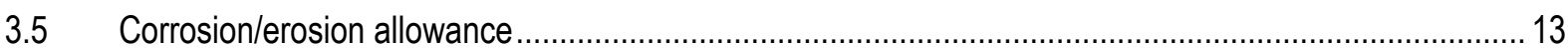

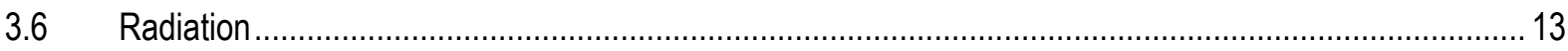

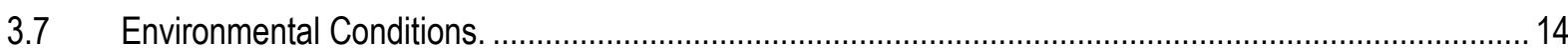

The exterior of the component is insulated such that heat transfer to ambient $70^{\circ} \mathrm{F}$ atmosphere is negligible..... 14

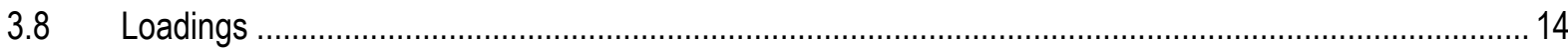

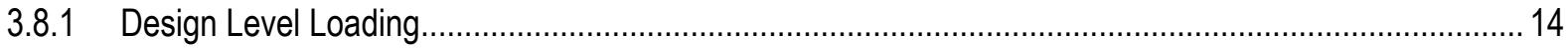

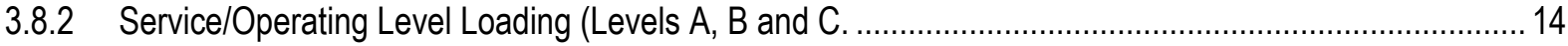

Table 3.1 - Time Periods for Level A, B and C Load Combinations ............................................................... 16

Table 3.2 - Loading Parameters Average Ramp Rates for Level A, B and C Load Combinations ..................... 17

Table 3.6a- Level C Loading Parameters Versus Time (SSE initiating loads) .................................................. 21

Figure 3.1 - Representative Example Problem (REP) Geometry Sketch ................................................... 23

Figure 3.2 - Service Level A Loads and Load Combinations; loadings versus time ......................................... 24

Figure 3.3 - Service Level B Loads and Load Combinations; loadings versus time ......................................... 25

Figure 3.4 - Service Level C Loads and Load Combinations; loadings versus time........................................... 26

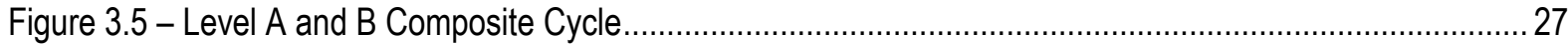




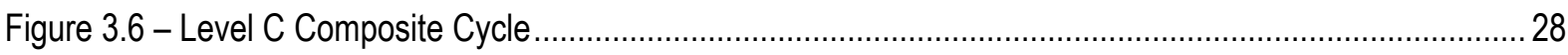

4.0 Suggested ABAQUS Finite Element Model and Material Properties ......................................................2 29

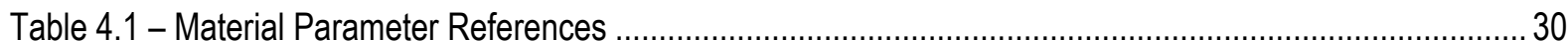

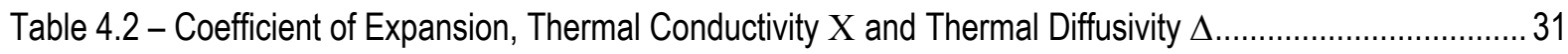

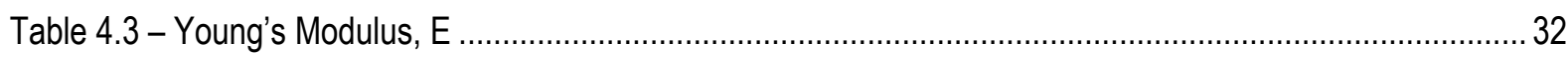

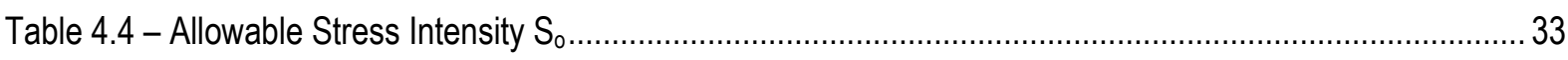

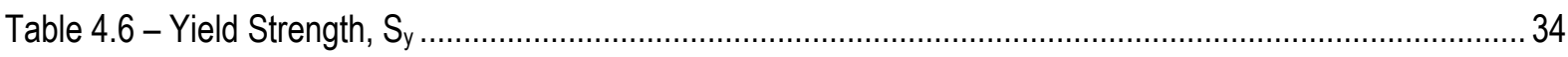

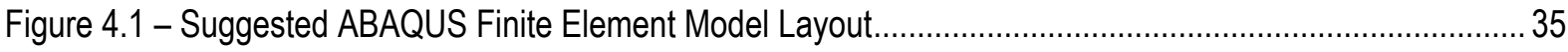

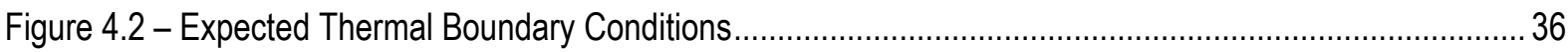

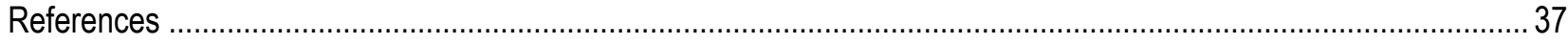

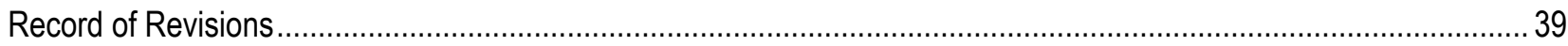

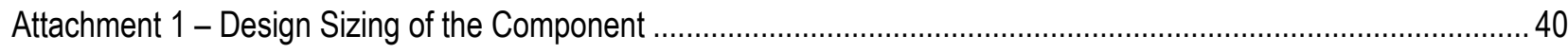


This report is a "limited scope design specification" for the Representative Example Problem (REP).

1. The Scope of Work is summarized as follows.

a. Define the model, loadings and methodology for the Representative Example problem (REP).

b. Use a nozzle-sphere intersection rather than the Section III Appendix A-6230 [Ref. 3] hemispherical head, cylinder, flat plate assembly.

c. The nozzle-sphere intersection is in accordance with the construction specified in Fig. NB-3338-2(a)-2 and Fig. NB-4244(a)-1.

d. Loadings are internal pressure, thermal time-dependent loads for Level $A, B$ and Level $C$ which are used to create the required composite load combination required by the Code Cases. Deadweight is ignored as negligible and seismic loading (static) is included as an initiating short-term load for the Level $C$ load.

e. Axial, bending and torsional piping reaction nozzle loads are specified (Design, Level A, B, C).

2. Section 2 provides the latest proposed Strain Limit Code Case [Ref. 4] and Creep-Fatigue Code Case [Ref. 5].

3. Section 3 describes the Representative Example Problem (REP), including geometry, loading, general conditions to the extent necessary to provide the basis for creating the analytical model of the REP.

4. Section 4 provides a suggested layout of the finite element model and other related suggestions.

5. Attachment 1 provides the "design sizing" of the REP using pressure and mechanical loads at conservatively defined times and temperatures at those times. 
The latest proposed Strain Limit Code Case [Ref. 4] and Creep-Fatigue Code Case [Ref. 5] are shown below. These are the Code Cases as written at the time of this report. They have changed as the project has proceeded, and they may continue to change based on further in-progress results of the use of the Code Cases.

$(4 / 14 / 2014)$

\section{Code Case XXXX. Satisfaction of Strain limits for Class 1 Components at Elevated Temperature Service Using Elastic-Perfectly Plastic Analysis.}

Inquiry: What alternative rules may be used for the evaluation of strain limits in compliance with $\mathrm{NH}-3252$ and Subsection NH, Appendix T.

Response: Strain limits may be evaluated using elastic-perfectly plastic material models instead of the procedures of $\mathrm{NH}-\mathrm{T}-1320, \mathrm{NH}-\mathrm{T}-1330$ and NH-T-1713 when performed in accordance with the requirements of this Code Case.

\section{General Requirements}

Except as identified herein, all requirements of Section III, Subsection NH and applicable Code Cases apply to components designed in accordance with this Code Case.

The design methodology employed for evaluation of strain limits is based on rapid cycle ratcheting analyses using a small strain theory elastic-perfectly plastic material model where the yield stress is adjusted based on a pseudo yield stress selected to bound accumulated inelastic strain. Guidance on ratcheting analysis is provided in Appendix 1. In this code case the term "pseudo yield stress" refers to a temperature dependent isochronous stress based on the total time duration of high temperature service and a target inelastic strain, not to exceed the yield strength of the material at temperature and is explicitly defined in paragraph 4.2 .

\section{Load Definition.}

Define all applicable loads and load cases per NH-3113.2 Service Loadings.

\subsection{Composite Cycle Definition.}

For the purpose of performing an elastic-perfectly plastic ratcheting analysis an overall cycle must be defined which includes all relevant features from the individual Level A, B and C Service Loadings identified in the Design Specification. Relevant features include as a minimum the time dependent sequence of thermal, mechanical and pressure loading including starting and ending conditions. Such an overall cycle is defined herein as a composite cycle subject to the following requirements.

2.1.1. An individual cycle as defined in the Design Specifications cannot be further subdivided into individual cycles to satisfy these requirements.

2.1.2. Except as described in paragraph 2.1.3, below, a single cycle from each Level A, B and C Service Loading cycle type shall be included in the composite cycle for evaluation of strain limits.

2.1.3. Level C Service Loadings may be combined with the applicable Level A and B Service Loadings to define an additional composite cycle(s) to be evaluated separately from the composite cycle defined in paragraph 2.1.2. Multiple composite cycles that include Level C Service Loadings may be defined for separate evaluation. The total number of Level C Service Loading cycles shall not exceed 25.

\section{Numerical Model.}


Develop a numerical model of the component including all relevant geometry characteristics. The model used for the analysis shall be selected to accurately represent the component geometry, boundary conditions, and applied loads. The model must also be accurate for small details, such as small holes, fillets, corner radii, and other stress risers. The local temperature history shall be determined from a thermal transient analysis based on the thermal boundary conditions determined from the loading conditions defined in paragraph 2.

\section{Requirements for satisfaction of strain limits}

Perform a ratcheting analysis for each of the composite cyclic histories defined in paragraph 2.1. Each of these cyclic histories must be shown to be free from ratcheting based on the pseudo yield stress $S_{x T}$ as defined in paragraph 4.2. In the following steps, inelastic strain for a particular stress, time and temperature is obtained by subtracting the elastic strain from the total strain as given by the isochronous stress strain curve at the same stress, time and temperature. Additional requirements for weldments are shown in paragraph 5.

\subsection{Step 1: Define $t_{\text {design }}$ as the total time duration of high temperature service for all Level $A, B$, and $C$ Service} Loadings when the temperature is above the range covered by Tables $2 A, 2 B$, and 4 of Section II, Part $D$.

4.2. Step 2: Select a target inelastic strain, $x$, where $0<x<\varepsilon_{\text {avg }}$ and $\varepsilon_{\text {avg }}$ is equal to 0.01 for base metal or 0.005 for weldments. Define a pseudo yield stress $S_{x T}$ at each location, using the temperature determined from the transient thermal analysis. This pseudo yield stress is equal to the lesser of the quantities defined below in 4.2.1. and 4.2.2.

4.2.1. The yield strength $S_{y}$ given in Table I-14.5 of Subsection NH as modified by Subarticle NH-2160; 4.2.2. The stress to cause $x$ inelastic strain in time $t_{\text {design, }}$, as determined from the isochronous stress strain curves in Figure T1800 in Appendix T of Subsection NH.

4.3. Step 3: Perform a cyclic elastic-perfectly plastic analysis for each composite cycle defined in paragraph 2.1 .2 above with temperature-dependent pseudo yield stress $S_{x T}$. If ratcheting does not occur, obtain the plastic strain distribution throughout the component. The plastic strain, $\varepsilon_{p}$, is evaluated according to

$$
\varepsilon_{p}=\sqrt{\frac{2}{3}\left[\left(\varepsilon_{x}^{p}\right)^{2}+\left(\varepsilon_{y}^{p}\right)^{2}+\left(\varepsilon_{z}^{p}\right)^{2}+2\left(\varepsilon_{x y}^{p}\right)^{2}+2\left(\varepsilon_{y z}^{p}\right)^{2}+2\left(\varepsilon_{z x}^{p}\right)^{2}\right]}
$$

where the plastic strain components, $\varepsilon_{x}^{p}, \varepsilon_{y}^{p}, \varepsilon_{z}^{p}, \varepsilon_{x y}^{p}, \varepsilon_{y z}^{p}$ and $\varepsilon_{z x}^{p}$, are those accumulated at the end of the composite cycle.

4.4. Step 4. Assess acceptability in accordance with 4.4.1. and 4.4.2. below by using the plastic strains, $\varepsilon_{p}$, from Step 3. If the requirements of both 4.4.1. and 4.4.2. are satisfied, then the strain limits of NH-T-1310 for base metal and NHT-1713 for weldments are also considered satisfied. This condition is illustrated in Figure 1(a).

4.4.1. The requirement, $x+\varepsilon_{p} \leq \varepsilon_{\text {avg }}$, must be satisfied at least at one point for all through-thickness locations. As defined in Step 2, $\varepsilon_{\text {avg }}$ is equal to 0.01 for base metal or 0.005 for weldments. Failure of this requirement is illustrated in Figure 1(b).

4.4.2. The requirement, $x+\varepsilon_{p} \leq \varepsilon_{\text {local }}$, must be satisfied at all points. The local strain limit, $\varepsilon_{\text {local }}$, is equal to 0.05 for base metal and 0.025 for weldments. Failure of this requirement is illustrated in Figure 1 (c).

4.4.3. In order to proceed if either of the requirements of 4.4.1. or 4.4.2. are not satisfied, return to Step 2 and select a smaller value of the target inelastic strain, $x$. If it is not possible to find a value of $x$ that does not ratchet and also 
satisfies the requirements of Step 4, then the loading conditions of paragraph 2 applied to the component configuration defined in paragraph 3 do not met the requirements of this code case.
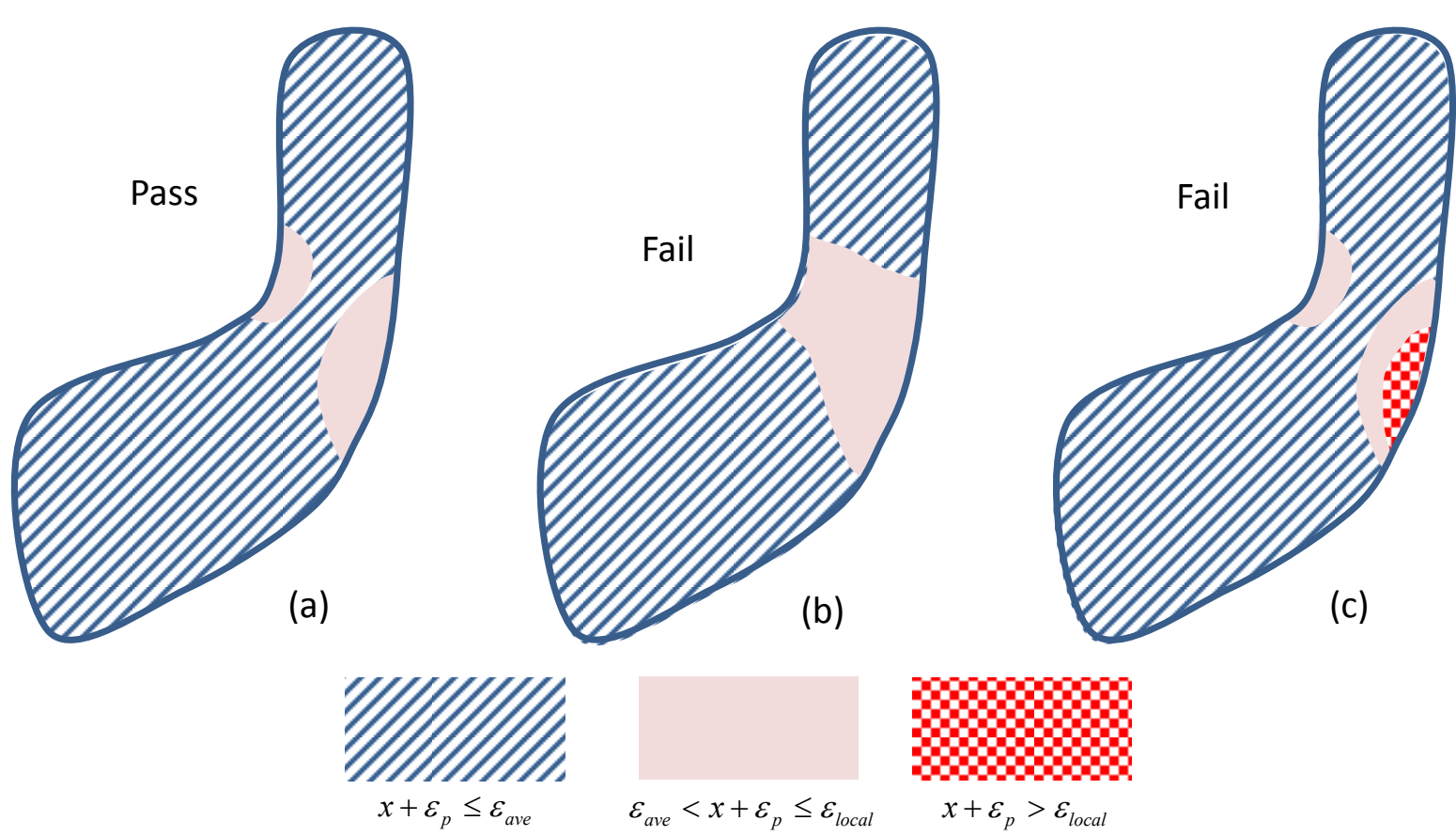

Figure 1. Strain limits Pass/Fail criteria illustrated

\section{Weldments}

Implementation of the strain limits for weldments defined above in paragraph 4 requires additional consideration.

\subsection{Weld region model boundaries}

The weld shown in Figure 2 represents a general full-penetration butt weld in a shell. Other weld configurations are needed for construction of an elevated temperature component in accordance with subsection $\mathrm{NH}$. Subsection $\mathrm{NH}$ 4200 refers to various Subsection NB-4000 paragraphs for weld configurations and requirements. These Subsection NB weld configurations are represented by the shaded region.

Figure 2 shows a full-penetration butt weld as an example. As shown, $w_{1}$ and $w_{2}$, as needed to define the weld region for use of this Case, are approximations consistent with the specified weld configuration and parameters. The specified weld region must include applicable stress concentrations in accordance with the requirements for analysis of geometry of subparagraph NH-T-1714. 


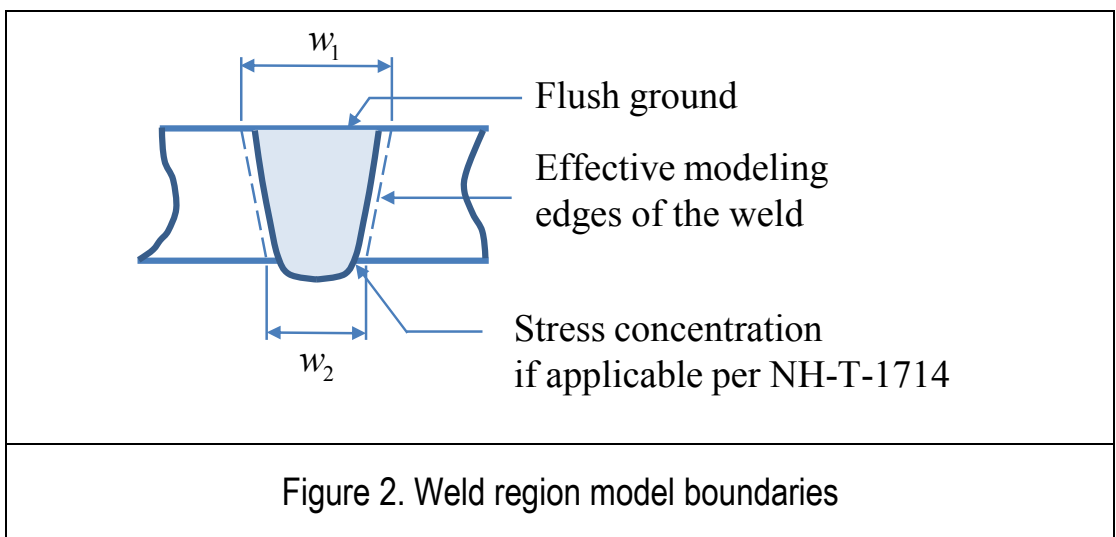

5.2. The requirements for analysis of geometry of subparagraph NH-T-1714 of Subsection NH are applicable for satisfaction of the requirements of this Code Case.

5.3. The thermal/physical properties of weldments may be assumed to be the same as the corresponding base metal for the base metal - weld combinations listed in Table NH-I-14.10.

\subsection{Dissimilar metal welds}

5.4.1. Requirements for dissimilar metal welds are in the course of preparation.

\section{APPENDIX 1 - RATCHETING ANALYSIS}

The steps to perform a ratcheting analysis to demonstrate compliance with strain limits are as follows:

i) Define Composite Cycle Load Time-Histories \& Step(s):

a. It may consist of histories of mechanical loads, pressure loads, displacements, temperatures and thermal boundary conditions.

b. Time-independent parts of the cycle may be truncated.

c. The cycle should not have discontinuities. Discontinuities arising from the selection of the specified cycles to form a composite cycle should be eliminated by a simple and reasonable transition from one state to the next.

d. Subject to the requirements in (ii), the composite cycle time does not affect the result of the ratcheting analysis.

e. Temperatures, thermal boundary conditions, boundary displacements and mechanical loads over a cycle should be cyclic; that is, begin and end at the same value.

f. A single analysis step may represent one cycle. Dividing a single cycle into more than one step to facilitate definition of the load cycle, and to ensure that maximum loads are analyzed, is often helpful.

ii) Define Analysis Types:

a. A sequentially coupled thermal-mechanical analysis of the composite cycle may be performed. First a thermal analysis is performed to generate temperature histories. Next the mechanical analyses are performed using these temperature histories as inputs. Care must be taken that times in the mechanical analysis step and in the previous thermal analysis are the same or do not conflict, depending on the requirements of the analysis software. 
b. Alternatively, a coupled thermal-mechanical analysis may be performed. The composite temperature history to be used in the mechanical analysis should be cyclic, that is the beginning and end temperature distributions should be the same.

iii) Define Material Properties:

a. For the thermal analyses, density, and temperature-dependent specific heat and conductivity will in general be required.

b. For the mechanical analyses the temperature-dependent properties required are modulus, Poisson's ratio and mean expansion coefficient. Density may also be required.

c. In addition the mechanical analyses temperature-dependent yield stress will need to be adjusted based on the selected pseudo yield stress $S_{x T}$ defined in paragraph 4.2.

iv) Perform Analyses:

a. Perform an elastic-perfectly plastic cyclic mechanical and thermal stress analysis using the temperaturedependent pseudo yield property defined above. Enough cycles are required to demonstrate ratcheting or the absence of ratcheting.

b. Care must be taken to ensure that the analysis deals with all the changes within a cycle. Elastic-plastic routines increase increment size where possible, and may miss a detail in the loading. A conservative limit to maximum increment size can address this problem, or division of the cycle into more than one step as in paragraph (i)(f) of this appendix.

v) Detect Ratcheting:

a. Ratcheting is defined as repeated non-cyclic deflections, that is between the beginning and end of a cycle, a repeated finite displacement change occurs somewhere in the structure.

b. Detecting ratcheting is most easily done by plotting nodal deflections over time. Cyclic (repeated) behavior indicates non-ratcheting. History plots of equivalent plastic strains will also identify ratcheting.

Rev 7, 04/15/2014

Code Case XXXXXXXXXX

Calculation of Creep-Fatigue for Class 1 Components at Elevated Temperature Service Using ElasticPerfectly Plastic Analysis.

Inquiry: What alternative rules may be used for the calculation of creep-fatigue damage in compliance with NH-3252 and Appendix T.

Response: Fatigue and cyclic creep damage may be evaluated using elastic-perfectly plastic material models instead of the procedures of T-1420, T-1430 and T-1715 when performed in accordance with the requirements of this Code Case.

\section{General Requirements}

Except as identified herein, all requirements of Section III, Subsection NH and applicable Code Cases apply to components designed in accordance with this Code Case.

The design methodology employed for evaluation of cyclic creep damage is based on rapid cycle elastic shakedown analyses using an elastic-perfectly plastic material model, small strain theory and a "pseudo" yield strength selected to bound creep damage. In this Code Case, "shakedown" refers to the achievement 
of cyclic elastic behavior throughout the part, based on real or pseudo yield properties. In this code case the term "pseudo yield stress" refers to a temperature dependent minimum stress-to-rutpure value based on a selected trial time duration, not to exceed the yield strength of the material at temperature and is explicitly defined in paragraph 4.2. Guidance on shakedown analysis is provided in Appendix 1. The combination of Levels A, B, and C Service loadings shall be evaluated for accumulated creep and fatigue damage, including hold time and strain rate effects. For a design to be acceptable, the creep and fatigue damage at each point in the component shall satisfy the following relation:

$$
D_{c}+D_{f} \leq D
$$

where

$D=$ total creep-fatigue damage as limited by FIG. T-1420-2 in Subsection NH.

$D_{c}=$ cyclic creep damage as determined in paragraph 4, below, of this Code Case

\section{Load Definition}

$D_{f}=$ fatigue damage as determined paragraph 5, below, of this Code Case

Define all applicable loads and load cases per NH-3113.2 Service Loadings

2.1. Composite Cycle Definition

For the purpose of performing an elastic perfectly plastic shakedown analysis, an overall cycle must be defined which includes all relevant features from the individual Level A, B and C Service Loadings identified in the Design Specification. Relevant features include as a minimum the time dependent sequence of thermal, mechanical and pressure loading including starting and ending conditions. Such an overall cycle is defined herein as a composite cycle subject to the following requirements.

2.1.1. An individual cycle as defined in the Design Specifications cannot be split into individual cycles to satisfy these requirements.

2.1.2. Except as described in 2.1.3., below, a single cycle from each Level A, B and C Service Loading cycle type shall be included in the composite cycle for evaluation of creep-fatigue.

2.1.3. Level C Service Loadings may be combined with the applicable Level A and B Service Loadings to define a composite cycle(s) to be evaluated separately from the cycle defined in 2.1.2. Multiple composite cycles that include Level C Service Loadings may be defined for separate evaluation. The total number of Level C Service Loading cycles shall not exceed 25.

\section{Numerical Model}

Develop a numerical model of the component including all relevant geometry characteristics. The model used for the analysis shall be selected to accurately represent the component geometry, boundary conditions, and applied loads. The model must also be accurate for small details, such as small holes, fillets, corner radii, and other stress risers. The local temperature history shall be determined from a thermal transient analysis based on the thermal boundary conditions determined from the loading conditions defined in 1.1 above.

\section{Calculation of Cyclic Creep Damage}

Perform a shakedown analysis for each of the composite cyclic histories defined in paragraph 2.1. Each of these cyclic histories must be shown to shakedown based on the pseudo yield stress defined in paragraph 4.2. Additional requirements for welds are found in paragraph 6.

4.1. Step 1: Define $t_{d e s i g n}$ as the total time duration for all Level A, B, and C Service Loadings when the temperature is above the range covered by Tables 2A, 2B, and 4 of Section II, Part D.

4.2. Step 2: Select a trial time duration, $T_{d}^{\prime}$ in order to define a pseudo yield stress, $S_{c t 1}$, at each location, using the temperature determined from the transient thermal analysis. This pseudo yield stress is equal to the lesser of the quantities defined below in 4.2.1. and 4.2.2. 


\subsubsection{The yield strength $S_{y}$ given in Table I-14.5 of Subsection NH as modified by Subarticle NH-2160; 4.2.2. $S_{t+1}$,} where $S_{t 1}$ is the minimum stress to rupture in time $T_{d}$ ' from Figs. I-14.6 of Subsection NH multiplied by the factor, $K$ ', from Table T-1411-1 of Subsection NH using the tabulated values for Elastic Analysis.

4.3. Step3: Perform a cyclic elastic-plastic analysis for each composite cycle defined in paragraph 2 above with temperature-dependent pseudo yield stress $S_{c t l}$. The assessment temperature shall be taken as the local instantaneous temperature at every location in the numerical model of the component. If shakedown occurs, that is, cycles with eventual elastic behavior everywhere, proceed to Step 4.

4.4. Step 4: Determine the maximum cyclic creep damage value applicable to every location in the numerical model from the expression:

$$
D_{c}=\left(t_{\text {design }}\right) /\left(T_{d}{ }^{\prime}\right)
$$

The above value of $D_{c}$ is used to evaluate total damage in $\mathrm{Eq}(1)$.

4.4.1. Steps 2, 3 and 4 may be repeated to revise the value of $D_{c}$ by selecting alternative values of the trial time duration, $T_{d}$ '. Longer values of $T_{d}$ ' will reduce the calculated creep damage. However, these longer values will lead to lower values of the pseudo yield stress, $S_{c t 1}$, which will make shakedown more difficult.

\section{Calculation of Fatigue Damage}

The fatigue damage summation, $D_{f}$, in Equation 1 is determined in accordance with Steps 1 through 3 below. Additional requirements for welds are found in paragraph 6 .

5.1. Step 1: Determine all the total, elastic plus plastic, strain components for the composite cycle at each point of interest from the shakedown analysis performed in Step 3 of paragraph 4 above.

5.2. Step 2: Calculating the equivalent strain range in accordance with NH-T-1413, or NH-T-1414 when applicable, of Subsection NH with Poisson's ratio $v^{*}=0.3$.

5.3. Step 3; Determine the fatigue damage for each composite cycle from the expression:

where

$$
D_{f}=\Sigma\left(n / N_{d}\right)_{j}
$$

$(n)_{j}=$ number of applied repetitions of cycle type, $j$

$\left(N_{d}\right)_{j}=$ number of design allowable cycles for cycle type, $j$, determined from one of the design

fatigue curves (Figs. T-1420-1 of Subsection NH) corresponding to the maximum metal temperature occurring during the cycle.

The value of $D_{f}$ used to evaluate total damage in Eq (1) is the maximum value at any location in the numerical model.

\section{Weldments}

Implementation of the evaluation of creep-fatigue damage in paragraphs 4 and 5 above for weldments requires additional consideration.

6.1. In the weld region, the pseudo yield strength value defined by $T_{d}$ ' in 4.2.2. is reduced further by multiplying the value of $S_{r t l}$ for the base metal by the applicable weld strength reduction factor from Table NH-I-14.10.

6.2. The number of allowable cycles, $\left(N_{d}\right)_{j}$, in the weld region is one half the number of allowable cycles from Figs. T-1420-1 for base materials.

6.3. The requirements for analysis of geometry of subparagraph T-1714 of Subsection NH are applicable for satisfaction of the requirements of this Code Case.

6.4. The thermal/physical properties of weldments may be assumed to be the same as the corresponding base metal for the base metal - weld combinations listed in Table NH-I-14.10.

6.5. Weld region model boundaries

The weld shown in Figure 1 represents a general full-penetration butt weld in a shell. Other weld configurations are needed for construction of an elevated temperature component in accordance with subsection NH. Subsection NH-4200 refers to various Subsection NB-4000 paragraphs for weld 
configurations and requirements. These Subsection NB weld configurations are represented by the shaded region.

Figure 1 shows a full-penetration butt weld as an example. As shown, w1 and w2, as needed to define the weld region for use of this Case, are approximations consistent with the specified weld configuration and parameters. The specified weld region must include applicable stress concentrations in accordance with the requirements for analysis of geometry of subparagraph T-1714.

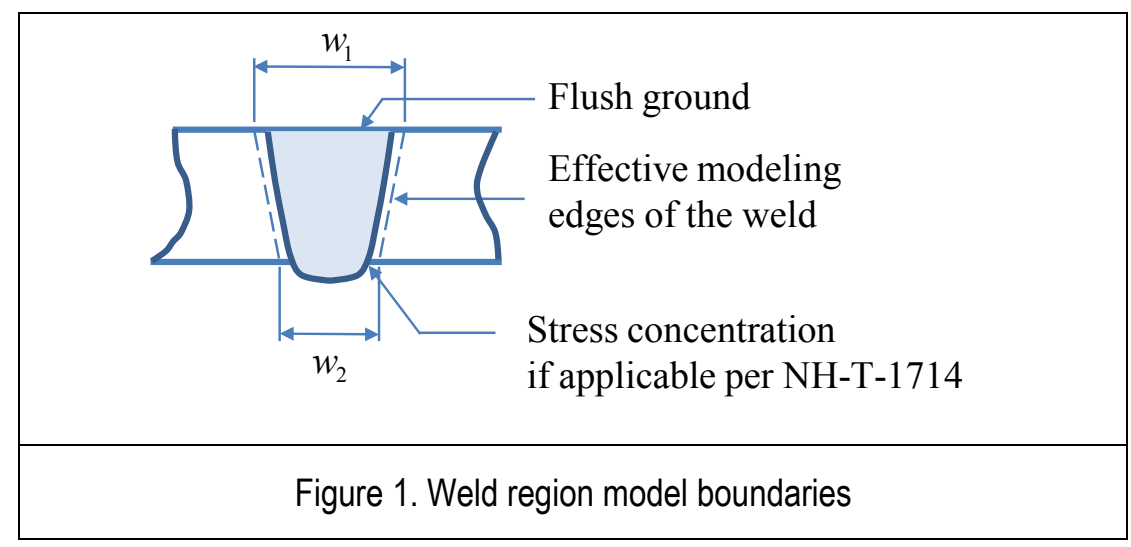

6.5. Dissimilar metal welds

6.5.1. The requirements for dissimilar metal welds are in the course of preparation.

\section{Appendix 1. Shakedown Analysis.}

The steps to perform a shakedown analysis to calculated bounding cyclic creep damage are as follows:

vi) Define the load cycle to be considered.

a. It may consist of histories of mechanical loads, pressure loads, displacements, temperatures and thermal boundary conditions.

b. Time-independent parts of the cycle may be truncated.

c. The cycle should not have discontinuities. Discontinuities arising from the selection of the specified cycles to form a composite cycle should be eliminated by a simple and reasonable transition from one state to the next.

d. The composite cycle time does not affect the result of the shakedown analysis.

e. The loading and boundary conditions must be cyclic, that is all values at the beginning and at the end of the cycle must be identical.

vii) Define analysis types

a. A thermal analysis of the composite cycle may be performed to generate temperature histories for use in the mechanical analysis. Care must be taken that times in the mechanical analysis step and in the previous thermal analysis are the same or do not conflict, depending on the requirements of the analysis software.

b. Alternatively, a coupled thermal-mechanical analysis may be performed. For the thermal analyses, density, and temperature-dependent specific heat and conductivity will in general be required.

viii) Define material properties 
a. For thermal analyses, density, temperature- dependent specific heat and conductivity will generally be required.

b. For the mechanical analyses the temperature-dependent properties required are modulus, Poisson's ratio and mean expansion coefficient. Density may also be required.

ix) Perform analyses

a. Perform an elastic-plastic cyclic mechanical and thermal stress analysis using the temperature-dependent yield property defined above. Enough cycles are required to demonstrate shakedown or otherwise.

b. Care must be taken to ensure that the analysis deals with all the changes within a cycle. Elastic-plastic routines increase increment size where possible, and may miss a detail in the loading. A conservative limit to maximum increment size can address this problem, or division of the cycle into more than one step as in vi).

x) Shakedown

a. Shakedown is defined in this Code Case as eventual elastic behavior everywhere in the model.

b. Failure to shakedown may be identified by plotting histories plots of equivalent plastic strain.

\section{END OF PROPOSED CODE CASES}


This Section is a "Limited Scope Design Specification" for the REP. The term "Limited Scope" means that only the items necessary to perform the evaluation of the component are included, and not the fabrication, inspection, test and administrative requirements which are not necessary for this scope of work. In that regard, the following items are stated to be the basis for analysis of this REP using the two proposed Code Cases [Ref. 4] and [Ref. 5].

\subsection{Component Classification and Basis for Selecting the Representative Example Problem Geometry}

The Representative Example Problem (REP) is chosen to represent one typical portion of a nuclear, hightemperature Section III, Division 1, Class 1 vessel - a radial nozzle in a spherical head. NOTE: The REP was initially suggested to be the head-shell-flat head geometry in A-6230 of Appendix A [Ref. 3].

\subsection{Description of the REP Geometry}

The REP Geometry and associated dimensions are shown in Figure 3.1. The geometry is part of an elevated temperature pressure vessel consisting of a hemispherical head and an attached nozzle using Figure NB3338-2(a)-2 Sketch (c) and NB-4244(a)-1 Sketch (b) and (d) [Ref. 16]. The dimensions of the head and nozzle cylinder are set to meet the design pressure and design temperature, operating pressures and temperatures and the corresponding mechanical pipe loadings on the nozzle. The transition reinforcement region is set to meet the reinforcement requirements of NB-3330. The nozzle and head are attached by a full-penetration butt weld at the required distance (1.5t) from the transition reinforcement region as shown in Figure NB-4244(a)-1 Sketch (b).

\subsection{Materials of Construction.}

The materials of construction are 316 forged stainless steel for both the spherical head and nozzle. The weld material for the weld between the nozzle forging and the spherical head is as shown below.

a. Material Specifications: Table NH-I-14.1(a): SA-182, F316 (forgings for nozzle and head, $\mathrm{S}_{\mathrm{u}} 70 \mathrm{ksi}$ )

b. Welding Specifications: Table NH-I-14.1(b): SFA-5.4 E316

c. Weld profile: full-penetration butt weld per code case with $w_{1}=4$ in and $w_{2}=1.5 \mathrm{in}$.

3.4 Design Life and Working Fluid

d. The Design Life is $100,000 \mathrm{hr}$ for Levels A, B and C.

e. The working fluid is inert gas with thermal conditions specified by fluid temperature and heat transfer (film) coefficients specified herein.

3.5 Corrosion/erosion allowance

No Corrosion/erosion allowance is applicable.

3.6 Radiation 
The component is not exposed to radiation.

3.7 Environmental Conditions.

The exterior of the component is insulated such that heat transfer to ambient $70^{\circ} \mathrm{F}$ atmosphere is negligible.

3.8 Loadings

a. The loadings for the REP include Design and Level A, B and C Service/Operating loads.

b. No Level $D$ loads are specified.

c. No Test Loads are specified.

\subsubsection{Design Level Loading}

a. Internal Pressure; Design Conditions; $P_{\text {int.des }}=700$ psig at $T_{\text {.des }}=1,200^{\circ} \mathrm{F}$

b. Mechanical Loads Design Condition; piping reaction loads on the end of the nozzle

i. Axial Load; $F_{\text {des }}=30,000 \mathrm{lb}$ (tension)

ii. Shear Force, $V_{. x . d e s}=4,000 \mathrm{lb}$

iii. Bending moment; $M_{z \text {.des }}=53,500 \mathrm{lb}$-in $(4,458 \mathrm{ft}-\mathrm{lb})$ due to the shear force induced moment developed at the mid-thickness of the shell.

iv. Torsional moment; $\mathrm{M}_{\mathrm{Y} \text {.des }}=20,000 \mathrm{lb}$-in

c. Thermal Loads $(\Pi)$; isothermal at $1,200^{\circ} \mathrm{F}$

\subsubsection{Service/Operating Level Loading (Levels A, B and C.}

a. Internal Pressure (Levels $A, B$ and $C$ )

v. Level A Conditions; $P_{\text {int.Lev.A }}=675$ psig (maximum); see Fig. 3.2

vi. Level $B$ Conditions; $P_{\text {int.Lev. } B}=750$ psig (maximum); see Fig. 3.3

vii. Level $C$ Conditions $P_{\text {int.Lev. }}=775$ psig (maximum); see Fig. 3.4

b. Mechanical Loads (Levels A, B and C); piping reaction loads, "FVMT" on the end of the nozzle; Axial loads are labeled $F(t)$; bending moment is labeled $M_{Z}(t)$; torsional moment is labeled "T" or $M_{Y}(t)$. Maximum Level B loads are $125 \%$ of the Design Loads and Maximum Level $C$ loads are $200 \%$ of the Design Loads in accordance with Figures 3.2, 3.3 and 3.4. The values are summarized below. 


\begin{tabular}{cccccc}
\hline & & Nozzle Axial & Nozzle Shear & Nozzle Bending & Nozzle Torsion \\
\hline & $\%$ & $F_{Y}(\mathrm{lb})$ & $V_{X}(\mathrm{lb})$ & $M_{z}(\mathrm{lb}$-in $)$ & $M_{Y}(\mathrm{lb}$-in) \\
\hline Design (100 \%) & 100 & 30000 & 4000 & 53500 & 20000 \\
\hline Level A max & 100 & 30000 & 4000 & 53500 & 20000 \\
\hline Level A min & 0 & 0 & 0 & 0 & 0 \\
\hline Level B max & 125 & 37500 & 5000 & 66875 & 25000 \\
\hline Level B min & 100 & 30000 & 4000 & 53500 & 20000 \\
\hline Level C max & 200 & 60000 & 8000 & 107000 & 40000 \\
\hline Level C min & -150 & -45000 & -6000 & -80250 & -30000 \\
\hline Max & & 60000 & 8000 & 107000 & 40000 \\
\hline Min & & -45000 & -6000 & -80250 & -30000 \\
\hline
\end{tabular}

$* * \mathrm{M}_{\mathrm{Z}}=\mathrm{V}_{\mathrm{X}}\left(\mathrm{d}_{\mathrm{Y}}+\mathrm{t}_{\text {shell }} / 2\right)$

c. Thermal Loads ( $\Pi$, Levels $A, B$ and $C)$

i. Level A Conditions; see Fig. 3.2

ii. Level B Conditions; see Fig. 3.3

iii. Level C Conditions; see Fig. 3.4

3.8.3 Load Combinations (Levels A, B and C)

$\Pi_{(t)}$ : signifies working fluid conditions (Temperature, $T$ and film coefficient, $h$ ) on the inside surfaces. Thermal boundary conditions are shown in Fig. 3.5. M: signifies the mechanical (pipe reaction loads on the nozzle) $P$.int: signifies internal pressure

Four load combinations are specified:

1. Design Level: $P_{\text {int.des }}+M_{\text {.des }}$ at design temperature, $T_{. D}$ isothermal conditions

2. Service Level $A$ : $P_{\text {int.Lev. } A(t)}+M_{\text {.Lev. } A(t)}+\prod_{(t) L e v e l}$; ; see Figure 3.2

3. Service Level B: $P_{\text {int.Lev. } B(t)}+M_{\text {Lev. } B(t)}+\prod_{(t) L e v e l ~}$; see Figure 3.3

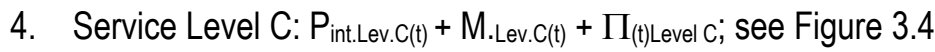

\subsubsection{Composite Cycles for Code Case Evaluation}

The Code Cases [Ref. 4], [Ref. 5] require development of a Level A, B and C Composite Cycle. The requirements for the Composite Cycle are described in Section 1.2 of the Strain Code Case and in Section 2.1 of the Creep-Fatigue Code Case. However, the PVP papers [Ref. 12] and [Ref. 13] explain that it is useful, if not necessary, to create a separate Level $C$ composite cycle. This work defines a separate Level $C$ Composite Cycle. The Level A and B and Level C Composite Cycles are specified as follows.

\subsubsection{Level A and B Composite Cycle; see Figure 3.5}




\subsubsection{Level C composite Cycle; see Figure 3.6}

Table 3.1 - Time Periods for Level A, B and C Load Combinations

\begin{tabular}{|c|c|c|c|c|c|}
\hline Time Period & $\operatorname{Tim}(\min )$ & No. cycles & total time (min) & total time (hr) & total time (sec) \\
\hline$t_{\text {A.up }}$ & 3,000 & 90 & 270,000 & 4,500 & $16,200,000$ \\
\hline$t_{\text {A.SS }}$ & 24,000 & 90 & $2,160,000$ & 36,000 & $129,600,000$ \\
\hline t.A.down & 4,500 & 90 & 405,000 & 6,750 & $24,300,000$ \\
\hline t.B.up & 20 & 782 & 15,640 & 261 & 938,400 \\
\hline$t_{\text {B.down }}$ & 540 & 782 & 422,280 & 7,038 & $25,336,800$ \\
\hline$t_{\text {B.HS }}$ & 1,440 & 782 & $1,126,080$ & 18,768 & $67,564,800$ \\
\hline$t_{\text {. B.recover }}$ & 2,040 & 782 & $1,595,280$ & 26,588 & $95,716,800$ \\
\hline$t_{\text {.C.SSE.up }}$ & 1 & 25 & 25 & 0.417 & 1,500 \\
\hline t.C.SSE.down & 1 & 25 & 25 & 0.417 & 1,500 \\
\hline t.c.sse.recover $r$ & 1 & 25 & 25 & 0.417 & 1,500 \\
\hline t.c.up & 25 & 25 & 625 & 10.417 & 37,500 \\
\hline t.c.down & 150 & 25 & 3,750 & 62.500 & 225,000 \\
\hline$t_{\text {c.recover }}$ & 60 & 25 & 1,500 & 25 & 90,000 \\
\hline TOTAL & & & $6,000,230$ & 100,004 ** & $360,013,800$ \\
\hline
\end{tabular}

** Design Life set to $100,000 \mathrm{hr}$. 
Table 3.2 - Loading Parameters Average Ramp Rates for Level A, B and C Load Combinations

\begin{tabular}{|c|c|c|c|c|c|c|c|}
\hline Ramp Rates & time (sec) & time (sec) & time (sec) & parameter & parameter & parameter & ramp rate \\
\hline Ramp Designation & initial & duration (above) & final (calc) & initial & delta (calc) & final & per hr \\
\hline A.T.up & 0 & 180000 & 180000 & 70 & 1030 & 1100 & 20.600 \\
\hline At.sS & 180000 & 1440000 & 1620000 & 1100 & 0 & 1100 & 0.000 \\
\hline A.T.down & 1620000 & 270000 & 1890000 & 1100 & -1030 & 70 & -13.733 \\
\hline A.P.up & 0 & 180000 & 180000 & 0 & 675 & 675 & 13.500 \\
\hline A.P.SS & 180000 & 1440000 & 1620000 & 675 & 0 & 675 & 0.000 \\
\hline A.P.down & 1620000 & 270000 & 1890000 & 675 & -675 & 0 & -9.000 \\
\hline A.FVMT.up & 0 & 180000 & 180000 & 0 & 100 & 100 & 2.000 \\
\hline A.FVMT.SS & 180000 & 1440000 & 1620000 & 100 & 0 & 100 & 0.000 \\
\hline A. FVMT.down & 1620000 & 270000 & 1890000 & 100 & -100 & 0 & -1.333 \\
\hline B.T.up & 0 & 1,200 & 1200 & 1100 & 75 & 1175 & 225.000 \\
\hline B.T.down & 1200 & 32400 & 33600 & 1175 & -775 & 400 & -86.111 \\
\hline B.T.HS & 33600 & 86400 & 120000 & 400 & 0 & 400 & 0.000 \\
\hline B.T.recover & 120000 & 122400 & 242400 & 400 & 700 & 1100 & 20.588 \\
\hline B.P.up & 0 & 1,200 & 1200 & 675 & 75 & 750 & 225.000 \\
\hline B.P.down & 1200 & 32400 & 33600 & 750 & -75 & 675 & -8.333 \\
\hline B.P.HS & 33600 & 86400 & 120000 & 675 & 0 & 675 & 0.000 \\
\hline B.P.recover & 120000 & 122400 & 242400 & 675 & 0 & 675 & 0.000 \\
\hline B.FVMT.up & 0 & 1,200 & 1200 & 100 & 25 & 125 & 75.000 \\
\hline B.FVMT.down & 1200 & 32400 & 33600 & 125 & -25 & 100 & -2.778 \\
\hline$B_{\text {.FVMT.HS }}$ & 33600 & 86400 & 120000 & 100 & 0 & 100 & 0.000 \\
\hline B.FVMT.up.recover & 120000 & 122400 & 242400 & 100 & 0 & 100 & 0.000 \\
\hline$C_{\text {.FVMT.up }}$ & 0 & 60 & 60 & 100 & 100 & 200 & 6000.000 \\
\hline$C_{\text {.FVMT down }}$ & 60 & 60 & 120 & 200 & -350 & -150 & -21000.000 \\
\hline $\mathrm{C}_{\text {.FVMT.recover }}$ & 120 & 60 & 180 & -150 & 150 & 0 & 9000.000 \\
\hline$C_{\text {.T.up }}$ & 0 & 1500 & 1500 & 1100 & 200 & 1300 & 480.000 \\
\hline C.T.down & 1500 & 9000 & 10500 & 1300 & -1230 & 70 & -492.000 \\
\hline C.P.up & 0 & 1500 & 1500 & 675 & 100 & 775 & 240.000 \\
\hline$C_{\text {P.down }}$ & 1500 & 9000 & 10500 & 775 & -775 & 0 & -310.000 \\
\hline
\end{tabular}


Table 3.3 - Level A Loading Parameters Versus Time

\begin{tabular}{ccccc}
\hline Level A Up/Down & time (sec) & $\begin{array}{c}\text { Temperature } \\
\left({ }^{\circ} \mathrm{F}\right)\end{array}$ & Pressure (psi) & FVMT (\%) \\
\hline start up & 0 & 70 & 0 & 0 \\
\hline middle up & 90000 & 585 & 337.5 & 50 \\
\hline end up & 180000 & 1100 & 675 & 100 \\
\hline ss end & 1620000 & 1100 & 675 & 100 \\
\hline middle down & 1755000 & 585 & 337.5 & 50 \\
\hline end down & 1890000 & 70 & 0 & 0 \\
\hline
\end{tabular}

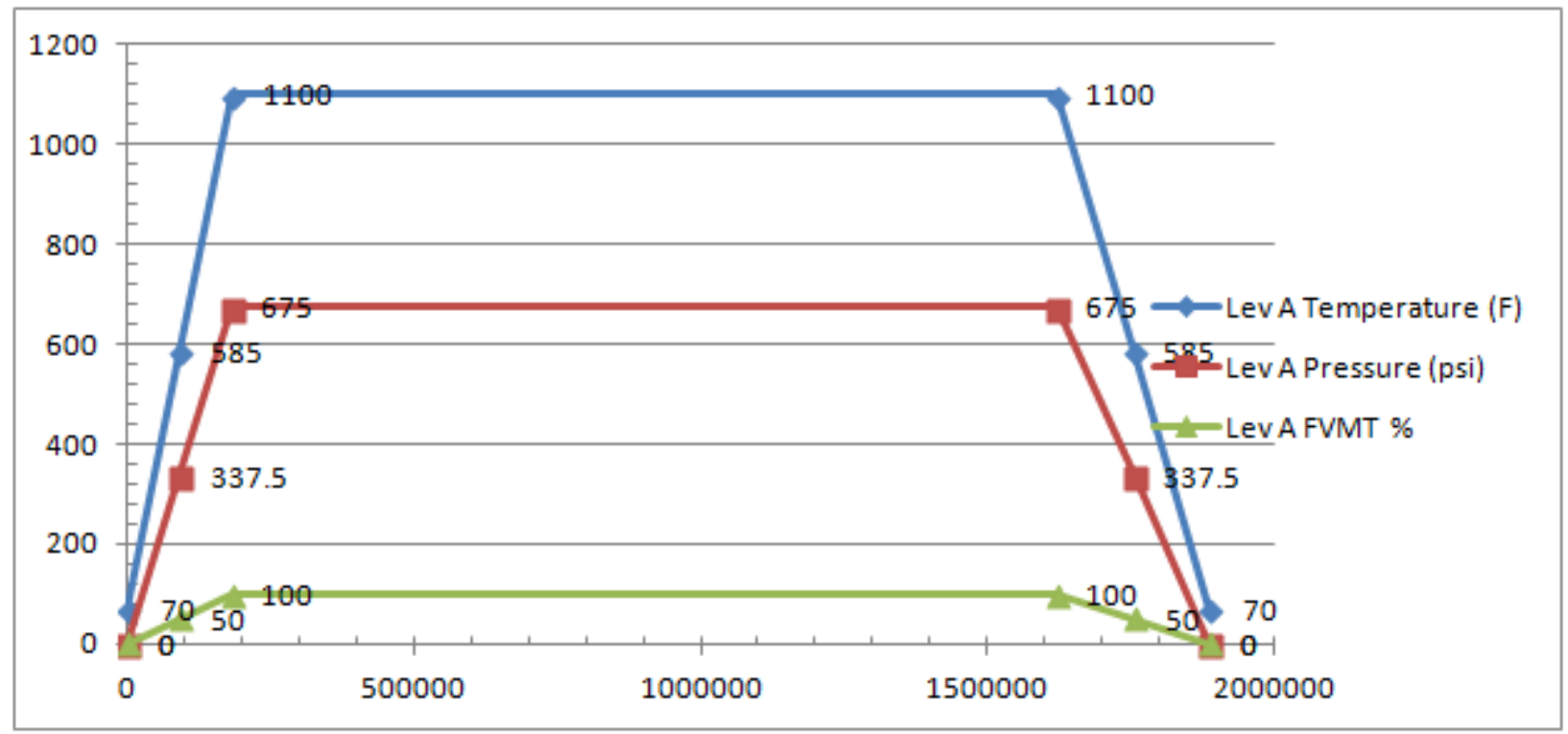


Table 3.4 - Level B Loading Parameters Versus Time (Up-Down Portion)

\begin{tabular}{|c|c|c|c|c|}
\hline Level B Up/Down & time (sec) & $\begin{array}{c}\text { Temperature } \\
\left({ }^{\circ} \mathrm{F}\right)\end{array}$ & Pressure (psi) & FVMT (\%) \\
\hline \multirow[t]{8}{*}{ start } & 0 & 1100 & 675.0 & 100.0 \\
\hline & 1100 & 1170.0 & 743.8 & 122.9 \\
\hline & 1120 & 1171.0 & 745.0 & 123.3 \\
\hline & 1140 & 1172.0 & 746.3 & 123.8 \\
\hline & 1160 & 1173.0 & 747.5 & 124.2 \\
\hline & 1170 & 1174.0 & 748.1 & 124.4 \\
\hline & 1180 & 1174.5 & 748.8 & 124.6 \\
\hline & 1190 & 1175.0 & 749.4 & 124.8 \\
\hline \multirow[t]{9}{*}{ peak } & 1200 & 1175 & 750.0 & 125.0 \\
\hline & 1210 & 1174.8 & 750.0 & 125.0 \\
\hline & 1220 & 1174.5 & 750.0 & 125.0 \\
\hline & 1230 & 1174.3 & 749.9 & 125.0 \\
\hline & 1240 & 1174.0 & 749.9 & 125.0 \\
\hline & 1300 & 1172.6 & 749.8 & 124.9 \\
\hline & 3000 & 1131.9 & 745.8 & 123.6 \\
\hline & 10000 & 850.0 & 729.6 & 118.2 \\
\hline & 30000 & 425.0 & 683.3 & 102.8 \\
\hline end & 33600 & 400 & 675.0 & 100.0 \\
\hline
\end{tabular}

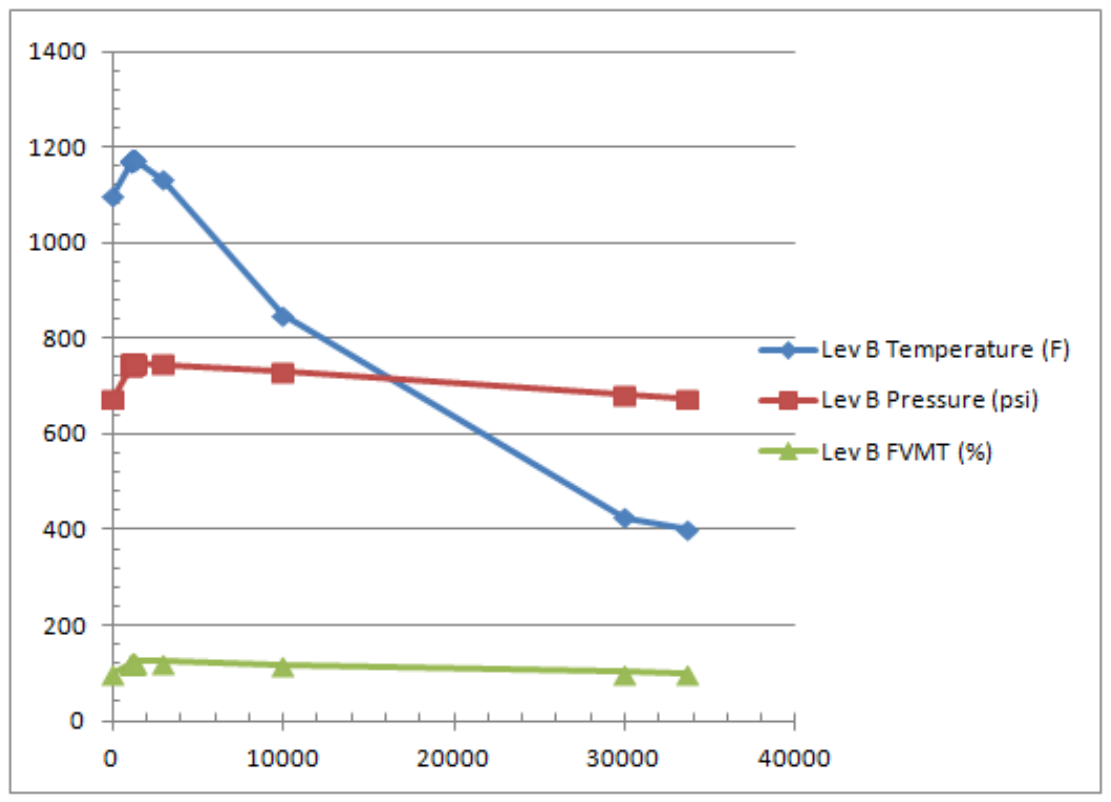

Becht Engineering Company - Becht Nuclear Services Division 114 Columbia Point Drive, Suite A - Richland, WA 99352 USA Tel. 509.943.1625 5224 Woodside Executive Court, Aiken, SC 29803 USA Tel. 803.648.7461 
Table 3.5 - Level B Loading Parameters Versus Time (Recover Portion)

\begin{tabular}{rcccc}
\hline Level B Recover & time (sec) & $\begin{array}{c}\text { Temperature } \\
(\mathrm{O})\end{array}$ & Pressure $(\mathrm{psi})$ & FVMT (\%) \\
\hline start & 120000 & 400 & 675 & 100 \\
\hline middle & 181200 & 750 & 675 & 100 \\
\hline end & 242400 & 1100 & 675 & 100 \\
\hline
\end{tabular}

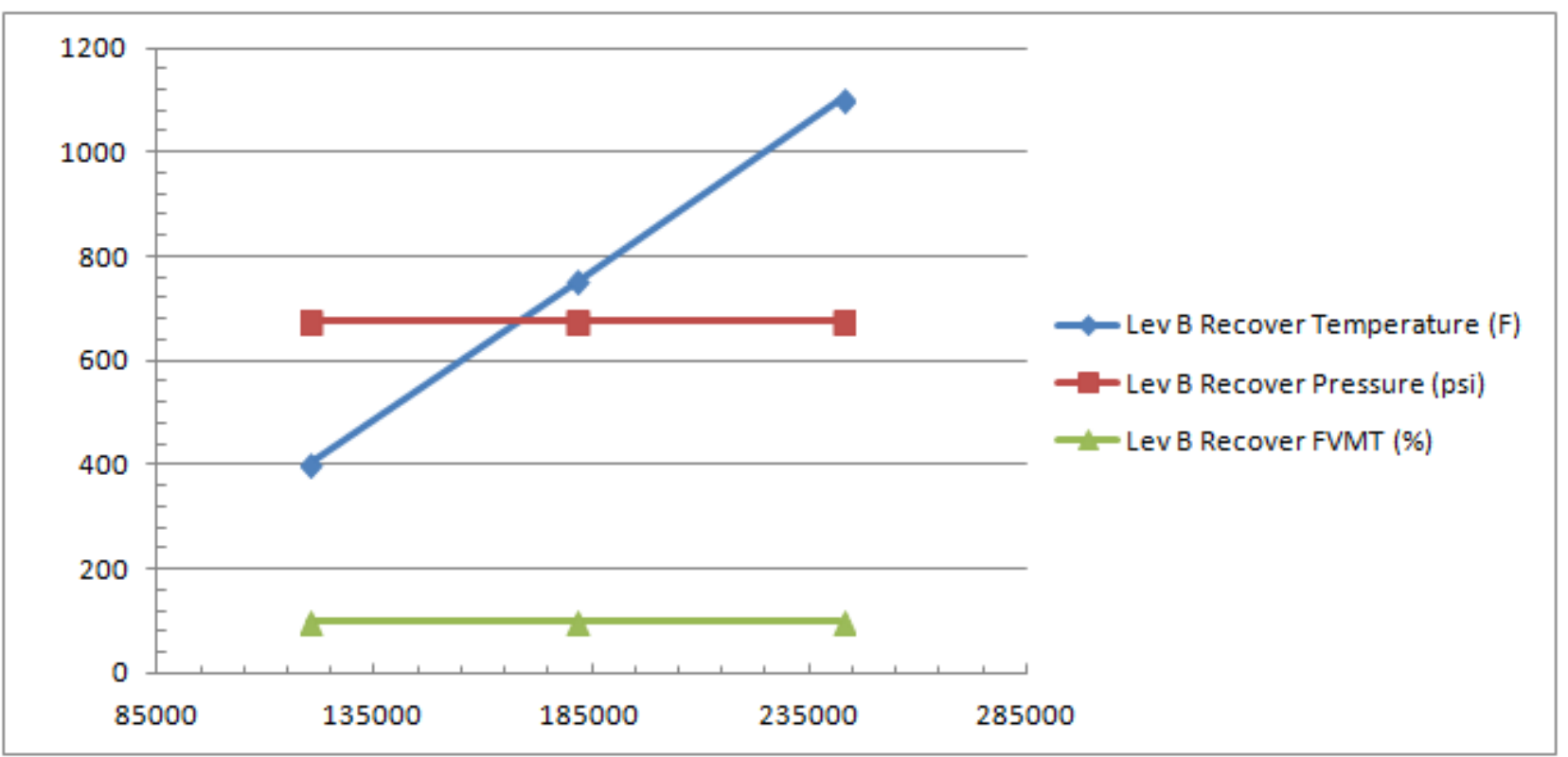


Table 3.6a- Level C Loading Parameters Versus Time (SSE initiating loads)

\begin{tabular}{ccccc}
\hline $\begin{array}{c}\text { Level C SSE } \\
\text { Initiation }\end{array}$ & time $(\mathrm{sec})$ & $\begin{array}{c}\text { Temperature } \\
(\mathrm{O})\end{array}$ & Pressure $(\mathrm{psi})$ & FVMT $(\%)$ \\
\hline start & -180 & 1100 & 675 & 100 \\
\hline peak & -120 & 1100 & 675 & 200 \\
\hline reaction & -60 & 1100 & 675 & -150 \\
\hline recover & 0 & 1100 & 675 & 100 \\
\hline
\end{tabular}

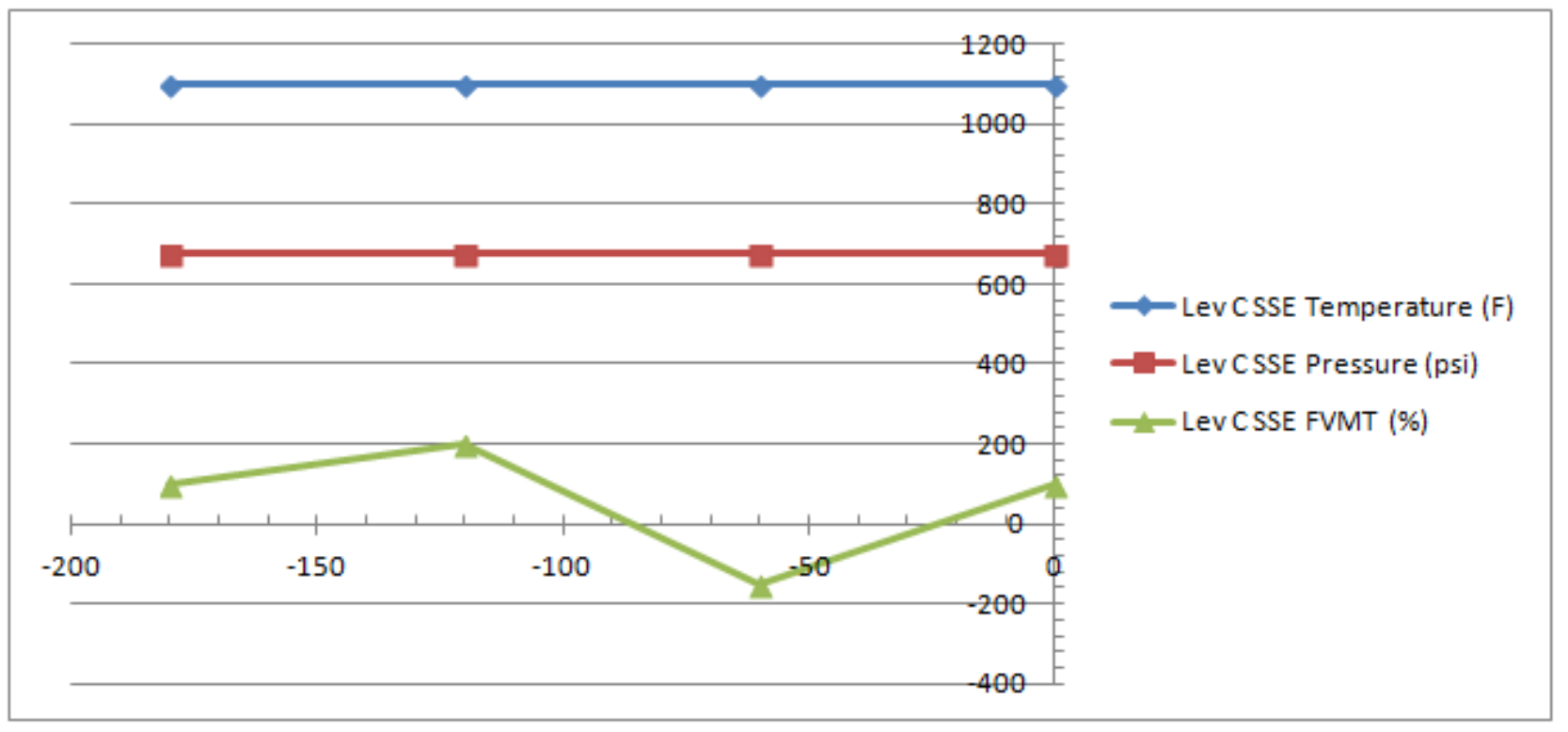


Table 3.6b- Level C Loading Parameters Versus Time (portion after SSE initiating loads)

\begin{tabular}{|c|c|c|c|c|}
\hline Level C & time (sec) & $\begin{array}{c}\text { Temperature } \\
\left({ }^{\circ} \mathrm{F}\right)\end{array}$ & Pressure (psi) & FVMT (\%) \\
\hline \multirow[t]{7}{*}{ Start } & 0 & 1100 & 675 & 100.0 \\
\hline & 1440 & 1290 & 771.00 & 86.3 \\
\hline & 1450 & 1292 & 771.67 & 86.2 \\
\hline & 1460 & 1294 & 772.33 & 86.1 \\
\hline & 1470 & 1296 & 773.00 & 86.0 \\
\hline & 1480 & 1298 & 773.67 & 85.9 \\
\hline & 1490 & 1299 & 774.33 & 85.8 \\
\hline \multirow[t]{10}{*}{ Peak } & 1500 & 1300 & 775 & 85.7 \\
\hline & 1510 & 1299 & 774.14 & 85.6 \\
\hline & 1520 & 1298 & 773.28 & 85.5 \\
\hline & 1530 & 1296 & 772.42 & 85.4 \\
\hline & 1540 & 1294 & 771.56 & 85.3 \\
\hline & 1550 & 1292 & 770.69 & 85.2 \\
\hline & 1560 & 1290 & 769.83 & 85.1 \\
\hline & 1600 & 1280 & 766.39 & 84.8 \\
\hline & 2000 & 1150 & 731.94 & 81.0 \\
\hline & 5000 & 700 & 473.61 & 52.4 \\
\hline End & 10500 & 70 & 0 & 0.0 \\
\hline
\end{tabular}

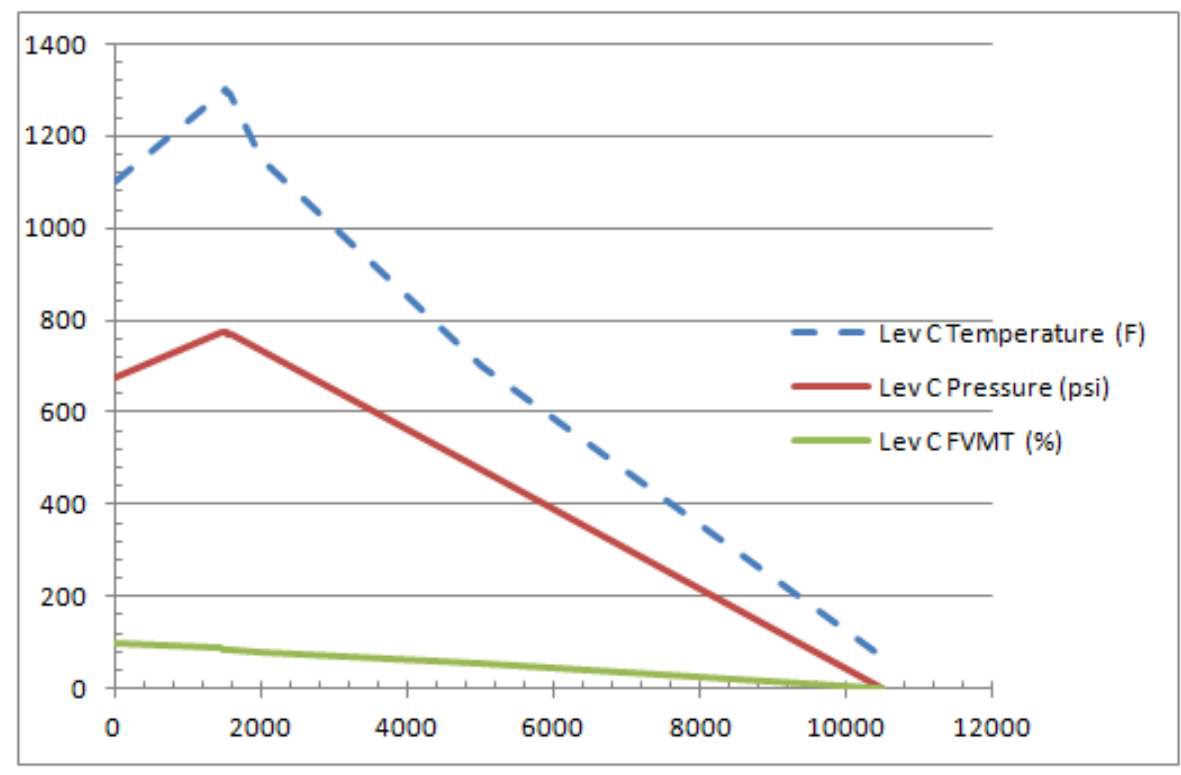

Becht Engineering Company - Becht Nuclear Services Division 114 Columbia Point Drive, Suite A - Richland, WA 99352 USA Tel. 509.943.1625 5224 Woodside Executive Court, Aiken, SC 29803 USA Tel. 803.648.7461 
Figure 3.1 - Representative Example Problem (REP) Geometry Sketch

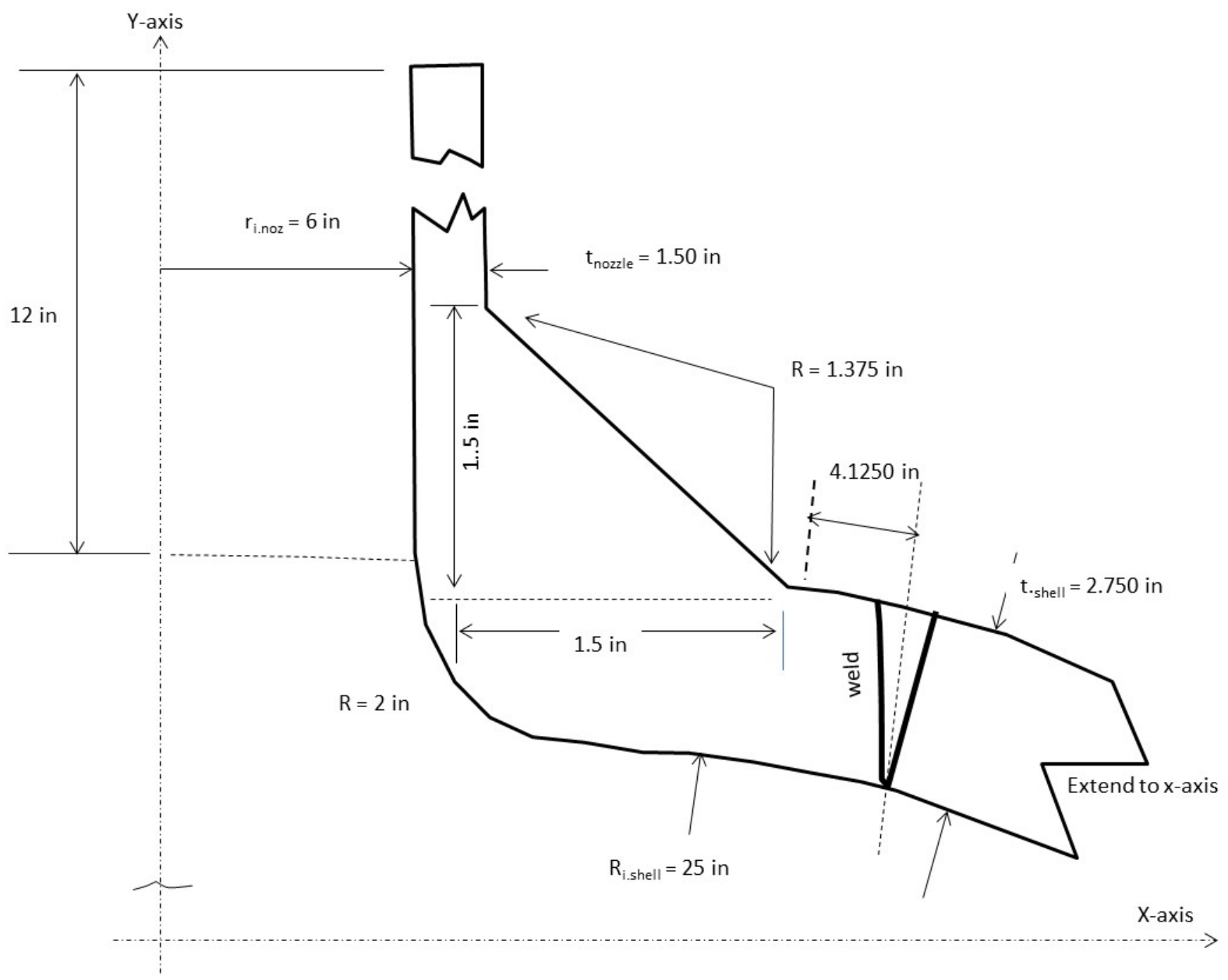


Figure 3.2 - Service Level A Loads and Load Combinations; loadings versus time

Times and ramp rates shown in Tables

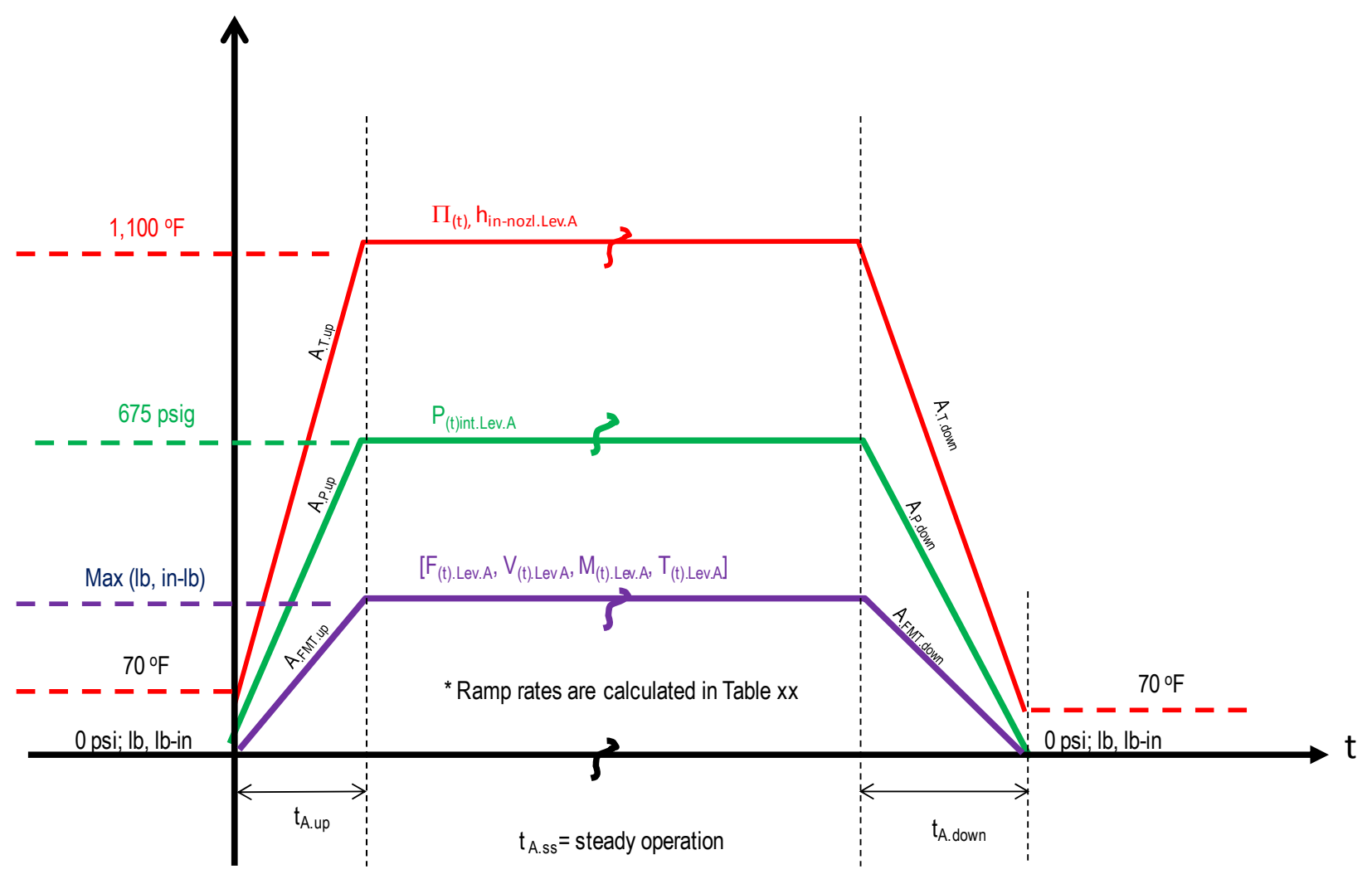


Figure 3.3 - Service Level B Loads and Load Combinations; loadings versus time

Times and ramp rates shown in Tables

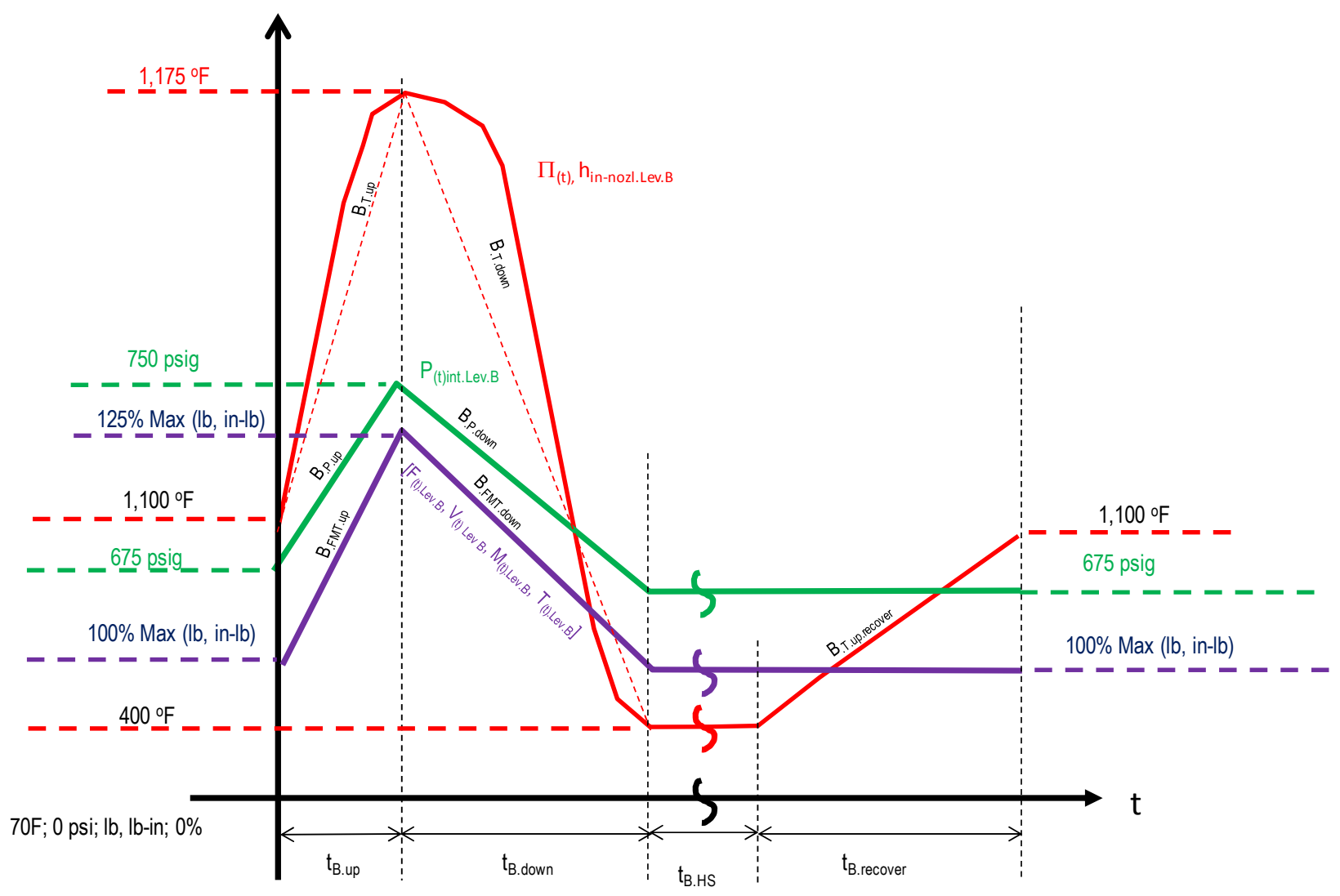


Figure 3.4 - Service Level C Loads and Load Combinations; loadings versus time

Times and ramp rates shown in Tables

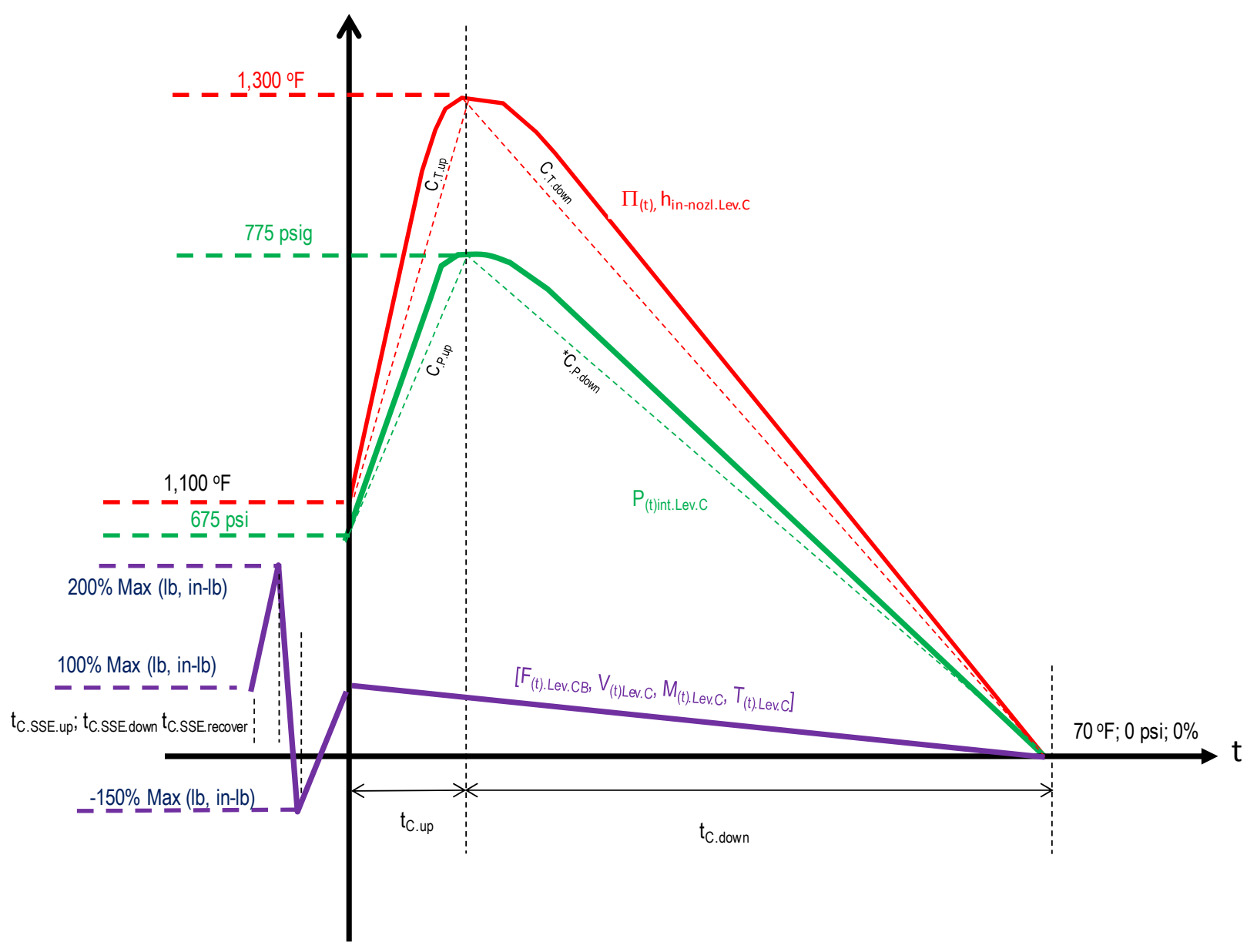


Figure 3.5 - Level A and B Composite Cycle

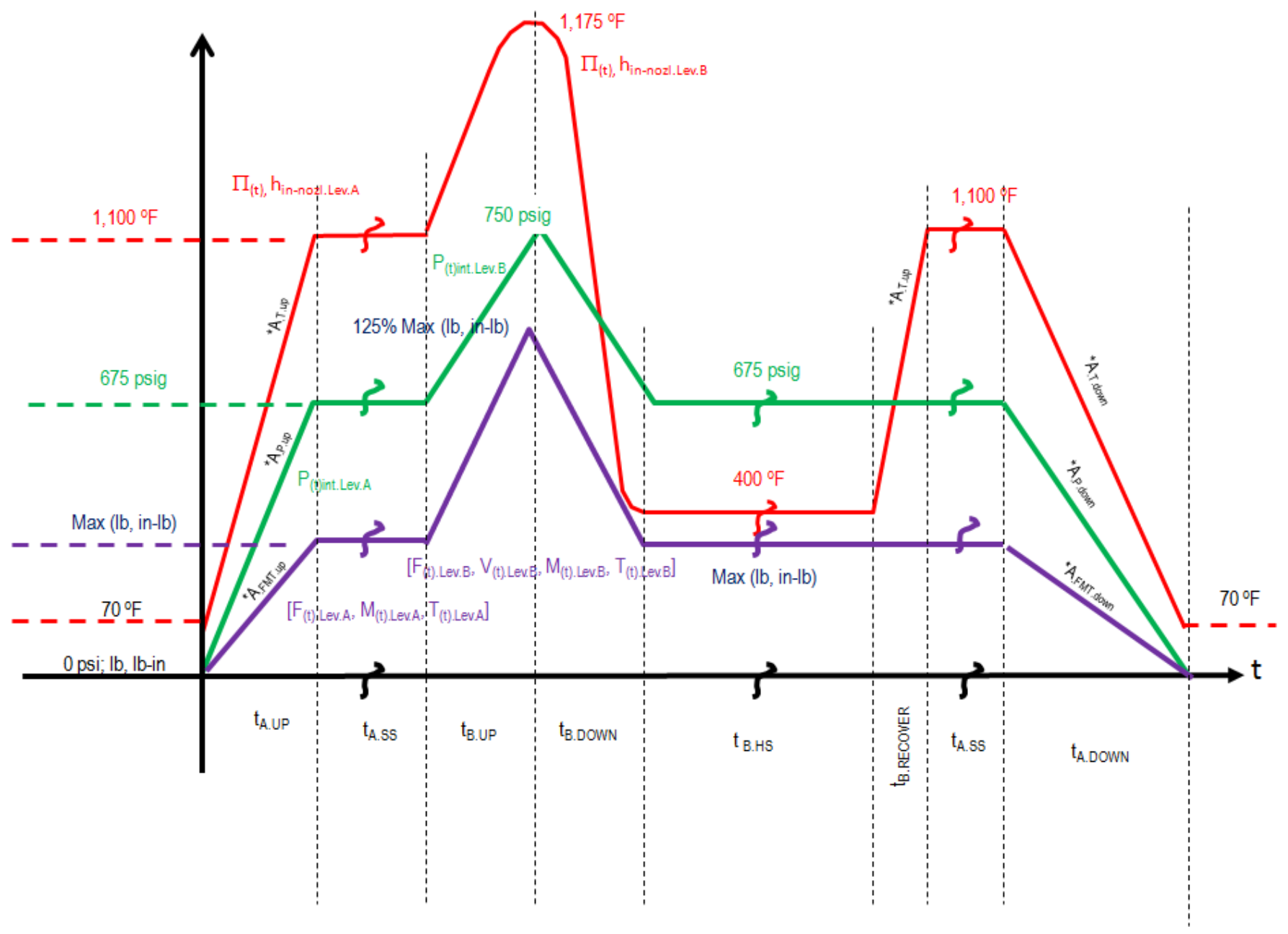


Figure 3.6 - Level C Composite Cycle

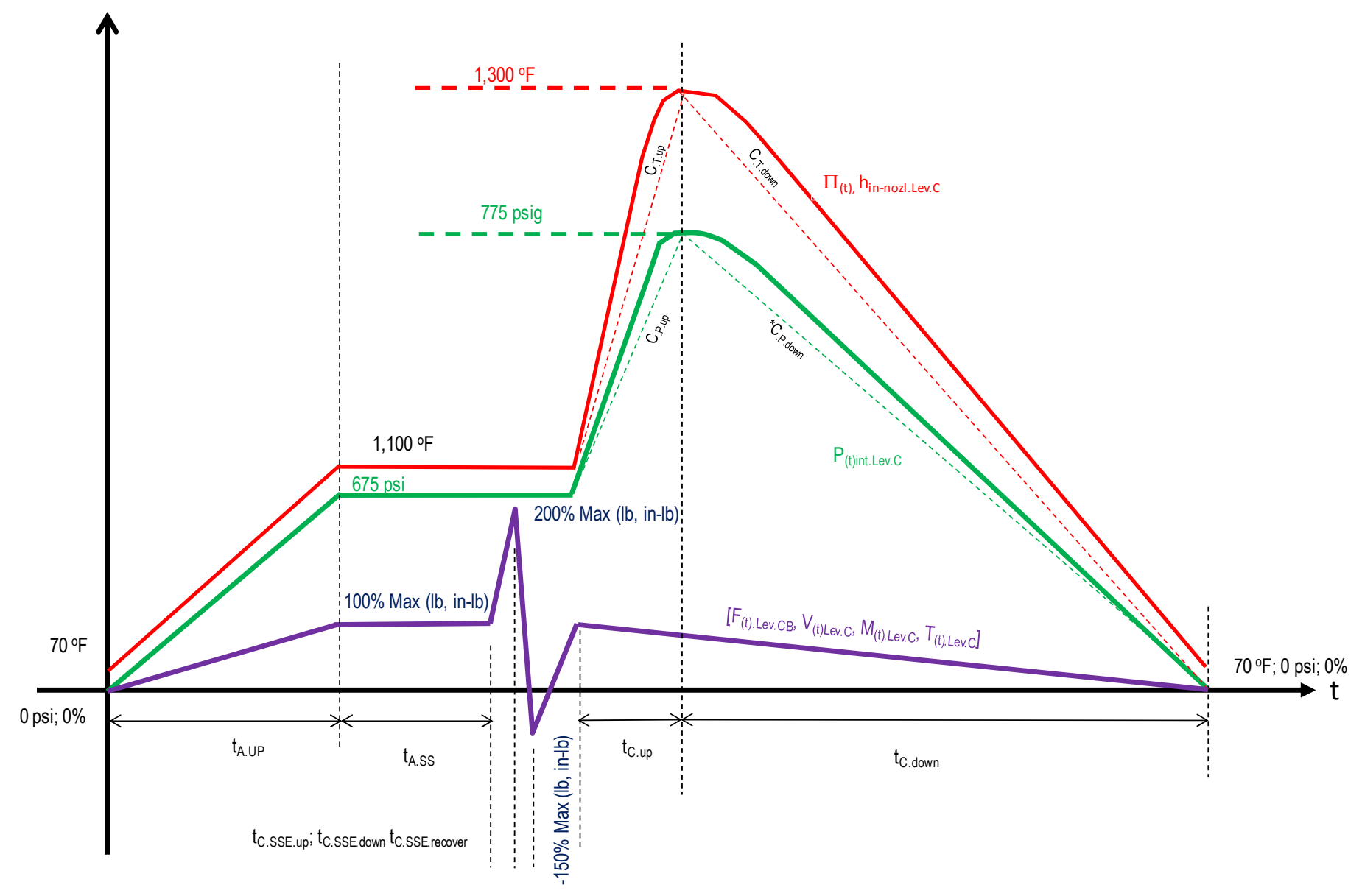


A suggested ABAQUS finite element model geometric layout in a 2D X-Y planar cut representation is shown in Fig. 4.1. Suggested characteristics include:

a. The weld between the nozzle forging and head is not explicitly modeled, i.e., the material properties of the weld are the same as the base material properties and the geometric boundaries of the weld are not explicitly defined. Section 2.1 of the proposed strain limit Code Case [Ref. 4] requires specific treatment of weld material for ratchet screening criteria.

b. The model will need to be 3D to capture the 3D loading, even though the geometry is axisymmetric.

c. The model should be of 3D solid elements (8-node or 20-node). Other element types may be used in an auxiliary fashion, such as for application of the piping loads to the end of the nozzle.

d. Element aspect ratios should be maintained within limits of accuracy for the selected element type.

e. Triangular-faced elements should be avoided or used only away from expected regions of high stress or strain.

f. Full-integration element should be used.

g. Non-linear geometry need not be used.

The sources for required material properties are in Table 4.1. Values for these properties are in subsequent Tables. Values for Specific Heat of 316 Stainless Steel are in accordance with references [Ref. 18], [Ref. 10], [Ref. 20]. [Ref. 21], [Ref. 22].

$C_{p}$ in units of BTU/lb-F

$$
\begin{aligned}
& a_{0}=1.071939 \times 10^{-1} \\
& a_{1}=6.034521 \times 10^{-5} \\
& a_{2}=-4.397679 \times 10^{-8} \\
& a_{3}=1.438572 \times 10^{-11}
\end{aligned}
$$

$$
C_{p}=\sum_{n=0}^{3} a_{n} T^{n}
$$

where $T$ is in $\mathrm{F}$.

To obtain $C_{p}$ in units of $\mathrm{J} / \mathrm{kg}-\mathrm{K}$, multiply the values in by $4.18680 \times 10^{3}$ 
Table 4.1 - Material Parameter References

\begin{tabular}{|c|c|c|c|}
\hline Material Parameter & Reference & Temperature Limit & $\begin{array}{l}\text { Value or } \\
\text { Table for Values }\end{array}$ \\
\hline $\begin{array}{l}\text { Coefficient of Thermal } \\
\text { Expansion, } \alpha\end{array}$ & $\begin{array}{l}\text { Section II, Part D, Table TE-1, Group 3; } \\
\text { coefficient B }\end{array}$ & $1,500^{\circ} \mathrm{F}$ & 4.2 \\
\hline $\begin{array}{l}\text { Thermal Conductivity } \\
\text { and Diffusivity }(\mathrm{X}, \Delta)\end{array}$ & Section II, Part D, Table TCD, Group K & $1,500^{\circ} \mathrm{F}$ & 4.2 \\
\hline Young's Modulus, E & Section II, Part D, Table TM-1, Group G & $1,500^{\circ} \mathrm{F}$ & 4.3 \\
\hline $\begin{array}{l}\text { Isochronous Stress } \\
\text { Strain Curves }\end{array}$ & $\begin{array}{l}\text { Figures NH-T-1800-B-1 through B-13 for } \\
316 \mathrm{SS}\end{array}$ & To 1400 o $F$ & See $\mathrm{NH}$ \\
\hline $\mathrm{S}_{0}$ & Table NH-I-14.2; 316SS & $1,500^{\circ} \mathrm{F}$ & 4.4 \\
\hline $\mathrm{S}_{\mathrm{mt}}$ & Table NH-I-14.3B; 316SS & $1,500^{\circ} \mathrm{F}$ & 4.5 \\
\hline $\mathrm{S}_{\mathrm{t}}$ & Table NH-I-14.4B; 316SS & $1,500^{\circ} \mathrm{F}$ & 4.5 \\
\hline $\mathrm{S}_{\mathrm{y}}$ & $\begin{array}{l}\text { Section II, Part D Table Y-1 (to 1,000F) } \\
\text { Table NH-I-14.5 316SS }\end{array}$ & $\begin{array}{c}1,500^{\circ} \mathrm{F} \\
>1,000^{\circ} \mathrm{F} \text { to } 1,500^{\circ} \mathrm{F}\end{array}$ & 4.6 \\
\hline $\mathrm{S}_{\mathrm{TR}}$ & Table NH-I-14.6B (by equation by ORNL) & $1,500^{\circ} \mathrm{F}$ & --- \\
\hline$v$ & Poisson's Ratio, Section II, Part D, Table PRD & $\mathrm{RT}-1,500^{\circ} \mathrm{F}$ & 0.31 \\
\hline$\rho$ & Density, Section II, Part D, Table PRD & $1,500^{\circ} \mathrm{F}$ & $0.290 \mathrm{lb} / \mathrm{in}^{3}$ \\
\hline $\mathrm{cp}$ & Specific Heat & $1,500^{\circ} \mathrm{F}$ & 4.2 \\
\hline
\end{tabular}


Table 4.2 - Coefficient of Expansion, Thermal Conductivity X and Thermal Diffusivity $\Delta$ $\alpha$ units: in/in/oF; $\quad \mathrm{X}(\mathrm{TC})$ units: BTU/hr - $\mathrm{ft}$ - ${ }^{\circ} \mathrm{F} ; \quad \Delta(\mathrm{TD})$ units: $\mathrm{ft} / \mathrm{hr} ; \mathrm{C}_{\mathrm{p}}$ units: BTU/lb-o $\mathrm{F}$

\begin{tabular}{|c|c|c|c|c|}
\hline$T$ & $\alpha$ avg "B" & TC & TD & $\mathrm{Cp}$ \\
\hline 70 & 8.5 & 8.200 & 0.139 & 0.1100 \\
\hline 100 & 8.6 & 8.300 & 0.140 & 0.1128 \\
\hline 150 & 8.8 & 8.600 & 0.142 & 0.1153 \\
\hline 200 & 8.9 & 8.800 & 0.145 & 0.1176 \\
\hline 250 & 9.1 & 9.100 & 0.147 & 0.1198 \\
\hline 300 & 9.2 & 9.300 & 0.150 & 0.1217 \\
\hline 350 & 9.4 & 9.500 & 0.152 & 0.1235 \\
\hline 400 & 9.5 & 9.800 & 0.155 & 0.1252 \\
\hline 450 & 9.6 & 10.000 & 0.157 & 0.1268 \\
\hline 500 & 9.7 & 10.200 & 0.160 & 0.1282 \\
\hline 550 & 9.8 & 10.500 & 0.162 & 0.1295 \\
\hline 600 & 9.9 & 10.700 & 0.165 & 0.1307 \\
\hline 650 & 9.9 & 10.900 & 0.167 & 0.1318 \\
\hline 700 & 10.0 & 11.200 & 0.170 & 0.1328 \\
\hline 750 & 10.0 & 11.400 & 0.172 & 0.1338 \\
\hline 800 & 10.1 & 11.600 & 0.175 & 0.1347 \\
\hline 850 & 10.2 & 11.900 & 0.177 & 0.1355 \\
\hline 900 & 10.2 & 12.100 & 0.180 & 0.1364 \\
\hline 950 & 10.3 & 12.300 & 0.182 & 0.1372 \\
\hline 1000 & 10.3 & 12.500 & 0.184 & 0.1379 \\
\hline 1050 & 10.4 & 12.800 & 0.187 & 0.1387 \\
\hline 1100 & 10.4 & 13.000 & 0.189 & 0.1395 \\
\hline 1150 & 10.5 & 13.200 & 0.191 & 0.1403 \\
\hline 1200 & 10.6 & 13.400 & 0.194 & 0.1411 \\
\hline 1250 & 10.6 & 13.600 & 0.196 & 0.1420 \\
\hline 1300 & 10.7 & 13.800 & 0.198 & 0.1429 \\
\hline 1350 & 10.7 & 14.100 & 0.200 & 0.1439 \\
\hline 1400 & 10.8 & 14.300 & 0.203 & 0.1450 \\
\hline 1450 & 10.8 & 14.500 & 0.205 & 0.1461 \\
\hline 1500 & 10.8 & 14.700 & 0.207 & 0.1473 \\
\hline
\end{tabular}


Table 4.3 - Young's Modulus, E

\begin{tabular}{cc}
\hline $\mathrm{T}\left({ }^{\circ} \mathrm{F}\right)$ & $\mathrm{E}(\mathrm{mpsi})$ \\
\hline 70 & 28.3 \\
\hline 200 & 27.5 \\
\hline 300 & 27.0 \\
\hline 400 & 26.4 \\
\hline 500 & 25.9 \\
\hline 600 & 25.3 \\
\hline 700 & 24.8 \\
\hline 800 & 24.1 \\
\hline 900 & 23.5 \\
\hline 1000 & 22.8 \\
\hline 1100 & 22.0 \\
\hline 1200 & 21.2 \\
\hline 1300 & 20.3 \\
\hline 1400 & 19.2 \\
\hline 1500 & 18.1 \\
\hline
\end{tabular}


Table 4.4 - Allowable Stress Intensity S。

\begin{tabular}{cc}
\hline$T\left({ }^{\circ} \mathrm{F}\right)$ & $\mathrm{S}_{0}(\mathrm{ksi})$ \\
\hline 800 & 15.9 \\
\hline 850 & 15.7 \\
\hline 900 & 15.6 \\
\hline 950 & 15.5 \\
\hline 1000 & 14.0 \\
\hline 1050 & 11.2 \\
\hline 1100 & 11.1 \\
\hline 1150 & 9.8 \\
\hline 1200 & 7.4 \\
\hline 1250 & 5.5 \\
\hline 1300 & 4.1 \\
\hline 1350 & 3.1 \\
\hline 1400 & 2.3 \\
\hline 1450 & 1.7 \\
\hline 1500 & 1.3 \\
\hline
\end{tabular}

Table 4.5 - Allowable Stress Intensities $S_{m t}$ and $S_{t}$ at 1, 10 and 100,000 hr (ksi)

\begin{tabular}{cccccccc}
\hline $\mathrm{T}$ & $\mathrm{S}_{\mathrm{mt}} ; 1 \mathrm{hr}$ & $\mathrm{S}_{\mathrm{mt}} ; 10 \mathrm{hr}$ & $\mathrm{S}_{\mathrm{mt}} ; 105 \mathrm{hr}$ & $\mathrm{T}$ & $\mathrm{S}_{\mathrm{t}} ; 1 \mathrm{hr}$ & $\mathrm{S}_{\mathrm{t}} ; 10 \mathrm{hr}$ & $\mathrm{S}_{\mathrm{t}} ; 10^{5} \mathrm{hr}$ \\
\hline 800 & 15.9 & 15.9 & 15.90 & 800 & 20.8 & 20.8 & 20.8 \\
\hline 850 & 15.7 & 15.7 & 15.70 & 850 & 20.6 & 20.6 & 20.6 \\
\hline 900 & 15.6 & 15.6 & 15.60 & 900 & 20.4 & 20.4 & 19.9 \\
\hline 950 & 15.5 & 15.5 & 15.50 & 950 & 20.1 & 20.1 & 18.4 \\
\hline 1000 & 15.4 & 15.4 & 15.40 & 1000 & 19.8 & 19.8 & 16.2 \\
\hline 1050 & 15.1 & 15.1 & 12.50 & 1050 & 19.4 & 19.4 & 12.5 \\
\hline 1100 & 14.8 & 14.8 & 9.50 & 1100 & 19.1 & 19.0 & 9.5 \\
\hline 1150 & 14.7 & 14.7 & 7.20 & 1150 & 18.5 & 17.7 & 7.2 \\
\hline 1200 & 14.6 & 14.6 & 5.50 & 1200 & 17.8 & 16.8 & 5.5 \\
\hline 1250 & 14.2 & 14.2 & 4.20 & 1250 & 17.1 & 15.2 & 4.2 \\
\hline 1300 & 13.8 & 12.8 & 3.10 & 1300 & 16.1 & 12.8 & 3.1 \\
\hline 1350 & 12.8 & 10.3 & 2.10 & 1350 & 14.2 & 10.3 & 2.1 \\
\hline 1400 & 11.3 & 8.2 & 1.50 & 1400 & 12.0 & 8.2 & 1.5 \\
\hline 1450 & 9.7 & 6.4 & 1.00 & 1450 & 9.7 & 6.4 & 1.0 \\
\hline 1500 & 7.8 & 4.9 & 0.65 & 1500 & 7.8 & 4.9 & 0.65 \\
\hline
\end{tabular}


Table 4.6 - Yield Strength, $S_{y}$

\begin{tabular}{cc}
\hline$T\left({ }^{\circ}\right)$ & $S_{y}(\mathrm{ksi})$ \\
\hline 70 & 30.0 \\
\hline 150 & 27.4 \\
\hline 200 & 25.9 \\
\hline 250 & 24.6 \\
\hline 300 & 23.4 \\
\hline 400 & 21.4 \\
\hline 500 & 20.0 \\
\hline 600 & 18.9 \\
\hline 650 & 18.5 \\
\hline 700 & 18.2 \\
\hline 750 & 17.9 \\
\hline 800 & 17.7 \\
\hline 850 & 17.5 \\
\hline 900 & 17.3 \\
\hline 950 & 17.1 \\
\hline 1000 & 17.0 \\
\hline 1050 & 16.8 \\
\hline 1100 & 16.6 \\
\hline 1150 & 16.3 \\
\hline 1200 & 16.0 \\
\hline 1250 & 15.5 \\
\hline 1300 & 14.9 \\
\hline 1350 & 14.2 \\
\hline 1400 & 13.3 \\
\hline 1450 & 12.3 \\
\hline 1500 & 10.9 \\
\hline & \\
\hline & \\
\hline 150
\end{tabular}


Figure 4.1 - Suggested ABAQUS Finite Element Model Layout

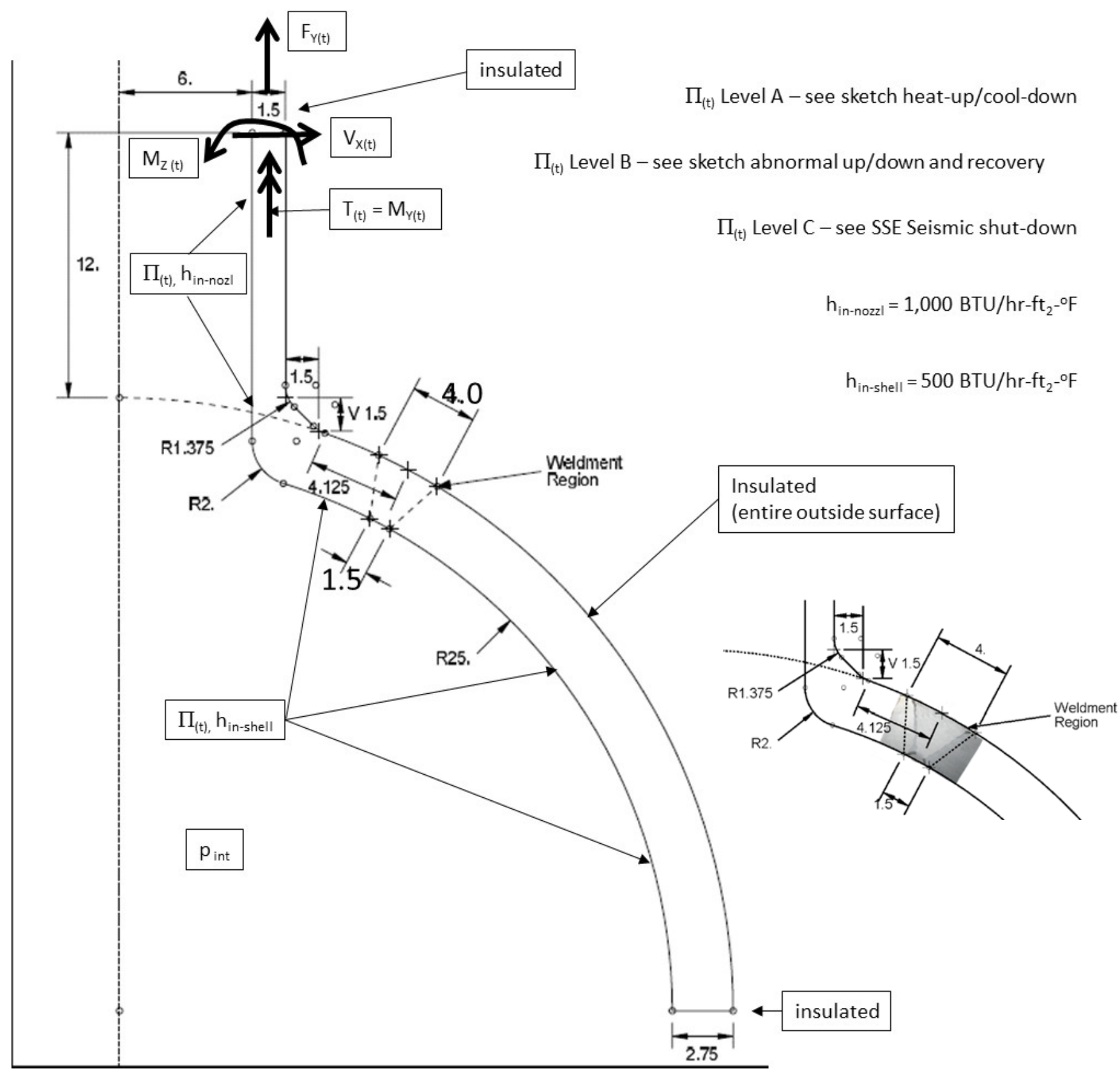


Figure 4.2 - Expected Thermal Boundary Conditions

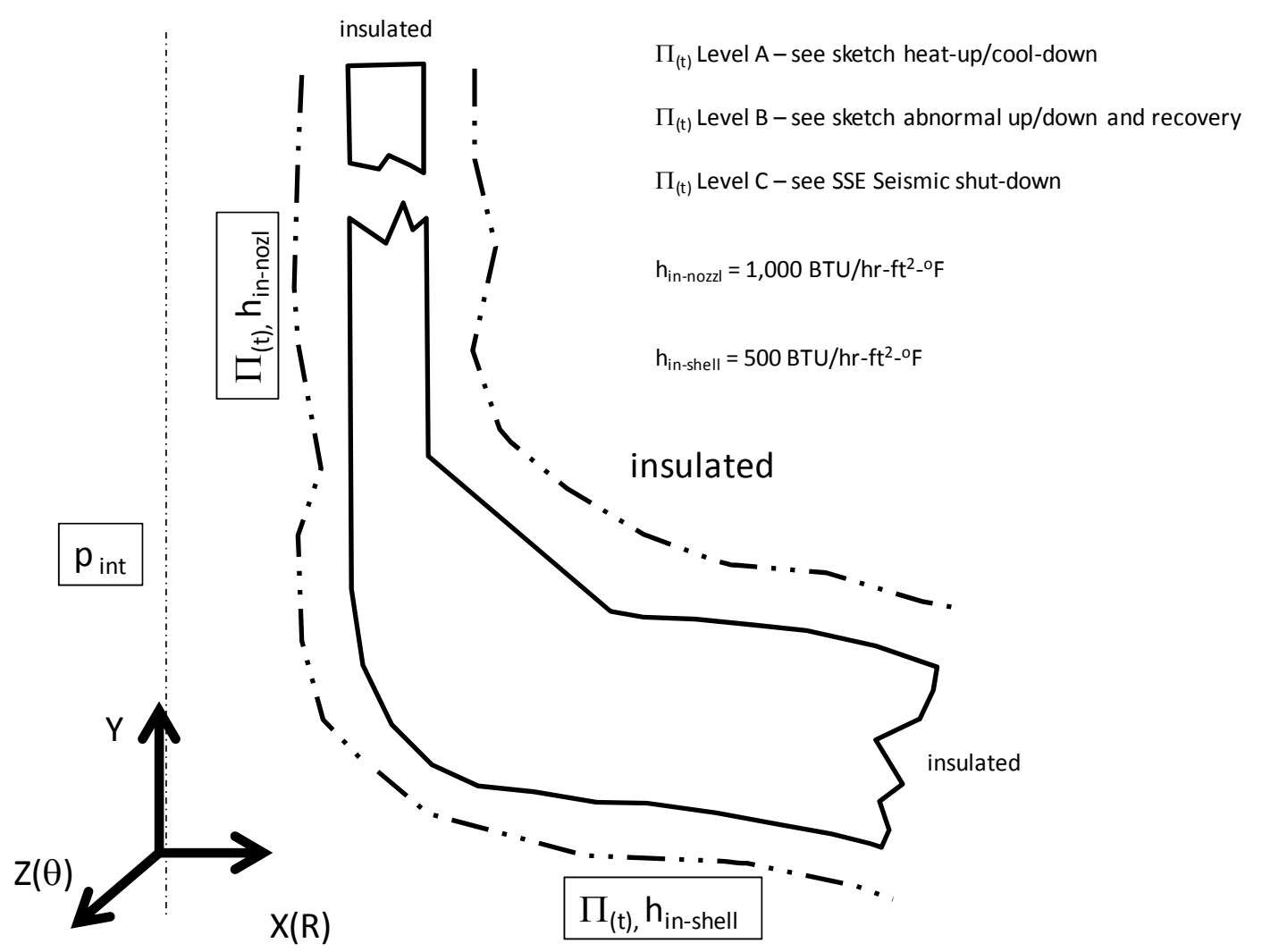


1. Intentionally blank.

2. Intentionally blank.

3. The American Society of Mechanical Engineers, Boiler and Pressure Vessel Code, Section III, Division 1 Appendices, 2013 Edition.

4. Strain Limit Code Case Xxxx Strain Limits CC -4-14-2014 - rev3, 4/14/2014

5. Creep-Fatigue Code Case xxxx Draft Creep-Fatigue RIJ Rev 7A (4-16-2014), 4/16/2014.

6. Intentionally blank

7. BNS Report 20362-R-002, Rev. 3, Elevated Temperature Code Case Representative Example Problem Report.

8. The American Society of Mechanical Engineers, Boiler and Pressure Vessel Code, Section III, Division 1, Subsection NH, "Class 1 Components in Elevated Temperature Service," 2013.

9. The American Society of Mechanical Engineers, Boiler and Pressure Vessel Code, Section II Part D, "Properties (Customary)," 2013 Edition.

10. Proceedings of the ASME PVP Conference Volume 215, pp 147-153, "Rules for Design of Alloy 617 Nuclear Components to Very High Temperatures," The American Society of Mechanical Engineers, New York, NY.

11. PVP2012-78081, "Elevated Temperature Primary Load Design Method Using Pseudo Elastic-Perfectly Plastic Model," Proceedings of the ASME 2012 Pressure Vessels and Piping Division Conference, The American Society of Mechanical Engineers, New York, NY.

12. PVP2012-78082, "Application of Elastic-Perfectly Plastic Cyclic Analysis to Assessment of Creep Strain," Proceedings of the ASME 2012 Pressure Vessels and Piping Division Conference, The American Society of Mechanical Engineers, New York, NY.

13. PVP2012-78083, "Application of Shakedown Analysis to Evaluation of Creep-Fatigue Limits," Proceedings of the ASME 2012 Pressure Vessels and Piping Division Conference, The American Society of Mechanical Engineers, New York, NY.

14. MathCad Version 15.

15. ABAQUS Version 6.11.1.

16. The American Society of Mechanical Engineers, Boiler and Pressure Vessel Code, Section III, Division 1, Subsection NB, "Class 1 Components," 2013.

17. Welding Research Council Bulletin 107, "Local Stress in Spherical and Cylindrical Shells Due to External Loadings, October 2002 Update, The Welding Research Council, New York, NY.

18. Douglas, T.B. and Victor, A. C., "Physical Properties of High Temperature Materials, Part III. The Heat Capacity of Zirconium, Several Zirconium Hydrides, and Certain Cladding Material from 0 to $9000 \mathrm{C}$, Relation to Other Thermodynamic Properties of Other Zr-H System," U. S. Air Force Rept. WADC-TR-57-374, Part II, 75 pp., 1957.

19. Lucks, C.F., Matolich, J., Van Velzor, J. A. "The Experimental Measurement of Thermal Conductivities, Specific Heats, and Densities of Metallic Transparent, and Protective Materials, Part III, U. S. Air Force Rept. AF-TR-6145, 71 pp, 1854 [Ref. AD 95406].

20. Douglas, T. B and Victor, A. C., "Enthalpy and Specific Heat of Nine Corrosion-Resistant Alloys at High Temperature, "J. Res. Nat. Bur. Stand., 65, 65-9, 1961.

21. Fieldhouse, I. B., Hedge, J. C., and Lang, J. I., "Measurement Thermal Properties," U. S. Air Force Rept. WADC-TR-58-274, 79 pp., 1958 [Ref. AD206 892].

22. Lang, J. I., "Specific Heat of Materials," in Thermodynamic and Transport Properties of Gases, Liquids and Siolids, ASME Symposium on Thermal Properties, 405-14, 1959. 
23. Lucks, C. F. and Deem, H. W., "Thermal Properties of Thirteen Metals," Am. Soc. Test Mater, Spec. Publ. 227, 29 pp., 1958.

24. Redmond, R. F. and Lones, J., "Enthalpies and Heat Capacities of Stainless Steel 316, Zirconium, and Lithium at Elevated Temperature," USAEC Rept. ORN-1342, 3-20, 1952. 


\section{Record of Revisions}

\begin{tabular}{|c|c|c|c|}
\hline Revision & Date & Description & By \\
\hline 0 & NA & There is no Rev. 0 & \\
\hline 1 & $9 / 30 / 2013$ & Original Release & GLH \\
\hline 2 & $10 / 31 / 2013$ & $\begin{array}{l}\text { Revised for new example geometry and } \\
\text { loadings and editorial updates } \\
\text { Section 1: Reference to Rev. } 2 \\
\text { Section 2: no changes } \\
\text { Section 3.2: change geometry sizes } \\
\text { Section 3.3: Change Level C composite } \\
\text { cycle to include Level A start-up } \\
\text { Section } 3.8 \text { reduce internal pressures; reduce } \\
\text { piping loads, adding shear; editorial changes } \\
\text { in 3.8.2.b; update Tables and Figures for new } \\
\text { loads and geometry. } \\
\text { Section 4: update Table } 4.1 \text { including density } \\
\text { from 0.291 to } 0.290 \text { and units to pci; update } \\
\text { Table 4.2 for TC and TD values for ASME II- } \\
\text { D Group, K; add specific heat; update } \\
\text { Figures 4.1 and } 4.2 \text {. } \\
\text { References: add Cp data references } \\
\text { Attachment 1: updated for new geometry and } \\
\text { loadings; editorial changes; additional } \\
\text { parameters defined; nozzle radii calculations } \\
\text { added. }\end{array}$ & GLH \\
\hline 3 & $\begin{array}{l}5 / 28 / 2014 \\
6 / 26 / 2014\end{array}$ & $\begin{array}{l}\text { Revised for updated code cases; consistent } \\
\text { model with weld zone modeled in accordance } \\
\text { with the code cases; eliminate Level C } \\
\text { evaluations; editorial changes and updates. }\end{array}$ & GLH \\
\hline
\end{tabular}




\section{Attachment 1 - Design Sizing of the Component}

Calculations are performed in MathCad [Ref. 14].

These are "sizing calculations" for the example problem consisting of a nozzle attached to a spherical shell in accordance with Section III, Division 1, Subsection NH using a nozzle shell attachment detail in NB-3338.2(a)-2 sketch (c) and Fig. NB-4244-1(a)-1 sketch (d). The sizing calculations are for Design level Conditions per NH-3222.1 and for the operating Level $\mathrm{A}$ and $\mathrm{B}$ conditions in $\mathrm{NH}-3323$. Level $\mathrm{C}$ loading is also evaluated. These sizing calculations are approximate. The sizing calculations will be confirmed by review of the elastic analysis of the finite element model of the example.

NOTES:

1. There is no specified corrosion allowance.

2. NH-3331(c) states that if analysis is performed at the nozzle/shell juncture and limits for membrane and membrane-plusbending are satisfied, the reinforcement requirements are waived. This is the case for this component, but reinforcement is calculated in advance of the detailed evaluation to set the dimensions of the transition region between the nozzle and shell using NB-3338.2(a)-2 sketch (c) and Figure NB-4424(a)-1 sketch (d).

3. Subsection NH, "Class 1 Components in Elevated Temperature Service," 2013 Edition [Ref. 8].

4. Subsection NB, "Class 1 Components," 2013 Edition [Ref. 16].

\section{Conclusions:}

1. The nozzle and shell are sized such that membrane stress intensities are appropriately significant, but not inappropriately close to the operating Level A, B and C limits due to short-term loading.

2. The sizing evaluation does not include thermal stresses.

3. The acceptability of the thermal stresses can be estimated by using Appendix T of Subsection $\mathrm{NH}$ once an initial thermal analyses of the Level A, B and C thermal loadings are performed.

4. The thermal stresses from Level $B$ and Level $C$ loads are expected to be severe - maybe too severe-- to be acceptable to Subsection NH or the proposed Code Cases.

5. If the thermal stresses are found to be too severe, the loadings on the REP will be adjusted.

Green shaded areas indicate INPUT. 


\section{Nozzle Geometry -- INPUT and related calculations}

$$
\begin{aligned}
& \mathrm{d}_{\mathrm{Y}}:=12 \cdot \text { in } \\
& \text { specified distance from end of nozzle to OD of shell } \\
& \mathrm{r}_{\text {i.n }}:=6 \text {-in } \\
& \text { specified inside radius of nozzle } \\
& \mathrm{t}_{\mathrm{n}}:=1.50 \cdot \text { in } \\
& \text { specified thickness of nozzle } \\
& r_{m . n}:=r_{i . n}+\frac{t_{n}}{2}=6.75 \cdot \text { in } \quad \text { mean radius of nozzle } \\
& \mathrm{d}_{\text {i.n }}:=2 \cdot \mathrm{r}_{\mathrm{in}}=12 \cdot \mathrm{in} \quad \text { inside diameter of nozzle } \\
& r_{o . n}:=r_{i . n}+t_{n}=7.5 \cdot \text { in } \quad \text { outside radius of nozzle (calculated from input) }
\end{aligned}
$$

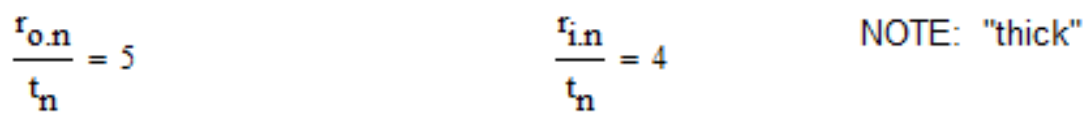

$$
\begin{aligned}
& A_{n}:=\pi \cdot\left(r_{o . n}^{2}-r_{i . n}^{2}\right)=63.617 \cdot \text { in }^{2} \quad \text { nozzle cross-sectional area } \\
& \mathrm{S}_{\mathrm{n}}:=\frac{\pi}{16} \cdot \frac{\left(\mathrm{r}_{\text {o.n }}{ }^{4}-\mathrm{r}_{\mathrm{i} . \mathrm{n}}^{4}\right)}{\mathrm{r}_{\mathrm{o} . \mathrm{n}}}=48.906 \cdot \mathrm{in}^{3} \quad \text { nozzle section modulus }
\end{aligned}
$$

\section{Shell Geometry -- INPUT and related calculations}

$$
\begin{aligned}
& R_{\text {i.s }}:=25 \cdot \text { in } \\
& \text { specified inside radius of spherical shell } \\
& \mathrm{t}_{\mathrm{s}}:=2.75 \cdot \text { in } \\
& \text { specified thickness of nozzle } \\
& R_{o . s}:=R_{i . s}+t_{s}=27.75 \cdot \text { in } \\
& \text { outside radius of shell (calculated from input) } \\
& R_{m . s}:=R_{i . s}+\frac{t_{s}}{2}=26.375 \cdot \text { in } \\
& \text { mean radius of shell } \\
& \frac{R_{0 . s}}{t_{s}}=10.091 \\
& \frac{R_{\text {i.s }}}{t_{s}}=9.091
\end{aligned}
$$




\section{Design Level Loads -- INPUT}

$\begin{array}{ll}\mathrm{p}_{\text {des }}:=700 \cdot \mathrm{psi} & \text { Design Level internal design pressure } \\ \mathrm{p}_{\text {Lev.A.max }}:=675 \cdot \mathrm{psi} & \text { Level A maximum pressure } \\ \mathrm{p}_{\text {Lev.B.max }}:=750 \cdot \mathrm{psi} & \text { Level B maximum pressure } \\ \mathrm{p}_{\text {Lev.C.max }}:=775 \cdot \mathrm{psi} & \text { Level C maximum pressure } \\ \mathrm{F}_{\text {des }}:=30000 \cdot 1 \mathrm{bf} & \text { Design Level "FVMT" axial load, } \mathrm{F} . \\ \mathrm{V}_{\text {des }}:=4000 \cdot 1 \mathrm{bf} & \text { Design Level "FVMT" shear load, V. }\end{array}$ $\mathrm{M}_{\text {des }}:=\left(\mathrm{d}_{\mathrm{Y}}+\frac{\mathrm{t}_{\mathrm{s}}}{2}\right) \cdot \mathrm{V}_{\mathrm{des}}=5.35000 \times 10^{4} \cdot$ in $\cdot 1 \mathrm{bf} \quad \begin{aligned} & \text { Design Level bending moment, } \mathrm{M} \text {; } \\ & \text { the resultant bending moment due }\end{aligned}$ to specified shear and distance to$$
\mathrm{M}_{\mathrm{des}}=4.458 \times 10^{3} \cdot \mathrm{ft} \cdot 1 \mathrm{bf}
$$ mid-thickness of the shell.

\begin{tabular}{|c|c|}
\hline $\operatorname{Trq}_{\text {des }}:=20000 \cdot$ in $\cdot 1 b f$ & Design Level "FVMT" torsional moment, $\mathrm{T}$. \\
\hline $\mathrm{T}_{\mathrm{des}}:=1200^{\circ} \mathrm{F}$ & Design Temperature \\
\hline $\mathrm{T}_{\max . \text { Lev.A }}:=1100^{\circ} \mathrm{F}$ & maximum Level A temperature \\
\hline $\mathrm{T}_{\max . \mathrm{Lev} . \mathrm{B}}:=1175^{\circ} \mathrm{F}$ & maximum Level B temperature \\
\hline $\mathrm{T}_{\max . L e v . C}:=1300^{\circ} \mathrm{F}$ & maximum Level $\mathrm{C}$ temperature \\
\hline $\mathrm{k}_{\text {Lev } . A B}:=1.0$ & $\begin{array}{l}\text { Factor for Level A maximum up-ramp mechanical } \\
\text { loads. }\end{array}$ \\
\hline $\mathrm{k}_{\text {Lev.B } B}:=1.25$ & $\begin{array}{l}\text { Factor for Level B maximum up-ramp mechanical } \\
\text { loads. }\end{array}$ \\
\hline $\mathrm{k}_{\text {Lev.C }}:=2$ & $\begin{array}{l}\text { Factor for Level } \mathrm{C} \text { maximum up-ramp mechanical } \\
\text { loads. }\end{array}$ \\
\hline $\mathrm{n}_{\text {cyc.Lev. } \mathrm{B}}:=850$ & number of cycles Level B loading \\
\hline $\mathrm{n}_{\text {cyc.Lev.C }}:=25$ & number of cycles Level C loading \\
\hline
\end{tabular}




$$
\begin{aligned}
& \mathrm{t}_{\mathrm{gt} .1100 \mathrm{~F} . \mathrm{Lev} \cdot \mathrm{B}}:=350 \cdot \mathrm{sec} \quad \text { time above } 1100 \mathrm{~F} \text { in one Level B cycle } \\
& t_{\text {gt.1100F.Lev.C }}=390 \cdot \mathrm{sec} \quad \text { time above } 1100 \mathrm{~F} \text { in one Level } \mathrm{C} \text { cycle } \\
& t_{\max . L e v . A}:=100000 \cdot \mathrm{hr} \quad \begin{array}{l}
\text { time at maximum temperature, leve } \\
\text { (conservative at entire design life) }
\end{array}
\end{aligned}
$$

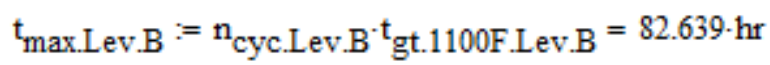

$$
\begin{aligned}
& \text { time above } 1100 \mathrm{~F} \text { in one Level B cycle Page } 43 \text { of } 49
\end{aligned}
$$

time at maximum temperature, Level $\mathrm{B}$; all time above $1100 \mathrm{~F}$ for number of cycles. NOTE: $1100 \mathrm{~F}$ is used here to be conservative with respect to the $1200 \mathrm{~F}$ design temperature for determoining this time.

$$
\mathrm{t}_{\max \cdot L \mathrm{ev} \cdot \mathrm{C}}:=\mathrm{n}_{\text {cyc.Lev.C }} \mathrm{t}_{\text {gt.1100F.Lev.C }}=2.70 \mathrm{~s} \cdot \mathrm{hr}
$$

time at maximum temperature, Level $\mathrm{C}$; all time above $1100 \mathrm{~F}$ for number of cycles. NOTE: $1100 \mathrm{~F}$ is used here to be conservative with respect to the $1200 \mathrm{~F}$ design temperature for determoining this time.

NOTE: Deadweight is not significant enough to be included in the sizing calculations.

\section{Material Specification -- INPUT}

316 SS as permitted by $\mathrm{NH}-2000$.

\section{Allowable Stress Intensities -- INPUT}

$$
\begin{aligned}
& t_{\text {life }}:=100000 \cdot h r \\
& \mathrm{~S}_{\mathrm{o}}:=7.4 \cdot \mathrm{ksi} \\
& \mathrm{S}_{\mathrm{mt} . \mathrm{DL}}:=5.5 \cdot \mathrm{ksi} \\
& \text { specified component design life } \\
& \text { Design Level basic allowable stress at } 1200 \mathrm{~F} \text {; see } \\
& \text { Section } 4 \text { Tables. } \\
& S_{m t} \text { value for Level A, B, C tTemperatures }<1200 \\
& \mathrm{~F} \text { for } 100,000 \mathrm{hr} \text { (time not covered by other } S_{\mathrm{mt}} \\
& \text { and } S_{t} \text { values below); see Section } 4 \text { Tables. } \\
& \mathrm{S}_{\text {mt.Lev.B.maxT }}:=14.6 \cdot \mathrm{ksi} \\
& 1200 \mathrm{~F}, 100 \mathrm{hr} \text { to cover } \mathrm{t}_{\text {max. Lev. } \mathrm{B}} \\
& \mathrm{S}_{\text {t.Lev.C.max } \mathrm{T}}:=16.1 \cdot \mathrm{ksi} \\
& 1300 \mathrm{~F}, 1 \mathrm{hr} \text { to cover } \mathrm{t}_{\text {max. Lev.C }}
\end{aligned}
$$




\section{Sizing Calculations for Design Level and Level A and B Loadings: Nozzle}

First consider loading applicable to beyond steady state operating loads of the design life, i.e., not the transient loading stresses that are the short-term loads, but conservatively use the entire design life for time.

$$
\begin{aligned}
& \mathrm{p}_{\text {Lev.AB.max }}:=\mathrm{p}_{\text {des }}=700 \cdot \mathrm{psi} \\
& \mathrm{S}_{\text {sizing. } \mathrm{DL}}:=\min \left(\mathrm{S}_{\mathrm{o}}, \mathrm{S}_{\mathrm{mt} . \mathrm{DL}}\right)=5.5 \cdot \mathrm{ksi} \\
& \mathrm{t}_{\mathrm{n} . \mathrm{r}}:=\frac{\mathrm{p}_{\text {Lev.AB.max }} \cdot \mathrm{r}_{\mathrm{i} \cdot \mathrm{n}}}{\mathrm{S}_{\text {sizing.DL }}-\frac{\mathrm{p}_{\text {Lev.B.max }}}{2}}=0.82 \cdot \text { in } \\
& \mathrm{t}_{\mathrm{n}}=1.5 \cdot \mathrm{in} \\
& \frac{t_{n . r}}{t_{n}}=0.546 \\
& \text { conservatively set Level A and B } \\
& \text { internal pressure to Design Level } \\
& \text { proessure } \\
& \text { covers Design and Level A } \\
& \text { required nozzle thickness for } \\
& \text { pressure } \\
& \text { nozzle thinkness provided } \\
& \text { ACCEPTABLE when ratio } \leq \mathbf{1 . 0} \\
& P_{m} \text { stress intensity } \\
& \frac{\mathrm{p}_{\text {Lev.AB.max }}{ }^{-\mathrm{r}_{\text {inn }}}}{\mathrm{t}_{\mathrm{n}}}=2.800 \cdot \mathrm{ksi} \quad \text { longitudinal due to pressue } \\
& \frac{F_{\text {des }} \cdot k_{\text {Lev. } . A B}}{A_{n}}=0.472 \cdot \mathrm{ksi} \quad \text { longitudinal due to axial pipe load } \\
& \frac{\mathrm{M}_{\text {des }} \cdot \mathrm{k}_{\mathrm{Lev} \cdot \mathrm{AB}}}{\mathrm{S}_{\mathrm{n}}}=1.094 \cdot \mathrm{ksi} \quad \text { longitudinal due to bending pipe load } \\
& \sigma_{\text {noz.long }}:=\frac{\mathrm{p}_{\text {Lev.AB.max }} \cdot \mathrm{r}_{\mathrm{inn}}}{2 \mathrm{t}_{\mathrm{n}}}+\frac{\mathrm{F}_{\text {des }} \cdot \mathrm{k}_{\mathrm{Lev} \cdot \mathrm{AB}}}{\mathrm{A}_{\mathrm{n}}}+\frac{\mathrm{M}_{\text {des }} \cdot \mathrm{k}_{\text {Lev } \cdot A B}}{\mathrm{~S}_{\mathrm{n}}}=2.966 \cdot \mathrm{ksi} \\
& \sigma_{\text {noz.hoop }}:=\frac{\mathrm{p}_{\text {Lev.AB.max }}{ }^{-r_{i n n}}}{t_{n}}=2.8 \cdot \mathrm{ksi}
\end{aligned}
$$




$$
\begin{aligned}
& \tau_{\text {noz.trq }}:=\frac{\operatorname{Trq}_{\text {des }} \cdot \mathrm{k}_{\text {Lev.AB }}}{2 \cdot \mathrm{S}_{\mathrm{n}}}=0.204 \cdot \mathrm{ksi} \\
& \mathrm{S} 1_{\text {noz }}:=\frac{\sigma_{\text {noz.long }}+\sigma_{\text {noz.hoop }}}{2}+\sqrt{\left(\frac{\sigma_{\text {noz.long }}-\sigma_{\text {noz.hoop }}}{2}\right)^{2}+\tau_{\text {noz.trq }}} 2^{2} \\
& \mathrm{~S} 1_{\mathrm{noz}}=3.103 \cdot \mathrm{ksi} \\
& \mathrm{S} 2_{\text {noz }}:=\frac{\sigma_{\text {noz.long }}+\sigma_{\text {noz.hoop }}}{2}-\sqrt{\left(\frac{\sigma_{\text {noz.long }}-\sigma_{\text {noz.hoop }}}{2}\right)^{2}+\tau_{\text {noz.trq }}}{ }^{2} \\
& \mathrm{~S} 2_{\mathrm{noz}}=2.662 \cdot \mathrm{ksi} \\
& \mathrm{S} 3_{\mathrm{noz}}:=\frac{-\mathrm{p}_{\mathrm{des}}}{2}=-0.35 \cdot \mathrm{ksi} \\
& \mathrm{S} 12_{\text {noz }}:=\mathrm{S} 1_{\text {noz }}-\mathrm{S} 2_{\text {noz }}=0.441 \cdot \mathrm{ksi} \\
& \mathrm{S} 23_{\mathrm{noz}}:=\mathrm{S} 2_{\mathrm{noz}}-\mathrm{S} 3_{\mathrm{noz}}=3.012 \cdot \mathrm{ksi} \\
& \mathrm{S} 31_{\mathrm{noz}}:=\mathrm{S} 3_{\mathrm{noz}}-\mathrm{S} 1_{\mathrm{noz}}=-3.453 \cdot \mathrm{ksi} \\
& \mathrm{SI}_{\text {noz.Pm }}:=\max \left(\left|\mathrm{S} 12_{\text {noz }}\right|,\left|\mathrm{S} 23_{\text {noz }}\right|,\left|\mathrm{S} 31_{\text {noz }}\right|\right)=3.453 \cdot \mathrm{ksi} \\
& \frac{\mathrm{SI}_{\text {noz.Pm }}}{\mathrm{S}_{\text {sizing.DL }}}=0.628
\end{aligned}
$$

\section{ACCEPTABLE when ratio $\leq \mathbf{1 . 0}$}

Consider the Level B short-term maximum loading at short-term maximum temperatures. The following approximate evaluation is used.

The maximum Level B mechanical loads are 1.25 times the design and Level A loads, and the maximum Level $\mathrm{C}$ loads are 2 times the Design and Level A loads. See Section 3.3.

The short-term $S_{m t}$ value for the maximum temperature for Level $B$ is more than double the design load (DL) $S_{m t}$ value as shown below. The $S_{t}$ value for the short-term Level $C$ maximum loads is even higher, and therefore using the Level B $\mathrm{S}_{\mathrm{mt}}$ values below cover evaluation of Level $\mathrm{C}$ short-term loads and maximum temperatures.

On this basis, the estimated $\mathrm{P}_{\mathrm{m}}$ acceptance ratios for both Level $\mathrm{B}$ and Level $\mathrm{C}$ maximum 


$$
\begin{aligned}
& \mathrm{S}_{\mathrm{mt} \cdot \mathrm{Lev} \cdot \mathrm{B} \cdot \operatorname{maxT}}=14 \cdot 6 \cdot \mathrm{ksi} \\
& \frac{\mathrm{S}_{\mathrm{mt} \cdot \mathrm{Lev} \cdot \mathrm{B} \cdot \max \mathrm{T}}}{\mathrm{S}_{\mathrm{mt} \cdot \mathrm{DL}}}=2.655
\end{aligned}
$$

Conservatively for Level B and C; factor 2.0 is for Level C FVMT loads.

$$
\begin{array}{lcc}
\mathrm{p}_{\text {Lev.C.max }}=0.775 \cdot \mathrm{ksi} & \mathrm{p}_{\text {des }}=0.7 \cdot \mathrm{ksi} & \mathrm{S}_{\text {mt.Lev.B.maxT }}=14.6 \cdot \mathrm{ksi} \\
\mathrm{S}_{\mathrm{mt} . \mathrm{DL}}=5.5 \cdot \mathrm{ksi} & \mathrm{SI}_{\text {noz.Pm }}=3.453 \cdot \mathrm{ksi} & \mathrm{S}_{\text {sizing.DL }}=5.5 \cdot \mathrm{ksi} \\
\frac{\mathrm{k}_{\text {Lev.C }}\left(\frac{\mathrm{p}_{\text {Lev.C.max }}}{\mathrm{p}_{\text {des }}}\right)}{\frac{\mathrm{S}_{\mathrm{mt} \cdot \text { Lev.B.maxT }}}{\mathrm{S}_{\mathrm{mt} . \mathrm{DL}}}} \cdot \frac{\mathrm{SI}_{\text {noz.Pm }}}{\mathrm{S}_{\text {sizing.DL }}}=0.524 & \text { ACCEPTABLE when ratio } \leq 1.0
\end{array}
$$

\section{Sizing Calculations for Design Level and Level A and B Loadings: Shell}

NOTE: These calculations Ignore piping loads effects in the spherical shell, which cause $P_{L}$ and $P+Q$ stresses in the shell. $P_{L}$ and $P+Q$ stress intensiteis are calculated with WRC-107 [17] methodology and eventually by elastic FEA evaluation for elastically checking the FEA model to be used for elastic-perfectly plastic evaluation of the proposed Code Cases.

$$
t_{\mathrm{s} . \mathrm{r}}:=\frac{\mathrm{p}_{\text {Lev.AB.max }} \cdot \mathrm{R}_{\mathrm{i} . \mathrm{s}}}{2 \mathrm{~S}_{\text {sizing.DL }}-\frac{\mathrm{p}_{\text {Lev.A.max }}}{2}}=1.641 \text {.in } \begin{aligned}
& \text { required shell thickness for design and } \\
& \text { Level A pressure. }
\end{aligned}
$$

$\mathrm{t}_{\mathrm{s}}=2.75 \cdot$ in shell thickness provided

$$
\begin{array}{ll}
\frac{t_{\mathrm{s} . \mathrm{r}}}{\mathrm{t}_{\mathrm{s}}}=0.597 & \text { ACCEPTABLE wh } \\
\frac{\mathrm{p}_{\text {Lev.AB.max }} \cdot \mathrm{R}_{\mathrm{i} . \mathrm{s}}}{2 \cdot \mathrm{t}_{\mathrm{s}}}=3.182 \cdot \mathrm{ksi} & 0.5 \cdot \mathrm{p}_{\text {des }}=0.35 \cdot \mathrm{ksi}
\end{array}
$$


$\mathrm{SI}_{\mathrm{Pm} . \text { shell }}:=\frac{\mathrm{p}_{\text {Lev } \cdot A B \cdot \max } \cdot \mathrm{R}_{\mathrm{i} . \mathrm{s}}}{2 \cdot \mathrm{t}_{\mathrm{s}}}+0.5 \cdot \mathrm{p}_{\text {Lev } \cdot A B \cdot \max }=3.532 \cdot \mathrm{ksi}$

conservatively covers nearly the entire design life for levels $A$ and $B$, i.e., $S_{\text {.sizing.DL }}$

is for the design temperature and for the entire design life.

$$
\frac{\mathrm{SI}_{\mathrm{Pm} . \text { shell }}}{\mathrm{S}_{\text {sizing.DL }}}=0.642
$$

\section{ACCEPTABLE when ratio $\leq 1.0$}

Applying the same ratios as described above for the nozzle, the shell's acceptance ratio for Level A, B and C is conservatively computed as follows.

$$
\frac{\mathrm{k}_{\text {Lev.C }} \cdot\left(\frac{\mathrm{p}_{\text {Lev.C.max }}}{\mathrm{p}_{\text {des }}}\right)}{\frac{\mathrm{S}_{\text {mt.Lev.B.max } \mathrm{T}}}{\mathrm{S}_{\mathrm{mt} \cdot \mathrm{DL}}}} \cdot \frac{\mathrm{SI}_{\text {Pm.shell }_{\text {s }}}}{\mathrm{S}_{\text {sizing.DL }}}=0.536
$$

\section{ACCEPTABLE when ratio $\leq \mathbf{1 . 0}$}

The WRC-107 analysis of the nozzle/sphere intersection treating the nozzle as a rigid attachment with an outside radius extending to the end of the transition material in the shell is summarized below. This is an approximate analysis of the interaction loads for this elevated temperature component using the $(P+Q)$ stresses and comparing them to the typical elastic analysis limit of $3 S$. Showing that the $(P+Q)$ stresses remain less than the $3 S_{\mathrm{mt}}$ and $3 \mathrm{~S}_{\mathrm{t}}$ limits for design loads and short-term Level A, B and C loads is approximate. It does not include the significant thermal portion of $Q$, which will be evaluated using the proposed Code Cases.

$\mathrm{PQ}_{\mathrm{DL}}:=9.0 \cdot \mathrm{ksi}$ from WRC-107 analysis of juncture as described

$$
\frac{\mathrm{PQ}_{\mathrm{DL}}}{3 \cdot \mathrm{S}_{\mathrm{mt} . \mathrm{DL}}}=0.545
$$

$\mathrm{PQ}_{\mathrm{Lev} \cdot \mathrm{B}}:=\mathrm{k}_{\mathrm{Lev} \cdot \mathrm{B}} \cdot \mathrm{PQ}_{\mathrm{DL}}=11.25 \cdot \mathrm{ksi}$

$$
\frac{\mathrm{PQ}_{\text {Lev.B }}}{3 . \mathrm{S}_{\text {mt.Lev.B.max }}}=0.257
$$

\section{ACCEPTABLE when ratio $\leq 1.0$}

from load-ratioing design level $B$ FVMT loads. This $\mathrm{k}_{\text {.Lev. }}$ factor conservatively covers the ratio for Level $B$ pressure load, which is less than $\mathrm{k}_{\text {.Lev. }} \mathrm{B}^{\text {- }}$

\section{ACCEPTABLE when ratio $\leq 1.0$}


$\mathrm{PQ}_{\text {Lev.C }}:=\mathrm{k}_{\text {Lev.C }} \cdot \mathrm{PQ}_{\mathrm{DL}}=18 \cdot \mathrm{ksi}$

$\frac{\mathrm{PQ}_{\text {Lev.C }}}{3 \cdot \mathrm{S}_{\text {t.Lev.C.maxT }}}=0.373$ from load-ratioing design level $\mathrm{C}$ FVMT loads. This $\mathrm{k}_{\text {.Lev.C }}$ factor conservatively covers the ratio for Level $B$ pressure load, which is less than $\mathrm{k}_{\text {.Lev.C. }}$

\section{ACCEPTABLE when ratio $\leq \mathbf{1 . 0}$}

Reinforcement to set transition size using NB-3334 and reference to NB-3338.2(a)-2 sketch c.

NB-3334.1(a) Limits along vessel wall.

$$
\begin{aligned}
& \mathrm{L}_{\mathrm{s} . a 1}:=\mathrm{d}_{\mathrm{inn}}-\mathrm{r}_{\mathrm{i} . \mathrm{n}}-\mathrm{t}_{\mathrm{n} . \mathrm{r}}=5.18 \cdot \mathrm{in} \\
& \mathrm{L}_{\mathrm{s} . \mathrm{a} 2}:=\mathrm{r}_{\mathrm{i} . \mathrm{n}}+\left(\mathrm{t}_{\mathrm{n}}+\mathrm{t}_{\mathrm{s}}\right)=10.25 \cdot \text { in } \\
& \mathrm{L}_{\mathrm{s} . \mathrm{b} 1}:=\mathrm{r}_{\mathrm{i} . \mathrm{n}}+0.5 \cdot \sqrt{\mathrm{R}_{\mathrm{m} \cdot \mathrm{s}} \cdot \mathrm{t}_{\mathrm{s}}}=10.258 \cdot \mathrm{in} \\
& \mathrm{L}_{\mathrm{s} . \mathrm{b} 2}:=\mathrm{r}_{\mathrm{i} . \mathrm{n}}+\frac{2}{3} \cdot\left(\mathrm{t}_{\mathrm{s}}+\mathrm{t}_{\mathrm{n}}\right)=8.833 \cdot \mathrm{in}
\end{aligned}
$$

NB-3334.1(a) Limits along vessel wall.

$$
\begin{aligned}
& \mathrm{L}_{\mathrm{n} \cdot \mathrm{b}}:=\frac{\sqrt{\mathrm{r}_{\mathrm{m} \cdot \mathrm{n}} \cdot \mathrm{t}_{\mathrm{n}}}}{2}=1.591 \cdot \mathrm{in} \\
& \mathrm{A}_{\mathrm{r}}:=\mathrm{t}_{\mathrm{s} \cdot \mathrm{r}} \cdot 2 \cdot \mathrm{r}_{\mathrm{i} \cdot \mathrm{n}}=19.695 \cdot \mathrm{in}^{2}
\end{aligned}
$$

total reinforcement area both sides

Subtract reinforcement areas in shell and nozzle based on reinforcement dimensions, each size of nozzle centerline.

$$
A_{\text {r.net }}:=\frac{A_{r}}{2}-L_{s . a 2} \cdot\left(t_{n}-t_{n . r}\right)-L_{n \cdot b} \cdot\left(t_{s}-t_{s . r}\right)=1.109 \cdot \text { in }^{2}
$$

Compute legs of triangular reinforcement region, $x$ to provide $A_{\text {r.net }}=1 / 2 x^{2}$.

$\mathrm{x}:=\sqrt{2 \cdot \mathrm{A}_{\mathrm{r} . n e t}}=1.489 \cdot \mathrm{in} \quad$ basic dimension of triangular transition region 


\section{Blend Radii per NB-3338.2(a)-2 Sketch (c) and NB-3339.1(b)-1 Sketch (b)}

Although NB-3338 and NB-3339 are not being used, the dimensional information regarding blend radii for the REP is being applied.

\section{NB-3338.2(a)-2 Sketch (c)}

$$
\begin{aligned}
& \mathrm{r}_{1.3338 \cdot \min }:=0.1 \cdot \mathrm{t}_{\mathrm{s}}=0.275 \mathrm{in} \\
& \mathrm{r}_{1.3338 \cdot \max }:=\mathrm{t}_{\mathrm{s}}=2.75 \mathrm{in} \\
& \mathrm{r}_{2.3338}:=\max \left(\frac{\mathrm{t}_{\mathrm{n}}}{2}, \frac{\mathrm{t}_{\mathrm{s}}}{2}\right)=1.375 \mathrm{in} \\
& { }_{\mathrm{deg}}:=45 \\
& \mathrm{r}_{3.3338}:=0.002 \cdot \theta_{\operatorname{deg}} \cdot 2\left(\mathrm{r}_{\mathrm{inn}}+\mathrm{t}_{\mathrm{n}}\right)=1.35 \mathrm{in}
\end{aligned}
$$

\section{NB-3339.1(b)-1 Sketch (b)}

$$
\begin{aligned}
& \mathrm{r}_{1.3339 \cdot \min }:=0.1 \cdot \mathrm{t}_{\mathrm{s}}=0.275 \mathrm{in} \\
& \mathrm{r}_{1.3339 \cdot \max }:=0.5 \cdot \mathrm{t}_{\mathrm{s}}=1.375 \mathrm{in} \\
& \mathrm{r}_{3.3339}:=\max \left[\sqrt{\frac{\theta}{90}\left(2 \cdot \mathrm{r}_{i . n}\right) \cdot \mathrm{t}_{\mathrm{n} . \mathrm{r}}} \frac{\left.{ }^{\theta} \frac{\mathrm{deg}}{90} \cdot \mathrm{t}_{\mathrm{n}}\right]=2.217 \mathrm{in}}{\mathrm{r}_{4.3339}:=\left(1-\sqrt{\frac{\theta \text { deg }}{90}}\right) \sqrt{\left(2 \cdot \mathrm{r}_{\text {i.n }}\right) \mathrm{t}_{\mathrm{n} . \mathrm{r}}}=0.918 \mathrm{in}}\right.
\end{aligned}
$$

The following values are chosen:

1. The inside nozzle radius the range of $r_{1}$ for both 3338 and 3339 is between 0.275 in and 2.75 in.; 2.0 inch is chosen.

2. The outside nozzle-to-transition blend radius, $r_{3}$, for both 3338 and 3339 , the values are either 1.375 or 2.217 in; 1.375 in is chosen.

3. The outside transition-to-shell blend radius $r_{2}$ for 3338 or $r_{4}$ for 3339 is either 1.375 in or 0.918 in; 1.375 in is chosen.

\section{END OF SIZING CALCULATIONS}




\section{Elevated Temperature Code Case Representative Example Problem Analysis}

Document No. 20362-R-002

Revision No. 3

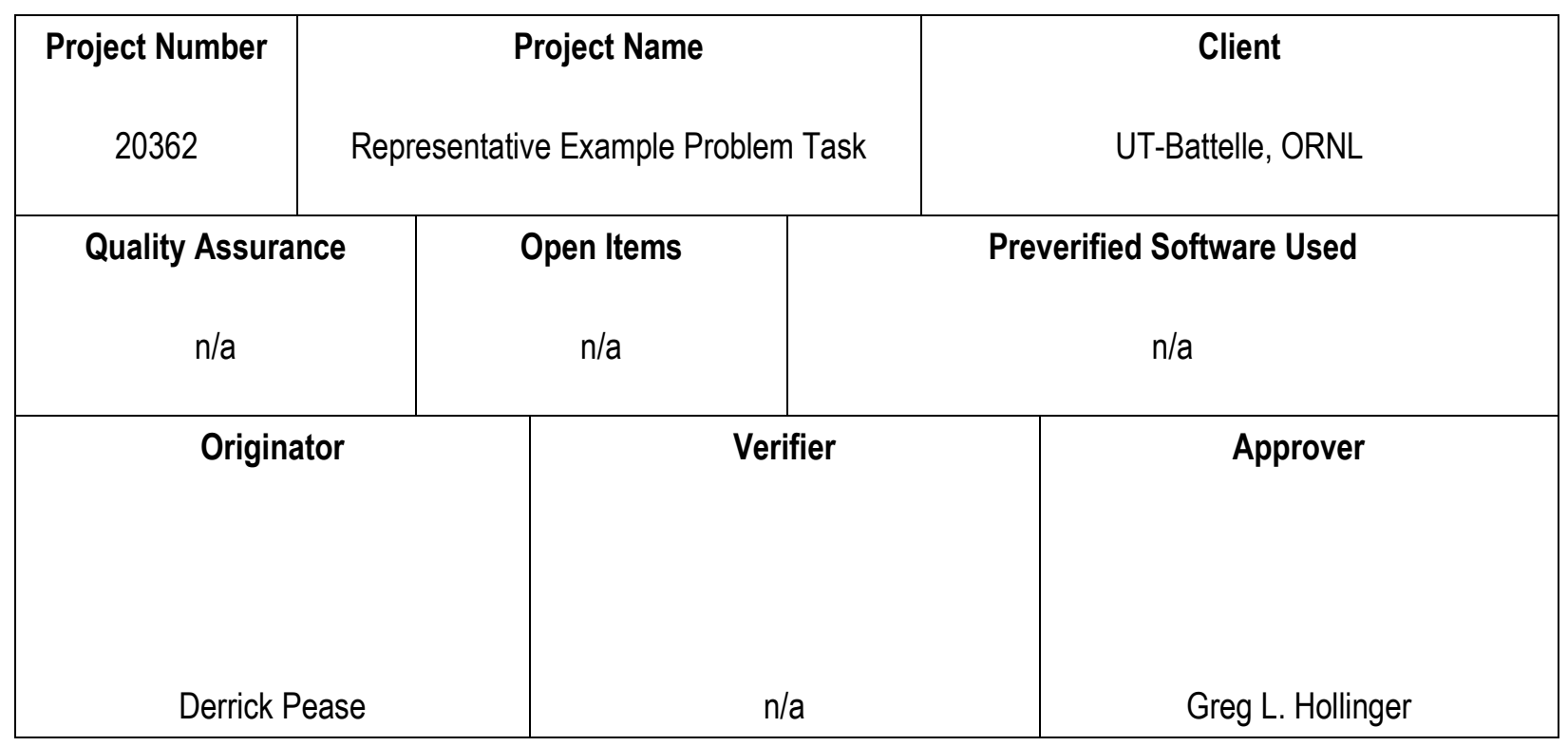




\section{Table of Contents}

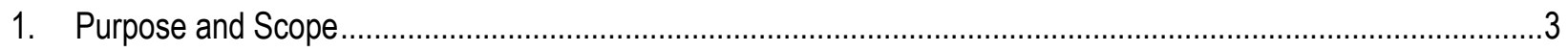

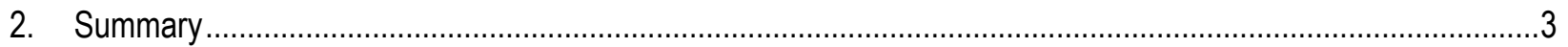

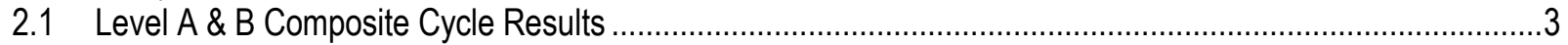

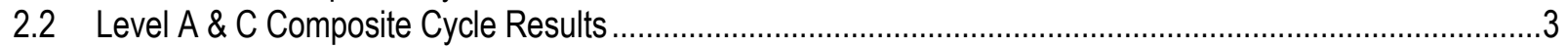

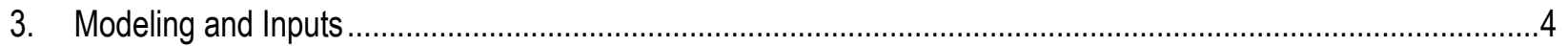

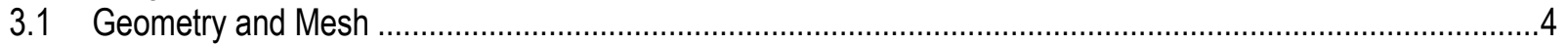

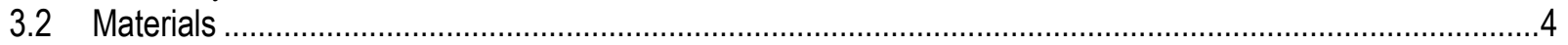

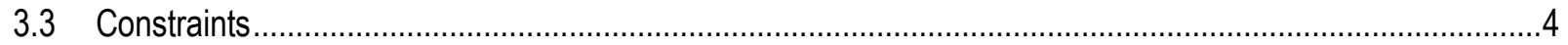

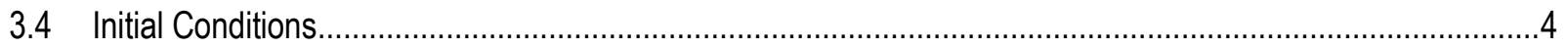

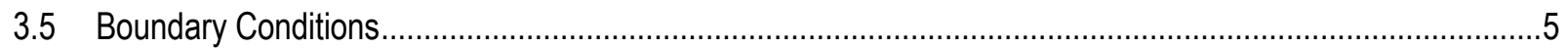

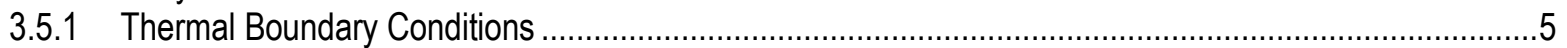

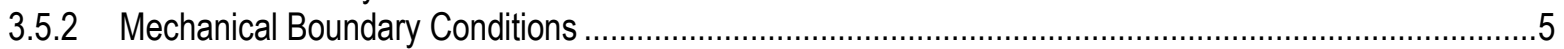

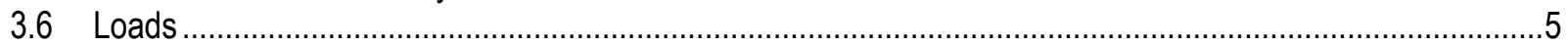

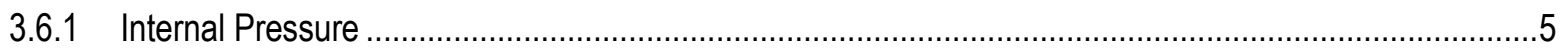

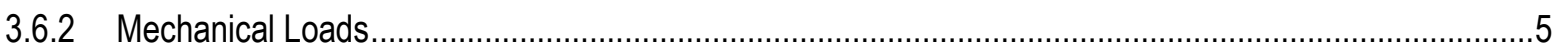

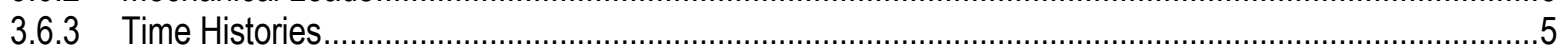

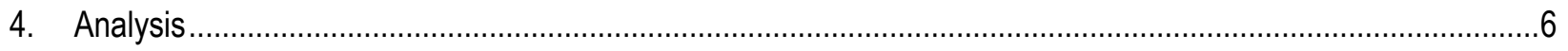

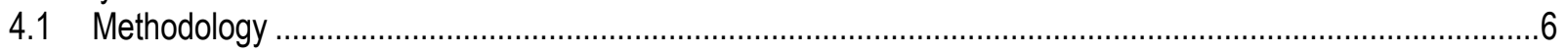

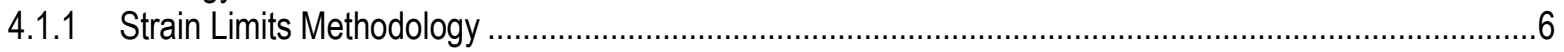

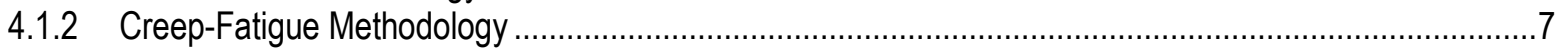

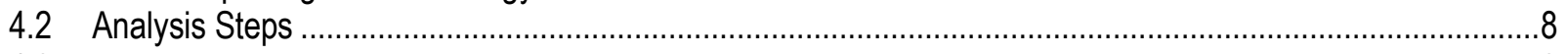

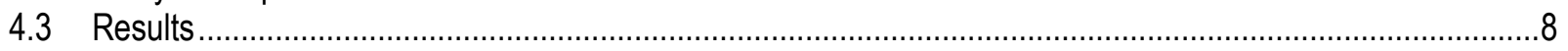

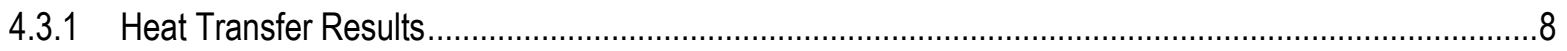

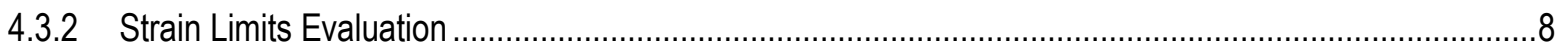

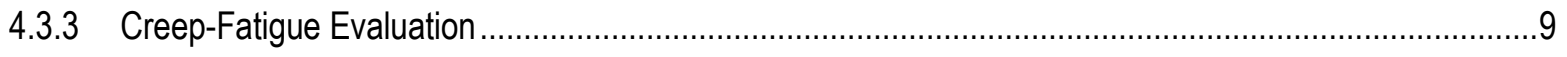

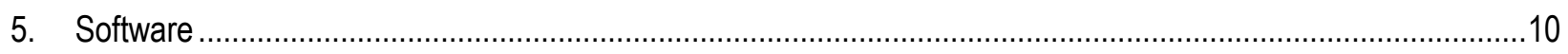

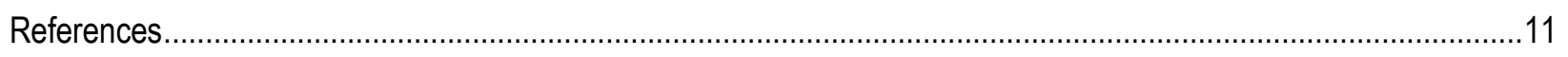

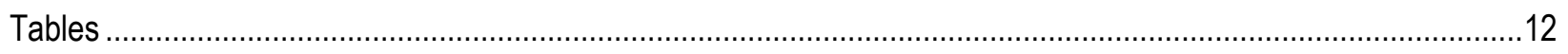

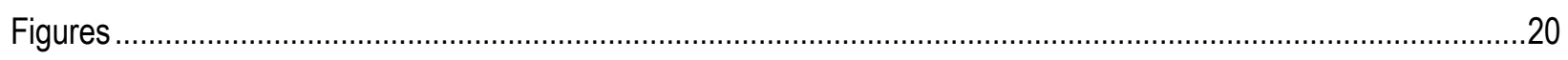

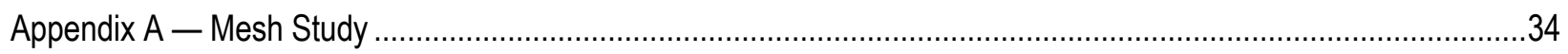

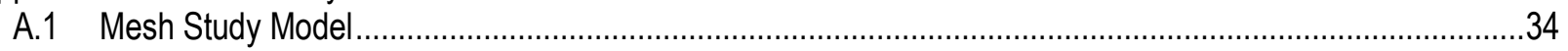

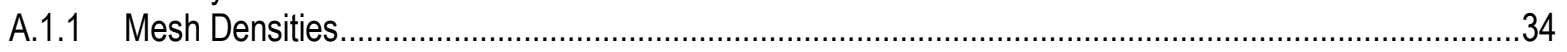

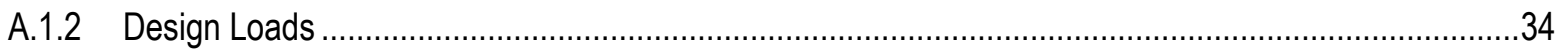

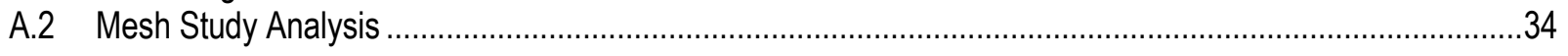

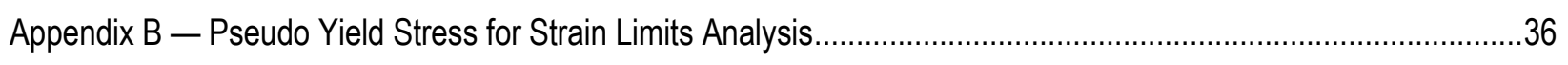

Appendix C — Pseudo Yield Stress for Creep-Fatigue Analysis ......................................................................47

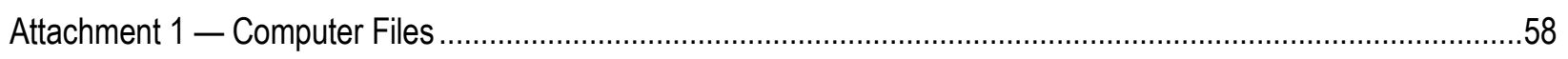

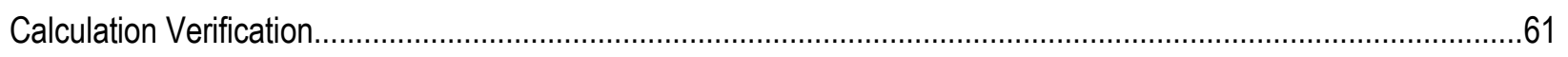

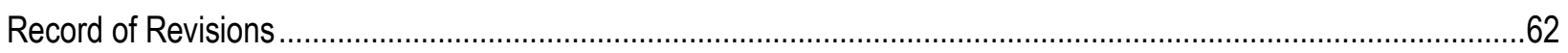




\section{Purpose and Scope}

The purpose of this report is to document the implementation of the strain limits code case and the creep-fatigue code case [Ref. 1, Section 2.0] using the representative example problem (REP) vessel defined in the REP Design Specification [Ref. 1]. To investigate the impact of the weldment on the analyses, two versions of the REP vessel are modeled: one with base metal only (REP-B) and one with the weldment (REP-W).

\section{Summary}

The implementation evaluations of the strain limits code case and the creep fatigue code case in the Design Specification [Ref. 1] are successful using the two REP models and evaluations. The implementation of the code cases requires trial-and-error finite element EPP runs with starting target inelastic strains (for strain limits evaluation) or target creep damage (for creep-fatigue evaluation), iterated with successively smaller values and adjusted pseudo yield stress curves until the criteria in the code cases are met. The results are summarized as follows.

\subsection{Level A \& B Composite Cycle Results}

The Level A \& B Composite Cycle is evaluated using both the REP Base Metal Only model (REP-B) and the REP with Weldment model (REP-W). Both evaluations meet the strain limits code case evaluation criteria and the creepfatigue code case evaluation criteria.

Level A \& B Composite Cycle strain limits code case evaluation: The controlling base metal location for both models is at the outer surface of the shell-to-nozzle transition where nozzle bending due to the nozzle end shear load produces maximum strains. The EPP plastic strain developed at this location for the base metal only model and the model with the weldment is small $-0.0006 \%$ and $0.0009 \%$, respectively. Since the weldment does not yield during the level A \& B loadings there is not a controlling weldment location. Furthermore, since the weldment behaves elastically with the same properties as the base metal, both models behave with only a slight difference in base metal plastic strains. That difference is attributed to the differences in the model meshes.

Level A \& B Composite Cycle creep-fatigue code case evaluation: The controlling base metal location for both models is at the outer surface of the shell-to-nozzle transition, rotated approximately $45^{\circ}$ from where nozzle bending due to the nozzle end shear load produces maximum strains. The Level A \& B cycle type maximum equivalent strain range at this location for both the base metal only model and the model with the weldment is $0.110 \%$. However, for the Level B cycle type they are slightly different, $0.076 \%$ and $0.077 \%$ respectively. The controlling weldment location is on the inside surface of the shell on the outermost weld-base metal interface. The maximum equivalent strain range at this location from both models is $0.083 \%$ for the Level B cycle type and $0.037 \%$ for the Level A cycle type.

\subsection{Level A \& C Composite Cycle Results}

The Level A \& C Composite Cycle is evaluated using only the REP-B model. The evaluation exceeds the strain limit code case evaluation criteria due to significant plastic strains developing within 2 pseudo-cycles. The evaluation exceeds the creep-fatigue code case evaluation criteria due to ratcheting, albeit stable ratcheting and with a target creep damage of 1.0. Further trials of different target creep damages are not performed since reducing the target creep damage only reduces the pseudo yield strength making it even more difficult to achieve shakedown.

No evaluation of the Level A \& C Composite Cycle with the REP-W model is performed since based on the criteria not being met for the REP-B model, the same unmet criteria would be obtained. 


\section{Modeling and Inputs}

Both the REP-B and REP-W vessels are modeled in Abaqus 6.13-4 as shown in Figure 3-1.

\subsection{Geometry and Mesh}

The geometry profile of the REP vessels used to generate the 3D half-symmetric models of the REP vessels is shown in Figure 3.1-1. The REP vessels are modeled using 8-node linear brick elements with full integration (C3D8) for stress analyses and 8-node linear heat transfer brick elements (DC3D8) for heat transfer analyses. The same mesh, as shown in Figure 3.1-2 for the REP-B model and Figure 3.1-3 for the REP-W model, is used for both element types. The selected mesh density is based on the mesh study in Appendix A.

\subsection{Materials}

The REP vessel base metal is modeled using 316 forged stainless steel properties in accordance with material specification SA-182 grade F316 and the weldment is modeled using 316 stainless steel weld properties in accordance with SFA-5.4 grade E316. The material properties included in the model are: density, specific heat and conductivity for heat transfer analyses and modulus of elasticity, Poisson's ratio, mean thermal expansion coefficient and yield stress for stress analyses. The values used in the FEA model are listed in Table 3.2-1 through Table 3.2-3.

For the strain limits evaluation, the yield stress is set as a temperature dependent "pseudo yield stress" based on the total time duration of high temperature service, $t_{d}$, and the selected target inelastic strain, $x$. This "pseudo yield stress" is equal to the lesser of the yield strength given in Table I-14.5 of Subsection NH as modified by Subarticle $\mathrm{NH}-2160$; and the stress to cause $x$ accumulated inelastic strain in time $t_{d}$, as determined from the isochronous stress strain curves in Figure T-1800 in Appendix T of Subsection NH. Appendix B provides the computations used to develop the temperature dependent pseudo yield stress data for each selected target inelastic strain, $x$.

For the creep-fatigue evaluation, the yield stress is set as a temperature dependent "pseudo yield stress" based on the allowable time duration, $T_{d, k}$, for trial $k$. This "pseudo yield stress" is equal to the lesser of the yield strength and the minimum stress-to-rupture in time $T_{d, k}$, where yield strength is given in Table I-14.5 of Subsection $\mathrm{NH}$ as modified by Sub-article NH-2160; and the minimum stress-to-rupture is from Figure I-14.6B of Subsection $\mathrm{NH}$ multiplied by the elastic analysis factor from Table T-1411-1 of Subsection $\mathrm{NH}$. For weldments the minimum stressto-rupture is reduced by the appropriate stress rupture factors in Tables I-14.10B-3 of Subsection NH. Appendix C provides the computations used to develop the temperature dependent base metal and weldment pseudo yield stress data for each trial time $T_{d, k}$.

High temperature service for SA-182 grade F316 is defined as temperatures above the maximum temperature limit, $T_{\max }=800^{\circ} \mathrm{F}$, listed in Table 2A of Section II Part D [Ref. 2].

\subsection{Constraints}

The end of the nozzle and the half-symmetry plane of the vessel are constrained to center nodes, one for applying nozzle loads and the other for applying boundary conditions as shown in Figure 3-1. The constraints are defined using kinematic couplings with all degrees of freedom constrained except radially, to allow for thermal expansion.

\subsection{Initial Conditions}

The entire vessel is assigned an initial condition temperature of $70^{\circ} \mathrm{F}$. 


\subsection{Boundary Conditions}

\subsubsection{Thermal Boundary Conditions}

The heat transfer thermal boundary conditions due to convection inside the vessel are applied, as shown in Figure 3.5.1-1, with the same time dependent sink temperature and with the following different film coefficients.

- $\quad$ Nozzle Internal Film Coefficient = 1,929.01E-06 BTU/s-in'- ${ }^{\circ} \mathrm{F}$

- Shell Internal Film Coefficient $=964.506 \mathrm{E}-06 \mathrm{BTU} / \mathrm{s}-\mathrm{in}^{2}{ }^{\circ} \mathrm{F}$

The exterior surface of the vessel has insulated boundary conditions.

\subsubsection{Mechanical Boundary Conditions}

The vessel is fully constrained in all degrees of freedom at the symmetry center node as shown in Figure 3-1.

\subsection{Loads}

\subsubsection{Internal Pressure}

The internal pressure is applied to the inside surface of the vessel and nozzle as shown in Figure 3-1. The time dependent reaction, $F_{p}(t)$, due to pressure at the nozzle end is applied as an additional axial load computed as follows.

$$
F_{p}(t)=P(t) \pi r_{i}^{2}=P(t) \times 113.097 i n^{2}
$$

where

$$
\begin{aligned}
P(t) & =\text { time dependent internal pressure, } \mathrm{psi} \\
r_{i} & =\text { internal radius of nozzle, } 6 \text { in }
\end{aligned}
$$

\subsubsection{Mechanical Loads}

The nozzle axial load, shear force and torsional moment are applied to the nozzle end center node as shown in Figure 3-1. These mechanical loads are based on the design loads, listed in Table 3.6.2-1, which are scaled by a time dependent mechanical load factor to obtain time dependent mechanical loads.

\subsubsection{Time Histories}

The temperature, pressure, and mechanical load time histories for each composite cycle are listed in Table 3.6.3-1 and plotted in Figure 3.6.3-1 and Figure 3.6.3-2.

Temperature is applied to the heat transfer analysis model using a single tabular amplitude as a function of total time.

To facilitate a restart analysis in Abaqus for evaluating multiple cycles, the pressure and mechanical loads are applied to the stress analysis model using individual step tabular amplitudes as a function of step time.

The total time duration of high temperature service, $t_{d}$, for all Level A, B and C Service Loadings is determined in Table 3.6.3-2. 


\section{Analysis}

\subsection{Methodology}

Two types of analyses are run for each set of composite cycles. A transient heat transfer analysis is performed to establish the temperature field in the vessel throughout the composite cycle. Stress analyses are performed with the time dependent temperature field results from the heat transfer analysis to obtain the strains in the vessel due to both mechanical loads and thermal expansion. Note: Each cycle of a stress analysis using a "pseudo yield stress" has no direct correlation to the number of design or fatigue cycles and is hence defined as a "pseudo-cycle".

A pseudo-cyclic analysis is performed using the restart option to analyze multiple pseudo-cycles of a composite cycle. After the initial pseudo-cycle is analyzed, the analysis is restarted at the end of the previous pseudo-cycle to continue with another set of composite cycle loadings. This restart process is repeated until a sufficient number of pseudo-cycles have been reached.

\subsubsection{Strain Limits Methodology}

The strain limits methodology is developed in accordance with the Strain Limits Code Case in Section 2 of the Design Specification [Ref. 1].

For the strain limits evaluation, stress analyses are performed where the "pseudo yield stress" is adjusted based on the selected target inelastic strains, $x$. Initially the target inelastic strain is selected as the averaged inelastic strain limit, $\epsilon_{\text {avg }},(1 \%$ for base metal and $0.5 \%$ for weld metal).

With the target inelastic strain selected; a pseudo-cyclic analysis is performed where an intermediate check is performed at the end of each pseudo-cycle. If there exists a through thickness region where the total inelastic strain (target inelastic strain plus plastic strains) exceed the averaged inelastic strain limit, $x+\epsilon_{p}>\epsilon_{\text {avg }}$, then the target inelastic strain, $x$, is reduced. Some effort is made to maximize the region where total inelastic stains are less than the averaged inelastic strain limit before proceeding to the next pseudo-cycle. If further reduction of $x$ decreases this region then the target inelastic strain selection has been optimized. Once optimized, if there still exists a through thickness region where total inelastic strains exceed the averaged inelastic strain limit then it is concluded that the strain limits criteria cannot be met. Otherwise, additional pseudo-cycles are analyzed until ratcheting has ceased.

Ratcheting is evaluated at every location in the model by checking the change in plastic strain, $\Delta \epsilon_{p}$, between the beginning and end of a single pseudo-cycle. Ratcheting has ceased when there is no change in plastic strain throughout the whole model between the beginning and end of a single pseudo-cycle.

Plastic strains are evaluated as:

$$
\epsilon_{p}=\sqrt{\frac{2}{3}\left(\epsilon_{x . p}^{2}+\epsilon_{y . p}^{2}+\epsilon_{z . p}^{2}+2 \epsilon_{x y . p}^{2}+2 \epsilon_{y z . p}^{2}+2 \epsilon_{z x . p}^{2}\right)}
$$

Note: The Abaqus output variable for this value is PEMAG.

The total inelastic strain is defined by adding the target inelastic strain, $x$, to the computed plastic strains, $\epsilon_{p}$ :

$$
\epsilon_{\text {tot }}=x+\epsilon_{p}
$$

The averaged strain limits are evaluated such that there exists at least one point for all through-thickness locations that meets the following criteria:

$$
\epsilon_{\text {tot }} \leq \epsilon_{\text {avg }}
$$

where

$\epsilon_{\text {avg }}=1 \%$ for base metal regions or $0.5 \%$ for weldment regions 
The local strain limits are evaluated such that all locations meet the following criteria:

$$
\epsilon_{\text {tot }} \leq \epsilon_{\text {local }}
$$

where

$$
\epsilon_{\text {local }}=5 \% \text { for base metal regions or } 2.5 \% \text { for weldment regions }
$$

Section 4.1.1 is repeated for different values of $x$ until criteria (4-3) and (4-4) have been meet and ratcheting has ceased. If no value of $x$ meets these requirements then it is concluded that the strain limits criteria cannot be met.

\subsubsection{Creep-Fatigue Methodology}

The creep-fatigue methodology is developed in accordance with the Creep-Fatigue Code Case in Section 2 of the Design Specification [Ref. 1].

For the creep-fatigue evaluation stress analyses are performed where the "pseudo yield stress" is adjusted based on the allowable time duration, $T_{d, k}$ for the current trial, $k$. The allowable time duration is determined by selecting a target cyclic creep damage value, $D_{c, k}$, for trial $k$ (initially selected as 1.0) using the following equation:

$$
T_{d, k}=t_{d} / D_{c, k}
$$

where

$t_{d}=$ duration of high temperature service

With the target creep damage selected, a pseudo-cyclic analysis is performed for the current trial. If the pseudocyclic analysis does not shakedown for the initial trial (with creep damage of 1.0) then the creep-fatigue evaluation fails since longer trial times, $T_{d, k}$, will only make shakedown more difficult.

Shakedown is evaluated at every location in the model by checking the maximum change in plastic strain over every increment of a single pseudo-cycle. Shakedown is achieved when there is no change in plastic strain throughout the whole model during a single pseudo-cycle, i.e. the model is behaving elastic.

Using the strain results from the pseudo-cycle that shakes down, the maximum equivalent strain range, $\Delta \epsilon_{\max , k j}$, are computed for each cycle type $j$ of trial $k$ over every point in time, $i$, for each potential extreme condition point in time, $o$, at every location in the component:

$$
\Delta \epsilon_{\max , k j}=\max \left[\frac{\sqrt{2}}{2\left(1+v^{*}\right)} \sqrt{\left(\Delta \epsilon_{x i}-\Delta \epsilon_{y i}\right)^{2}+} \begin{array}{c}
\left(\Delta \epsilon_{y i}-\Delta \epsilon_{z i}\right)^{2}+ \\
\left(\Delta \epsilon_{z i}-\Delta \epsilon_{x i}\right)^{2}+ \\
6\left(\Delta \epsilon_{x y i}^{2}+\Delta \epsilon_{y z i}^{2}+\Delta \epsilon_{z x i}^{2}\right)
\end{array}\right]
$$

where

$$
\begin{aligned}
v^{*} & =\text { Poisson's ratio } \\
& =0.3[\text { Ref. } 1, \text { Section } 5.2 \text { of the Creep-Fatigue Code Case] } \\
\Delta \boldsymbol{\epsilon}_{i} & =\boldsymbol{\epsilon}_{i}-\boldsymbol{\epsilon}_{o} \\
& =\text { change in strain components from potential extreme condition point in time, } o, \text { to point in time, } i
\end{aligned}
$$

The range of potential extreme condition points in time, $o$, includes every time point up to the current point in time, $i$, being evaluated. This ensures that every possible combination of the points in time are considered such that the maximum equivalent strain range is obtained.

A point of consideration, $p$, is selected in the component to evaluate fatigue damage based on the location where the largest strain ranges occur in both the base metal and the weldment.

The number of design allowable cycles, $N_{d, k p j}$, are determined for cycle type $j$ of trial $k$ at point $p$ from the design fatigue curve for $316 \mathrm{SS}$ [Ref. 3, Figure NH-T-1420-1B] where the strain range, $\epsilon_{t}$, is defined as $\epsilon_{t}=\Delta \epsilon_{\max , k j}$ and the maximum metal temperature is $1175^{\circ} \mathrm{F}$ for the $\mathrm{A} \& \mathrm{~B}$ composite cycle and $1300^{\circ} \mathrm{F}$ for the $\mathrm{A} \& \mathrm{C}$ composite cycle. Note: for strain ranges within the weld region, the number of design allowable cycles are reduced by $50 \%$. 
The total fatigue damage, $D_{f, k p}$, is computed for trial $k$ at point $p$ :

$$
D_{f, k p}=\sum_{j} \frac{n_{j}}{N_{d, k p j}}
$$

where

$$
n_{j}=\text { number of applied cycles for cycle type } j
$$

If the total fatigue damage is not less than 1.0 then the creep-fatigue evaluation has failed.

The allowable creep-fatigue damage, $D_{k p}$, is determined for trial $k$ at point $p$ :

$$
D_{k p}=D_{f, k p}+\max \left[\begin{array}{c}
1+\frac{D_{i c}-1}{D_{i f}} D_{f, k p} \\
\frac{D_{i c}}{D_{i f}-1}\left(D_{f, k p}-1\right)
\end{array}\right]
$$

where

$\left(D_{i f}, D_{i c}\right)=$ creep-fatigue damage envelope intersection parameters [Ref. 3, Figure NH-T-1420-2] $=(0.3,0.3)$ for 316 stainless steel

The total creep-fatigue damage for trial $k$ is computed and compared to the allowable damage for trial $k$ at point $p$ :

$$
D_{f, k p}+D_{c, k} \leq D_{k p}
$$

Note: The creep damage used in this equation is not necessarily the creep damage at a specific point, but is the "maximum cyclic creep damage over the structure" as specified in Section 4.4 of the Creep Fatigue Code Case.

If the total creep-fatigue damage exceeds the allowable damage then a reduced target creep damage, $D_{c, k+1}$, is selected for the next trial, $k+1$, based on the following equation:

$$
D_{c, k+1} \leq D_{k p}-D_{f, k p}
$$

Section 4.1 .2 is repeated until either the creep-fatigue evaluation passes the criterion of equation (4-9) or fails due to excessive creep or fatigue damage or both.

\subsection{Analysis Steps}

Each composite cycle is broken up into discrete steps and when necessary limits to maximum time increments are applied to ensure that the analysis deals with all the changes within a cycle. The step names and durations are summarized in Table 4.2-1 and Table 4.2-2 and are plotted with the time history amplitudes in Figure 4.2-1 and Figure 4.2-2.

\subsection{Results}

\subsubsection{Heat Transfer Results}

The temperature contour results of the heat transfer analyses are shown in Figure 4.3.1-1 and Figure 4.3.1-2.

\subsubsection{Strain Limits Evaluation}

The results of the strain limits evaluations for each composite cycle are presented in Table 4.3.2-1 and Figure 4.3.2-1 through Figure 4.3.2-5.

\subsubsection{Level A \& B Composite Cycle Evaluation}

The REP-B model strain limits evaluation for the Level A \& B Composite Cycle with a target base metal inelastic strain of $1 \%$ passes after two pseudo-cycles with a maximum total inelastic strain of $1.0006 \%$.

The REP-W model strain limits evaluation for the Level A \& B Composite cycle with a target base metal inelastic strain of $1 \%$ and a target weldment inelastic strain of $0.5 \%$ passes after three pseudo-cycles with a maximum total 
inelastic strain of $1.0009 \%$ in the base metal at the nozzle to shell transition and $0.5 \%$ in the weldment, with no plastic strain in the weldment.

\subsubsection{Level A \& C Composite Cycle Evaluation}

The base metal only strain limits evaluation for the Level A \& C Composite Cycle does not pass. With an optimized target base metal inelastic strain of $0.60 \%$, the region of total inelastic strains less than the average strain limit is maximized, but after two pseudo-cycles the total inelastic strain near the region of where shakedown would occur is well over the $1.0 \%$ limit.

Since the base metal only evaluation did not pass for the Level A \& C Composite Cycle it is concluded that the REP with weldment evaluation will not pass either, and is thus not evaluated.

\subsubsection{Creep-Fatigue Evaluation}

The results of the creep-fatigue evaluations for each composite cycle are presented in Table 4.3.3-1 \& Table 4.3.3-2 and Figure 4.3.3-1 through Figure 4.3.3-5.

\subsubsection{Level A \& B Composite Cycle REP-B Model Evaluation}

The REP-B model Level A \& B Composite Cycle analysis with a target creep damage of 0.90 passes after 3 pseudocycles.

Figure 4.3.3-1 shows the maximum change in plastic strain during pseudo-cycle 3 is $0.0 \%$ indicating that shakedown has occurred and the model is behaving elastically.

Figure 4.3.3-2 shows the maximum equivalent strain ranges for each cycle type. Based on the location of the largest strain ranges, the point at which fatigue damage is evaluated is selected as element 49099 integration point 1, which is located on the outside surface of the shell-to-nozzle transition at the radius into the nozzle neck.

Table 4.3.3-2 lists a maximum equivalent strain range of $0.110 \%$ from the first cycle type of the fatigue evaluation for 90 applied repetitions of Level A \& B loadings between increment 10 of the Level A: Ramp Down step to increment 9 of the Level B: Peak Up step.

Table 4.3.3-1 lists the Level A\&B cycle type fatigue damage as 0.00045 based on a conservatively selected $2 \mathrm{E}+5$ allowable number of cycles from the $316 \mathrm{SS} \mathrm{NH}$ fatigue curve.

Table 4.3.3-2 lists a maximum equivalent strain range of $0.076 \%$ from the second cycle type for 692 applied repetitions (782 Level B cycles - 90 previously applied repetitions) of the Level B only loadings between increment 9 of the Level B: Peak Up step to increment 9 of the Level B: Ramp Down 2 step.

Table 4.3.3-1 lists the Level B only cycle type fatigue damage as 0.00346 based on a conservatively selected $2 E+5$ allowable number of cycles from the $316 \mathrm{SS} \mathrm{NH}$ fatigue curve.

Table 4.3.3-1 also lists the total creep-fatigue damage as 0.904 and the allowable creep-fatigue damage as 0.995 , which is sufficiently greater than the calculated value. This places the creep-fatigue damage within the NH-T-1420-2 creep-fatigue interaction envelope, thus meeting the criteria for creep-fatigue interaction.

\subsubsection{Level A \& B Composite Cycle REP-W Model Evaluation}

The REP-W model Level A \& B Composite Cycle analysis with a target creep damage of 0.95 passes after 3 pseudocycles.

Figure 4.3.3-3 shows the maximum change in plastic strain during pseudo-cycle 3 is $0.0 \%$ indicating that shakedown has occurred and the model is behaving elastically.

\section{Base Metal Evaluation:}

Figure 4.3.3-4 shows the maximum equivalent strain ranges for each cycle type. Based on the location of the largest strain ranges, the point at which fatigue damage is evaluated is selected as element 45139 integration point 7 , which is located on the outside surface of the shell-to-nozzle transition at the radius into the nozzle neck. 
Table 4.3.3-2 lists a maximum equivalent strain range of $0.108 \%$ from the first cycle type of the fatigue evaluation for 90 applied repetitions of Level A \& B loadings between increment 10 of the Level A: Ramp Down step to increment 9 of the Level B: Peak Up step.

Table 4.3.3-1 lists the Level A\&B cycle type fatigue damage as 0.00045 based on a conservatively selected $2 \mathrm{E}+5$ allowable number of cycles from the $316 \mathrm{SS} \mathrm{NH}$ fatigue curve.

Table 4.3.3-2 lists a maximum equivalent strain range of $0.077 \%$ from the second cycle type for 692 applied repetitions (782 Level B cycles - 90 previously applied repetitions) of the Level B only loadings between increment 9 of the Level B: Peak Up step to increment 9 of the Level B: Ramp Down 2 step.

Table 4.3.3-1 lists the Level B only cycle type fatigue damage as 0.00346 based on a conservatively selected $2 \mathrm{E}+5$ allowable number of cycles from the $316 \mathrm{SS} \mathrm{NH}$ fatigue curve.

Table 4.3.3-1 also lists the total creep-fatigue damage as 0.954 and the allowable creep-fatigue damage as 0.995, which is sufficiently greater than the calculated value. This places the creep-fatigue damage within the NH-T-1420-2 creep-fatigue interaction envelope, thus meeting the criteria for creep-fatigue interaction for the base metal.

\section{Weldment Evaluation:}

Figure 4.3.3-4 shows the maximum equivalent strain ranges for each cycle type. Based on the location of the largest strain ranges, the point at which fatigue damage is evaluated is selected as element 53273 integration point 3 , which is located on the inside surface of the weldment.

Table 4.3.3-2 lists a maximum equivalent strain range of $0.083 \%$ from the first cycle type of the fatigue evaluation for 782 applied repetitions of the Level B only loadings between increment 9 of the Level B: Peak Down 2 step to increment 8 of the Peak Up step.

Table 4.3.3-1 lists the Level $B$ only cycle type fatigue damage as 0.00782 based on a conservatively selected $1 \mathrm{E}+5$ allowable number of cycles from the 316 SS NH fatigue curve for weld material.

Table 4.3.3-2 lists a maximum equivalent strain range of $0.037 \%$ from the second cycle type for 90 applied repetitions of the Level A only loadings between increment 1 of the Level A: Ramp Down step to increment 2 of the Level A: Ramp Up step.

Table 4.3.3-1 lists the Level A only cycle type fatigue damage as 0.0009 based on a conservatively selected $1 \mathrm{E}+5$ allowable number of cycles from the $316 \mathrm{SS} \mathrm{NH}$ fatigue curve for weld material.

Table 4.3.3-1 also lists the total creep-fatigue damage as 0.958 and the allowable creep-fatigue damage as 0.988 , which is sufficiently greater than the calculated value. This places the creep-fatigue damage within the NH-T-1420-2 creep-fatigue interaction envelope, thus meeting the criteria for creep-fatigue interaction for the weldment.

\subsubsection{Level A \& C Composite Cycle Evaluation}

The base metal only creep-fatigue evaluation for the Level A \& C Composite Cycle with a target creep damage of 1.0 does not pass after 20 pseudo-cycles.

As shown in Figure 4.3.3-5, the change in plastic strain after each pseudo-cycle is $0.28 \%$ indicating that stable ratcheting continues and shakedown does not occur. Further reduction of the target creep damage will only produce weaker pseudo-yield stresses, resulting in even more severe ratcheting.

Since the base metal only evaluation did not pass for the Level A \& C Composite Cycle the REP with weldment evaluation will not pass either.

\section{Software}

Abaqus $6.13-4$ is used to perform the analyses in this report.

The input and output files used to perform the analysis and are listed in Attachment 1. 


\section{Comprehensive Report -- Page 61 of 112}

\section{References}

1. 20362-R-001 Rev. 3, Elevated Temperature Code Case Representative Example Problem Specification Report in accordance with Modification 3 of the Subcontract

2. The American Society of Mechanical Engineers, Boiler and Pressure Vessel Code, Section II, Part D, "Materials, Properties", 2013

3. The American Society of Mechanical Engineers, Boiler and Pressure Vessel Code, Section III, Division 1, Subsection NH, "Class 1 Components in Elevated Temperature Service," 2013 
Comprehensive Report -- Page 62 of 112

\section{Tables}

Table 3.2-1 Poisson's Ratio and Density

\begin{tabular}{|lccc|}
\hline Material Parameter & \multicolumn{1}{c}{ Reference } & Temperature Range & Value \\
\hline Poisson's Ratio & Section II, Part D, Table PRD & $70^{\circ} \mathrm{F}$ to $1,500^{\circ} \mathrm{F}$ & 0.31 \\
Density, Ib-s ${ }^{2} / \mathrm{in}^{4}$ & Section II, Part D, Table PRD & $70^{\circ} \mathrm{F}$ to $1,500^{\circ} \mathrm{F}$ & $7.51 \mathrm{E}-04$ \\
\hline
\end{tabular}

Notes:

(1) Weight is converted to mass by dividing by standard gravity $\left(386.1 \mathrm{in} / \mathrm{s}^{2}\right)$.

Table 3.2-2 Mechanical Properties

\begin{tabular}{|c|c|c|c|}
\hline Temperature, ${ }^{\circ} \mathrm{F}$ & Modulus of Elasticity, psi & Temperature, ${ }^{\circ} \mathrm{F}$ & Yield Stress, psi \\
\hline 70 & $28.3 \mathrm{E}+6$ & 70 & $30.0 \mathrm{E}+3$ \\
\hline 200 & $27.5 \mathrm{E}+6$ & 100 & $30.0 \mathrm{E}+3$ \\
\hline 300 & $27.0 \mathrm{E}+6$ & 200 & $25.9 E+3$ \\
\hline 400 & $26.4 \mathrm{E}+6$ & 300 & $23.4 \mathrm{E}+3$ \\
\hline 500 & $25.9 \mathrm{E}+6$ & 400 & $21.4 \mathrm{E}+3$ \\
\hline 600 & $25.3 \mathrm{E}+6$ & 500 & $20.0 \mathrm{E}+3$ \\
\hline 700 & $24.8 \mathrm{E}+6$ & 600 & $18.9 E+3$ \\
\hline 800 & $24.1 \mathrm{E}+6$ & 650 & $18.5 E+3$ \\
\hline 900 & $23.5 \mathrm{E}+6$ & 700 & $18.2 E+3$ \\
\hline 1000 & $22.8 \mathrm{E}+6$ & 750 & $17.9 \mathrm{E}+3$ \\
\hline 1100 & $22.0 \mathrm{E}+6$ & 800 & $17.7 \mathrm{E}+3$ \\
\hline 1200 & $21.2 \mathrm{E}+6$ & 850 & $17.5 \mathrm{E}+3$ \\
\hline 1300 & $20.3 E+6$ & 900 & $17.3 E+3$ \\
\hline 1400 & $19.2 \mathrm{E}+6$ & 950 & $17.1 \mathrm{E}+3$ \\
\hline \multirow[t]{11}{*}{1500} & $18.1 \mathrm{E}+6$ & 1000 & $17.0 \mathrm{E}+3$ \\
\hline & & 1050 & $16.8 E+3$ \\
\hline & & 1100 & $16.6 E+3$ \\
\hline & & 1150 & $16.3 E+3$ \\
\hline & & 1200 & $16.0 \mathrm{E}+3$ \\
\hline & & 1250 & $15.5 E+3$ \\
\hline & & 1300 & $14.9 E+3$ \\
\hline & & 1350 & $14.2 \mathrm{E}+3$ \\
\hline & & 1400 & $13.3 E+3$ \\
\hline & & 1450 & $12.3 E+3$ \\
\hline & & 1500 & $10.9 E+3$ \\
\hline
\end{tabular}


Comprehensive Report -- Page 63 of 112

Table 3.2-3 Thermal Properties

\begin{tabular}{|c|c|c|c|}
\hline $\begin{array}{l}\text { Temperature, } \\
{ }^{\circ} \mathrm{F}\end{array}$ & $\begin{array}{c}\text { Mean Thermal } \\
\text { Expansion Coefficient, } \\
\text { in/in- }{ }^{\circ} \mathrm{F}\end{array}$ & $\begin{array}{l}\text { Conductivity, } \\
\text { BTU/s-in- }{ }^{\circ} \mathrm{F}\end{array}$ & $\begin{array}{l}\text { Specific Heat, } \\
\text { BTU-in/s's-lb- }{ }^{\circ} F\end{array}$ \\
\hline 70 & $8.50 \mathrm{E}-06$ & 1.90E-04 & 42.94 \\
\hline 100 & 8.60E-06 & 1.92E-04 & 43.55 \\
\hline 150 & 8.80E-06 & 1.99E-04 & 44.52 \\
\hline 200 & $8.90 \mathrm{E}-06$ & $2.04 \mathrm{E}-04$ & 45.41 \\
\hline 250 & $9.10 \mathrm{E}-06$ & $2.11 \mathrm{E}-04$ & 46.24 \\
\hline 300 & $9.20 \mathrm{E}-06$ & $2.15 \mathrm{E}-04$ & 47.00 \\
\hline 350 & $9.40 \mathrm{E}-06$ & $2.20 \mathrm{E}-04$ & 47.70 \\
\hline 400 & $9.50 \mathrm{E}-06$ & 2.27E-04 & 48.35 \\
\hline 450 & $9.60 \mathrm{E}-06$ & $2.31 \mathrm{E}-04$ & 48.94 \\
\hline 500 & $9.70 \mathrm{E}-06$ & $2.36 \mathrm{E}-04$ & 49.49 \\
\hline 550 & $9.80 \mathrm{E}-06$ & $2.43 \mathrm{E}-04$ & 49.99 \\
\hline 600 & $9.80 \mathrm{E}-06$ & $2.48 \mathrm{E}-04$ & 50.45 \\
\hline 650 & $9.90 \mathrm{E}-06$ & $2.52 \mathrm{E}-04$ & 50.88 \\
\hline 700 & $1.00 \mathrm{E}-05$ & $2.59 \mathrm{E}-04$ & 51.28 \\
\hline 750 & $1.00 \mathrm{E}-05$ & $2.64 \mathrm{E}-04$ & 51.65 \\
\hline 800 & $1.01 \mathrm{E}-05$ & 2.69E-04 & 52.00 \\
\hline 850 & $1.02 \mathrm{E}-05$ & $2.75 \mathrm{E}-04$ & 52.34 \\
\hline 900 & $1.02 E-05$ & $2.80 \mathrm{E}-04$ & 52.65 \\
\hline 950 & $1.03 E-05$ & $2.85 \mathrm{E}-04$ & 52.96 \\
\hline 1000 & 1.03E-05 & $2.89 \mathrm{E}-04$ & 53.26 \\
\hline 1050 & $1.04 \mathrm{E}-05$ & $2.96 \mathrm{E}-04$ & 53.56 \\
\hline 1100 & $1.04 \mathrm{E}-05$ & $3.01 \mathrm{E}-04$ & 53.86 \\
\hline 1150 & $1.05 \mathrm{E}-05$ & 3.06E-04 & 54.17 \\
\hline 1200 & 1.06E-05 & 3.10E-04 & 54.49 \\
\hline 1250 & 1.06E-05 & $3.15 E-04$ & 54.83 \\
\hline 1300 & $1.07 E-05$ & 3.19E-04 & 55.18 \\
\hline 1350 & $1.07 \mathrm{E}-05$ & 3.26E-04 & 55.56 \\
\hline 1400 & $1.08 \mathrm{E}-05$ & 3.31E-04 & 55.97 \\
\hline 1450 & $1.08 \mathrm{E}-05$ & 3.36E-04 & 56.41 \\
\hline 1500 & 1.08E-05 & $3.40 \mathrm{E}-04$ & 56.88 \\
\hline
\end{tabular}


Comprehensive Report -- Page 64 of 112

Table 3.6.2-1 Mechanical Design Loads

\begin{tabular}{|ll|}
\hline \multicolumn{1}{|c|}{ Load } & \multicolumn{1}{c|}{ Value } \\
\hline Nozzle Axial Load & $30,000 \mathrm{lbf}$ \\
Nozzle Shear Force & $4,000 \mathrm{lbf}$ \\
Nozzle Torsional Moment & $20,000 \mathrm{lbf}-$ in \\
\hline
\end{tabular}

Table 3.6.3-1 Time Histories

\begin{tabular}{|c|c|c|c|c|c|c|c|}
\hline \multicolumn{4}{|c|}{ Level A \& B Composite Cycle } & \multicolumn{4}{|c|}{ Level A \& C Composite Cycle } \\
\hline $\begin{array}{l}\text { Time, } \\
\text { sec }\end{array}$ & $\begin{array}{c}\text { Temperature, } \\
{ }^{\circ} \mathrm{F}\end{array}$ & $\begin{array}{c}\text { Pressure, } \\
\text { psi }\end{array}$ & $\begin{array}{l}\text { Mechanical } \\
\text { Load Factor }\end{array}$ & $\begin{array}{l}\text { Time, } \\
\text { sec }\end{array}$ & $\begin{array}{c}\text { Temperature, } \\
{ }^{\circ} \mathrm{F}\end{array}$ & $\begin{array}{c}\text { Pressure, } \\
\text { psi }\end{array}$ & $\begin{array}{l}\text { Mechanical } \\
\text { Load Factor }\end{array}$ \\
\hline 0 & 70.0 & 0.0 & 0.000 & 0 & 70.0 & 0.0 & 0.000 \\
\hline 180000 & 1100.0 & 675.0 & 1.000 & 180000 & 1100.0 & 675.0 & 1.000 \\
\hline 1620000 & 1100.0 & 675.0 & 1.000 & 1620000 & 1100.0 & 675.0 & 1.000 \\
\hline 1621100 & 1170.0 & 743.8 & 1.229 & 1620060 & 1100.0 & 675.0 & 2.000 \\
\hline 1621120 & 1171.0 & 745.0 & 1.233 & 1620120 & 1100.0 & 675.0 & -1.500 \\
\hline 1621140 & 1172.0 & 746.3 & 1.238 & 1620180 & 1100.0 & 675.0 & 1.000 \\
\hline 1621160 & 1173.0 & 747.5 & 1.242 & 1621620 & 1290.0 & 771.0 & 0.863 \\
\hline 1621170 & 1174.0 & 748.1 & 1.244 & 1621630 & 1292.0 & 771.7 & 0.862 \\
\hline 1621180 & 1174.5 & 748.8 & 1.246 & 1621640 & 1294.0 & 772.3 & 0.861 \\
\hline 1621190 & 1175.0 & 749.4 & 1.248 & 1621650 & 1296.0 & 773.0 & 0.860 \\
\hline 1621200 & 1175.0 & 750.0 & 1.250 & 1621660 & 1298.0 & 773.7 & 0.859 \\
\hline 1621210 & 1174.8 & 750.0 & 1.250 & 1621670 & 1299.0 & 774.3 & 0.858 \\
\hline 1621220 & 1174.5 & 750.0 & 1.250 & 1621680 & 1300.0 & 775.0 & 0.857 \\
\hline 1621230 & 1174.3 & 749.9 & 1.250 & 1621690 & 1299.0 & 774.1 & 0.856 \\
\hline 1621240 & 1174.0 & 749.9 & 1.250 & 1621700 & 1298.0 & 773.3 & 0.855 \\
\hline 1621300 & 1172.6 & 749.8 & 1.249 & 1621710 & 1296.0 & 772.4 & 0.854 \\
\hline 1623000 & 1131.9 & 745.8 & 1.236 & 1621720 & 1294.0 & 771.6 & 0.853 \\
\hline 1630000 & 850.0 & 729.6 & 1.182 & 1621730 & 1292.0 & 770.7 & 0.852 \\
\hline 1650000 & 425.0 & 683.3 & 1.028 & 1621740 & 1290.0 & 769.8 & 0.851 \\
\hline 1653600 & 400.0 & 675.0 & 1.000 & 1621780 & 1280.0 & 766.4 & 0.848 \\
\hline 1740000 & 400.0 & 675.0 & 1.000 & 1622180 & 1150.0 & 731.9 & 0.810 \\
\hline 1862400 & 1100.0 & 675.0 & 1.000 & 1625180 & 700.0 & 473.6 & 0.524 \\
\hline 3302400 & 1100.0 & 675.0 & 1.000 & 1630680 & 70.0 & 0.0 & 0.000 \\
\hline 3572400 & 70.0 & 0.0 & 0.000 & 3070680 & 70.0 & 0.0 & 0.000 \\
\hline 5012400 & 70.0 & 0.0 & 0.000 & & & & \\
\hline
\end{tabular}


Table 3.6.3-2 Total Time Druation of High Temperature Service

\begin{tabular}{|c|c|c|c|c|c|c|}
\hline Step Name & $\begin{array}{c}\text { Duration, } \\
\text { sec }\end{array}$ & $\begin{array}{c}\text { Temperature, } \\
{ }^{\circ} \mathrm{F}\end{array}$ & $\begin{array}{c}\text { Duration } \\
\text { Above 800F, } \\
\text { sec }\end{array}$ & No. Cycles & $\begin{array}{l}\text { Total Time, } \\
\text { sec }\end{array}$ & $\begin{array}{c}\text { Total Time } \\
\text { Above } 800 \mathrm{~F}, \\
\text { sec }\end{array}$ \\
\hline Level A: Initial State & & 70 & & & & \\
\hline Level A: Ramp Up & 180,000 & 1100 & 52,427 & 90 & $16,200,000$ & $4,718,447$ \\
\hline Level A: Steady State & $1,440,000$ & 1100 & $1,440,000$ & 90 & $129,600,000$ & $129,600,000$ \\
\hline Level A: Ramp Down & 270,000 & 70 & 78,641 & 90 & $24,300,000$ & $7,077,670$ \\
\hline Level B: Initial State & & 1100 & & & & \\
\hline Level B: Ramp Up & 1,100 & 1170 & 1,100 & 782 & 860,200 & 860,200 \\
\hline Level B: Peak Up & 100 & 1175 & 100 & 782 & 78,200 & 78,200 \\
\hline Level B: Peak Down & 100 & 1172.6 & 100 & 782 & 78,200 & 78,200 \\
\hline Level B: Ramp Down 1 & 1,700 & 1131.9 & 1,700 & 782 & $1,329,400$ & $1,329,400$ \\
\hline Level B: Ramp Down 2 & 7,000 & 850 & 7,000 & 782 & $5,474,000$ & $5,474,000$ \\
\hline Level B: Ramp Down 3 & 20,000 & 425 & 2,353 & 782 & $15,640,000$ & $1,840,000$ \\
\hline Level B: Ramp Down 4 & 3,600 & 400 & 0 & 782 & $2,815,200$ & 0 \\
\hline Level B: Hold State & 86,400 & 400 & 0 & 782 & $67,564,800$ & 0 \\
\hline Level B: Recover & 122,400 & 1100 & 52,457 & 782 & $95,716,800$ & $41,021,486$ \\
\hline Level C: Initial State & & 1100 & & & & \\
\hline Level C: SSE Up & 60 & 1100 & 60 & 25 & 1,500 & 1,500 \\
\hline Level C: SSE Down & 60 & 1100 & 60 & 25 & 1,500 & 1,500 \\
\hline Level C: SSE Recover & 60 & 1100 & 60 & 25 & 1,500 & 1,500 \\
\hline Level C: Ramp Up & 1,440 & 1290 & 1,440 & 25 & 36,000 & 36,000 \\
\hline Level C: Peak Up & 60 & 1300 & 60 & 25 & 1,500 & 1,500 \\
\hline Level C: Peak Down & 100 & 1280 & 100 & 25 & 2,500 & 2,500 \\
\hline Level C: Ramp Down 1 & 400 & 11450 & 400 & 25 & 10,000 & 10,000 \\
\hline Level C: Ramp Down 2 & 3,000 & 700 & 2,972 & 25 & 75,000 & 74,302 \\
\hline Level C: Ramp Down 3 & 5,500 & 70 & 0 & 25 & 137,500 & 0 \\
\hline Total: & & & & & $359,923,800$ & $192,206,405$ \\
\hline
\end{tabular}


Table 4.2-1 Level A \& B Composite Cycle Analysis Steps

\begin{tabular}{|lcccc|}
\hline \multicolumn{1}{|c}{ Step Name } & $\begin{array}{c}\text { Duration, } \\
\text { sec }\end{array}$ & $\begin{array}{c}\text { Step } \\
\text { End Time, } \\
\text { sec }\end{array}$ & $\begin{array}{c}\text { Maximum } \\
\text { Time } \\
\text { Increment, } \\
\text { sec }\end{array}$ & $\begin{array}{c}\text { Maximum } \\
\text { Temperature } \\
\text { Change, } \\
{ }^{\circ} \mathbf{F}\end{array}$ \\
\hline Level A: Ramp Up & 180,000 & 180,000 & auto & 50 \\
Level A: Steady State 1 & $1,440,000$ & $1,620,000$ & auto & 50 \\
Level B: Ramp Up & 1,100 & $1,621,100$ & auto & 5 \\
Level B: Peak Up & 100 & $1,621,200$ & 10 & 1 \\
Level B: Peak Down & 100 & $1,621,300$ & 10 & 1 \\
Level B: Ramp Down 1 & 1,700 & $1,623,000$ & auto & 1 \\
Level B: Ramp Down 2 & 7,000 & $1,630,000$ & auto & 10 \\
Level B: Ramp Down 3 & 20,000 & $1,650,000$ & auto & 50 \\
Level B: Ramp Down 4 & 3,600 & $1,653,600$ & auto & 5 \\
Level B: Hold State & 86,400 & $1,740,000$ & auto & 5 \\
Level B: Recover & 122,400 & $1,862,400$ & auto & 50 \\
Level A: Steady State 2 & $1,440,000$ & $3,302,400$ & auto & 50 \\
Level A: Ramp Down & 270,000 & $3,572,400$ & auto & 50 \\
Shutdown: Steady State & $1,440,000$ & $5,012,400$ & auto & 50 \\
\hline
\end{tabular}

Table 4.2-2 Level A \& C Composite Cycle Analysis Steps

\begin{tabular}{|lcccc|}
\hline \multicolumn{1}{|c}{ Step Name } & $\begin{array}{c}\text { Duration, } \\
\text { sec }\end{array}$ & $\begin{array}{c}\text { Step } \\
\text { End Time, } \\
\text { sec }\end{array}$ & $\begin{array}{c}\text { Maximum } \\
\text { Time } \\
\text { Increment, } \\
\text { sec }\end{array}$ & $\begin{array}{c}\text { Maximum } \\
\text { Temperature } \\
\text { Change, } \\
{ }^{\circ} \mathbf{F}\end{array}$ \\
\hline Level A: Ramp Up & 180,000 & 180,000 & auto & 50 \\
Level A: Steady State 1 & $1,440,000$ & $1,620,000$ & auto & 50 \\
Level C: SSE Up & 60 & $1,620,060$ & auto & 50 \\
Level C: SSE Down & 60 & $1,620,120$ & auto & 50 \\
Level C: SSE Recover & 60 & $1,620,180$ & auto & 50 \\
Level C: Ramp Up & 1,440 & $1,621,620$ & auto & 10 \\
Level C: Peak Up & 60 & $1,621,680$ & 10 & 1 \\
Level C: Peak Down & 100 & $1,621,780$ & 10 & 1 \\
Level C: Ramp Down 1 & 400 & $1,622,180$ & auto & 5 \\
Level C: Ramp Down 2 & 300 & $1,625,180$ & auto & 10 \\
Level C: Ramp Down 3 & 5,500 & $1,630,680$ & auto & 50 \\
Shutdown: Steady State & $1,440,000$ & $3,070,680$ & auto & 50 \\
\hline
\end{tabular}


Table 4.3.2-1 Strain Limits Evaluation Results

\begin{tabular}{|c|c|c|c|c|c|c|c|c|c|c|}
\hline \multirow[t]{2}{*}{$\frac{0}{0}$} & \multirow[t]{2}{*}{$\begin{array}{l}\text { बळ } \\
\frac{0}{2}\end{array}$} & \multicolumn{2}{|c|}{$\begin{array}{l}\text { Target Creep } \\
\text { Strain }\end{array}$} & \multirow[t]{2}{*}{ 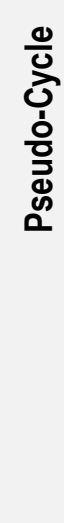 } & \multirow[t]{2}{*}{$\begin{array}{l}\text { Ratcheting } \\
\text { Check } \\
\left(\max \left|\Delta \epsilon_{p}\right|\right)\end{array}$} & \multicolumn{2}{|c|}{$\begin{array}{c}\text { Average Strain } \\
\text { Check } \\
\text { Min. Thickness(1) } \\
\text { x Max. Length(2) Region } \\
\text { Not Exceeding Limit: } \\
\epsilon_{\text {tot }} \leq \epsilon_{\text {avg }}\end{array}$} & \multicolumn{2}{|c|}{$\begin{array}{l}\text { Local Strain Check } \\
\qquad \max \left(\epsilon_{t o t}\right)\end{array}$} & \multirow[t]{2}{*}{ Status } \\
\hline & & $\begin{array}{l}\text { Base } \\
\text { Metal }\end{array}$ & Weld & & & $\begin{array}{c}\text { Base } \\
\text { Metal } \\
(1.0 \% \text { limit })\end{array}$ & $\begin{array}{c}\text { Weld } \\
(0.5 \% \text { limit })\end{array}$ & $\begin{array}{l}\text { Base } \\
\text { Metal } \\
(5.0 \% \\
\text { limit })\end{array}$ & $\begin{array}{l}\text { Weld } \\
(2.5 \% \\
\text { limit })\end{array}$ & \\
\hline \multirow{5}{*}{ 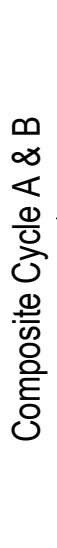 } & \multirow{2}{*}{ 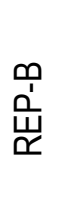 } & \multirow{2}{*}{$1.00 \%$} & \multirow{2}{*}{$\mathrm{n} / \mathrm{a}$} & 1 & $\begin{array}{c}\text { Yes } \\
(0.0006 \%)\end{array}$ & $\begin{array}{l}\sim 99 \% \times \\
100 \%\end{array}$ & $\mathrm{n} / \mathrm{a}$ & $1.0006 \%$ & $\mathrm{n} / \mathrm{a}$ & $\begin{array}{l}\text { Optimized } \\
\text { and Cycle }\end{array}$ \\
\hline & & & & 2 & $\begin{array}{l}\text { No } \\
(0 \%)\end{array}$ & $\begin{array}{l}\sim 99 \% x \\
100 \%\end{array}$ & $\mathrm{n} / \mathrm{a}$ & $1.0006 \%$ & $\mathrm{n} / \mathrm{a}$ & PASS \\
\hline & \multirow{3}{*}{ 竞 } & \multirow{3}{*}{$1.00 \%$} & \multirow{3}{*}{$0.50 \%$} & 1 & $\begin{array}{c}\text { Yes } \\
(0.0009 \%)\end{array}$ & $\begin{array}{c}\sim 99 \% x \\
100 \%\end{array}$ & $\begin{array}{c}100 \% x \\
100 \%\end{array}$ & $1.0009 \%$ & $\mathrm{n} / \mathrm{a}$ & $\begin{array}{l}\text { Optimized } \\
\text { and Cycle }\end{array}$ \\
\hline & & & & 2 & $\begin{array}{c}\text { Yes } \\
(0.00003 \%)\end{array}$ & $\begin{array}{c}\sim 99 \% x \\
100 \%\end{array}$ & $\begin{array}{c}100 \% x \\
100 \%\end{array}$ & $1.0009 \%$ & $\mathrm{n} / \mathrm{a}$ & Cycle \\
\hline & & & & 3 & $\begin{array}{l}\text { No } \\
(0 \%)\end{array}$ & $\begin{array}{l}\sim 99 \% x \\
100 \%\end{array}$ & $\begin{array}{c}100 \% x \\
100 \%\end{array}$ & $1.0009 \%$ & $0.50 \%$ & PASS \\
\hline \multirow{5}{*}{ 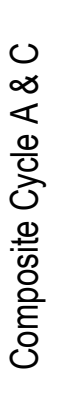 } & \multirow{5}{*}{ 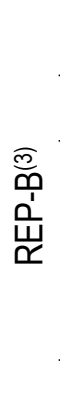 } & $1.00 \%$ & $\mathrm{n} / \mathrm{a}$ & 1 & Yes & $0 \% \times 0 \%$ & $\mathrm{n} / \mathrm{a}$ & & $\mathrm{n} / \mathrm{a}$ & Reduce \\
\hline & & $0.65 \%$ & $\mathrm{n} / \mathrm{a}$ & 1 & Yes & $0 \% x \sim 98 \%$ & $\mathrm{n} / \mathrm{a}$ & & $\mathrm{n} / \mathrm{a}$ & Reduce \\
\hline & & \multirow{2}{*}{$0.60 \%$} & \multirow{2}{*}{$\mathrm{n} / \mathrm{a}$} & 1 & $\begin{array}{c}\text { Yes } \\
(1.0 \%)\end{array}$ & $0 \% \times \sim 98 \%$ & $\mathrm{n} / \mathrm{a}$ & $1.6 \%$ & $\mathrm{n} / \mathrm{a}$ & $\begin{array}{l}\text { Optimized } \\
\text { and Cycle }\end{array}$ \\
\hline & & & & 2 & $\begin{array}{c}\text { Yes } \\
(1.1 \%)\end{array}$ & $0 \% x \sim 88 \%$ & $\mathrm{n} / \mathrm{a}$ & $2.7 \%$ & $\mathrm{n} / \mathrm{a}$ & FAIL \\
\hline & & $0.55 \%$ & $\mathrm{n} / \mathrm{a}$ & 1 & Yes & $0 \% \times \sim 96 \%$ & $\mathrm{n} / \mathrm{a}$ & & $\mathrm{n} / \mathrm{a}$ & Increase \\
\hline
\end{tabular}

Notes:

(1) The average strain limit is satisfied when the minimum distance through the thickness where $\epsilon_{\text {tot }} \leq \epsilon_{\text {avg }}$ (measured in percentage of wall thickness) is greater than $0 \%$.

(2) The maximum lateral length where $\epsilon_{t o t} \leq \epsilon_{\text {avg }}$ is measured in percentage of total lateral length of the region being evaluated.

(3) The Composite Cycle A\&C REP-B model is the model used in 20362-R-002 Rev. 1. 
Comprehensive Report -- Page 68 of 112

Table 4.3.3-1 Creep-Fatigue Evaluation Results

\begin{tabular}{|c|c|c|c|c|c|c|c|c|c|c|c|}
\hline$\frac{0}{0}$ & $\begin{array}{l}\overline{0} \\
\frac{0}{2}\end{array}$ & 들 & $\begin{array}{c}\text { Target } \\
\text { Creep } \\
\text { Damage }\end{array}$ & $\begin{array}{l}\text { Shakedown } \\
\text { (Pseudo- } \\
\text { Cycle) }\end{array}$ & $\begin{array}{c}\text { Cycle Type } \\
\text { (Applied } \\
\text { Repetitions) }\end{array}$ & $\begin{array}{c}\text { Maximum } \\
\text { Equivalent } \\
\text { Strain } \\
\text { Range }\end{array}$ & $\begin{array}{l}\text { Allowable } \\
\text { Cycles }^{(1)}\end{array}$ & $\begin{array}{l}\text { Fatigue } \\
\text { Damage }\end{array}$ & $\begin{array}{c}\text { Total } \\
\text { Damage }\end{array}$ & 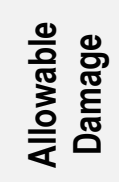 & 宽 \\
\hline \multirow{11}{*}{ 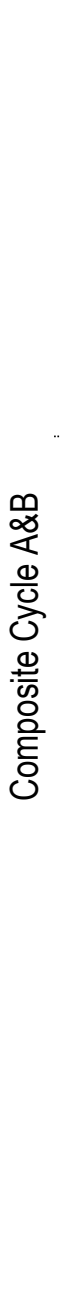 } & \multirow{4}{*}{ 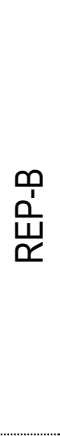 } & \multirow{4}{*}{ 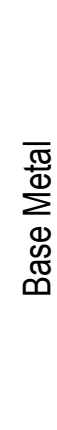 } & \multirow{2}{*}{1.00} & \multirow{2}{*}{$\begin{array}{l}\text { Yes } \\
(3)\end{array}$} & $\begin{array}{c}\text { Level A \& B } \\
(90)\end{array}$ & $0.110 \%$ & $2.0 \mathrm{E}+5$ & 0.00045 & \multirow{2}{*}{1.004} & \multirow{2}{*}{0.995} & \multirow{2}{*}{ 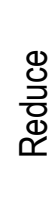 } \\
\hline & & & & & $\begin{array}{l}\text { Level B } \\
(692)\end{array}$ & $0.076 \%$ & $2.0 \mathrm{E}+5$ & 0.00346 & & & \\
\hline & & & \multirow{2}{*}{0.90} & \multirow{2}{*}{$\begin{array}{l}\text { Yes } \\
(3)\end{array}$} & $\begin{array}{l}\text { Level A \& B } \\
(90)\end{array}$ & $0.110 \%(2)$ & $2.0 \mathrm{E}+5$ & 0.00045 & \multirow{2}{*}{0.904} & \multirow{2}{*}{0.995} & \multirow{2}{*}{ 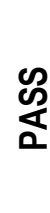 } \\
\hline & & & & & $\begin{array}{l}\text { Level B } \\
(692)\end{array}$ & $0.076 \%(2)$ & $2.0 \mathrm{E}+5$ & 0.00346 & & & \\
\hline & \multirow{7}{*}{ 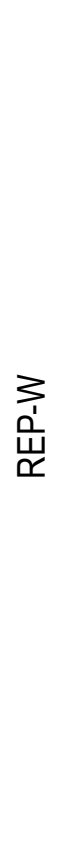 } & \multirow{5}{*}{ 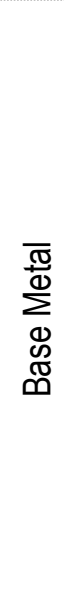 } & \multirow{2}{*}{1.00} & \multirow{2}{*}{$\begin{array}{l}\text { Yes } \\
(3)\end{array}$} & $\begin{array}{l}\text { Level A \& B } \\
(90)\end{array}$ & $0.108 \%$ & $2.0 \mathrm{E}+5$ & 0.00045 & \multirow{2}{*}{1.004} & \multirow{2}{*}{0.995} & \multirow{2}{*}{ 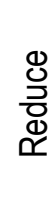 } \\
\hline & & & & & $\begin{array}{l}\text { Level B } \\
(692)\end{array}$ & $0.077 \%$ & $2.0 \mathrm{E}+5$ & 0.00346 & & & \\
\hline & & & \multirow{2}{*}{0.95} & \multirow{2}{*}{$\begin{array}{l}\text { Yes } \\
(3)\end{array}$} & $\begin{array}{l}\text { Level A \& B } \\
\quad(90)\end{array}$ & $0.108 \%(2)$ & $2.0 \mathrm{E}+5$ & 0.00045 & \multirow{2}{*}{0.954} & \multirow{2}{*}{0.995} & \multirow{2}{*}{$\stackrel{\mathscr{L}}{\infty}$} \\
\hline & & & & & $\begin{array}{l}\text { Level B } \\
(692)\end{array}$ & $0.077 \%(2)$ & $2.0 \mathrm{E}+5$ & 0.00346 & & & \\
\hline & & & 0.90 & $\begin{array}{l}\text { No } \\
(20)\end{array}$ & & & & & & & 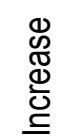 \\
\hline & & \multirow{2}{*}{ 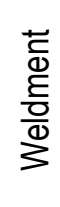 } & \multirow{2}{*}{0.95} & \multirow{2}{*}{$\begin{array}{l}\text { Yes } \\
(3)\end{array}$} & $\begin{array}{l}\text { Level B } \\
(782)\end{array}$ & $0.083 \%(2)$ & $1.0 \mathrm{E}+5$ & 0.00782 & \multirow{2}{*}{0.958} & \multirow{2}{*}{0.988} & \multirow{2}{*}{ क } \\
\hline & & & & & $\begin{array}{c}\text { Level A } \\
(90)\end{array}$ & $0.037 \%(2)$ & $1.0 \mathrm{E}+5$ & 0.00090 & & & \\
\hline 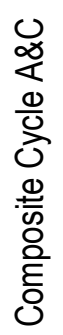 & 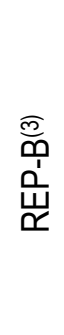 & 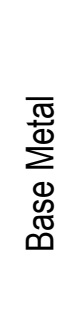 & 1.00 & $\begin{array}{l}\text { No } \\
(20)\end{array}$ & $\mathrm{n} / \mathrm{a}$ & $\mathrm{n} / \mathrm{a}$ & $\mathrm{n} / \mathrm{a}$ & $\mathrm{n} / \mathrm{a}$ & $>1$ & $\mathrm{n} / \mathrm{a}$ & 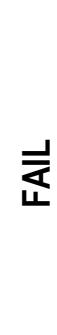 \\
\hline
\end{tabular}

(1) Allowable Cycles are conservatively taken at the next highest strain range in the Table for Figure NH-T-1420-1B.

(2) See Table 4.3.3-2 for maximum equivalent strain range evaluations.

(3) The Composite Cycle A\&C REP-B model is based on the model used in 20362-R-002 Rev. 1. 
Table 4.3.3-2 Creep-Fatigue Final Maximum Equivalent Strain Range Evaluations for Composite Cycle A\&B

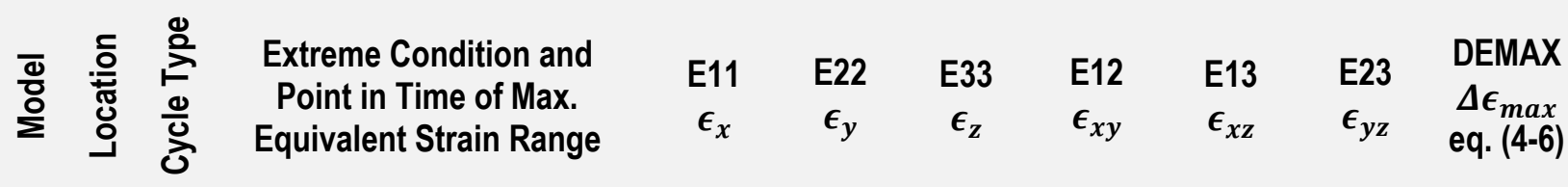

\begin{tabular}{|c|c|c|c|c|c|c|c|c|c|}
\hline ז் & $\stackrel{\infty}{\infty}$ & $\begin{array}{l}\text { Level A: Ramp Down, } \\
\text { Increment } 10\end{array}$ & $\epsilon_{o}$ & $0.0007 \%$ & $0.0001 \%$ & $0.0007 \%$ & $0.0019 \%$ & $0.0003 \%$ & $0.0016 \%$ \\
\hline 言 & 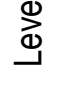 & $\begin{array}{l}\text { Level B: Peak Up } \\
\text { Increment } 9\end{array}$ & $\epsilon_{i}$ & $1.1639 \%$ & $1.1797 \%$ & $1.1655 \%$ & $0.0449 \%$ & $-0.0511 \%$ & $0.0453 \%$ \\
\hline$\frac{\bar{\Psi}}{\frac{\tilde{\pi}}{\Phi}}$ & $\underline{\emptyset}$ & $\begin{array}{l}\text { Level B: Ramp Down } 2 \\
\text { Increment } 9\end{array}$ & $\epsilon_{o}$ & $1.0042 \%$ & $0.9991 \%$ & $1.0050 \%$ & $0.0126 \%$ & $-0.0220 \%$ & $0.0104 \%$ \\
\hline 忍 & د & $\begin{array}{l}\text { Level B: Peak Up } \\
\text { Increment } 9\end{array}$ & $\epsilon_{i}$ & $1.1639 \%$ & $1.1797 \%$ & $1.1655 \%$ & $0.0449 \%$ & $-0.0511 \%$ & $0.0453 \%$ \\
\hline
\end{tabular}

\begin{tabular}{|c|c|c|c|c|c|c|c|c|c|}
\hline 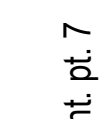 & $\stackrel{\infty}{\infty}$ & $\begin{array}{l}\text { Level A: Ramp Down, } \\
\text { Increment } 10\end{array}$ & $\epsilon_{o}$ & $0.0008 \%$ & $0.0001 \%$ & $0.0007 \%$ & $0.0015 \%$ & $0.0005 \%$ & $0.0013 \%$ \\
\hline$\frac{\overline{\bar{w}}}{\bar{m}}$ & $\stackrel{\Phi}{د}$ & $\begin{array}{l}\text { Level B: Peak Up } \\
\text { Increment } 9\end{array}$ & $\epsilon_{i}$ & $1.1639 \%$ & $1.1799 \%$ & $1.1656 \%$ & $0.0448 \%$ & $-0.0511 \%$ & $0.0451 \%$ \\
\hline$\frac{\dot{w}}{\frac{\pi}{0}}$ & $\underline{\oplus}$ & $\begin{array}{l}\text { Level B: Ramp Down } 2 \\
\text { Increment } 9\end{array}$ & $\epsilon_{o}$ & $1.0043 \%$ & $0.9990 \%$ & $1.0050 \%$ & $0.0121 \%$ & $-0.0218 \%$ & $0.0100 \%$ \\
\hline $\begin{array}{l}\bar{\Phi} \\
\stackrel{D}{D} \\
\infty\end{array}$ & $\Phi$ & $\begin{array}{l}\text { Level B: Peak Up } \\
\text { Increment } 9\end{array}$ & $\epsilon_{i}$ & $1.1639 \%$ & $1.1799 \%$ & $1.1656 \%$ & $0.0448 \%$ & $-0.0511 \%$ & $0.0451 \%$ \\
\hline $\begin{array}{l}m \\
+ \\
+ \\
+\end{array}$ & $\frac{\infty}{\Phi}$ & $\begin{array}{l}\text { Level B: Ramp Down 2, } \\
\text { Increment } 9\end{array}$ & $\epsilon_{o}$ & $1.0127 \%$ & $0.9781 \%$ & $1.0128 \%$ & $-0.0321 \%$ & $-0.0181 \%$ & $-0.0311 \%$ \\
\hline 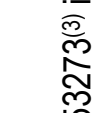 & త & $\begin{array}{l}\text { Level B: Peak Up, } \\
\text { Increment } 9\end{array}$ & $\epsilon_{i}$ & $1.1618 \%$ & $1.1687 \%$ & $1.1613 \%$ & $0.0064 \%$ & $0.0046 \%$ & $0.0050 \%$ \\
\hline $\begin{array}{l}\dot{\Psi} \\
\stackrel{\varpi}{\Phi}\end{array}$ & 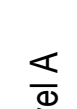 & $\begin{array}{l}\text { Level A: Ramp Down, } \\
\text { Increment } 1\end{array}$ & $\epsilon_{o}$ & $1.0803 \%$ & $1.0638 \%$ & $1.0802 \%$ & $-0.0153 \%$ & $-0.0085 \%$ & $-0.0153 \%$ \\
\hline$\frac{\overline{0}}{3}$ & ฮత & $\begin{array}{l}\text { Level A: Ramp Up, } \\
\text { Increment } 2\end{array}$ & $\boldsymbol{\epsilon}_{i}$ & $0.0347 \%$ & $0.0365 \%$ & $0.0346 \%$ & $0.0017 \%$ & $0.0010 \%$ & $0.0015 \%$ \\
\hline
\end{tabular}

Notes:

(1) Element 49099 is located on the outside surface of the shell to nozzle transition as shown in Figure 4.3.3-2.

(2) Element 45139 is located on the outside surface of the shell to nozzle transition as shown in Figure 4.3.3-4.

(3) Element 53273 is located on the inside surface of the weldment as shown in Figure 4.3.3-4. 
Figures

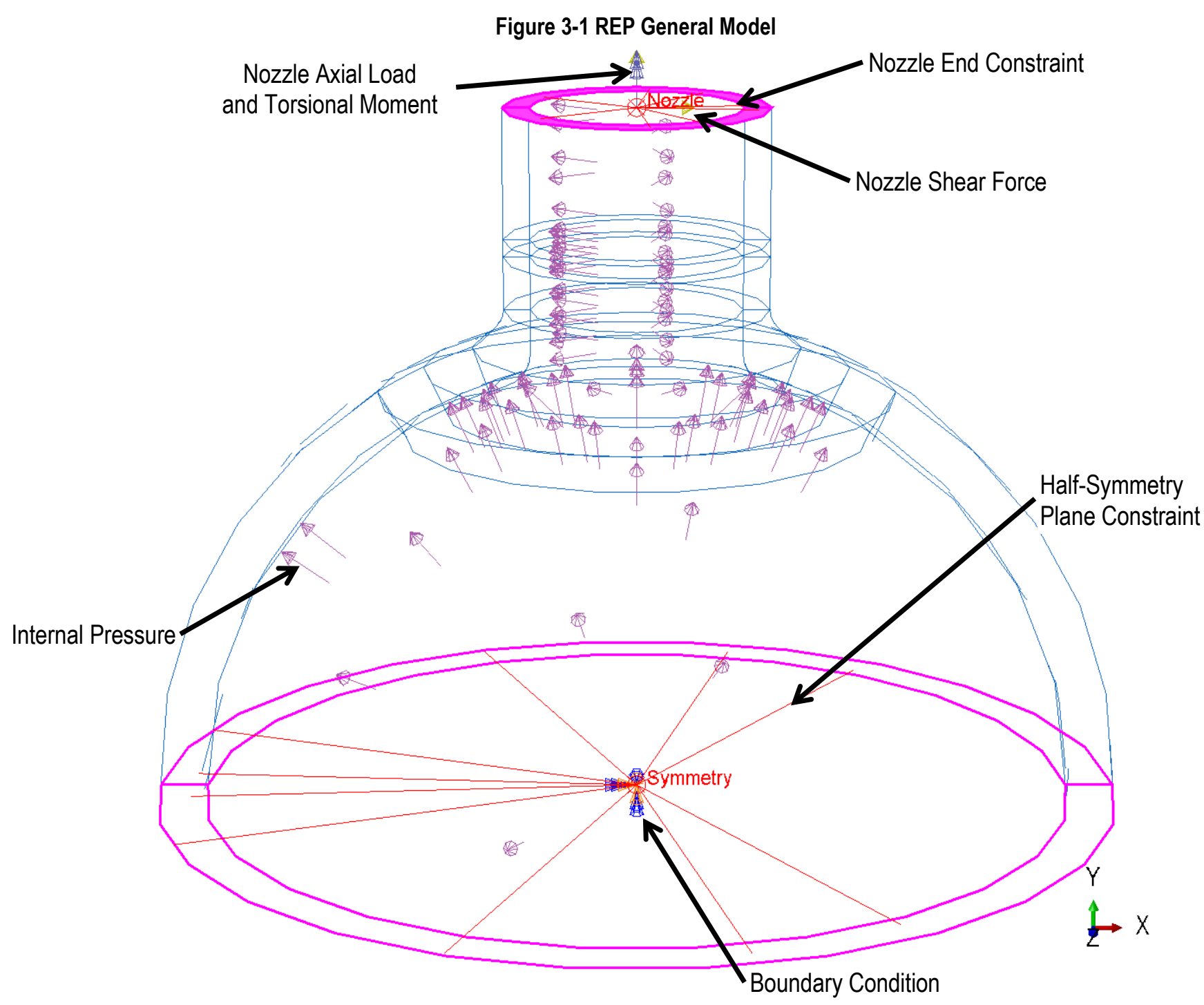

Note: The weldment is not shown in this generalization the two REP vessels. 
Comprehensive Report -- Page 71 of 112

Figure 3.1-1 REP Vessel Profile

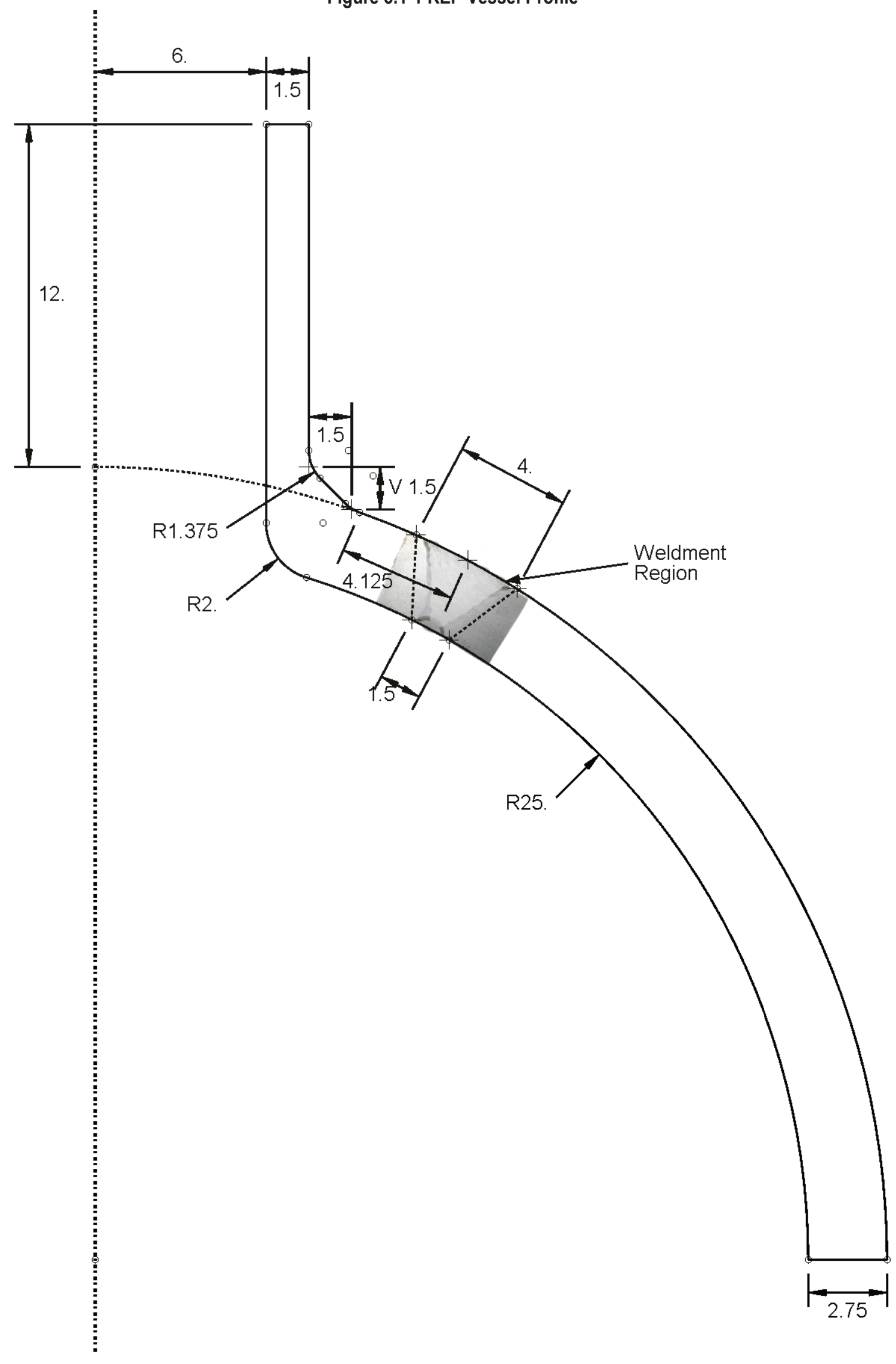


Comprehensive Report -- Page 72 of 112

Figure 3.1-2 REP Base Metal Only Vessel (REP-B) Mesh
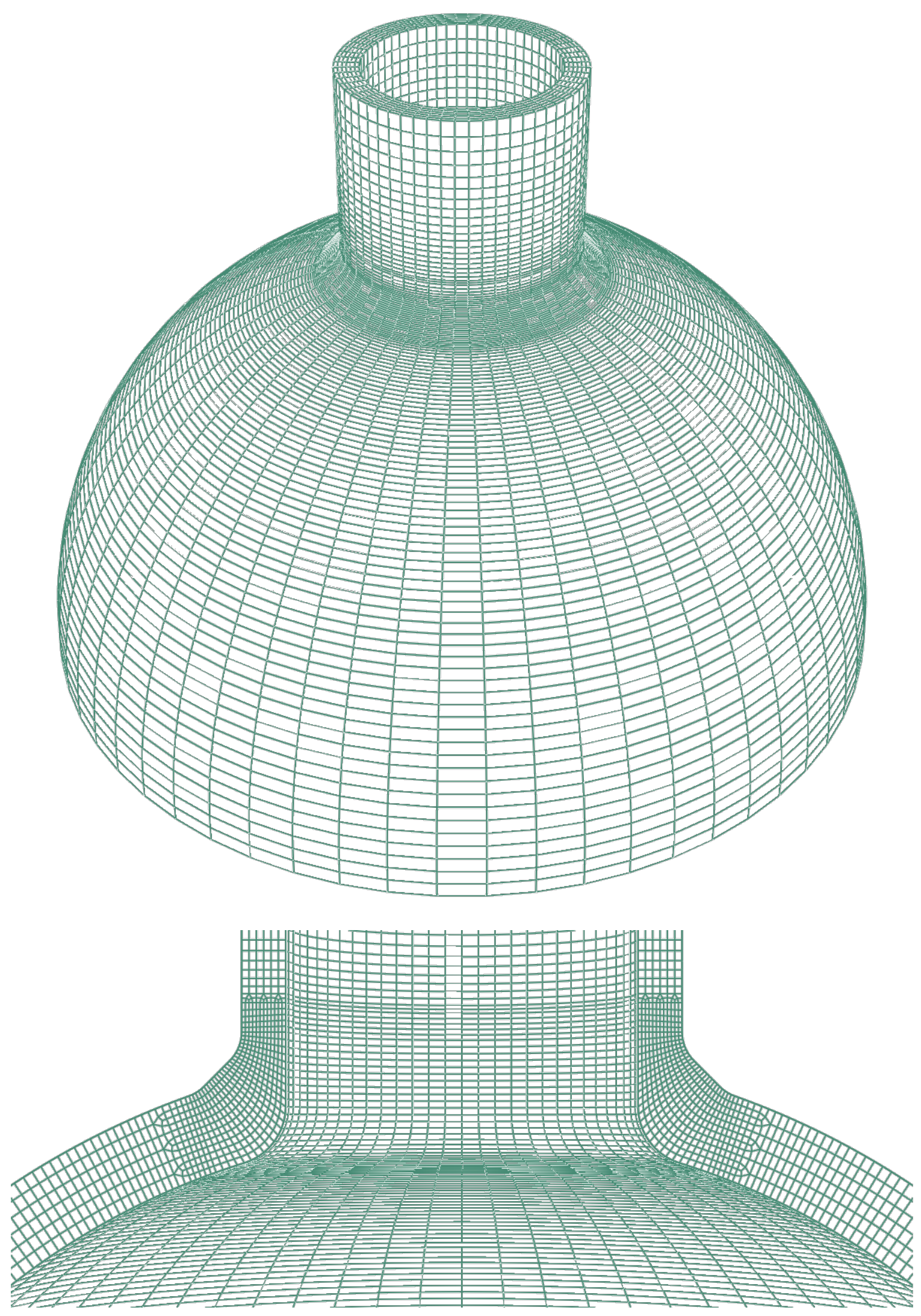


\section{Comprehensive Report -- Page 73 of 112}

Figure 3.1-3 REP Vessel with Weldment (REP-W) Mesh
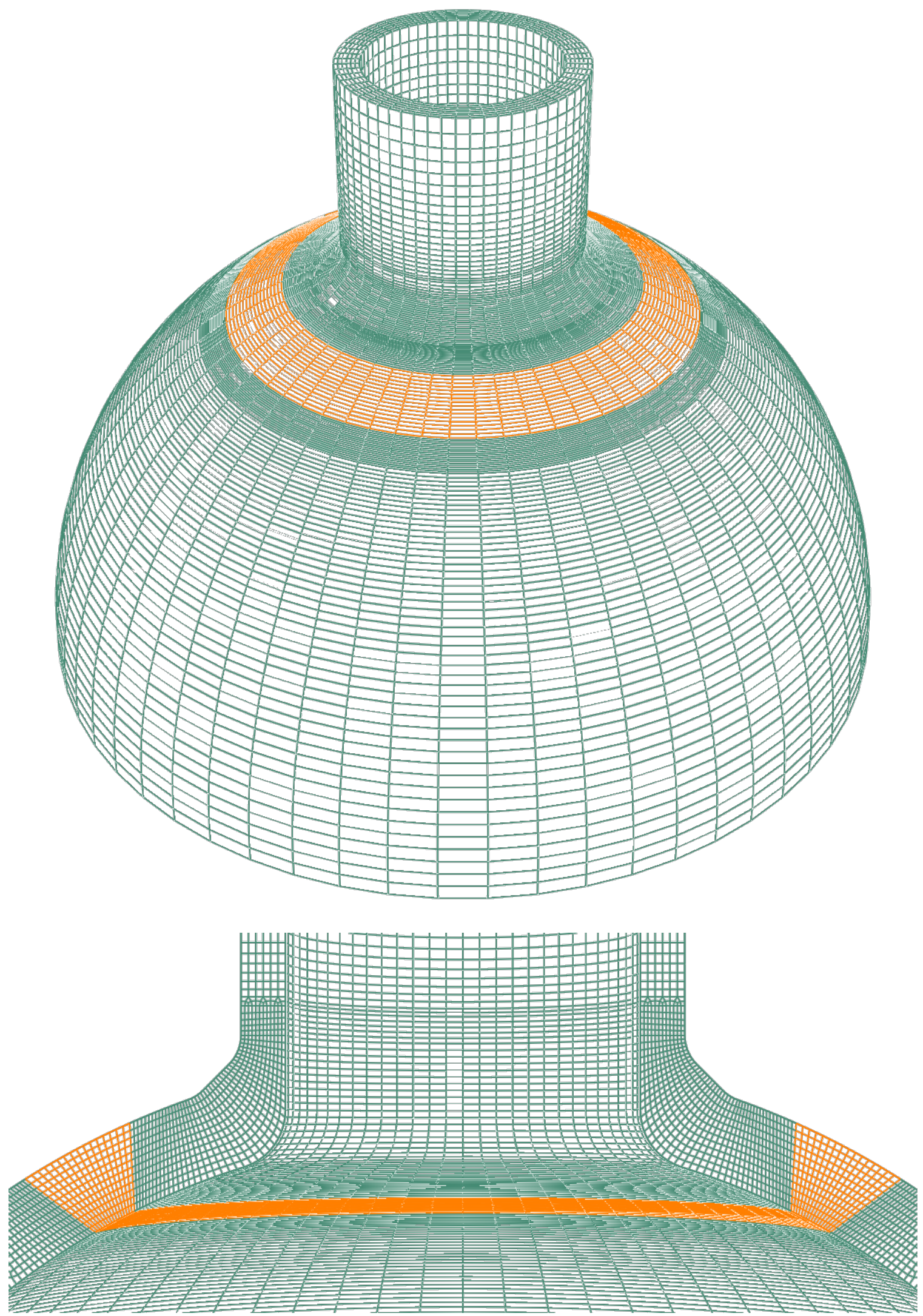
Comprehensive Report -- Page 74 of 112

Figure 3.5.1-1 Thermal Boundary Conditions

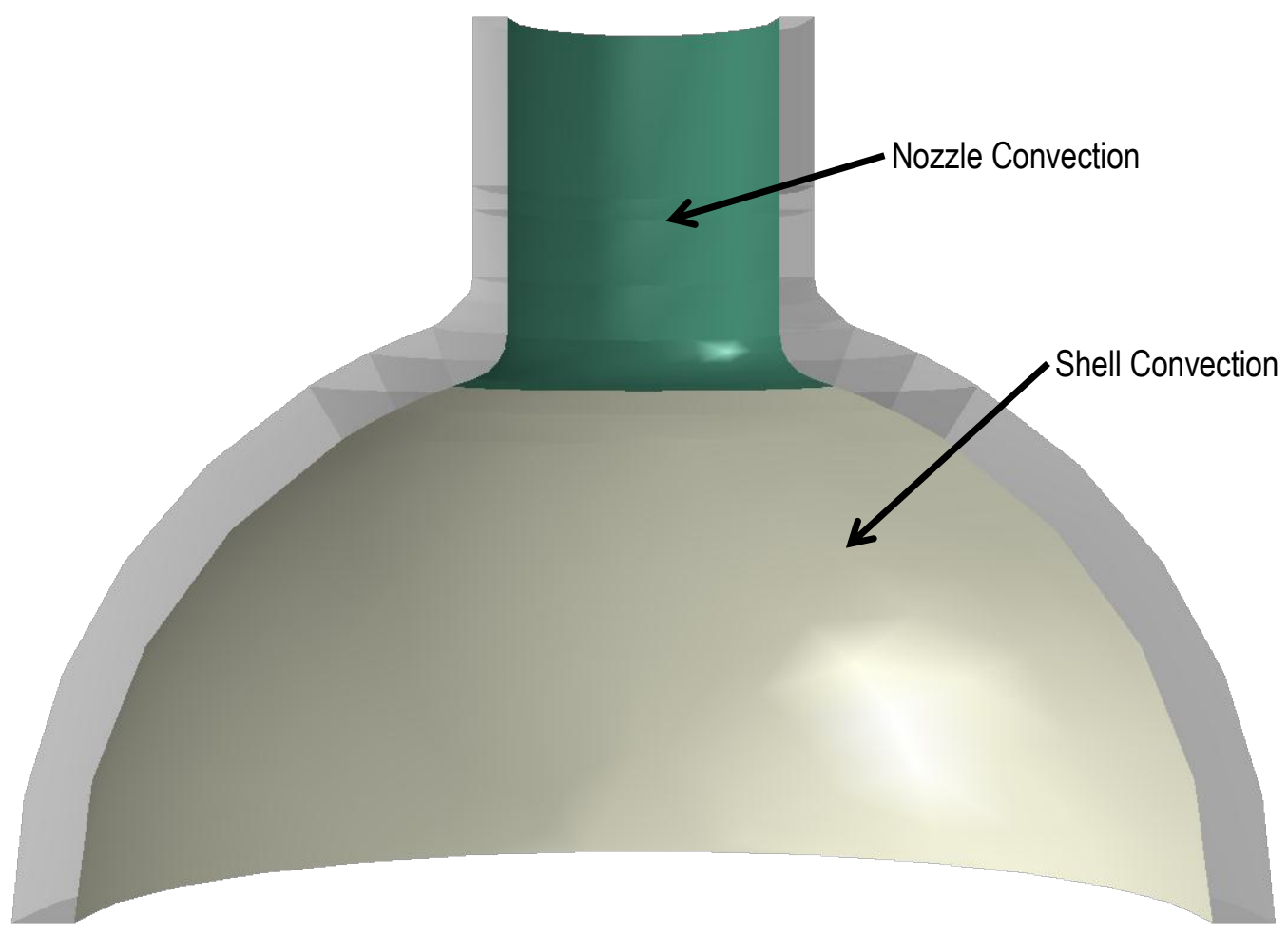


Figure 3.6.3-1 Level A \& B Composite Cycle Time History Plot

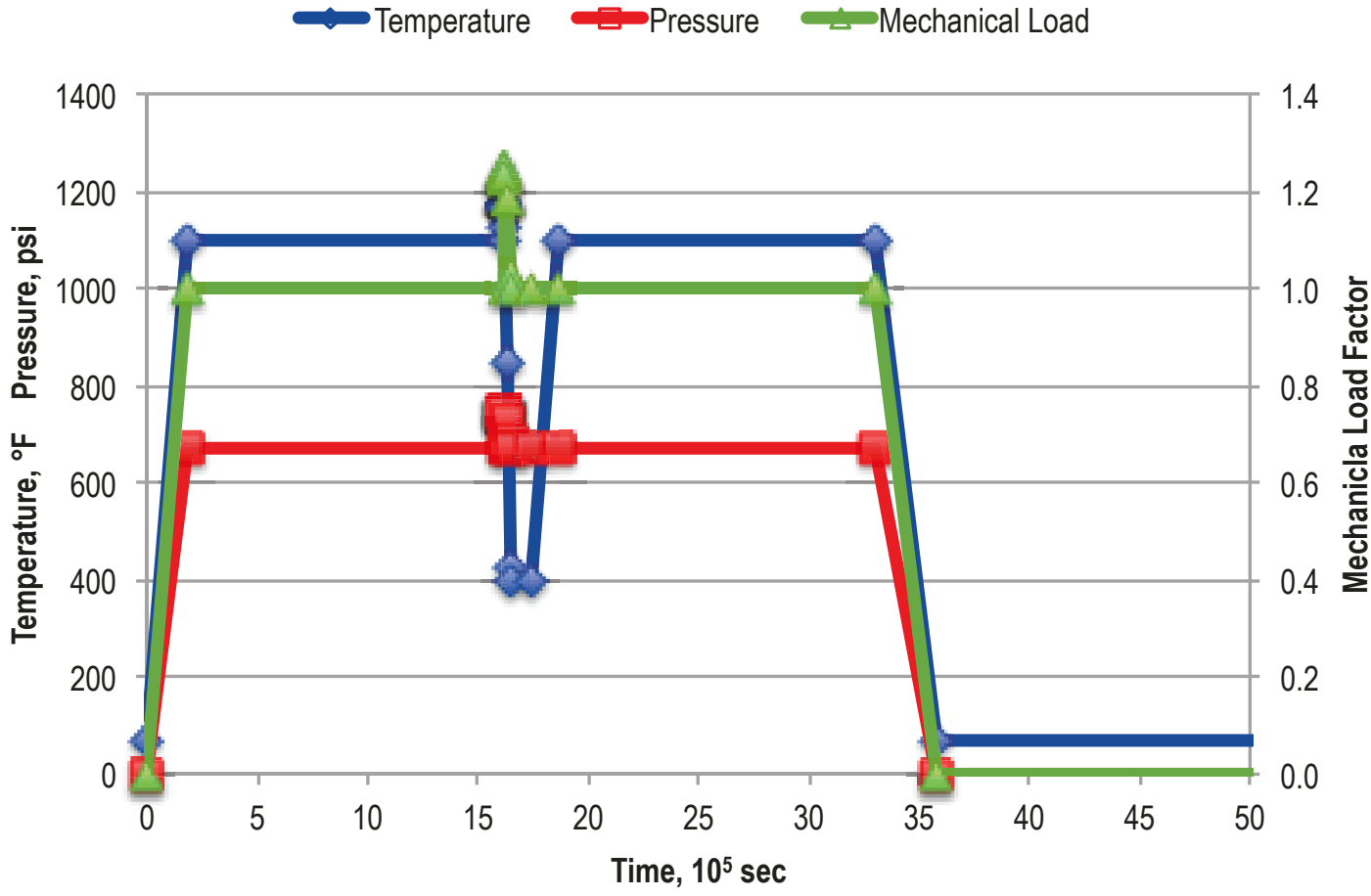

Figure 3.6.3-2 Level A \& C Composite Cycle Time History Plot

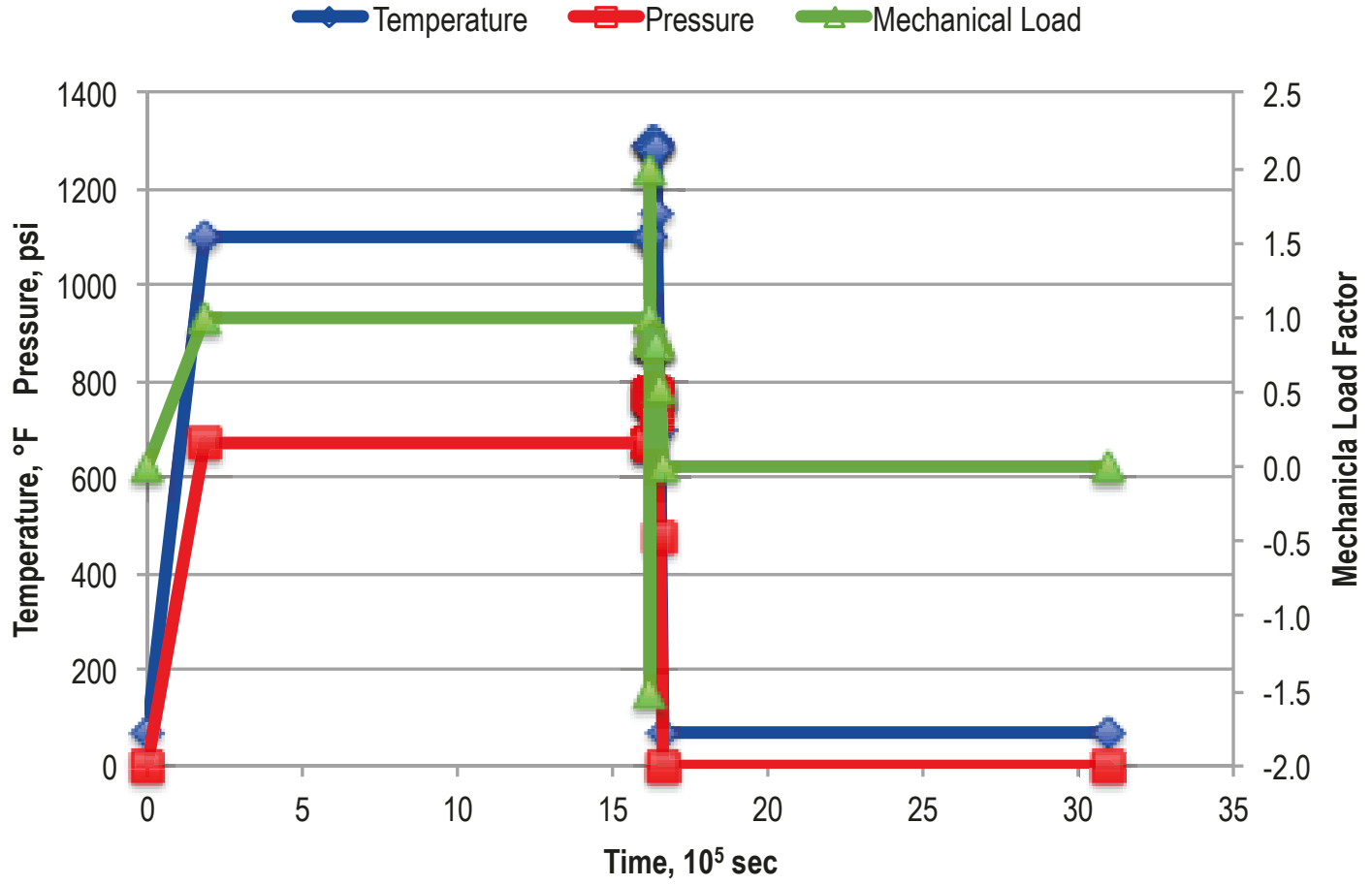


Figure 4.2-1 Level A \& B Composite Cycle Steps Plot

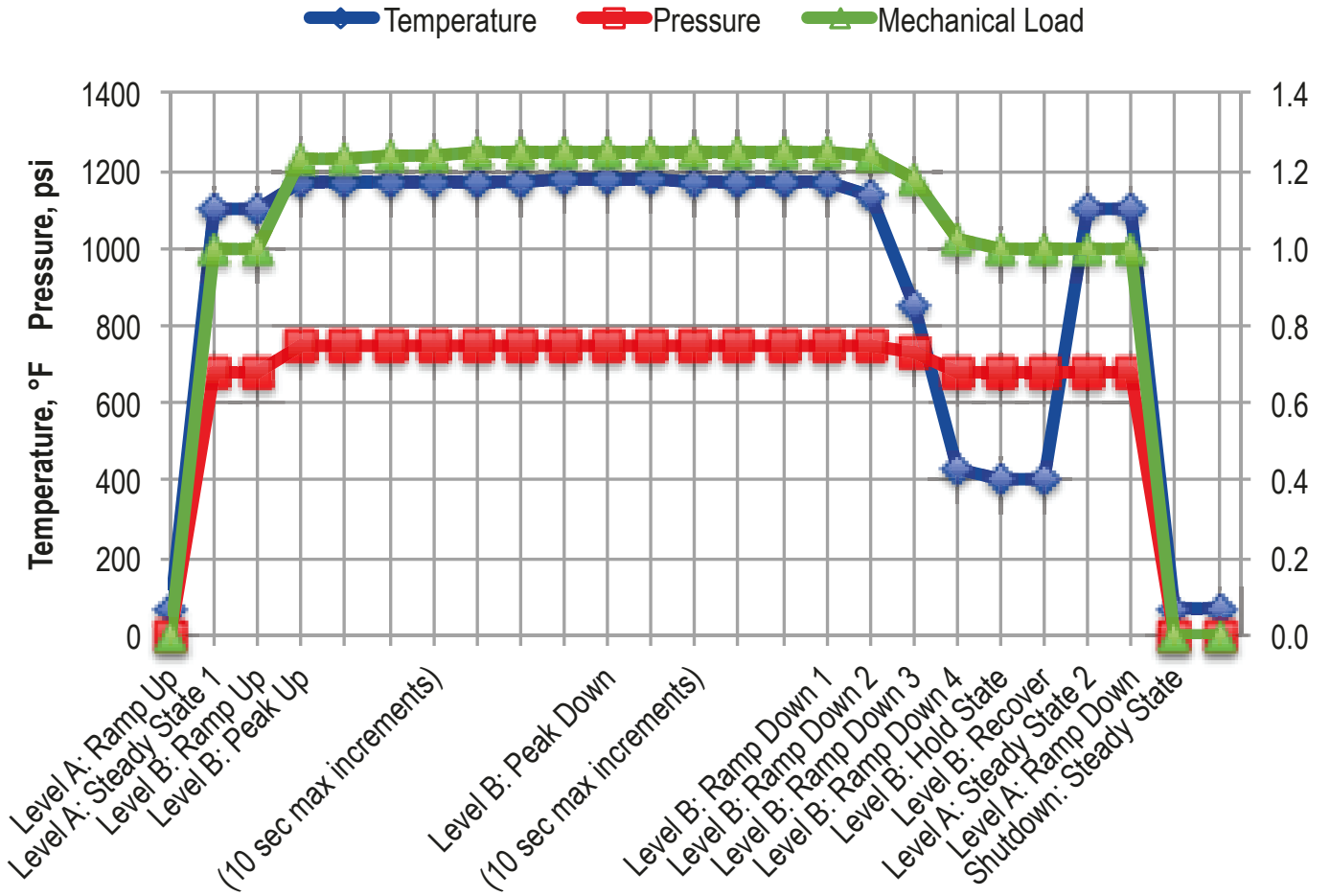

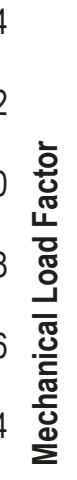

Figure 4.2-2 Level A \& C Composite Cycle Steps Plot
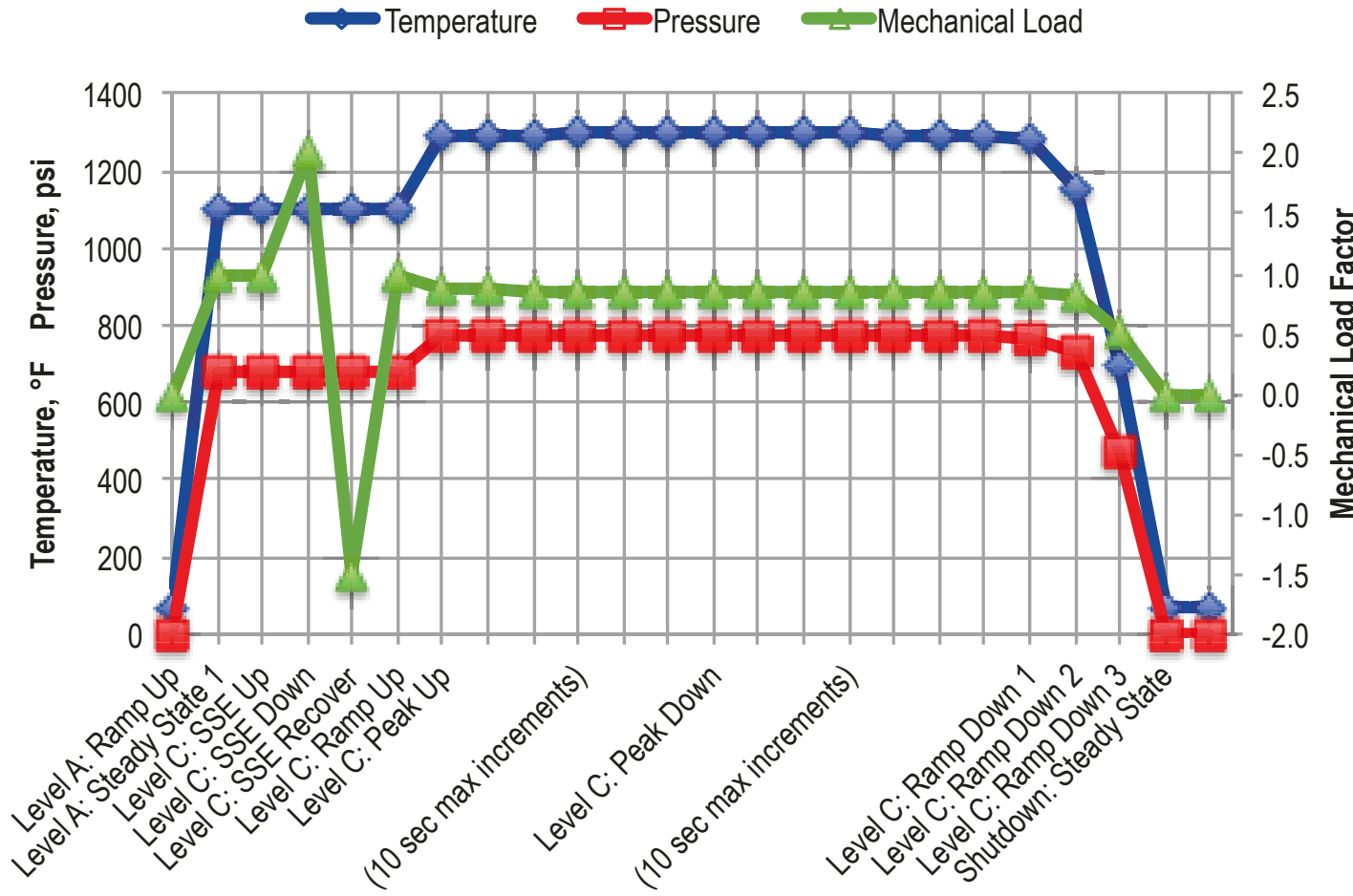
Comprehensive Report -- Page 77 of 112

Figure 4.3.1-1 Level A \& B Composite Cycle Temperature Contours

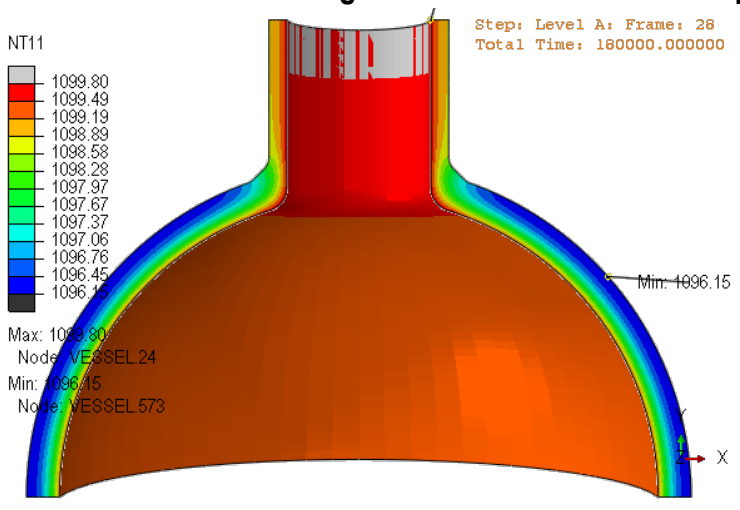

Level A: Ramp Up (1100 F)

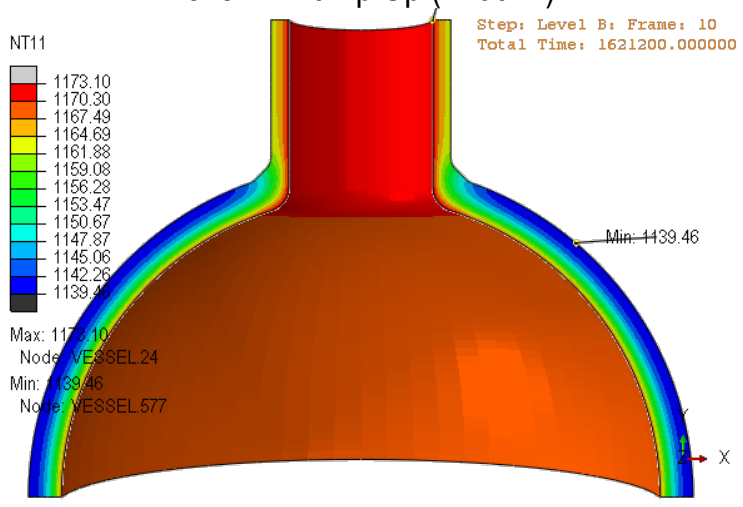

Level B: Peak Up $\left(1175^{\circ} \mathrm{F}\right)$

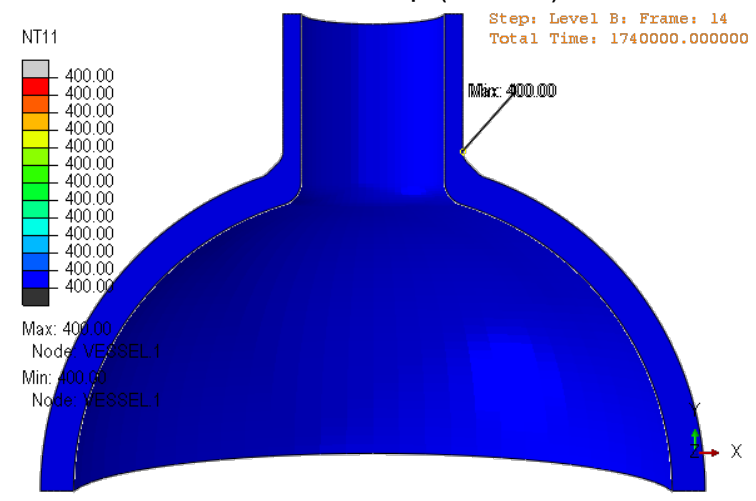

Level B: Hold State $\left(400^{\circ} \mathrm{F}\right)$

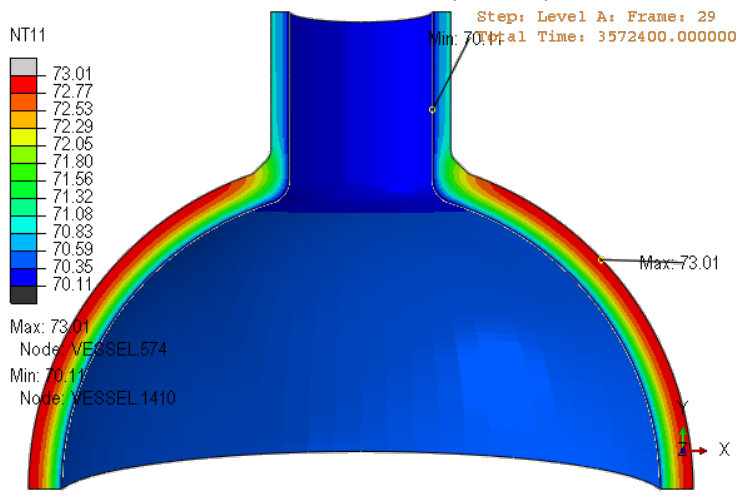

Level A: Ramp Down $\left(70^{\circ} \mathrm{F}\right)$

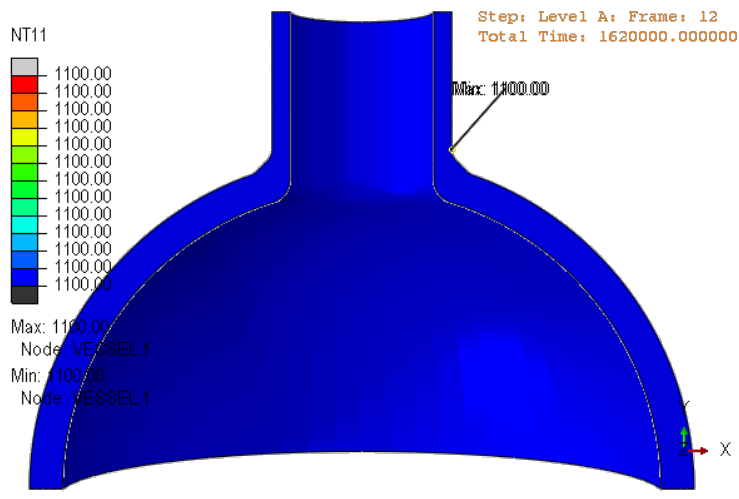

Level A: Steady State $1\left(1100^{\circ} \mathrm{F}\right)$

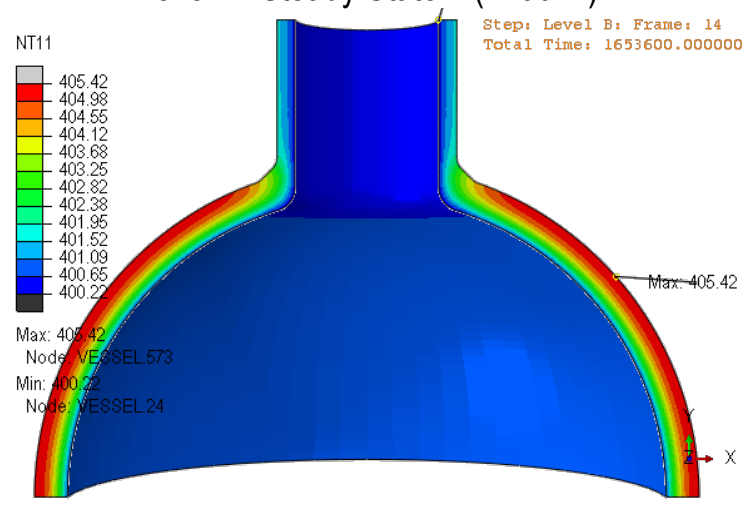

Level B: Ramp Down $4\left(400^{\circ} \mathrm{F}\right)$

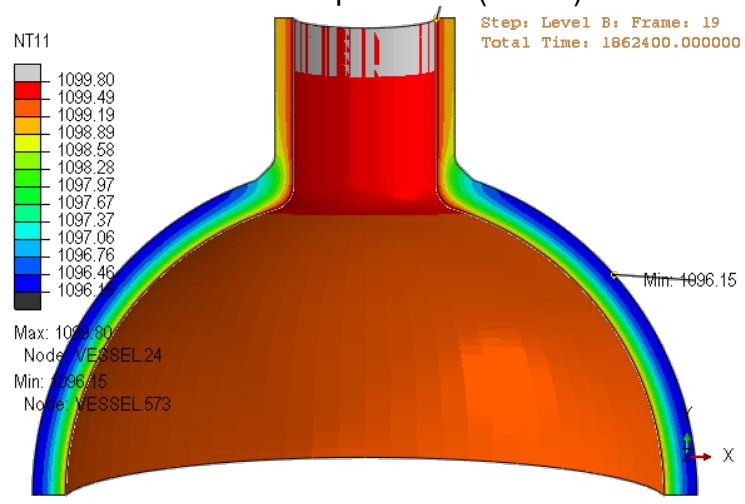

Level B: Recover $\left(1100^{\circ} \mathrm{F}\right)$

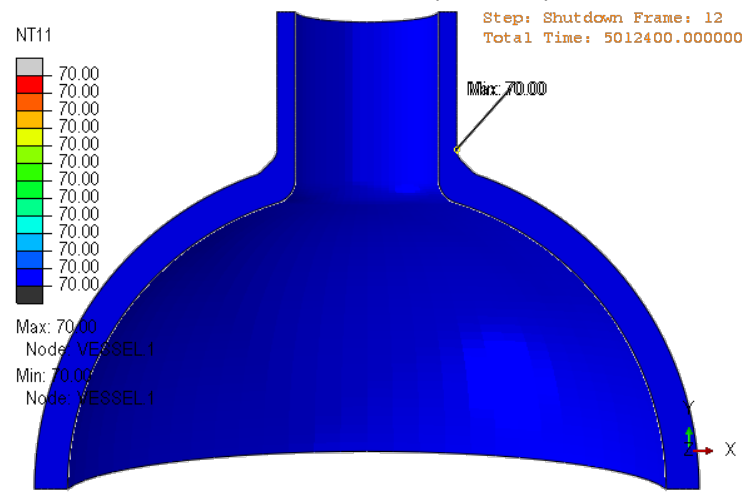

Shutdown: Steady State $\left(70^{\circ} \mathrm{F}\right)$ 
Comprehensive Report -- Page 78 of 112

Figure 4.3.1-2 Level A \& C Composite Cycle Temperature Contours

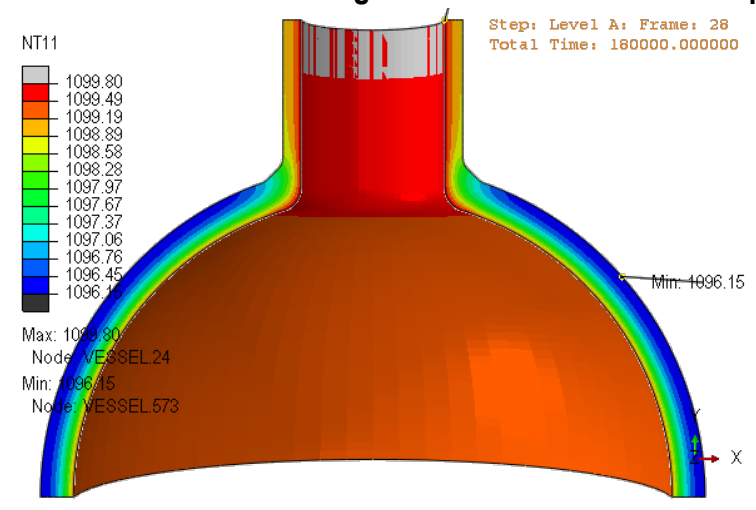

Level A: Ramp Up $\left(1100^{\circ} \mathrm{F}\right)$

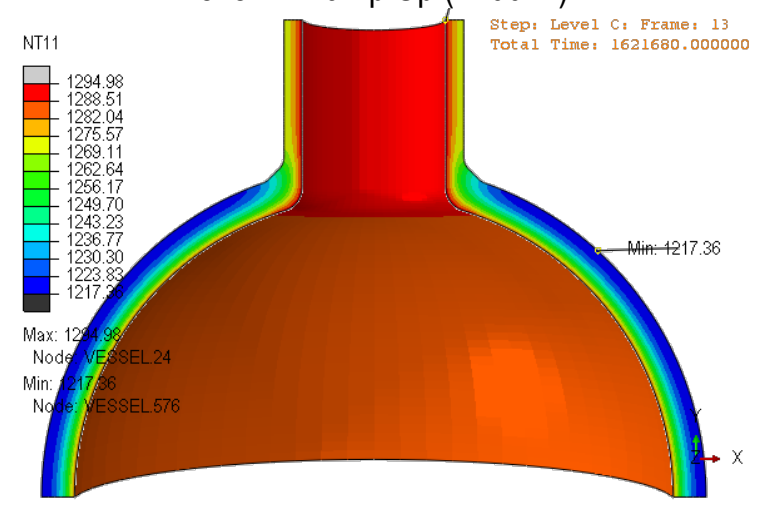

Level C: Peak Up $\left(1300^{\circ} \mathrm{F}\right)$

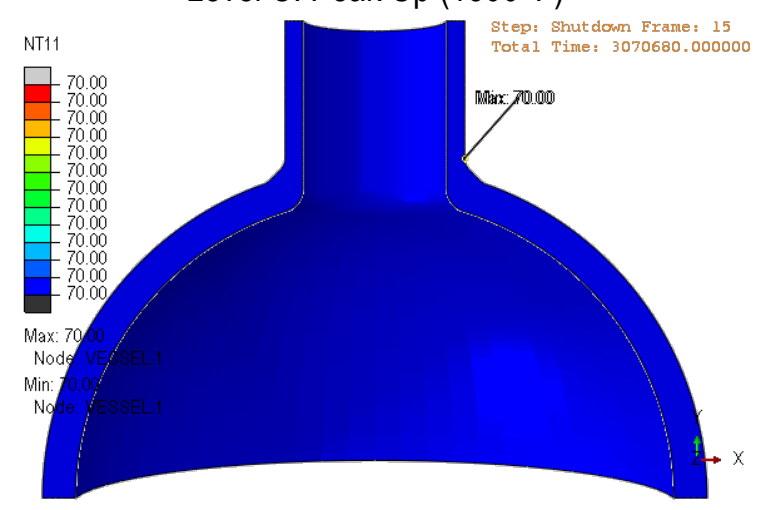

Shutdown: Steady State $\left(70^{\circ} \mathrm{F}\right)$

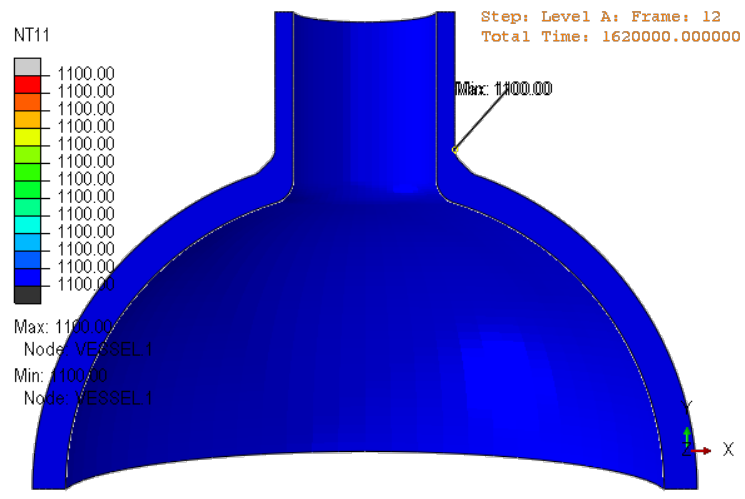

Level A: Steady State $1\left(1100^{\circ} \mathrm{F}\right)$

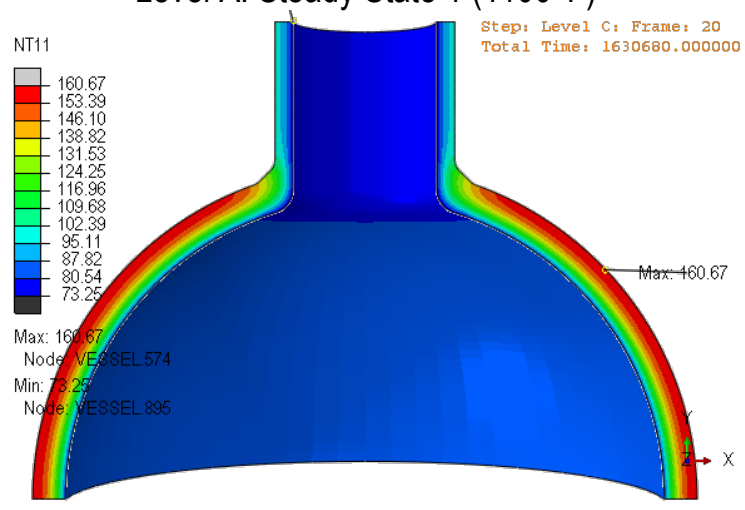

Level C: Ramp Down 3 ( $\left.70^{\circ} \mathrm{F}\right)$ 
Figure 4.3.2-1 Level A \& B Composite Cycle REP-B Strain Limits Ratcheting Check Change in Plasitc Inelastic Strain Magnitude 1.00\% Base Metal Target Inelastic Strain, Pseudo Cycle 2

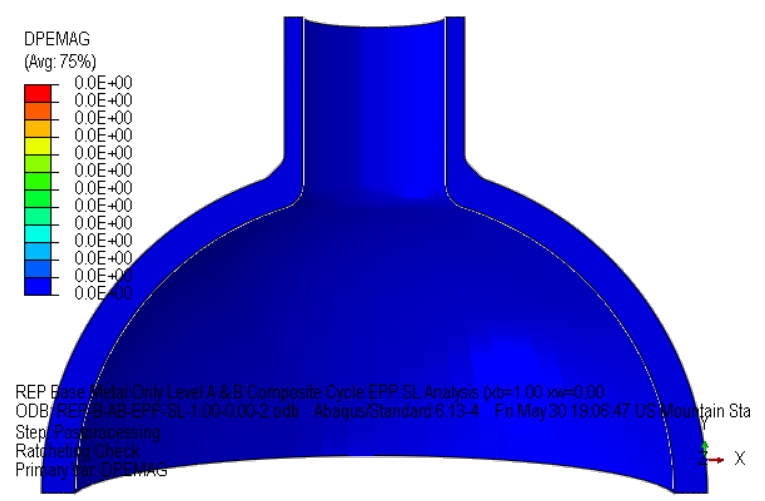

Figure 4.3.2-2 Level A \& B Composite Cycle REP-B Strain Limits Evaluation Total Inelastic Strain

$1.00 \%$ Base Metal Target Inelastic Strain, Pseudo Cycle 2
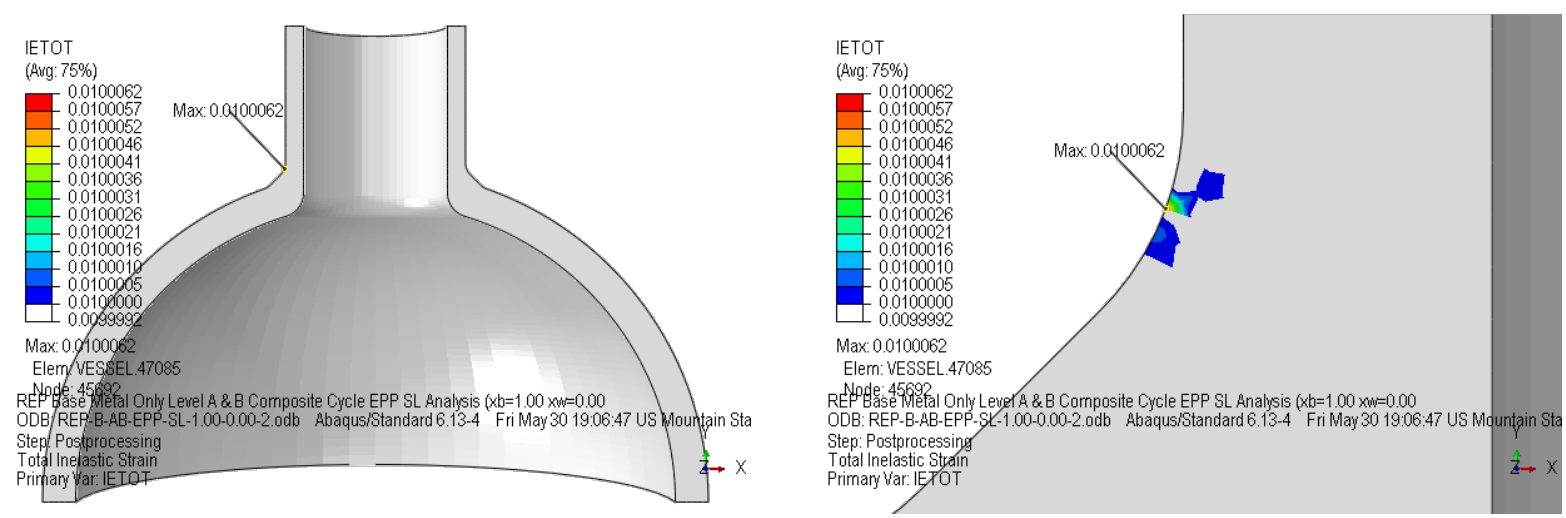
Figure 4.3.2-3 Level A \& B Composite Cycle REP-W Strain Limits Ratcheting Check Change in Plasitc Inelastic Strain Magnitude $1.00 \%$ Base Metal Target Inelastic Strain and 0.50\% Weldment Target Inelastic Strain

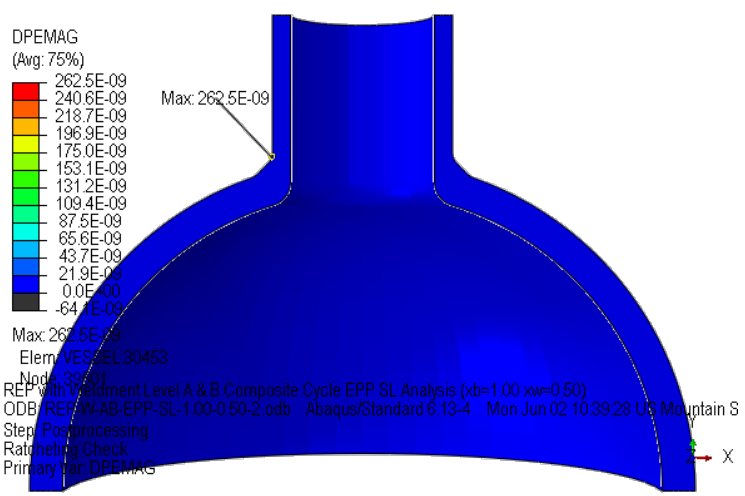

Pseudo Cycle 2

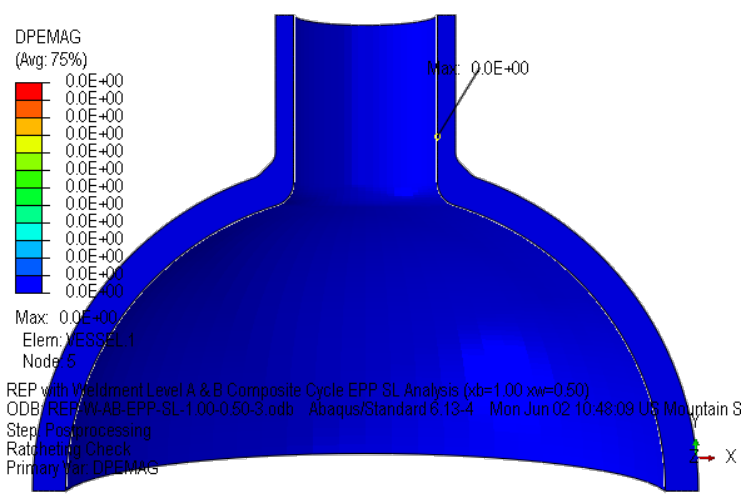

Pseudo Cycle 3

Figure 4.3.2-4 Level A \& B Composite Cycle REP-W Strain Limits Evaluation Total Inelastic Strain

1.00\% Base Metal Target Inelastic Strain and 0.50\% Weldment Target Inelastic Strain, Pseudo Cycle 3
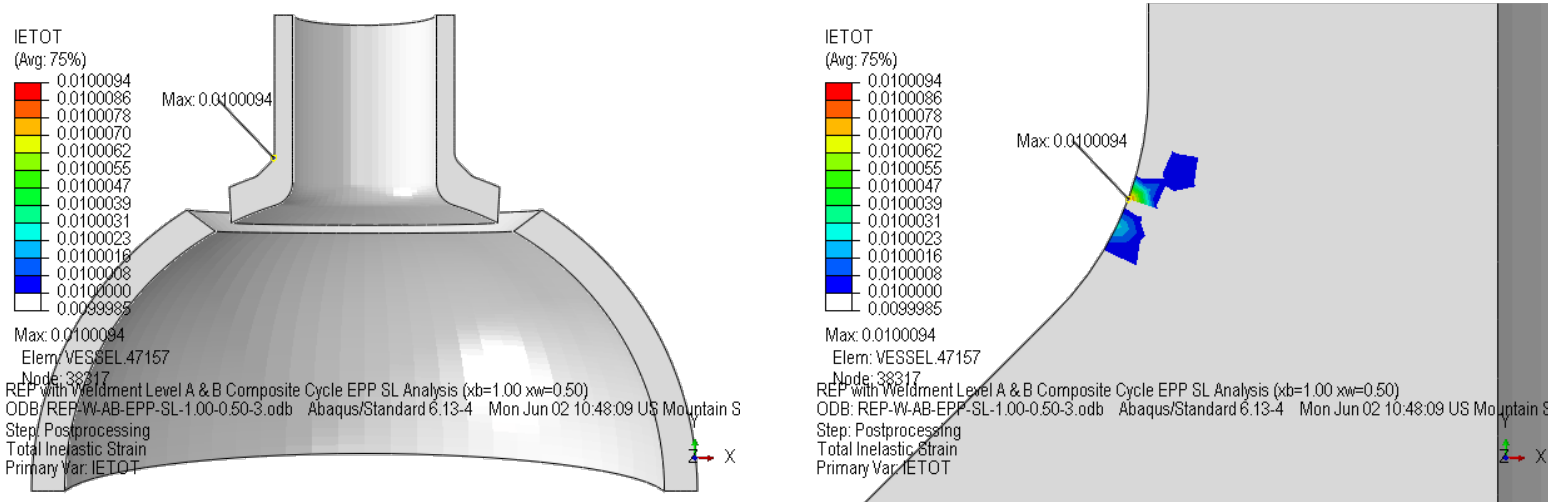

Base Metal

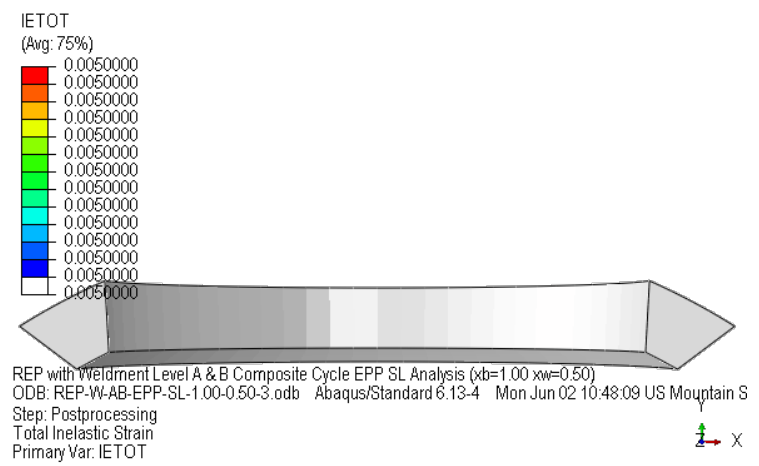

Weldment 
Figure 4.3.2-5 Level A \& C Composite Cycle Base Metal Only Strain Limits Evaluation Plastic Strain Magnitude $0.60 \%$ Target Inelastic Strain

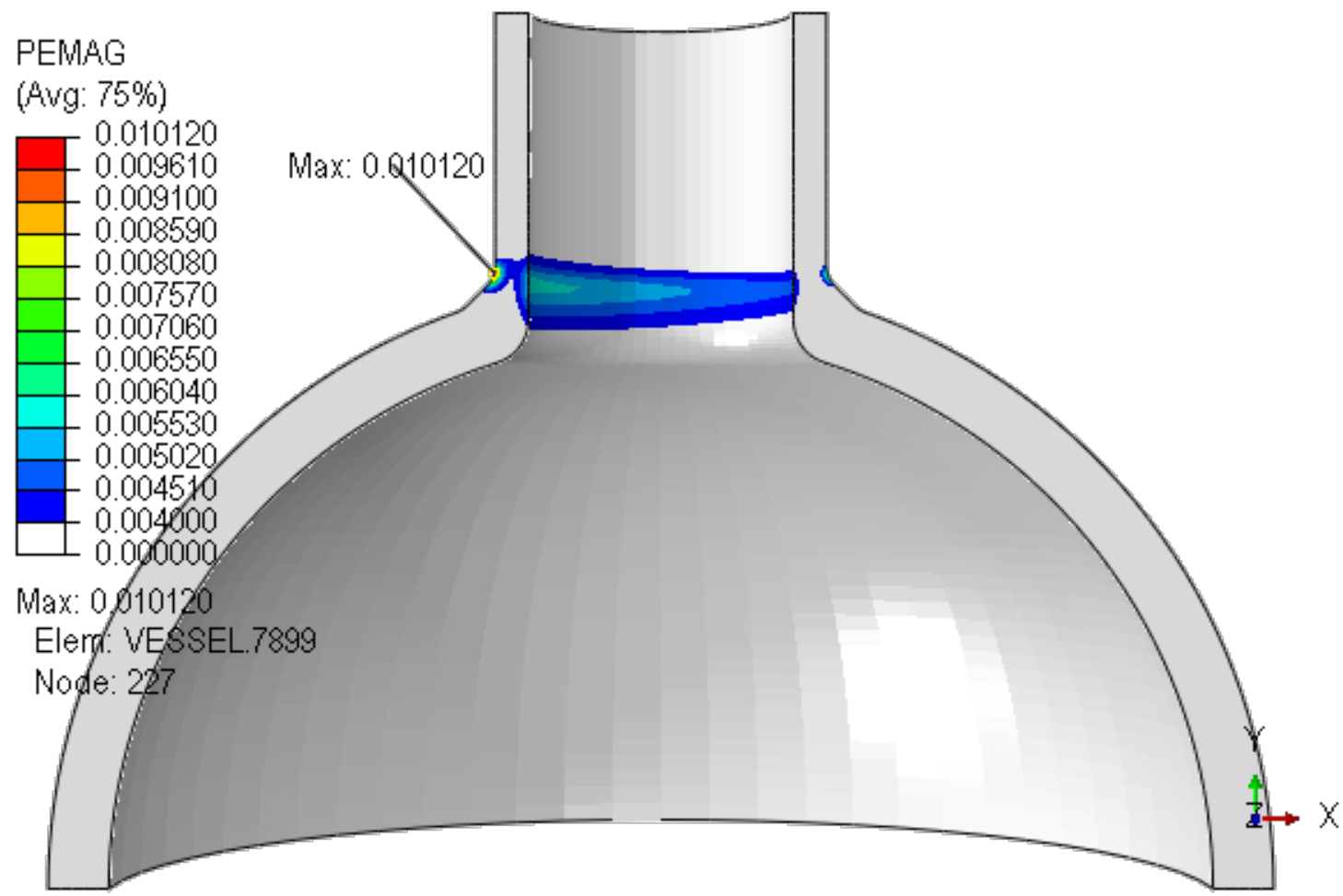

Pseudo Cycle 1

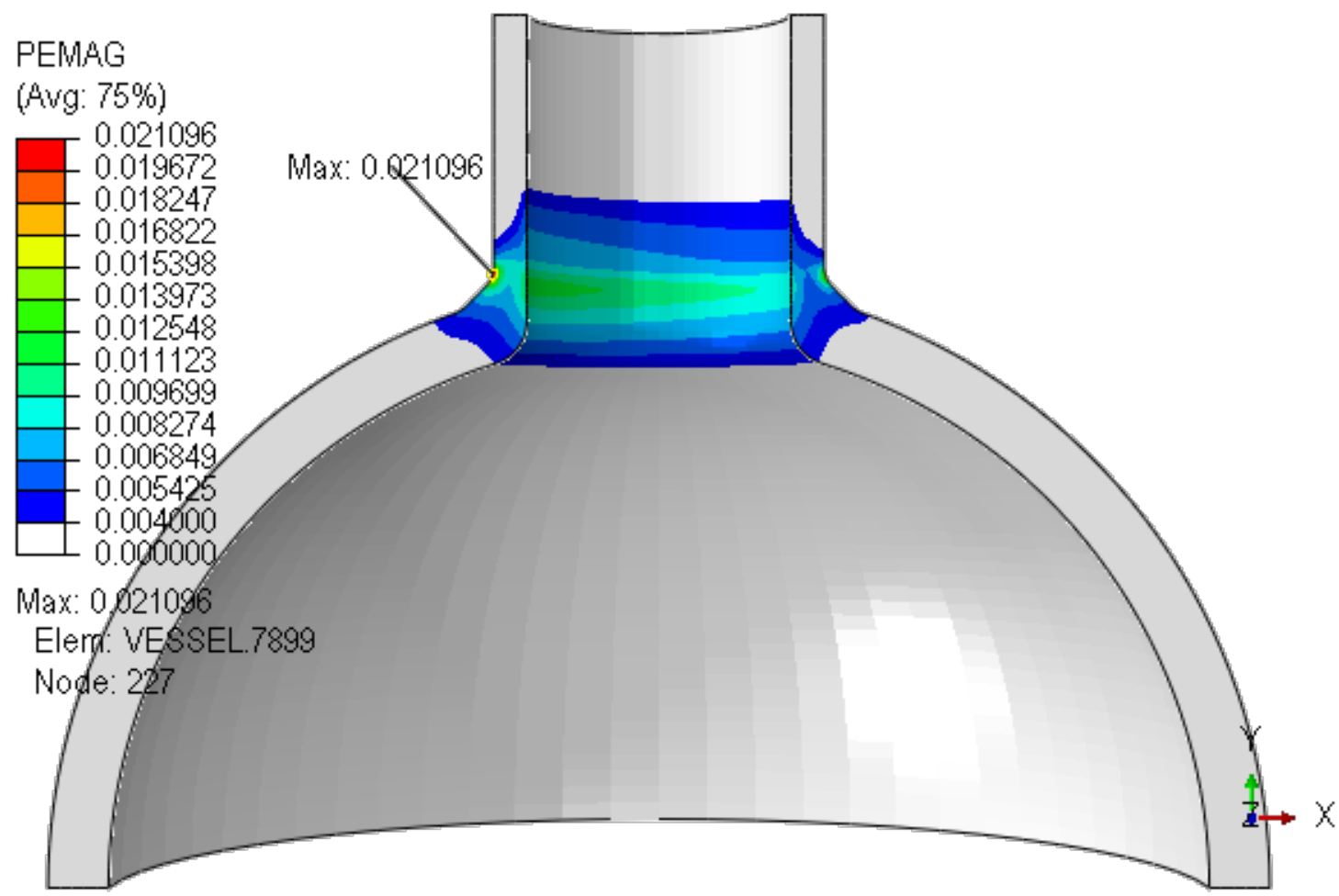

Pseudo Cycle 2

Notes:

(1) The Composite Cycle A\&C base metal only results are from 20362-R-002 Rev. 1. 
Figure 4.3.3-1 Level A \& B Composite Cycle REP-B Creep-Fatigue Shakedown Check Change in Plastic Strain Magnitude 0.90 Target Creep Damage

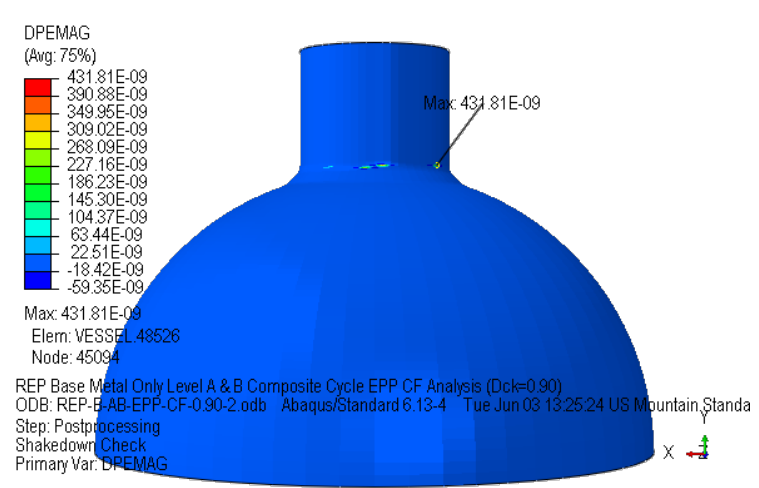

Pseudo Cycles 2

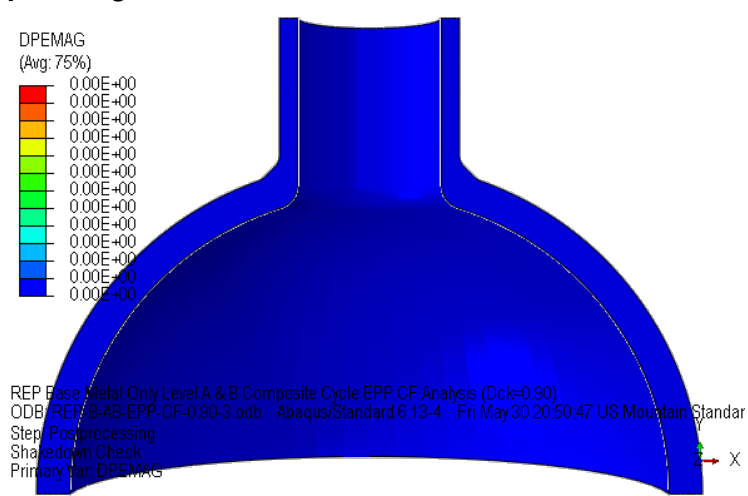

Pseudo Cycle 3

Figure 4.3.3-2 Level A \& B Composite Cycle REP-B Creep-Fatigue Evaluation Maximum Equivalent Strain Range 0.90 Target Creep Damage

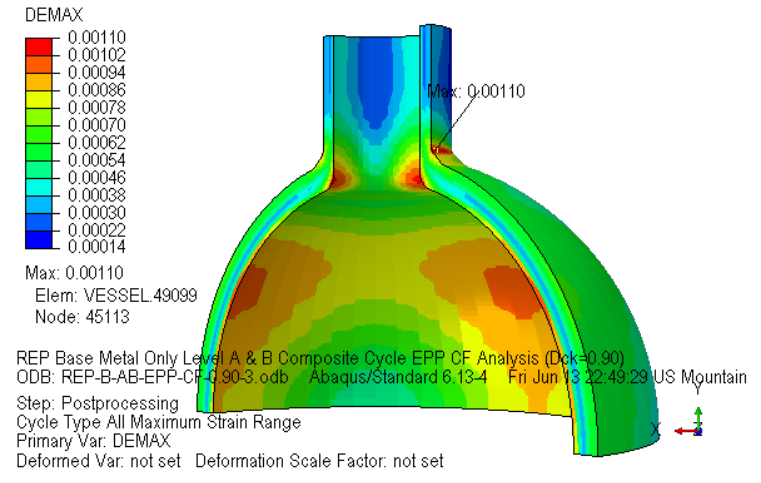

Level A \& B Cycle Type

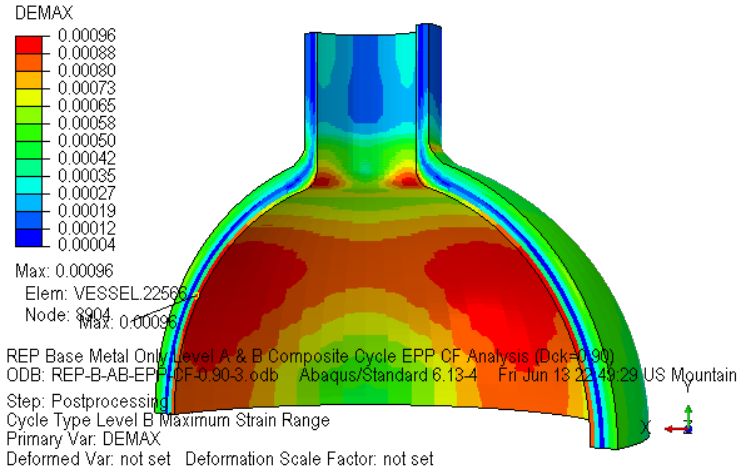

Level B Cycle Type

Figure 4.3.3-3 Level A \& B Composite Cycle REP-W Creep-Fatigue Shakedown Check Change in Plastic Strain Magnitude 0.95 Target Creep Damage
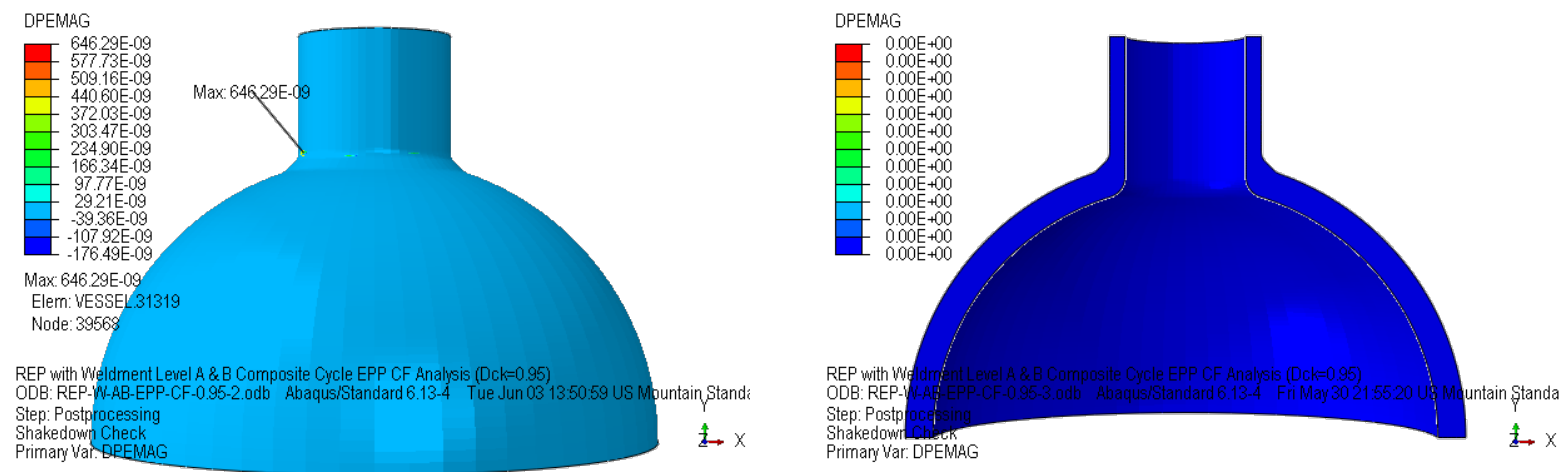

Change in Plastic Strain Magnitude for Shakedown Check (pseudo cycles 2 and 3) 
Figure 4.3.3-4 Level A \& B Composite Cycle REP-W Creep-Fatigue Evaluation Maximum Equivalent Strain Range 0.95 Target Creep Damage

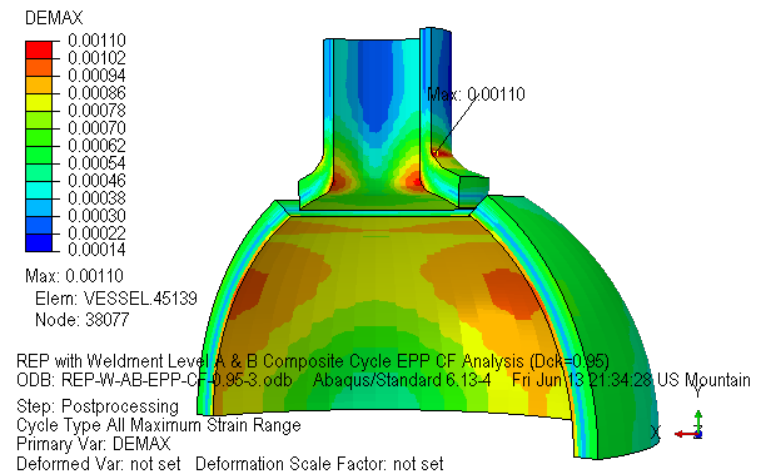

Base Metal, Level A \& B Cycle Type

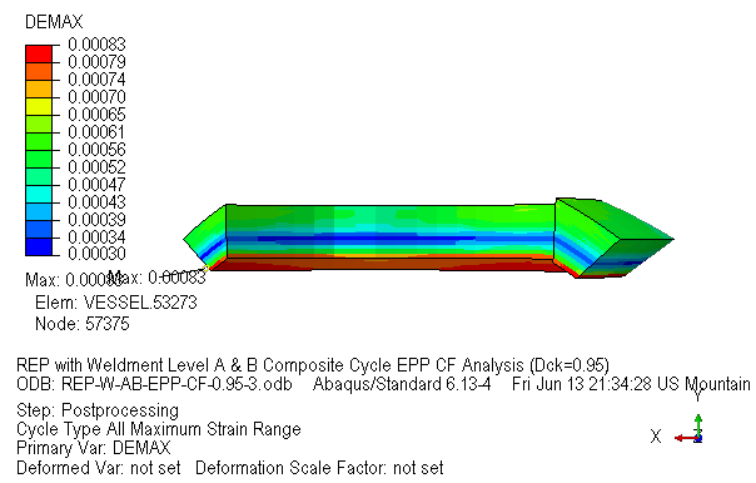

Weldment, Level A \& B Cycle Type

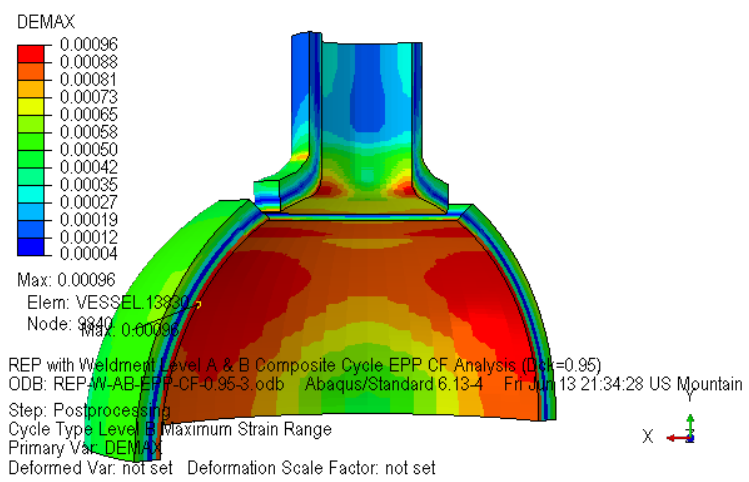

Base Metal, Level B Cycle Type

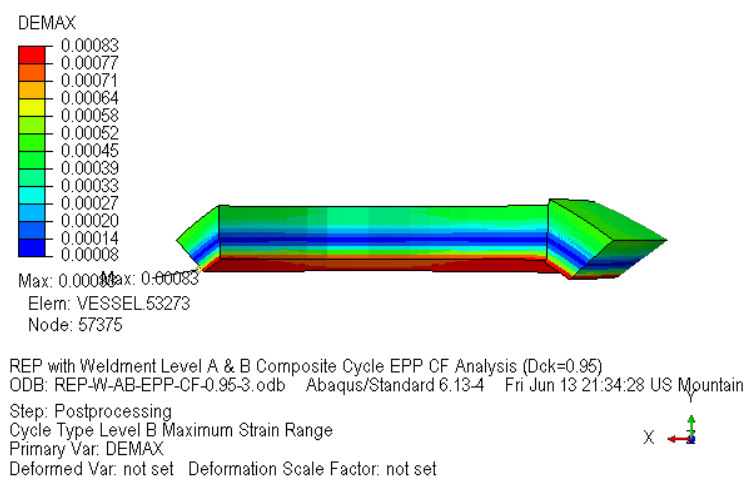

Weldment, Level B Cycle Type

Figure 4.3.3-5 Level A \& C Composite Cycle Base Metal Only Creep-Fatigue Shakedown Check 1.0 Target Creep Damage

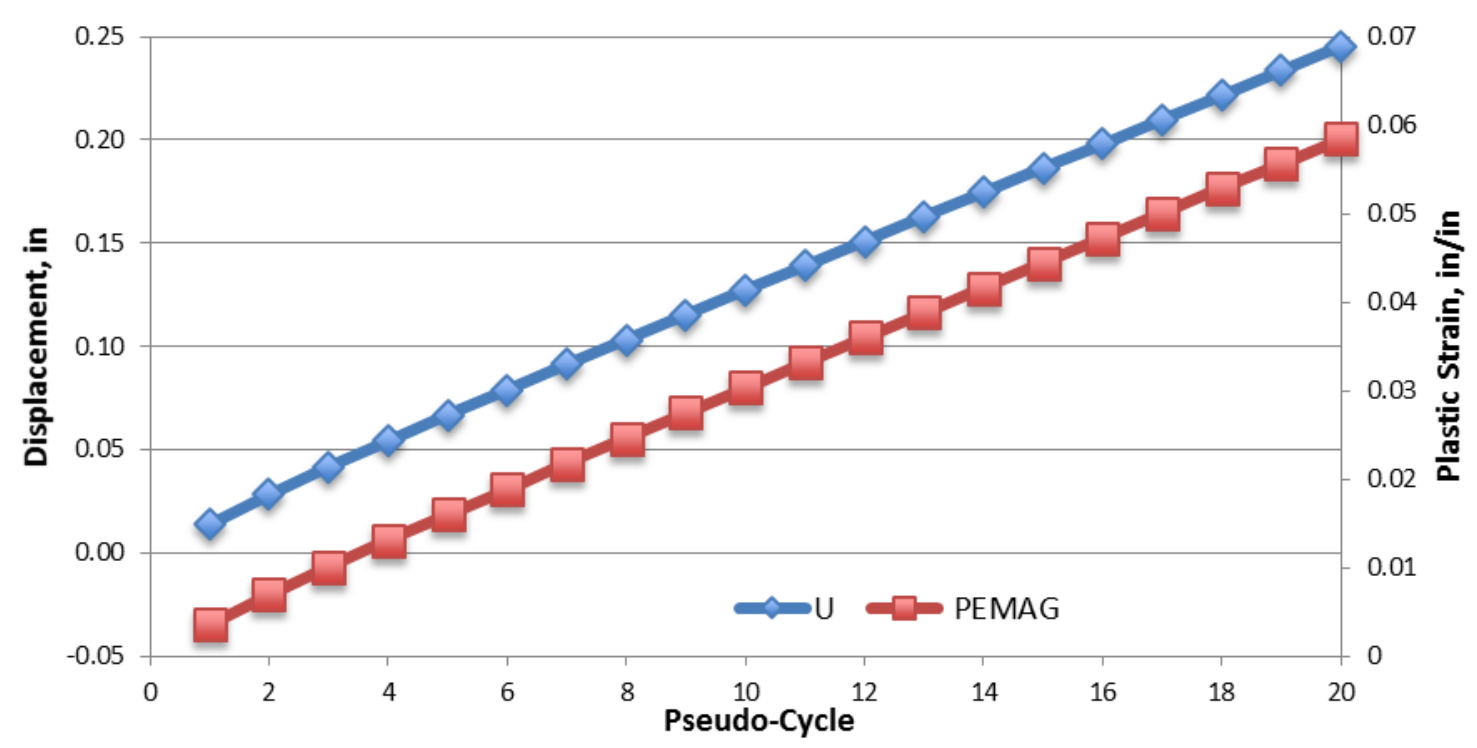

Notes:

(1) The Composite Cycle A\&C base metal only results are based on the model used in 20362-R-002 Rev. 1.

(2) The Composite Cycle A\&C exhibits signs of stable ratcheting of $0.28 \%$ plastic strain per cycle, therefore shakedown does not occur. 


\section{Appendix A - Mesh Study}

This mesh study provides the basis for selecting the appropriate mesh density of the REP vessel to obtain accurate results near the shell to nozzle junction where high stress and strains are expected.

\section{A.1 Mesh Study Model}

The model used to perform the mesh study is based on the REP vessel described in Section 0, applying isothermal static design loads on various models with different mesh densities.

\section{A.1.1 Mesh Densities}

The different mesh densities selected are listed in Table A-1.

Table A-1 Mesh Densities

\begin{tabular}{|lc|}
\hline Model Name & $\begin{array}{c}\text { Approximate } \\
\text { Size of Elements }\end{array}$ \\
\hline REP-1 & $1 "$ \\
REP-05 & $1 / 2^{\prime \prime}$ \\
REP-025 & $1 / 4^{\prime \prime}$ \\
REP-0125 & $1 / 8^{\prime \prime}$ \\
\hline
\end{tabular}

\section{A.1.2 Design Loads}

The design loads specified in the design specification [Ref. 1] are used for the mesh study as listed in Table A-2.

Table A-2 Design Loads

\begin{tabular}{|ll|}
\hline \multicolumn{1}{|c|}{ Load } & \multicolumn{1}{c|}{ Value } \\
\hline Design Pressure & $700 \mathrm{psi}$ \\
Design Temperature & $1200 \mathrm{~F}$ \\
Nozzle Axial Load & $30,000 \mathrm{lbf}$ \\
Nozzle Shear Force & $4,000 \mathrm{lbf}$ \\
Nozzle Torsional Moment & $20,000 \mathrm{lbf}-$-in \\
\hline
\end{tabular}

\section{A.2 Mesh Study Analysis}

Isothermal static stress analyses are run for each of the models listed in Table A-1. The results are compared in Table A-3 and Figure A-1 and Figure A-2. Based on these results all the models provide results with in $1 \%$.

Therefore, model REP-025 is selected as a conservatively adequate mesh density.

Table A-3 Maximum Tresca Stress Results, ksi

\begin{tabular}{|lcc|}
\hline Model Name & Design Pressure Only & All Design Loads \\
\hline REP-1 & 7.62 & 8.42 \\
REP-05 & 7.62 & 8.42 \\
REP-025 & 7.60 & 8.38 \\
REP-0125 & 7.59 & 8.37 \\
\hline
\end{tabular}




\section{Figure A-1 Design Pressure Only Tresca Stress Contours}
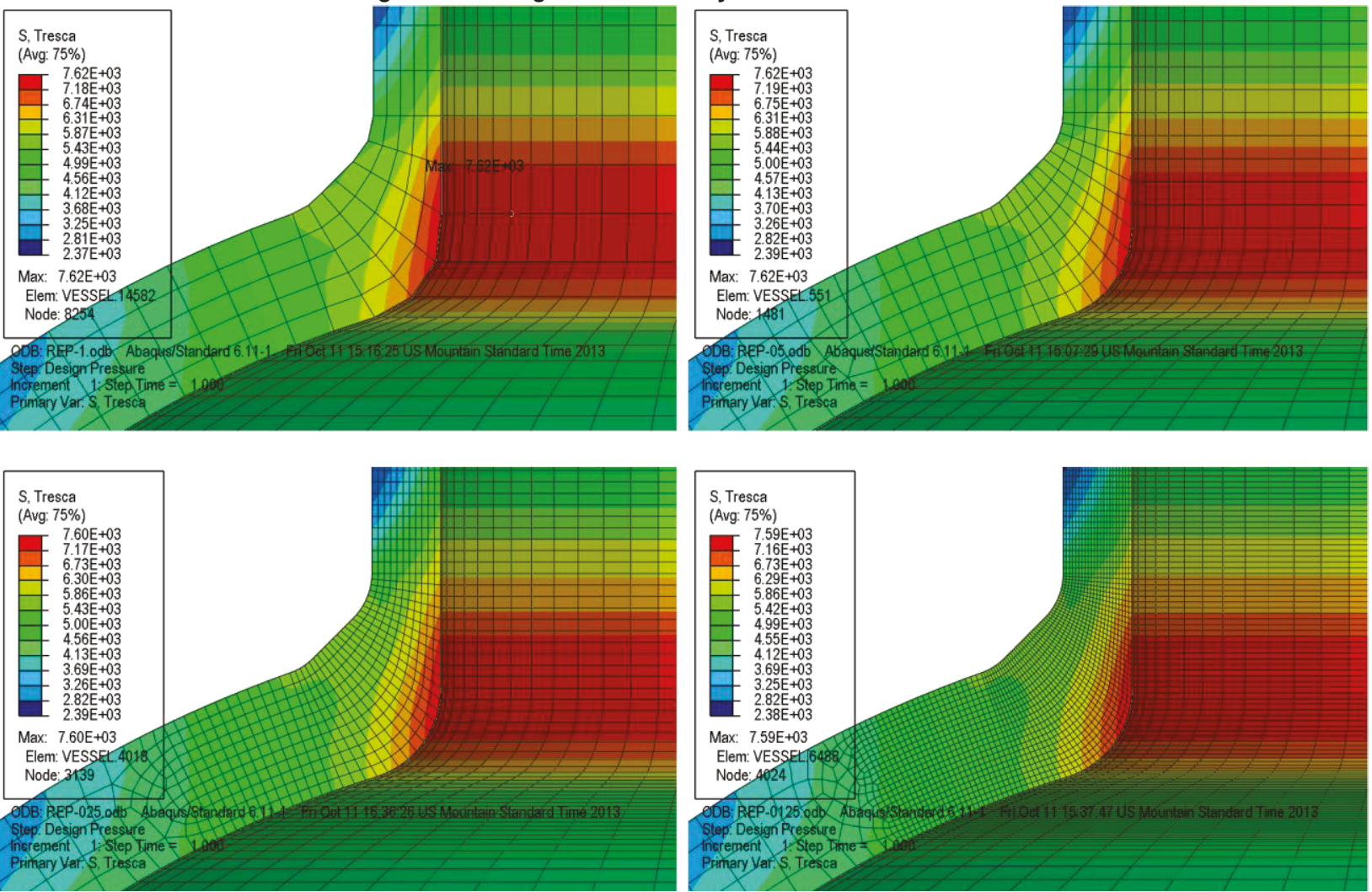

Figure A-2 All Design Loads Tresca Stress Contours
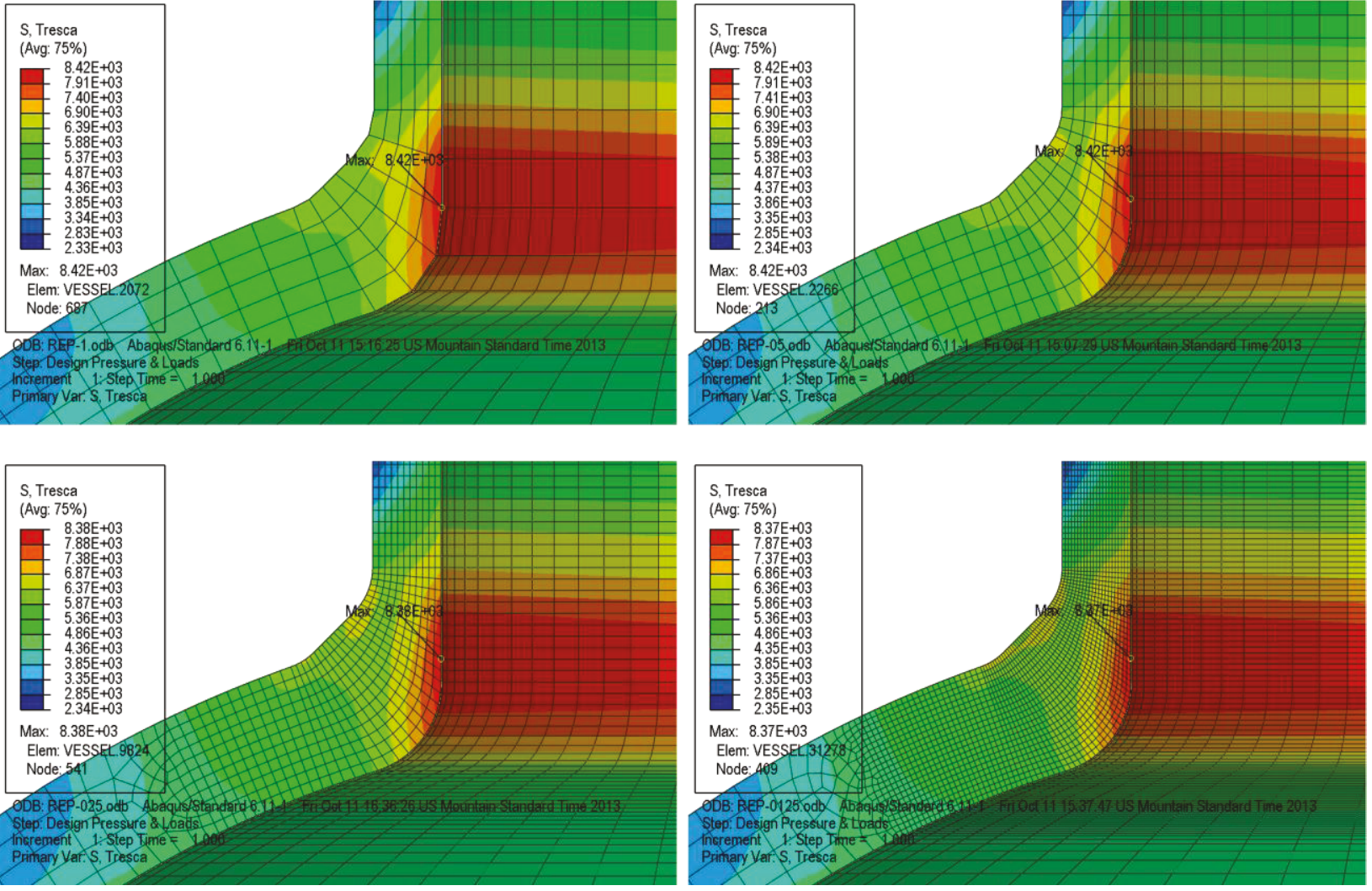


\section{Appendix B — Pseudo Yield Stress for Strain Limits Analysis}

This appendix defines the equations used to compute the temperature dependent Pseudo Yield Stress for the strain limits analysis at various target inelastic strain values.

\section{B.1 316H Yield Stress}

The equation for yield stress as a function of temperature is defined below.

$$
\begin{aligned}
& a_{0}:=1.10298556 \\
& a_{1}:=-1.47430259 \mathrm{e}-3 \\
& a_{2}:=1.52887261 \mathrm{e}-6 \\
& a_{3}:=-7.8404955 \mathrm{e}-10 \\
& a_{4}:=3.10394363 \mathrm{e}-13 \\
& a_{5}:=-1.17555515 \mathrm{e}-16 \\
& S_{y}(T):=\min \left[\sum_{n=0}^{5}\left[a_{n}\left(T /{ }^{\circ} \mathrm{F}\right)^{n}\right], 1\right] 30 \mathrm{ksi}
\end{aligned}
$$

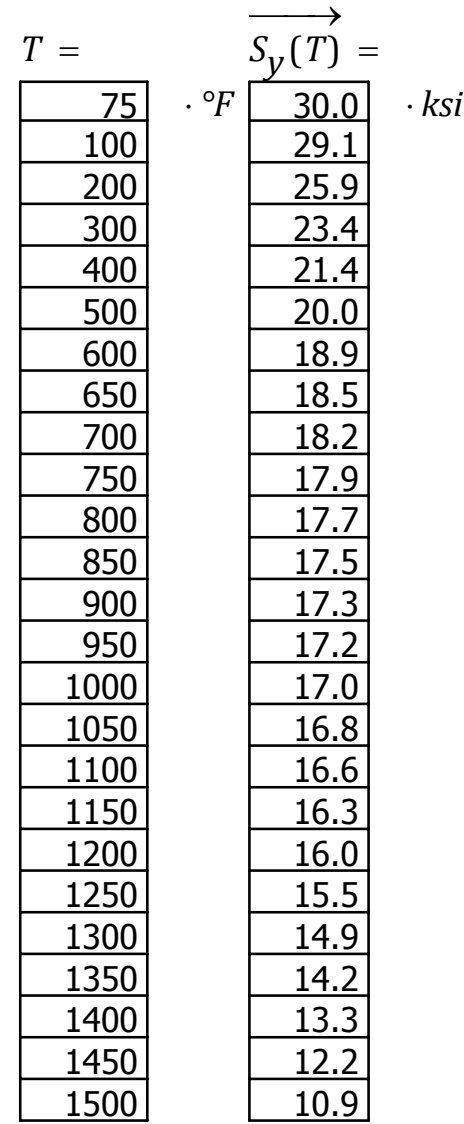

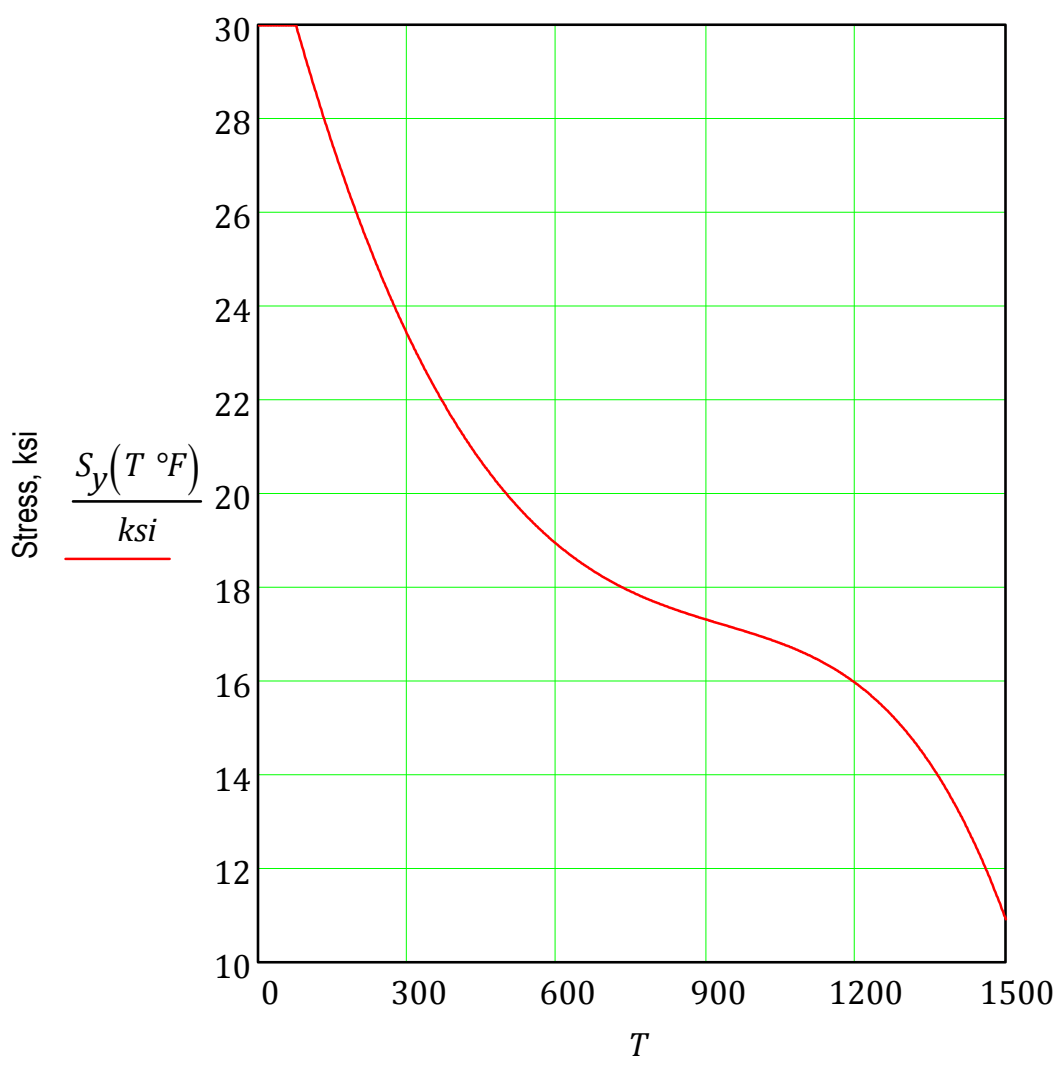

Temperature, ${ }^{\circ} \mathrm{F}$ 


\section{B.2 316H Hot Tensile Plastic Strain}

The hot tensile plastic strain parameters as a function of temperature are defined below.

$$
\begin{aligned}
& \sigma_{y}(T):=1.0\left(23402.6 \cdot p s i-8.04798 \cdot T \cdot \frac{p s i}{K}\right) \\
& \sigma_{p}(T):=\sigma_{y}(T)-8188.8 \cdot p s i+3.51356 \cdot T \cdot \frac{p s i}{K} \\
& K_{1}(T):=60786.5 \cdot p s i-13.7959 \cdot T \cdot \frac{p s i}{K} \\
& m_{1}(T):=0.309503+6.13279 \cdot 10^{-5} \cdot T \cdot \frac{1}{K} \\
& K_{2}(T):=\mid \begin{array}{l}
203100 p s i \text { if } \quad 600{ }^{\circ} \mathrm{F} \leq T \leq 1000^{\circ} \mathrm{F} \\
664859 \mathrm{psi}-569.369 \cdot \mathrm{T} \frac{\mathrm{psi}}{\mathrm{K}} \text { if } 1000^{\circ} \mathrm{F}<T<1200{ }^{\circ} \mathrm{F} \\
\text { NaN otherwise }
\end{array} \\
& m_{2}(T):=\mid \begin{array}{l}
0.7315 \text { if } 600{ }^{\circ} \mathrm{F} \leq T<1000{ }^{\circ} \mathrm{F} \\
1.65136-1.13423 \cdot 10^{-3} \cdot \mathrm{T} \cdot \frac{1}{\mathrm{~K}} \quad \text { if } \quad 1000^{\circ} \mathrm{F} \leq T \leq 1200{ }^{\circ} \mathrm{F} \\
\text { NaN otherwise }
\end{array} \\
& \varepsilon_{p}(\sigma, T):=\mid \begin{array}{l}
0 \quad \text { if } \quad \sigma<\sigma_{p}(T) \\
\text { otherwise }
\end{array}
\end{aligned}
$$

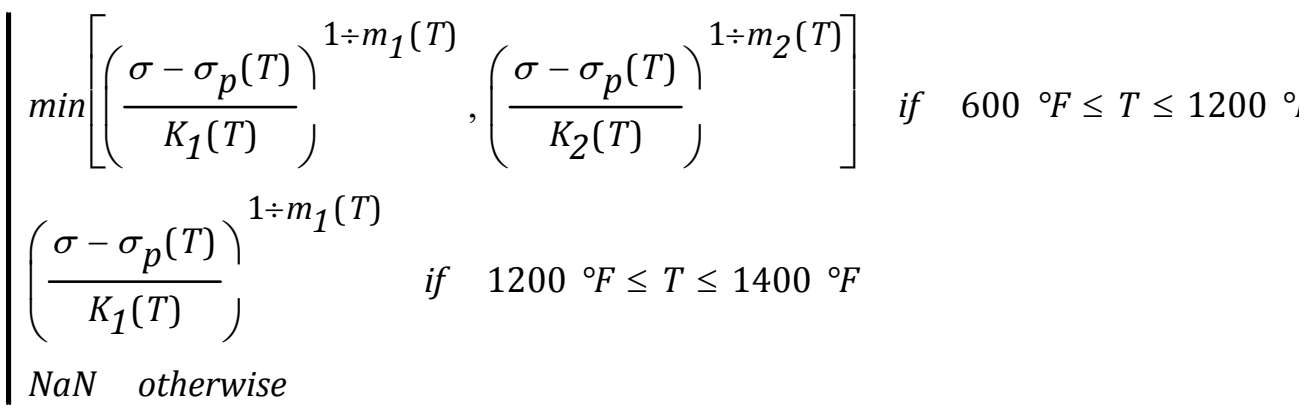




\section{B.3 316H Creep Strain}

The creep strain parameters as a function of temperature are defined below.

$$
\begin{aligned}
& G(T):=\mid \begin{array}{l}
0 \quad \text { if } \quad 800{ }^{\circ} \mathrm{F} \leq T<1000^{\circ} \mathrm{F} \\
1.28221 \%-1.58103 \cdot 10^{-3} \mathrm{~T} \frac{\%}{K} \quad \text { if } \quad 1000{ }^{\circ} \mathrm{F} \leq T<1100{ }^{\circ} \mathrm{F} \\
-0.271855 \%+2.13509 \cdot 10^{-4} T \frac{\%}{K} \quad \text { if } \quad 1100^{\circ} \mathrm{F} \leq T \leq 1200^{\circ} \mathrm{F} \\
-0.692411 \%+6.69643 \cdot 10^{-4} T \frac{\%}{K} \quad \text { if } \quad 1200^{\circ} \mathrm{F}<T<1300^{\circ} \mathrm{F} \\
-0.704318 \%+6.81818 \cdot 10^{-4} T \frac{\%}{K} \quad \text { if } \quad 1300^{\circ} \mathrm{F} \leq T \leq 1400^{\circ} \mathrm{F} \\
\text { NaN otherwise }
\end{array} \\
& H(T):=\mid \begin{array}{l}
0 \quad \text { if } \quad 800{ }^{\circ} \mathrm{F} \leq T<1000{ }^{\circ} \mathrm{F} \\
-3.20553 \cdot 10^{-4} \frac{\%}{p s i}+3.95256 \cdot 10^{-7} \mathrm{~T} \frac{\%}{\mathrm{psi} \cdot \mathrm{K}} \quad \text { if } \quad 1000^{\circ} \mathrm{F} \leq T<1100^{\circ} \mathrm{F}
\end{array} \\
& 6.79633 \cdot 10^{-5} \frac{\%}{p s i}-5.33767 \cdot 10^{-8} \mathrm{~T} \frac{\%}{p s i \cdot K} \quad \text { if } \quad 1100^{\circ} \mathrm{F} \leq T \leq 1200{ }^{\circ} \mathrm{F} \\
& 1.73103 \cdot 10^{-4} \frac{\%}{p s i}-1.67411 \cdot 10^{-7} \mathrm{~T} \frac{\%}{p s i \cdot K} \quad \text { if } \quad 1200^{\circ} \mathrm{F}<T<1300^{\circ} \mathrm{F} \\
& \begin{array}{l}
1.7608 \cdot 10^{-4} \frac{\%}{p s i}-1.70455 \cdot 10^{-7} T \frac{\%}{p s i \cdot K} \text { if } 1300^{\circ} \mathrm{F} \leq T \leq 1400{ }^{\circ} \mathrm{F} \\
\text { NaN otherwise }
\end{array} \\
& D(T):=\mid \begin{array}{l}
5.7078 \cdot 10^{13} \frac{1}{h r} \quad \text { if } 800{ }^{\circ} \mathrm{F} \leq T<1000^{\circ} \mathrm{F} \\
-4.4986 \cdot 10^{17} \frac{1}{\mathrm{hr}}+5.54768 \cdot 10^{14} \mathrm{~T} \frac{1}{\mathrm{hr} \cdot \mathrm{K}} \quad \text { if } \quad 1000^{\circ} \mathrm{F} \leq T \leq 1075.5^{\circ} \mathrm{F} \\
2.86941 \cdot 10^{17} \frac{1}{\mathrm{hr}}-3.09286 \cdot 10^{14} \mathrm{~T} \frac{1}{\mathrm{hr} \cdot \mathrm{K}} \quad \text { if } \quad 1075.5^{\circ} \mathrm{F}<T \leq 1200^{\circ} \mathrm{F}
\end{array} \\
& \begin{array}{l}
1.3369 \cdot 10^{10} e^{\frac{10878.5 K}{T}} \frac{1}{h r} \text { if } 1200{ }^{\circ} \mathrm{F}<T \leq 1400^{\circ} \mathrm{F} \\
\text { NaN otherwise }
\end{array} \\
& \beta(T):=\mid \begin{array}{l}
-4.257 \cdot 10^{-4} \frac{1}{p s i}+7.733 \cdot 10^{-7} T \frac{1}{p s i \cdot K} \quad \text { if } \quad 800{ }^{\circ} \mathrm{F} \leq T \leq 1400{ }^{\circ} \mathrm{F} \\
\text { NaN } \quad \text { otherwise }
\end{array}
\end{aligned}
$$




$$
\begin{aligned}
& n(T):=\mid \begin{array}{l}
4.6 \quad \text { if } 800{ }^{\circ} \mathrm{F} \leq T<1000{ }^{\circ} \mathrm{F} \\
-80.9236+0.105455 \mathrm{~T} \frac{1}{K} \quad \text { if } 1000{ }^{\circ} \mathrm{F} \leq T \leq 1075.5^{\circ} \mathrm{F} \\
50.1136-0.0482143 \mathrm{~T} \frac{1}{K} \quad \text { if } 1075.5^{\circ} \mathrm{F}<T \leq 1200^{\circ} \mathrm{F} \\
14.4647-9.54954 \cdot 10^{-3} \mathrm{~T} \frac{1}{K} \quad \text { if } 1200{ }^{\circ} \mathrm{F}<T \leq 1400^{\circ} \mathrm{F} \\
\text { NaN otherwise }
\end{array} \\
& C(T):=\mid \begin{array}{l}
7.1 \quad \text { if } \quad 800{ }^{\circ} \mathrm{F} \leq T<1000{ }^{\circ} \mathrm{F} \\
25.5318-0.0227273 T \frac{1}{K} \quad \text { if } 1000{ }^{\circ} \mathrm{F} \leq T<1100^{\circ} \mathrm{F} \\
54.5625-0.05625 T \frac{1}{K} \quad \text { if } 1100{ }^{\circ} \mathrm{F} \leq T \leq 1200{ }^{\circ} \mathrm{F} \\
7.68378-5.4054 \cdot 10^{-3} \mathrm{~T} \frac{1}{K} \quad \text { if } 1200{ }^{\circ} \mathrm{F}<T \leq 1400{ }^{\circ} \mathrm{F} \\
\text { NaN otherwise }
\end{array} \\
& B(T):=\mid \begin{array}{l}
5.7078 \cdot 10^{13} \frac{1}{h r} \quad \text { if } \quad 800{ }^{\circ} \mathrm{F} \leq T<1000{ }^{\circ} \mathrm{F} \\
-3.92183 \cdot 10^{16} \frac{1}{\mathrm{hr}}+4.84416 \cdot 10^{13} \mathrm{~T} \frac{1}{\mathrm{hr} \cdot \mathrm{K}} \quad \text { if } \quad 1000{ }^{\circ} \mathrm{F} \leq T \leq 1075.5^{\circ} \mathrm{F}
\end{array} \\
& 1.44225 \cdot 10^{-8} \cdot e^{\frac{45475.8 K}{T}} \frac{1}{h r} \quad \text { if } 1075.5^{\circ} \mathrm{F}<T \leq 1200^{\circ} \mathrm{F} \\
& 2.85517 \cdot 10^{8} \cdot e^{\frac{10878.5 K}{T}} \frac{1}{h r} \quad \text { if } 1200^{\circ} \mathrm{F}<T \leq 1400^{\circ} \mathrm{F} \\
& \text { NaN otherwise }
\end{aligned}
$$




$$
\begin{aligned}
& L(T):=\mid \begin{array}{l}
M \leftarrow 43.1255-\frac{49995.0 \mathrm{~K}}{T} \text { if } \quad 800{ }^{\circ} \mathrm{F} \leq T<1000^{\circ} \mathrm{F} \\
\text { if } \quad 1000^{\circ} \mathrm{F} \leq T \leq 1075.5^{\circ} \mathrm{F}
\end{array} \\
& z \leftarrow T \frac{1}{K}-610 \\
& M \leftarrow-1153.38+16.4457 z-0.0754331 z^{2}+0.000107956 z^{3} \\
& \text { if } \quad 1075.5{ }^{\circ} \mathrm{F}<T<1100{ }^{\circ} \mathrm{F} \\
& z \leftarrow T \frac{1}{K}-610 \\
& M \leftarrow-274.235+1.15596 z-0.00115945 z^{2} \\
& \text { if } \quad 1100{ }^{\circ} \mathrm{F} \leq \mathrm{T} \leq 1200{ }^{\circ} \mathrm{F} \\
& z \leftarrow T \frac{1}{K}-610 \\
& M \leftarrow-274.235+1.15598 z-0.00115945 z^{2} \\
& \text { if } \quad 1200{ }^{\circ} \mathrm{F}<\mathrm{T} \leq 1400^{\circ} \mathrm{F} \\
& w \leftarrow T \frac{1}{K}-680 \\
& M \leftarrow-54.6029+0.118486 w-8.63568 \cdot 10^{-6} w^{2} \\
& M \leftarrow N a N \text { otherwise } \\
& e^{M} \frac{1}{h r} \\
& A(T):=\mid \begin{array}{l}
5.6229 \cdot 10^{12} \frac{\%}{h r} \text { if } 800{ }^{\circ} \mathrm{F} \leq T<1000{ }^{\circ} \mathrm{F} \\
-7.85348 \cdot 10^{15} \frac{\%}{h r}+9.69329 \cdot 10^{12} \mathrm{~T} \frac{\%}{\mathrm{hr} \cdot \mathrm{K}} \quad \text { if } 1000^{\circ} \mathrm{F} \leq T \leq 1075.5{ }^{\circ} \mathrm{F} \\
5.28787 \cdot 10^{-6} e^{\frac{39057.1 \mathrm{~K}}{T}} \frac{\%}{\mathrm{hr}} \text { if } 1075.5^{\circ} \mathrm{F}<T \leq 1200^{\circ} \mathrm{F} \\
6.03371 \cdot 10^{10} e^{\frac{4967.76 \mathrm{~K}}{T}} \frac{\%}{\mathrm{hr}} \text { if } 1200{ }^{\circ} \mathrm{F}<T \leq 1400{ }^{\circ} \mathrm{F} \\
\text { NaN otherwise }
\end{array} \\
& Q:=67000 \cdot \frac{\mathrm{cal}}{\mathrm{mol}} \quad R:=1.987 \frac{\mathrm{cal}}{\mathrm{mol} \cdot \mathrm{K}}
\end{aligned}
$$


The steady-state creep strain equation as a function of stress, temperature and time is defined below.

$$
\begin{array}{ll}
\varepsilon_{m}^{\prime}(\sigma, T):=A(T) \cdot \sinh \left(\frac{\beta(T) \cdot \sigma}{n(T)}\right)^{n(T)} e^{\frac{-Q}{R \cdot T}} & \\
\varepsilon_{c r . s S}(\sigma, T, t):=\varepsilon_{m}^{\prime}(\sigma, T) \cdot t & \text { steady-state creep strain }
\end{array}
$$

The short-time transient creep strain equation as a function of stress, temperature and time is defined below.

$$
\begin{aligned}
& s(\sigma, T):=\max \left(D(T) \cdot \sinh \left(\frac{\beta(T) \cdot \sigma}{n(T)}\right)^{n(T)} e^{\frac{-Q}{R \cdot T}}, 2.5 \cdot 10^{-2} \frac{1}{h r}\right) \\
& \varepsilon_{X}(\sigma, T):=\mid \begin{array}{l}
0 \quad \text { if } \sigma \leq 4000 \text { psi } \\
G(T)+H(T) \sigma \text { if } \sigma>4000 \text { psi }
\end{array} \\
& \varepsilon_{c r . S}(\sigma, T, t):=\varepsilon_{X}(\sigma, T) \cdot\left(1-e^{-s(\sigma, T) \cdot t}\right) \quad \text { short-time transient creep strain }
\end{aligned}
$$

The long-time transient creep strain equation as a function of stress, temperature and time is defined below.

$$
\begin{aligned}
& r(\sigma, T):=\max \left[B(T) \cdot \sinh \left(\frac{\beta(T) \cdot \sigma}{n(T)}\right)^{n(T)} e^{\frac{-Q}{R \cdot T}}, L(T)\left(\frac{\sigma}{p s i}\right)^{n(T)-3.6}\right] \\
& \varepsilon_{t}(\sigma, T):=C(T) \frac{\varepsilon_{m}^{\prime}(\sigma, T)}{r(\sigma, T)} \\
& \varepsilon_{C r . l}(\sigma, T, t):=\varepsilon_{t}(\sigma, T) \cdot\left(1-e^{-r(\sigma, T) \cdot t) \quad \text { long-time transient creep strain }}\right.
\end{aligned}
$$

The total creep strain equation as a function of stress, temperature and time is defined below.

$$
\varepsilon_{c r}(\sigma, T, t):=\varepsilon_{c r . s}(\sigma, T, t)+\varepsilon_{c r . l}(\sigma, T, t)+\varepsilon_{c r . s s}(\sigma, T, t) \quad \text { creep strain }
$$

\section{B.4 316H Total Inelastic Strain and Stress}

The total inelastic strain equation as a function of target creep strain, temperature and time is defined below.

$$
\varepsilon_{i n}(\sigma, T, t):=\varepsilon_{p}(\sigma, T)+\varepsilon_{c r}(\sigma, T, t) \quad \text { inelastic strain }
$$

The total inelastic stress is solved for by finding the root as defined below.

$$
\begin{aligned}
\sigma_{\text {in }}(\varepsilon, T, t):= & \begin{array}{l}
\sigma \leftarrow 30 k s i \\
\operatorname{root}\left(\varepsilon_{\text {in }}(\sigma, T, t)-\varepsilon, \sigma\right)
\end{array}
\end{aligned}
$$




\section{B.5 Pseudo Yield Stress}

The Pseudo Yield Stress equation as a function of target inelastic strain, temperature and time is defined below.

$$
S_{x T}(x, T, t):=\mid \begin{array}{l|l}
S_{y}(T) \text { if } & \begin{array}{l}
1 \quad \text { if } \quad \operatorname{IsNaN}\left(\varepsilon_{\text {in }}\left(S_{y}(T), T, t\right)\right) \\
x \geq \varepsilon_{\text {in }}\left(S_{y}(T), T, t\right) \text { otherwise }
\end{array} \\
\sigma_{\text {in }}(x, T, t) \text { otherwise }
\end{array}
$$

The function used to select temperature data points between temperatures $T_{0}$ and $T_{N}$ with a resolution of $T_{i n c}$ where linear interpolation between data points do not exceed a standard deviation of $\mathrm{dev}$ is defined below:

$$
\begin{aligned}
& T_{x T}\left(x, t, T_{0}, T_{N}, T_{\text {inc }}, \operatorname{dev}\right):=\| \begin{array}{l}
N \leftarrow \operatorname{trunc}\left(\frac{\left.T_{N}-T_{0}\right)}{T_{\text {inc }}}\right) \\
\text { for } \quad i \in 0 \ldots N
\end{array} \\
& \mid \begin{array}{l}
T_{i} \leftarrow T_{0}+i \cdot T_{i n c} \\
S_{i} \leftarrow S_{x T}\left(x, T_{i}, t\right)
\end{array} \\
& T^{*}{ }_{0} \leftarrow T_{0} \\
& j \leftarrow 0 \\
& i^{*} \leftarrow 0 \\
& \text { for } i \in 2 . . N \\
& T_{\text {sub }} \leftarrow \operatorname{submatrix}\left(T, i^{*}, i, 0,0\right) \\
& S_{\text {sub }} \leftarrow \operatorname{submatrix}\left(S, i^{*}, i, 0,0\right) \\
& \text { if } \operatorname{stderr}\left(\frac{T_{s u b}}{K}, \frac{S_{s u b}}{p s i}\right)>d e v \\
& i^{*} \leftarrow i-1 \\
& j \leftarrow j+1 \\
& T^{*} \mathrm{j} \leftarrow T_{i-1} \\
& T^{*}{ }^{*}+1 \leftarrow T_{N}
\end{aligned}
$$

The following pages list the pseudo yield stress data compared to the analytical functions for the various target inelastic strains used in the strain limit analyses based on these input parameters:

$$
\begin{array}{lll}
t_{d}:=192206405 \mathrm{sec}=5.339 \times 10^{4} \cdot \mathrm{hr} & \text { total time duration of high temperature service, see Table 3.6.3-2 } \\
T_{0}:=70{ }^{\circ} \mathrm{F} & T_{N}:=1400{ }^{\circ} \mathrm{F} & \text { start and end temperature } \\
T_{\text {inc }}:=1 \Delta^{\circ} \mathrm{F} & \mathrm{dev}:=10 & \text { temperature resolution and maximum allowed deviation }
\end{array}
$$


$x:=1.00 \% \quad T:=T_{x T}\left(x, t_{d}, T_{0}, T_{N}, T_{i n c}, d e v\right)$

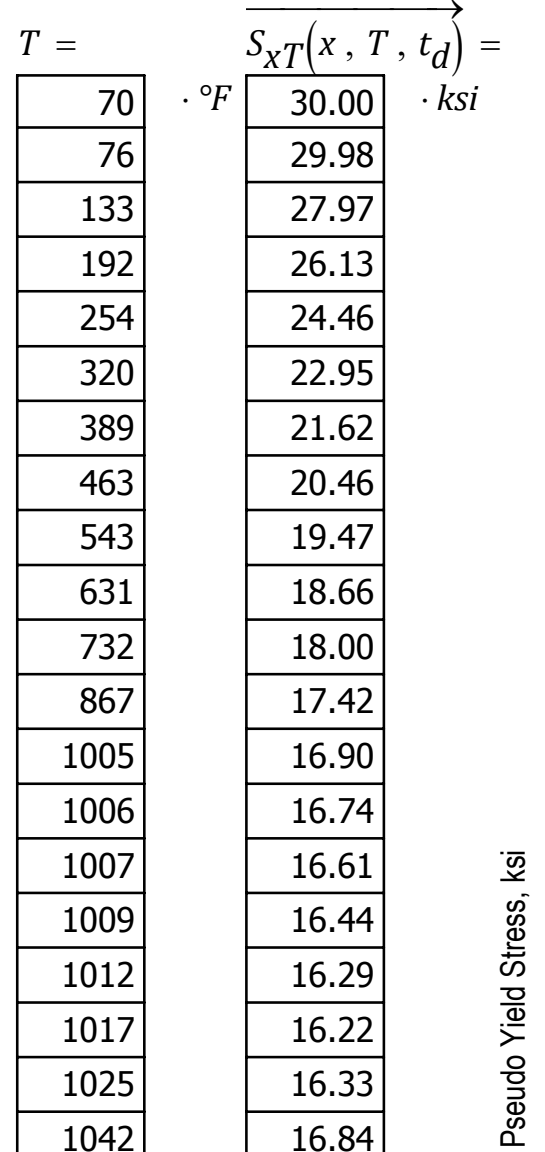

Pseudo Yield Stress for $1.00 \%$ Target Inelastic Strain

\begin{tabular}{|c|c|}
\hline 1097 & 16.56 \\
\hline 1114 & 15.38 \\
\hline 1138 & 13.43 \\
\hline 1182 & 9.71 \\
\hline 1201 & 8.24 \\
\hline 1233 & 6.79 \\
\hline 1267 & 5.48 \\
\hline 1305 & 4.29 \\
\hline 1346 & 3.24 \\
\hline 1392 & 2.33 \\
\hline 1400 & 2.20 \\
\hline
\end{tabular}

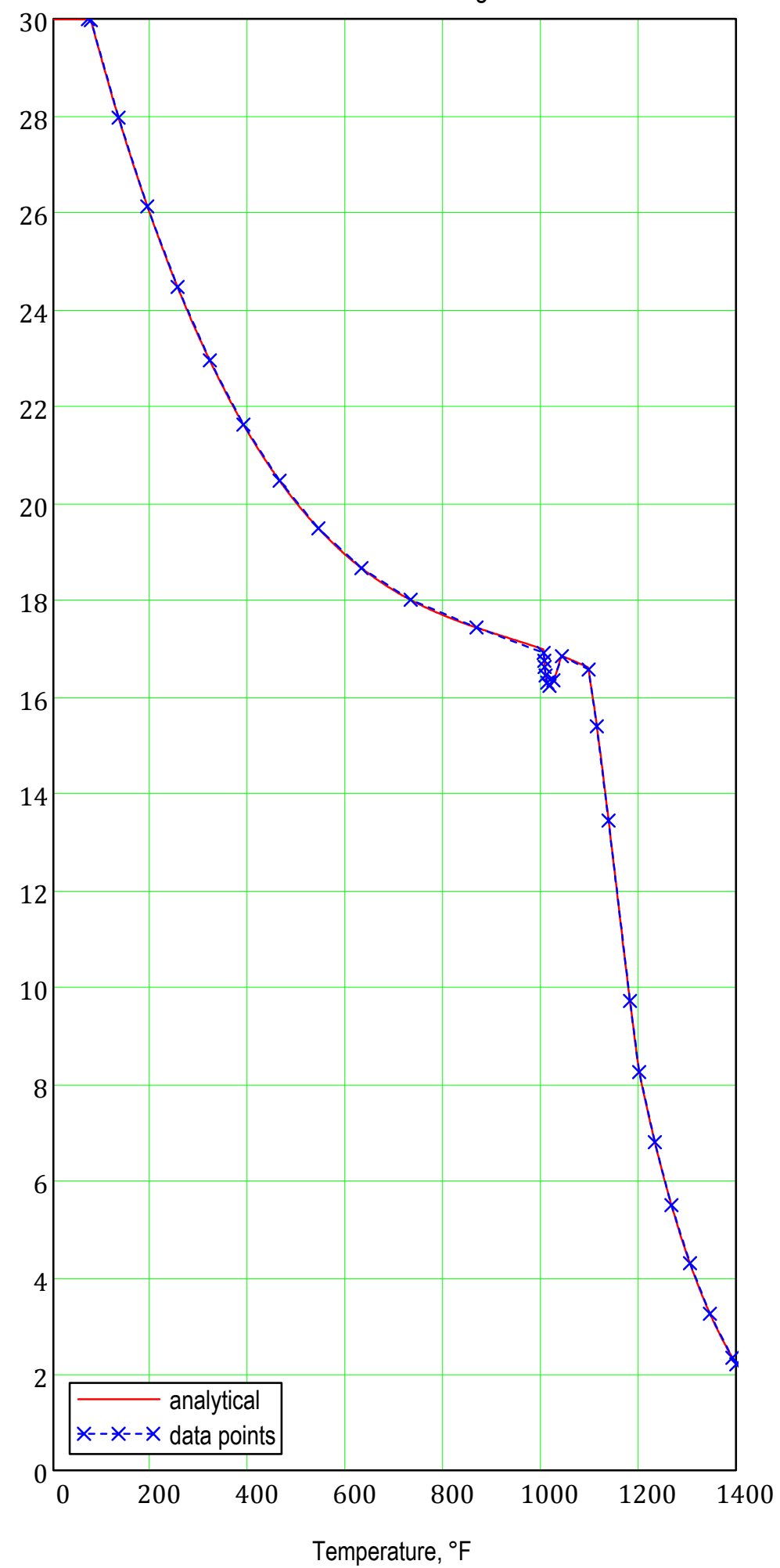


$x:=0.60 \% \quad T:=T_{x T}\left(x, t_{d}, T_{0}, T_{N}, T_{i n c}, d e v\right)$

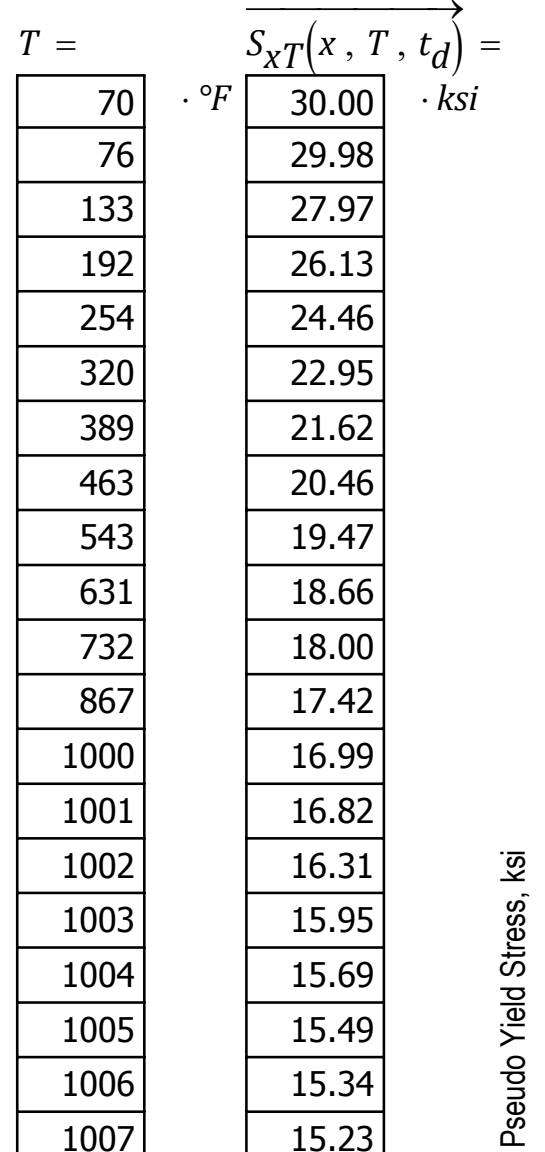

\section{Pseudo Yield Stress for $0.50 \%$ Target Inelastic Strain}

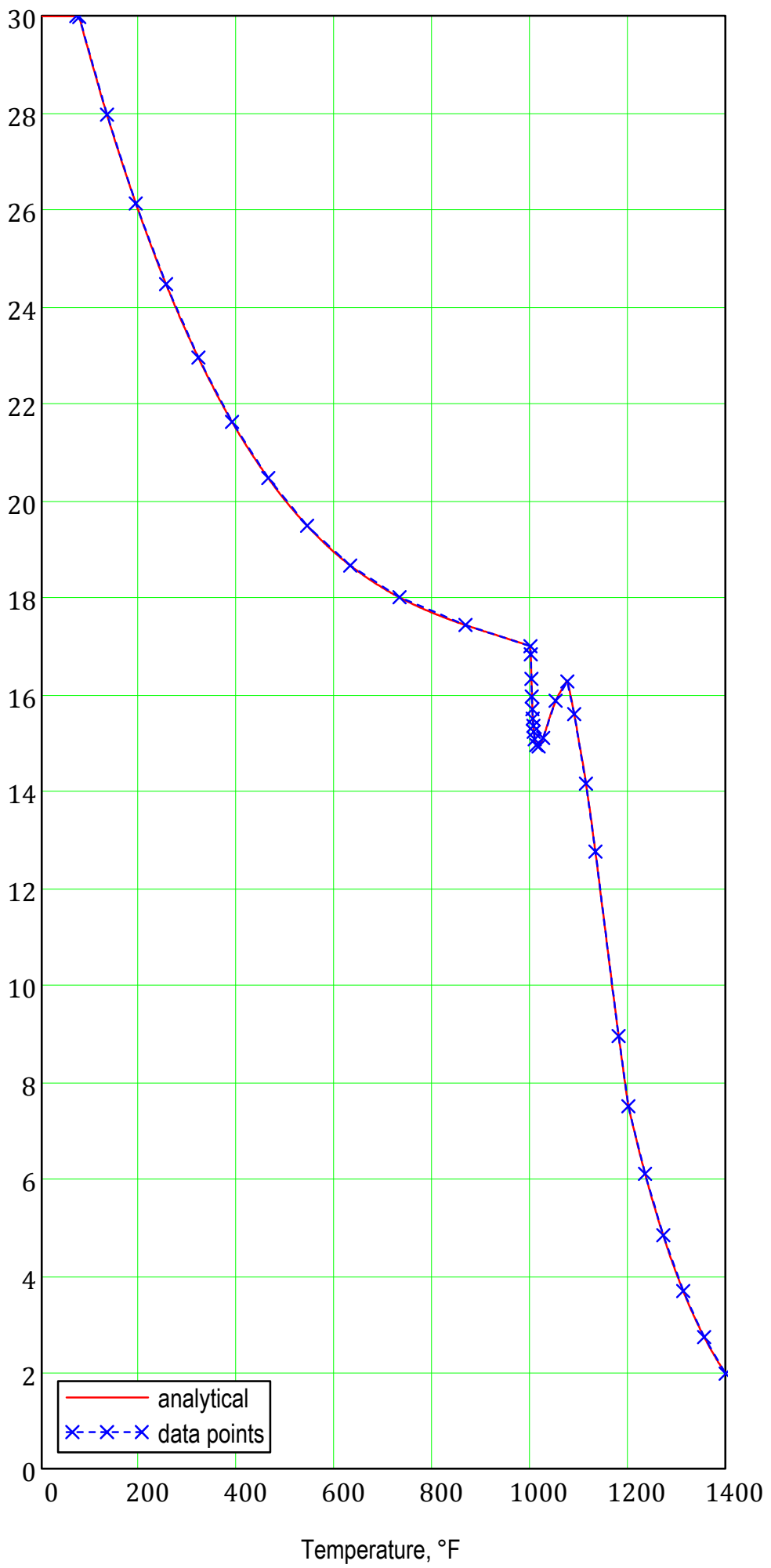


$x:=0.50 \% \quad T:=T_{x T}\left(x, t_{d}, T_{0}, T_{N}, T_{i n c}, d e v\right)$

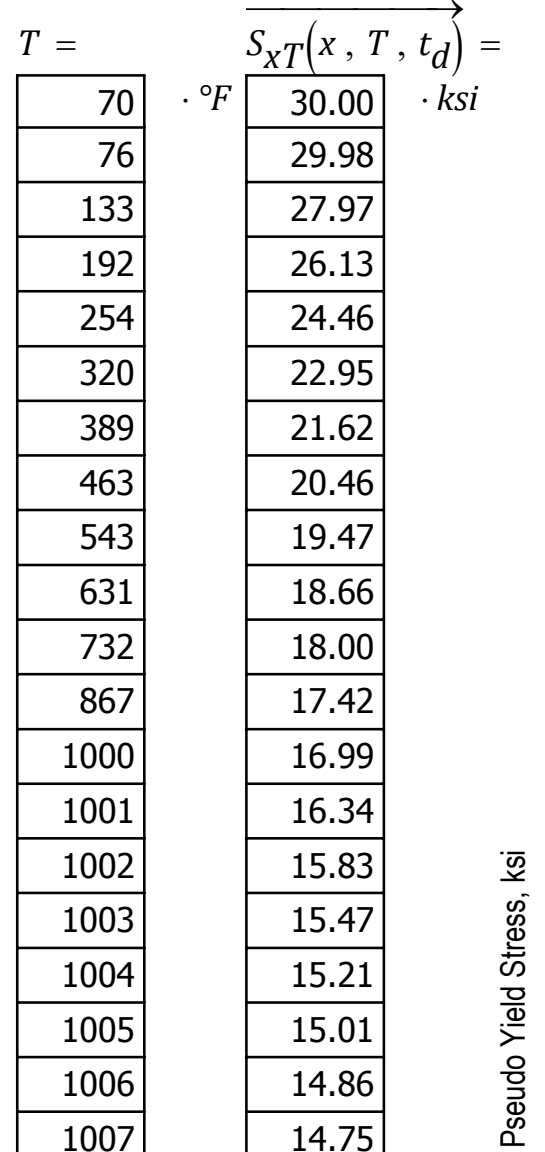

Pseudo Yield Stress for $0.40 \%$ Target Inelastic Strain

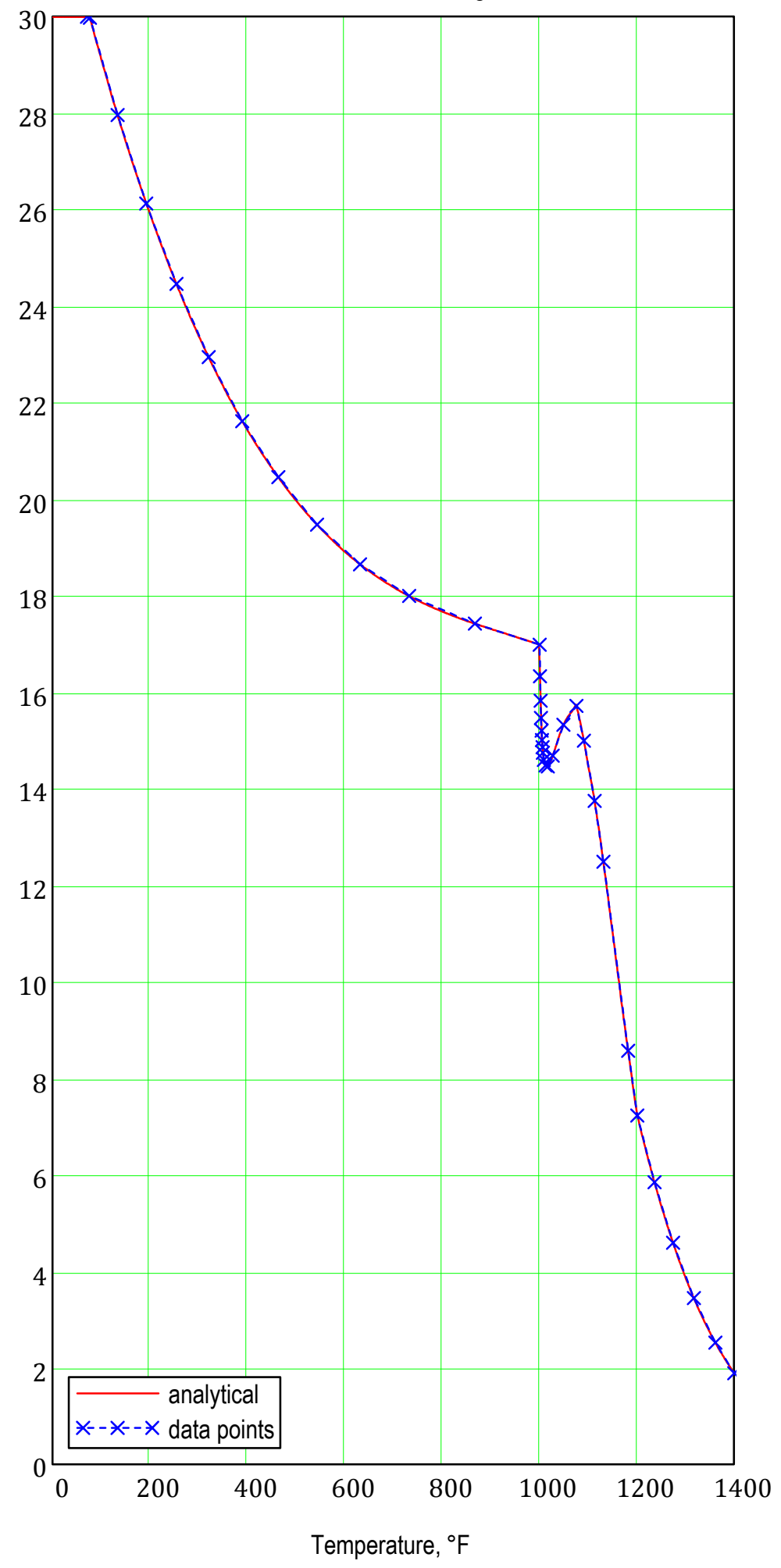


$x:=0.40 \% \quad T:=T_{x T}\left(x, t_{d}, T_{0}, T_{N}, T_{i n c}, d e v\right)$

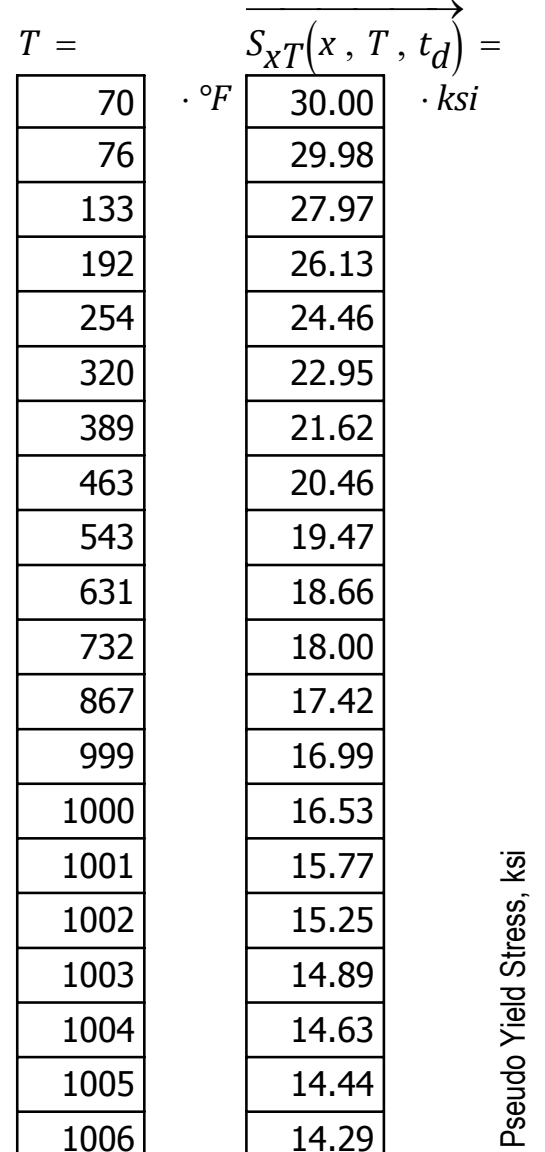

\section{Pseudo Yield Stress for $0.40 \%$ Target Inelastic Strain}

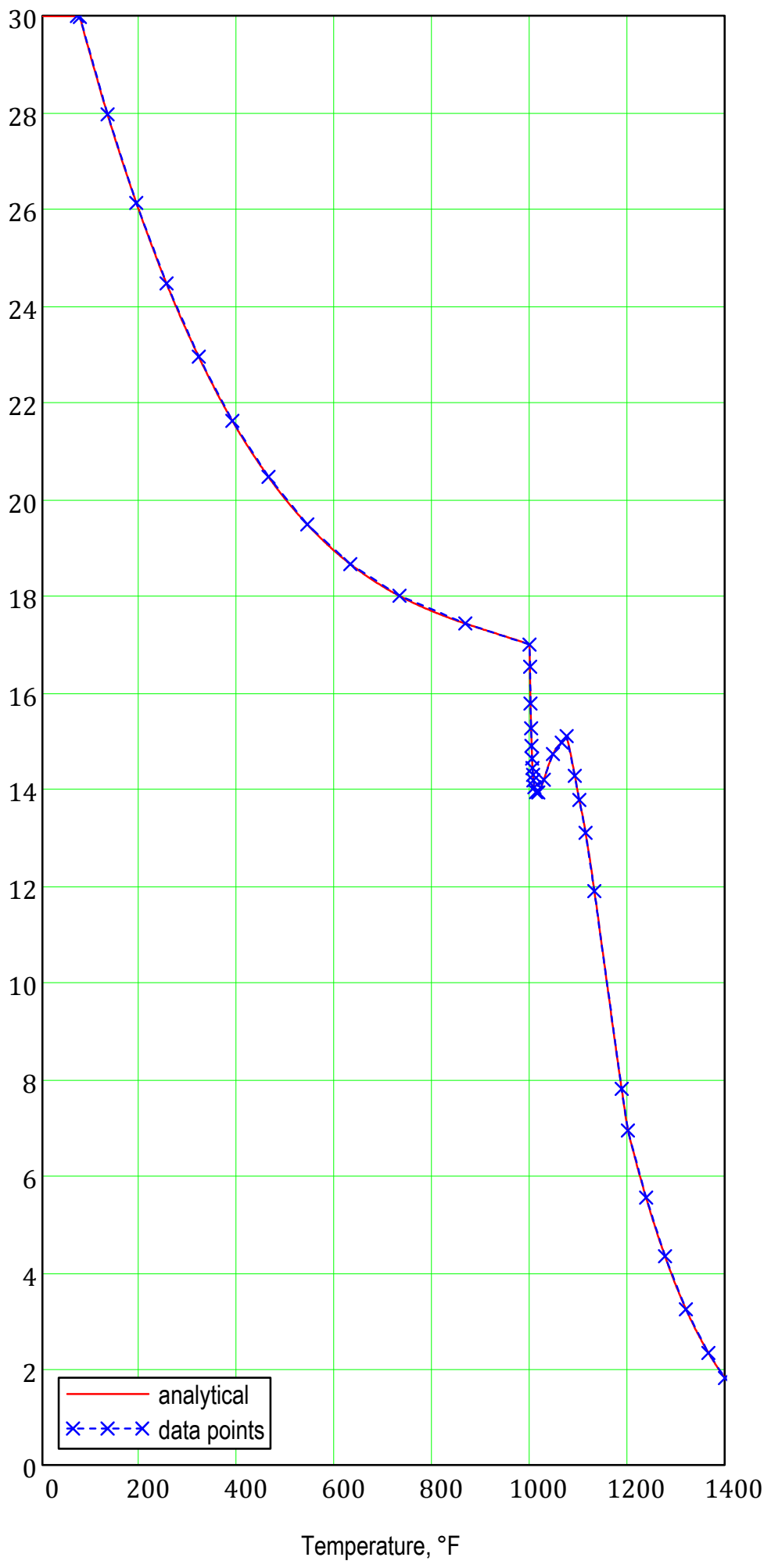




\section{Appendix C - Pseudo Yield Stress for Creep-Fatigue Analysis}

This appendix defines the equations used to compute the temperature dependent Pseudo Yield Stress for the creep-fatigue analysis at various selected trial time values.

\section{C.1 316H Yield Stress}

The equation for yield stress as a function of temperature is defined below.

$$
\begin{aligned}
& a_{0}:=1.10298556 \\
& a_{1}:=-1.47430259 \mathrm{e}-03 \\
& a_{2}:=1.52887261 \mathrm{e}-06 \\
& a_{3}:=-7.8404955 \mathrm{e}-10 \\
& a_{4}:=3.10394363 \mathrm{e}-13 \\
& a_{5}:=-1.17555515 \mathrm{e}-16
\end{aligned}
$$

\begin{tabular}{|c|c|c|}
\hline$T=$ & & ${ }_{y}(T)=$ \\
\hline 75 &.${ }^{\circ} \mathrm{F}$ & 30.0 \\
\hline 100 & & 29.1 \\
\hline 200 & & 25.9 \\
\hline 300 & & 23.4 \\
\hline 400 & & 21.4 \\
\hline 500 & & 20.0 \\
\hline 600 & & 18.9 \\
\hline 650 & & 18.5 \\
\hline 700 & & 18.2 \\
\hline 750 & & 17.9 \\
\hline 800 & & 17.7 \\
\hline 850 & & 17.5 \\
\hline 900 & & 17.3 \\
\hline 950 & & 17.2 \\
\hline 1000 & & 17.0 \\
\hline 1050 & & 16.8 \\
\hline 1100 & & 16.6 \\
\hline 1150 & & 16.3 \\
\hline 1200 & & 16.0 \\
\hline 1250 & & 15.5 \\
\hline 1300 & & 14.9 \\
\hline 1350 & & 14.2 \\
\hline 1400 & & 13.3 \\
\hline 1450 & & 12.2 \\
\hline 1500 & & 10.9 \\
\hline
\end{tabular}$$
S_{y}(T):=\min \left[\sum_{n=0}^{5}\left[a_{n}\left(T /{ }^{\circ} F\right)^{n}\right], 1\right] 30 \mathrm{ksi}
$$

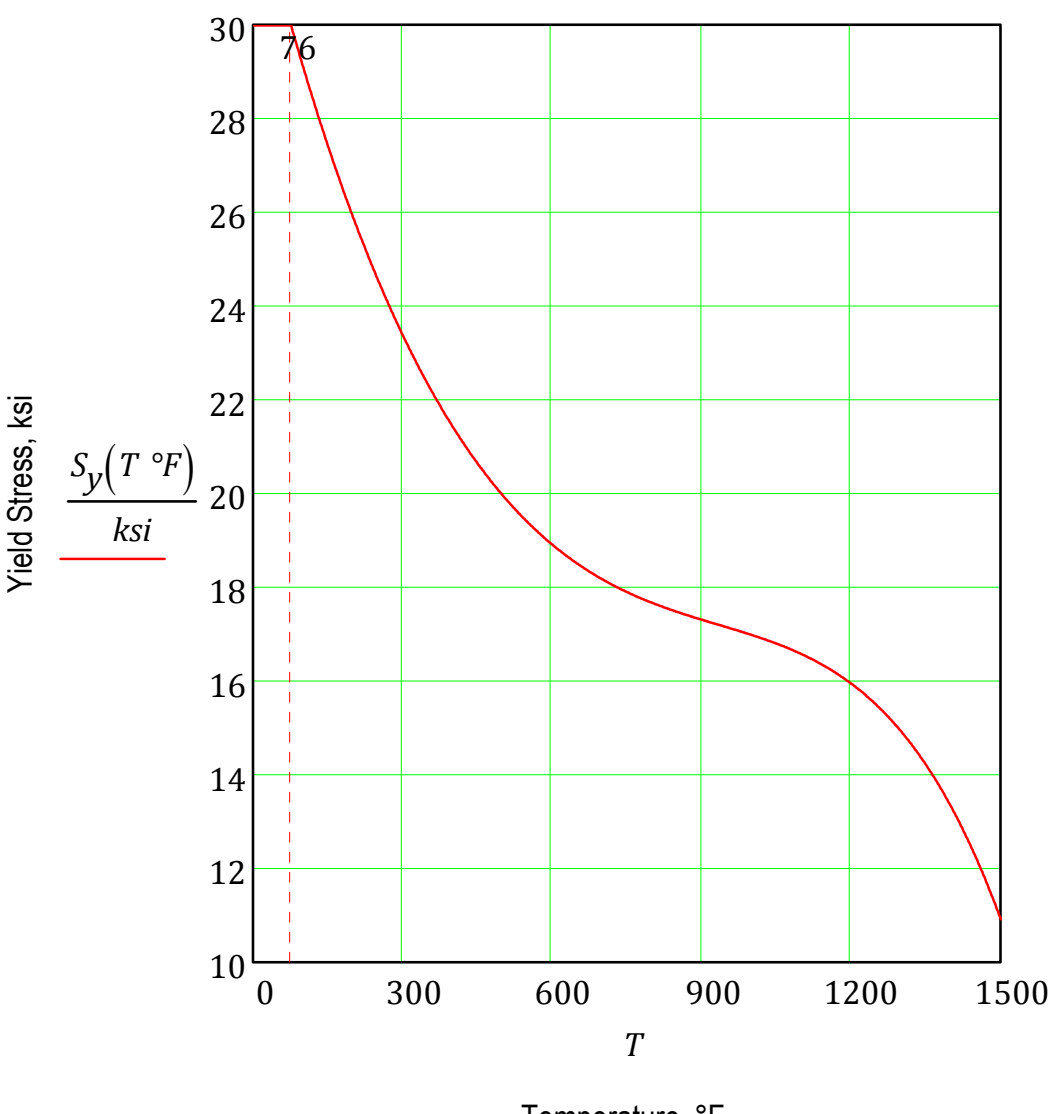

Temperature, ${ }^{\circ} \mathrm{F}$ 


\section{C.2 316H Tensile Strength}

The equation for tensile strength as a function of temperature is defined below.

$$
\begin{aligned}
& b_{0}:=1.08437074 \\
& b_{1}:=-1.25566465 \mathrm{e}-03 \\
& b_{2}:=2.41683284 \mathrm{e}-06 \\
& b_{3}:=-1.49661353 \mathrm{e}-09 \\
& b_{4}:=-1.59739404 \mathrm{e}-13 \\
& b_{5}:=1.89846445 \mathrm{e}-16 \\
& S_{u}(T):=\min \left[\sum_{n=0}^{5}\left[1.1 b_{n}\left(T /{ }^{\circ} \mathrm{F}\right)^{n}\right], 1\right] 75 \mathrm{ksi}
\end{aligned}
$$

\begin{tabular}{|c|c|c|}
\hline$T=$ & & $\overrightarrow{{ }_{u}(T)}=$ \\
\hline 75 & ${ }^{\circ} \mathrm{F}$ & 75.0 \\
\hline 100 & & 75.0 \\
\hline 200 & & 75.0 \\
\hline 300 & & 72.9 \\
\hline 400 & & 71.8 \\
\hline 500 & & 71.7 \\
\hline 600 & & 71.9 \\
\hline 650 & & 71.9 \\
\hline 700 & & 71.8 \\
\hline 750 & & 71.4 \\
\hline 800 & & 70.7 \\
\hline 850 & & 69.7 \\
\hline 900 & & 68.3 \\
\hline 950 & & 66.5 \\
\hline 1000 & & 64.3 \\
\hline 1050 & & 61.6 \\
\hline 1100 & & 58.4 \\
\hline 1150 & & 54.7 \\
\hline 1200 & & 50.6 \\
\hline 1250 & & 46.0 \\
\hline 1300 & & 41.0 \\
\hline 1350 & & 35.7 \\
\hline 1400 & & 30.0 \\
\hline 1450 & & 24.2 \\
\hline 1500 & & 18.2 \\
\hline
\end{tabular}

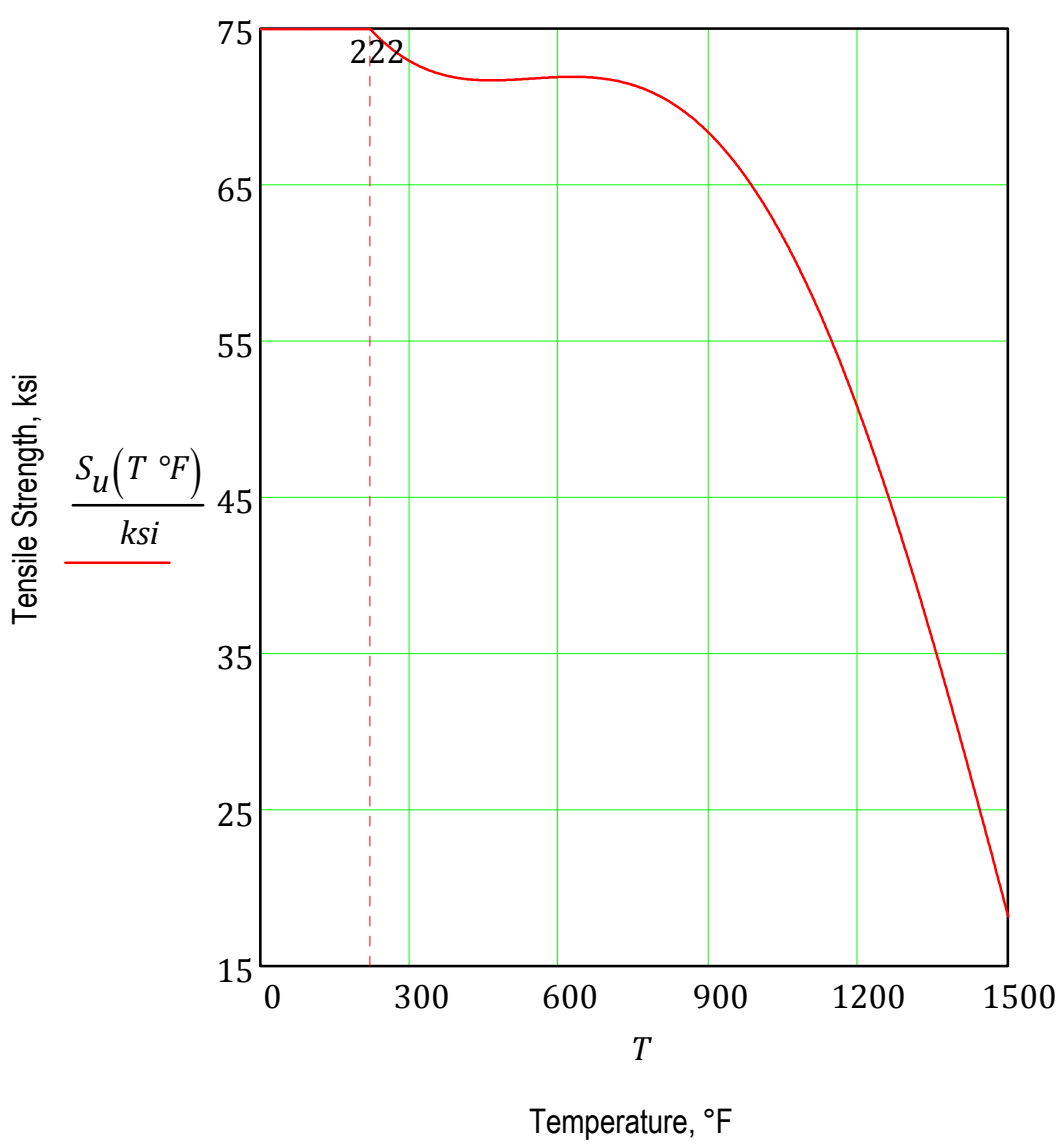




\section{C.3 316H Minimum Stress-to-Rupture}

The minimum stress-to-rupture equation as a function of time to rupture and temperature is defined below.

$$
\begin{aligned}
& a_{0}:=26377.99 \\
& a_{1}:=-1982.62 \\
& a_{2}:=-866.40 \\
& C_{L M C}:=16.282 \\
& S E E:=0.35 \\
& k s i=6.89476 \cdot \mathrm{MPa}
\end{aligned}
$$$$
a_{O^{\prime}}(t, T):=a_{O^{-}}\left(\log \left(\frac{t}{h r}\right)+C_{L M C}+1.65 S E E\right) \cdot\left(\frac{T}{K}\right)
$$$$
S_{r}(t, T):=\min \left(\begin{array}{cc}
\frac{-a_{1}-\sqrt{a_{1}{ }^{2}-4 a_{2} \cdot a^{\prime}{ }_{0}(t, T)}}{2 a_{2}} & \left.M P a, \frac{S_{u}(T)}{1.1}\right)
\end{array}\right)
$$

$$
t=
$$

$T=$

\begin{tabular}{|r|r|r|r|r|r|r|r|r|r|r|r|}
\hline 800 \\
\hline 850 \\
\hline 900 \\
\hline 950 \\
\hline 1000 \\
\hline 1050 \\
\hline 1100 \\
\hline 1150 \\
\hline 1200 \\
\hline 1250 \\
\hline 1300 \\
\hline 1350 \\
\hline 1400 \\
\hline 1450 \\
\hline 1500 \\
\hline 1050 \\
\hline 1100 \\
\hline 1150 \\
\hline 1200 \\
\hline 1250 \\
\hline 1300 \\
\hline 1350 \\
\hline 1400 \\
\hline 1450 \\
\hline 1500 \\
\hline 63.4 & 63.4 & 63.4 & 63.4 & 63.4 & 63.4 & 63.4 & 61.7 & 54.6 & 47.6 & 41.9 \\
\hline 62.1 & 62.1 & 62.1 & 62.1 & 62.1 & 62.1 & 57.8 & 50.2 & 44.0 & 38.1 & 33.2 \\
\hline 60.5 & 60.5 & 60.5 & 60.5 & 60.5 & 54.0 & 47.2 & 40.6 & 35.3 & 30.3 & 26.2 \\
\hline 58.4 & 58.4 & 58.4 & 58.4 & 51.6 & 44.2 & 38.4 & 32.7 & 28.2 & 23.9 & 20.5 \\
\hline 56.0 & 56.0 & 56.0 & 49.1 & 42.4 & 36.1 & 31.0 & 26.2 & 22.3 & 18.7 & 15.9 \\
\hline 53.1 & 53.1 & 47.9 & 40.6 & 34.8 & 29.2 & 24.9 & 20.8 & 17.6 & 14.5 & 12.2 \\
\hline 49.7 & 46.5 & 39.7 & 33.3 & 28.3 & 23.6 & 19.9 & 16.4 & 13.7 & 11.2 & 9.3 \\
\hline 46.0 & 38.7 & 32.8 & 27.3 & 22.9 & 18.9 & 15.7 & 12.8 & 10.6 & 8.5 & 7.0 \\
\hline 41.8 & 32.1 & 27.0 & 22.2 & 18.5 & 15.0 & 12.4 & 10.0 & 8.1 & 6.4 & 5.2 \\
\hline 37.3 & 26.5 & 22.1 & 17.9 & 14.8 & 11.9 & 9.7 & 7.7 & 6.1 & 4.8 & 3.8 \\
\hline 32.3 & 21.8 & 18.0 & 14.4 & 11.7 & 9.3 & 7.5 & 5.8 & 4.6 & 3.5 & 2.7 \\
\hline 27.0 & 17.8 & 14.5 & 11.5 & 9.3 & 7.2 & 5.7 & 4.4 & 3.4 & 2.5 & 1.9 \\
\hline 22.0 & 14.5 & 11.7 & 9.1 & 7.2 & 5.5 & 4.3 & 3.2 & 2.5 & 1.8 & 1.3 \\
\hline 16.5 & 11.7 & 9.3 & 7.2 & 5.6 & 4.2 & 3.2 & 2.4 & 1.7 & 1.2 & 0.9 \\
\hline 56.0 & 56.0 & 56.0 & 49.1 & 42.4 & 36.1 & 31.0 & 26.2 & 22.3 & 18.7 & 15.9 \\
\hline 53.1 & 53.1 & 47.9 & 40.6 & 34.8 & 29.2 & 24.9 & 20.8 & 17.6 & 14.5 & 12.2 \\
\hline 49.7 & 46.5 & 39.7 & 33.3 & 28.3 & 23.6 & 19.9 & 16.4 & 13.7 & 11.2 & 9.3 \\
\hline 46.0 & 38.7 & 32.8 & 27.3 & 22.9 & 18.9 & 15.7 & 12.8 & 10.6 & 8.5 & 7.0 \\
\hline 41.8 & 32.1 & 27.0 & 22.2 & 18.5 & 15.0 & 12.4 & 10.0 & 8.1 & 6.4 & 5.2 \\
\hline 37.3 & 26.5 & 22.1 & 17.9 & 14.8 & 11.9 & 9.7 & 7.7 & 6.1 & 4.8 & 3.8 \\
\hline 32.3 & 21.8 & 18.0 & 14.4 & 11.7 & 9.3 & 7.5 & 5.8 & 4.6 & 3.5 & 2.7 \\
\hline 27.0 & 17.8 & 14.5 & 11.5 & 9.3 & 7.2 & 5.7 & 4.4 & 3.4 & 2.5 & 1.9 \\
\hline 22.0 & 14.5 & 11.7 & 9.1 & 7.2 & 5.5 & 4.3 & 3.2 & 2.5 & 1.8 & 1.3 \\
\hline 16.5 & 11.7 & 9.3 & 7.2 & 5.6 & 4.2 & 3.2 & 2.4 & 1.7 & 1.2 & 0.9 \\
\hline
\end{tabular}


The stress rupture factors for SS 316 welds is interpolated from Table NH-I-14.10B-3 below.

$S R F:=$\begin{tabular}{|r|r|r|r|r|r|r|r|r|r|r|}
\hline 0 & 10 & 30 & 100 & 300 & 1000 & 3000 & $1 \cdot 10^{4}$ & $3 \cdot 10^{4}$ & $1 \cdot 10^{5}$ & $3 \cdot 10^{5}$ \\
\hline 800 & 1 & 1 & 0.99 & 0.98 & 0.97 & 0.96 & 0.95 & 0.94 & 0.92 & 0.88 \\
\hline 850 & 1 & 1 & 0.99 & 0.98 & 0.97 & 0.96 & 0.95 & 0.94 & 0.92 & 0.88 \\
\hline 900 & 1 & 1 & 0.97 & 0.94 & 0.91 & 0.89 & 0.88 & 0.86 & 0.82 & 0.78 \\
\hline 950 & 1 & 1 & 0.95 & 0.9 & 0.87 & 0.84 & 0.81 & 0.78 & 0.72 & 0.68 \\
\hline 1000 & 1 & 1 & 0.88 & 0.86 & 0.83 & 0.79 & 0.74 & 0.7 & 0.62 & 0.58 \\
\hline 1050 & 1 & 1 & 0.92 & 0.89 & 0.87 & 0.83 & 0.78 & 0.74 & 0.66 & 0.56 \\
\hline 1100 & 1 & 1 & 0.96 & 0.94 & 0.9 & 0.87 & 0.81 & 0.75 & 0.68 & 0.61 \\
\hline 1150 & 1 & 1 & 1 & 0.96 & 0.91 & 0.87 & 0.81 & 0.75 & 0.66 & 0.59 \\
\hline 1200 & 1 & 1 & 0.96 & 0.95 & 0.9 & 0.87 & 0.81 & 0.72 & 0.64 & 0.55 \\
\hline 1250 & 1 & 1 & 0.96 & 0.93 & 0.89 & 0.84 & 0.77 & 0.69 & 0.6 & 0.51 \\
\hline 1300 & 1 & 0.98 & 0.93 & 0.89 & 0.83 & 0.79 & 0.72 & 0.65 & 0.56 & 0.48 \\
\hline 1350 & 0.99 & 0.96 & 0.89 & 0.84 & 0.77 & 0.72 & 0.65 & 0.59 & 0.52 & 0.45 \\
\hline 1400 & 0.95 & 0.9 & 0.82 & 0.77 & 0.71 & 0.66 & 0.6 & 0.55 & 0.47 & 0.42 \\
\hline
\end{tabular}

$S R F_{T}:=\operatorname{submatrix}(S R F, 1, \operatorname{rows}(S R F)-1,0,0){ }^{\circ} \mathrm{F} \quad$ temperatures

$S R F_{t}:=\operatorname{submatrix}(S R F, 0,0,1, \operatorname{cols}(S R F)-1)^{T} \cdot h r \quad$ time

$S R F_{F}:=\operatorname{submatrix}(S R F, 1, \operatorname{rows}(S R F)-1,1, \operatorname{cols}(S R F)-1) \quad$ factors

Define 2D linear interpolation function:

$$
\operatorname{linterp} 2 D(v x, v y, Z, p, q):=\mid \begin{aligned}
& \text { for } \quad i \in 0 . . \operatorname{rows}(Z)-1 \\
& v p_{i} \leftarrow \operatorname{linterp}\left(v y, \operatorname{submatrix}(Z, i, i, 0, \operatorname{cols}(Z)-1)^{T}, q\right) \\
& \text { return linterp }(v x, v p, p)
\end{aligned}
$$

Define stress rupture factor for welds function:

$$
F_{r}(t, T):=\operatorname{linterp} 2 D\left(S R F_{T}, S R F_{t}, S R F_{F}, T, t\right)
$$




\section{C.4 Pseudo Yield Stress}

The Pseudo Yield Stress equation for base metal and weld as a function of trial allowable time duration and temperature for creep-fatigue analyses is defined below.

$$
\begin{array}{ll}
S_{c t b}\left(t, T, K^{\prime}\right):=\min \left(S_{y}(T), S_{r}(t, T) \cdot K^{\prime}\right) & \text { psyedo yield stress for base metal } \\
S_{c t w}\left(t, T, K^{\prime}\right):=\min \left(S_{y}(T), S_{r}(t, T) \cdot K^{\prime} \cdot F_{r}(t, T)\right) & \text { psyedo yield stress for weldments }
\end{array}
$$

The function used to select temperature data points between temperatures $T_{0}$ and $T_{N}$ with a resolution of $T_{i n c}$ where linear interpolation between data points do not exceed a standard deviation of $\mathrm{dev}$ is defined below:

$$
\begin{aligned}
& T_{c t}\left(t, T_{0}, T_{N}, T_{i n c}, K^{\prime}, S_{c t}, \operatorname{dev}\right):=\mid N \leftarrow \operatorname{trunc}\left(\frac{T_{N}-T_{0}}{T_{\text {inc }}}\right) \\
& \text { for } i \in 0 . . N \\
& \mid \begin{array}{l}
T_{i} \leftarrow T_{0}+i \cdot T_{i n c} \\
S_{i} \leftarrow S_{c t}\left(t, T_{i}, K^{\prime}\right)
\end{array} \\
& T^{*} 0 \leftarrow T_{0} \\
& j \leftarrow 0 \\
& i^{*} \leftarrow 0 \\
& \text { for } i \in 2 . . N \\
& T_{\text {sub }} \leftarrow \operatorname{submatrix}\left(T, i^{*}, i, 0,0\right) \\
& S_{\text {sub }} \leftarrow \operatorname{submatrix}\left(S, i^{*}, i, 0,0\right) \\
& \text { if } \operatorname{stder}\left(\frac{T_{\text {sub }}}{K}, \frac{S_{\text {sub }}}{p s i}\right)>\operatorname{dev} \\
& \mid \begin{array}{l}
i^{*} \leftarrow i-1 \\
j \leftarrow j+1 \\
T^{*} \mathrm{j} \leftarrow T_{i-1}
\end{array} \\
& T^{*} j+1 \leftarrow T_{N} \\
& T^{*}
\end{aligned}
$$

The following pages list the pseudo yield stress data compared to the analytical functions for the various trial times used in the creep-fatigue analyses based on these input parameters:

$$
\begin{array}{lll}
t_{d}:=192206405 \mathrm{sec}=5.339 \times 10^{4} \cdot \mathrm{hr} & \text { total time duration of high temperature service, see Table 3.6.3-2 } \\
T_{0}:=70{ }^{\circ} \mathrm{F} & T_{N}:=1400{ }^{\circ} \mathrm{F} & \text { start and end temperature } \\
T_{\text {inc }}:=1 \Delta^{\circ} \mathrm{F} & \mathrm{dev}:=10 & \text { temperature resolution and maximum allowed deviation }
\end{array}
$$


Pseudo Yield Stress for 1.00 target creep damage.

$$
\begin{aligned}
& D_{c, k}:=1.00 \quad K^{\prime}:=0.9 \\
& T_{d, k}:=\frac{t_{d}}{D_{c, k}}=5.339 \times 10^{4} \cdot h r
\end{aligned}
$$

Base Metal Pseudo Yield Stress:

$$
T_{b}:=T_{c t}\left(T_{d, k}, T_{0}, T_{N}, T_{i n c}, K^{\prime}, S_{c t b}, d e v\right)
$$

\begin{tabular}{l}
$S_{c t b}\left(T_{d, k}, T_{b}, K^{\prime}\right)$ \\
\hline 30.00 \\
\hline 29.98 \\
\hline 27.97 \\
\hline 26.13 \\
\hline 24.46 \\
\hline 22.95 \\
\hline 21.62 \\
\hline 20.46 \\
\hline 19.47 \\
\hline 18.66 \\
\hline 18.00 \\
\hline 17.42 \\
\hline 16.68 \\
\hline 14.60 \\
\hline 12.68 \\
\hline 10.86 \\
\hline 9.18 \\
\hline 7.64 \\
\hline 6.22 \\
\hline 4.94 \\
\hline 3.82 \\
\hline 2.83 \\
\hline 2.65 \\
\hline
\end{tabular}

$T_{b}=$

\begin{tabular}{|r|}
\hline 70 \\
\hline 76 \\
\hline 133 \\
\hline 192 \\
\hline 254 \\
\hline 320 \\
\hline 389 \\
\hline 463 \\
\hline 543 \\
\hline 631 \\
\hline 732 \\
\hline 867 \\
\hline 1071 \\
\hline 1098 \\
\hline 1126 \\
\hline 1156 \\
\hline 1188 \\
\hline 1222 \\
\hline 1259 \\
\hline 1299 \\
\hline 1342 \\
\hline 1390 \\
\hline 1400 \\
\hline
\end{tabular}

Weldment Pseudo Yield Stress:

$T_{w}:=T_{c t}\left(T_{d, k}, T_{0}, T_{N}, T_{i n c}, K^{\prime}, S_{c t w}, \operatorname{dev}\right)$
$T_{w}=$

\begin{tabular}{|r|}
\hline 70 \\
\hline 76 \\
\hline 133 \\
\hline 192 \\
\hline 254 \\
\hline 320 \\
\hline 389 \\
\hline 463 \\
\hline 543 \\
\hline 631 \\
\hline 732 \\
\hline 867 \\
\hline 990 \\
\hline 1000 \\
\hline 1044 \\
\hline 1084 \\
\hline 1134 \\
\hline 1181 \\
\hline 1221 \\
\hline 1262 \\
\hline 1304 \\
\hline 1348 \\
\hline 1400 \\
\hline
\end{tabular}

$\overrightarrow{S_{c t w}\left(T_{d, k}, T_{w}, K^{\prime}\right)}=$ $\cdot{ }^{\circ} \mathrm{F}$ 


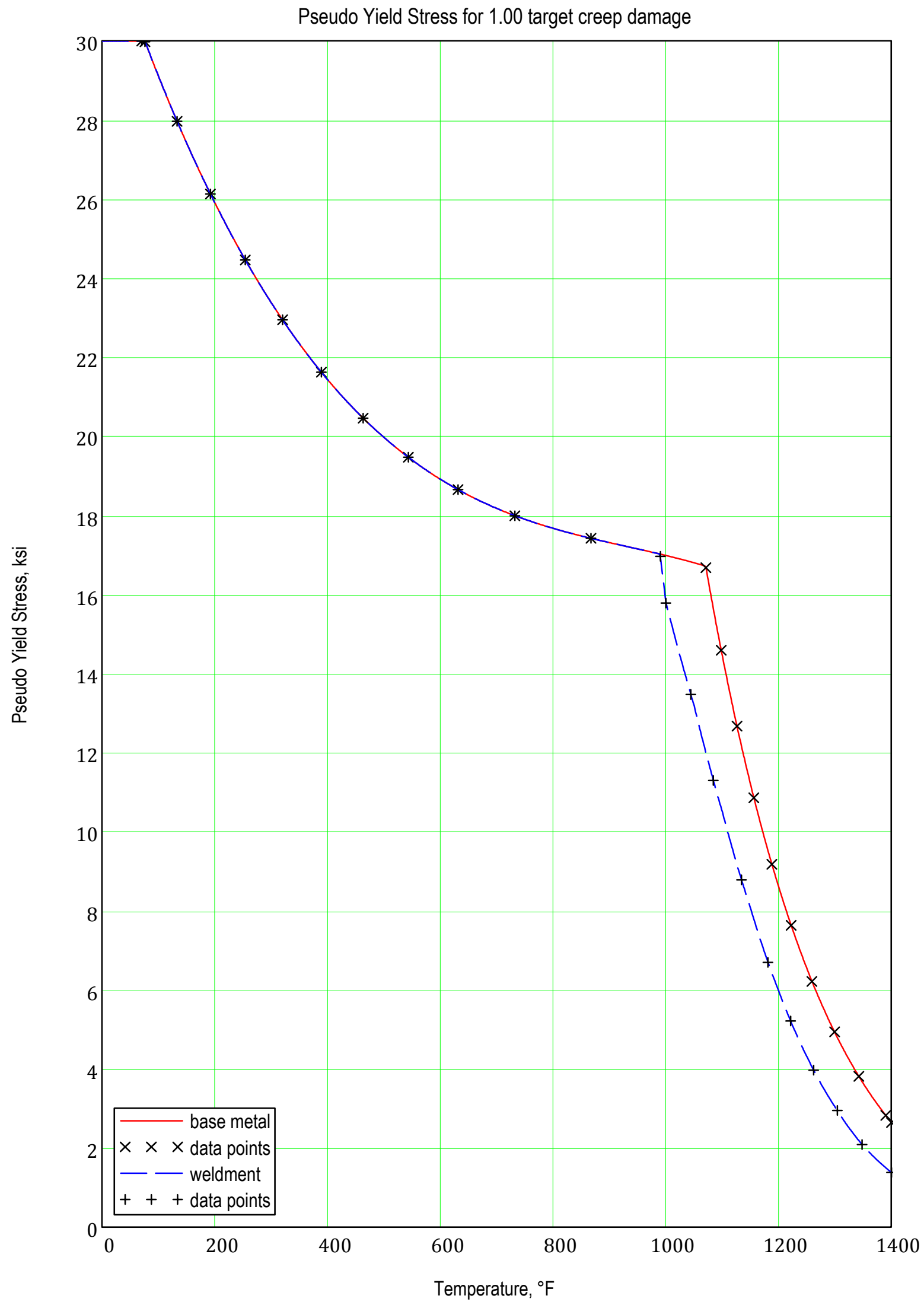


Pseudo Yield Stress for 0.95 target creep damage.

$$
\begin{aligned}
& D_{c, k}:=0.95 \quad K^{\prime}=0.9 \\
& T_{d, k}:=\frac{t_{d}}{D_{c, k}}=56201 \cdot h r
\end{aligned}
$$

Base Metal Pseudo Yield Stress:

$T_{b}:=T_{c t}\left(T_{d, k}, T_{0}, T_{N}, T_{i n c}, K^{\prime}, S_{c t b}, d e v\right)$

$T_{b}=$

\begin{tabular}{|r|}
\hline 70 \\
\hline 76 \\
\hline 133 \\
\hline 192 \\
\hline 254 \\
\hline 320 \\
\hline 389 \\
\hline 463 \\
\hline 543 \\
\hline 631 \\
\hline 732 \\
\hline 867 \\
\hline 1069 \\
\hline 1095 \\
\hline 1123 \\
\hline 1153 \\
\hline 1185 \\
\hline 1219 \\
\hline 1255 \\
\hline 1294 \\
\hline 1337 \\
\hline 1385 \\
\hline 1400 \\
\hline
\end{tabular}

\begin{tabular}{l}
\hline$S_{c t b}\left(T_{d, k}, T_{b},{ }^{\prime}\right.$ \\
\hline 30.00 \\
\hline 29.98 \\
\hline 27.97 \\
\hline 26.13 \\
\hline 24.46 \\
\hline 22.95 \\
\hline 21.62 \\
\hline 20.46 \\
\hline 19.47 \\
\hline 18.66 \\
\hline 18.00 \\
\hline 17.42 \\
\hline 16.72 \\
\hline 14.70 \\
\hline 12.76 \\
\hline 10.94 \\
\hline 9.24 \\
\hline 7.69 \\
\hline 6.30 \\
\hline 5.03 \\
\hline 3.90 \\
\hline 2.89 \\
\hline 2.62 \\
\hline
\end{tabular}

Weldment Pseudo Yield Stress:

$T_{w}:=T_{c t}\left(T_{d, k}, T_{0}, T_{N}, T_{i n c}, K^{\prime}, S_{c t w}, \operatorname{dev}\right)$

$T_{w}=$

\begin{tabular}{|r|}
\hline 70 \\
\hline 76 \\
\hline 133 \\
\hline 192 \\
\hline 254 \\
\hline 320 \\
\hline 389 \\
\hline 463 \\
\hline 543 \\
\hline 631 \\
\hline 732 \\
\hline 867 \\
\hline 988 \\
\hline 1000 \\
\hline 1044 \\
\hline 1084 \\
\hline 1134 \\
\hline 1181 \\
\hline 1222 \\
\hline 1263 \\
\hline 1307 \\
\hline 1351 \\
\hline 1400 \\
\hline
\end{tabular}

$\overrightarrow{S_{c t w}\left(T_{d, k}, T_{w}, K^{\prime}\right)}=$

\begin{tabular}{|r|}
\hline 30.00 \\
\hline 29.98 \\
\hline 27.97 \\
\hline 26.13 \\
\hline 24.46 \\
\hline 22.95 \\
\hline 21.62 \\
\hline 20.46 \\
\hline 19.47 \\
\hline 18.66 \\
\hline 18.00 \\
\hline 17.42 \\
\hline 17.02 \\
\hline 15.60 \\
\hline 13.31 \\
\hline 11.17 \\
\hline 8.67 \\
\hline 6.61 \\
\hline 5.11 \\
\hline 3.89 \\
\hline 2.84 \\
\hline 2.01 \\
\hline 1.36 \\
\hline
\end{tabular}




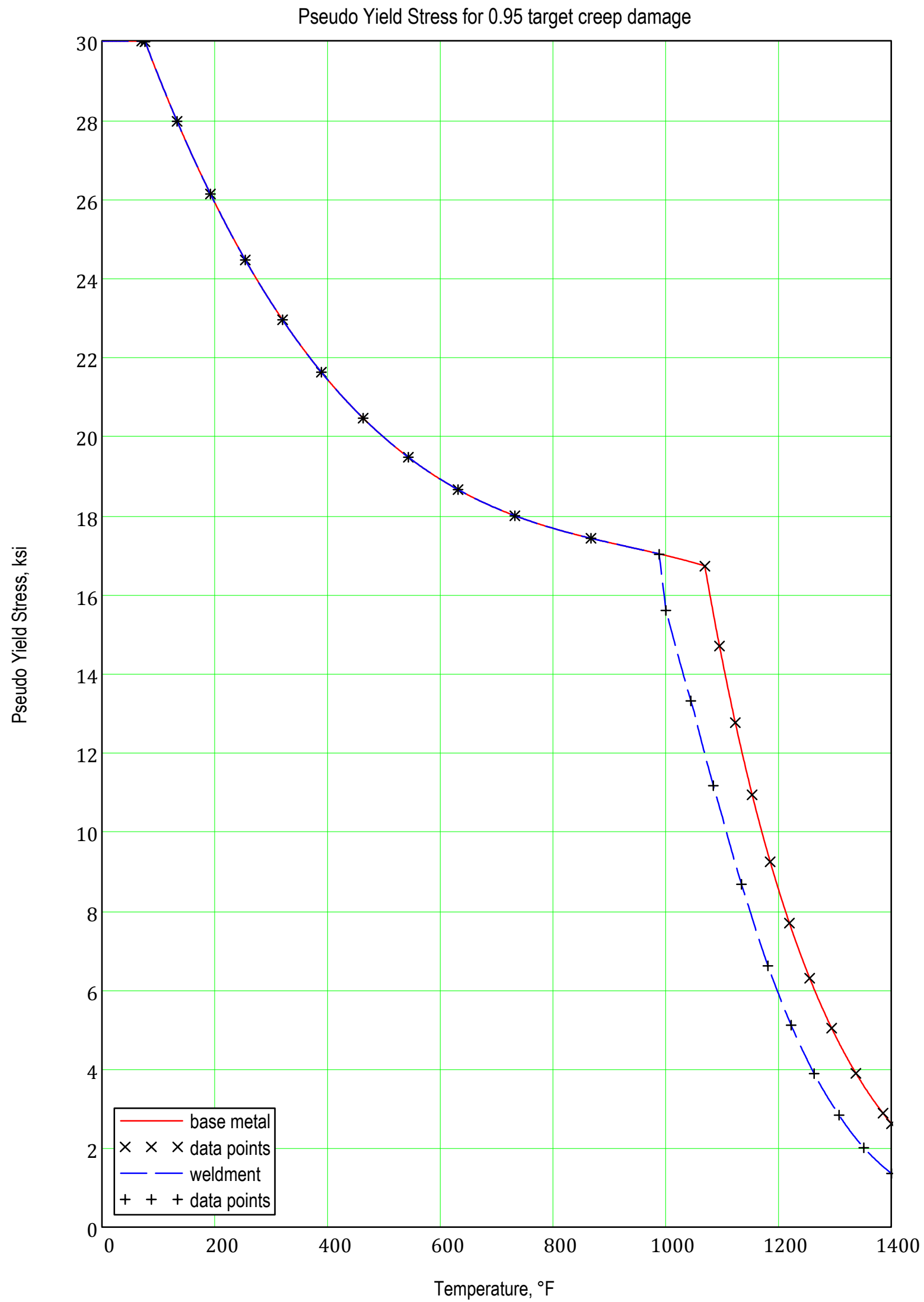


Pseudo Yield Stress for 0.90 target creep damage.

$$
\begin{aligned}
& D_{c, k}:=0.9 \quad K^{\prime}=0.9 \\
& T_{d, k}:=\frac{t_{d}}{D_{c, k}}=5.932 \times 10^{4} \cdot h r
\end{aligned}
$$

Base Metal Pseudo Yield Stress:

$$
T_{b}:=T_{c t}\left(T_{d, k}, T_{0}, T_{N}, T_{i n c}, K^{\prime}, S_{c t b}, d e v\right)
$$

\begin{tabular}{|r|}
\hline$S_{c t b}\left(T_{d, k}, T_{b}, K^{\prime}\right)$ \\
\hline 30.00 \\
\hline 29.98 \\
\hline 27.97 \\
\hline 26.13 \\
\hline 24.46 \\
\hline 22.95 \\
\hline 21.62 \\
\hline 20.46 \\
\hline 19.47 \\
\hline 18.66 \\
\hline 18.00 \\
\hline 17.42 \\
\hline 16.66 \\
\hline 14.65 \\
\hline 12.72 \\
\hline 10.90 \\
\hline 9.20 \\
\hline 7.66 \\
\hline 6.27 \\
\hline 5.01 \\
\hline 3.87 \\
\hline 2.87 \\
\hline 2.59 \\
\hline
\end{tabular}

$T_{b}=$

\begin{tabular}{|r|}
\hline 70 \\
\hline 76 \\
\hline 133 \\
\hline 192 \\
\hline 254 \\
\hline 320 \\
\hline 389 \\
\hline 463 \\
\hline 543 \\
\hline 631 \\
\hline 732 \\
\hline 867 \\
\hline 1068 \\
\hline 1094 \\
\hline 1122 \\
\hline 1152 \\
\hline 1184 \\
\hline 1218 \\
\hline 1254 \\
\hline 1293 \\
\hline 1336 \\
\hline 1384 \\
\hline 1400 \\
\hline
\end{tabular}

Weldment Pseudo Yield Stress:

$T_{w}:=T_{c t}\left(T_{d, k}, T_{0}, T_{N}, T_{i n c}, K^{\prime}, S_{c t w}, \operatorname{dev}\right)$ $\overrightarrow{S_{c t w}\left(T_{d, k}, T_{w}, K^{\prime}\right)}=$

\begin{tabular}{|r|}
\hline 70 \\
\hline 76 \\
\hline 133 \\
\hline 192 \\
\hline 254 \\
\hline 320 \\
\hline 389 \\
\hline 463 \\
\hline 543 \\
\hline 631 \\
\hline 732 \\
\hline 867 \\
\hline 987 \\
\hline 1000 \\
\hline 1045 \\
\hline 1085 \\
\hline 1134 \\
\hline 1180 \\
\hline 1222 \\
\hline 1263 \\
\hline 1307 \\
\hline 1352 \\
\hline 1400 \\
\hline
\end{tabular}

$\cdot{ }^{\circ} \mathrm{F}$

\begin{tabular}{|r|}
\hline 30.00 \\
\hline 29.98 \\
\hline 27.97 \\
\hline 26.13 \\
\hline 24.46 \\
\hline 22.95 \\
\hline 21.62 \\
\hline 20.46 \\
\hline 19.47 \\
\hline 18.66 \\
\hline 18.00 \\
\hline 17.42 \\
\hline 16.93 \\
\hline 15.40 \\
\hline 13.09 \\
\hline 10.98 \\
\hline 8.55 \\
\hline 6.55 \\
\hline 5.03 \\
\hline 3.82 \\
\hline 2.79 \\
\hline 1.96 \\
\hline 1.34 \\
\hline
\end{tabular}




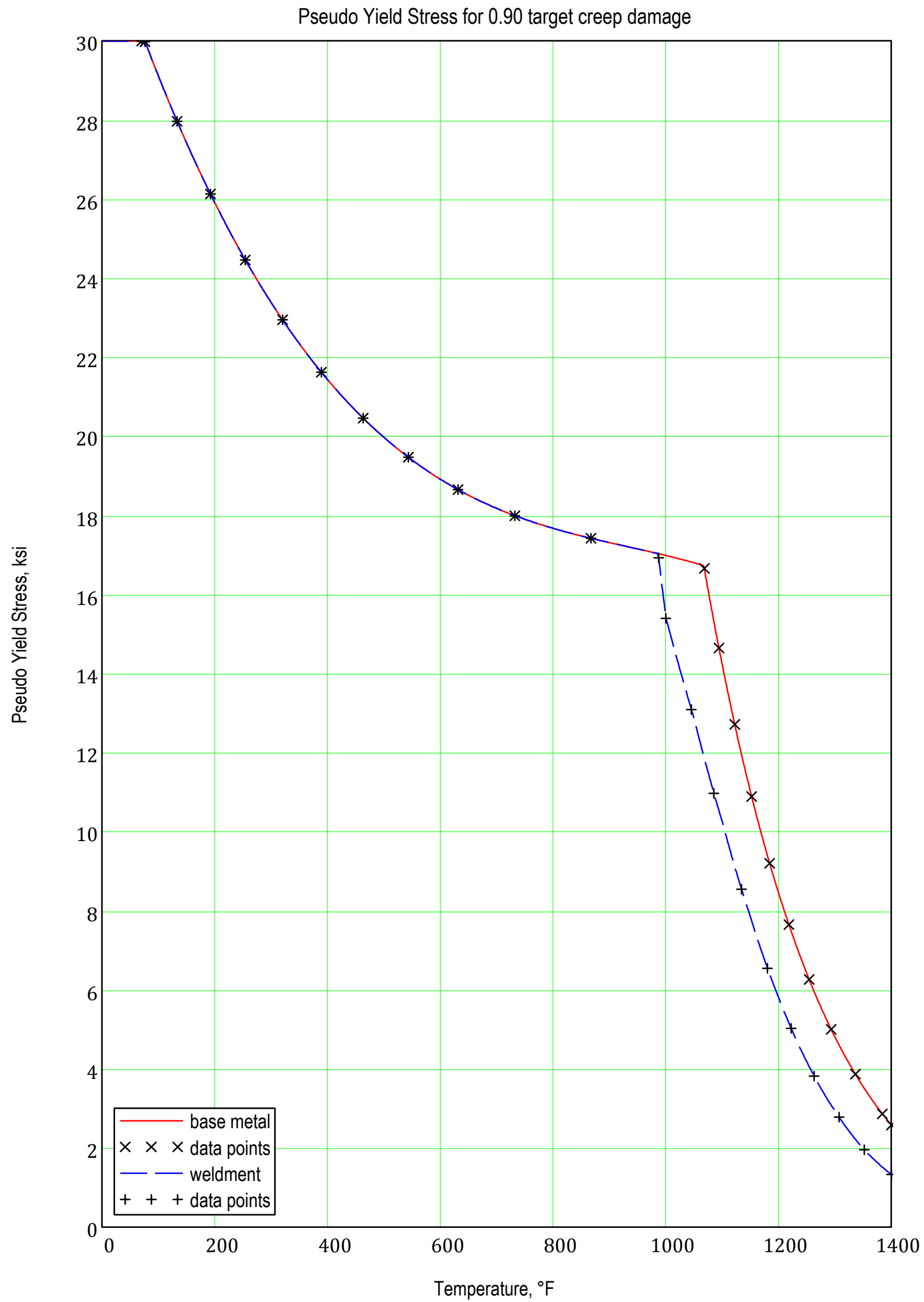




\section{Attachment 1 - Computer Files}

Input Files

\begin{tabular}{|c|c|}
\hline Input File Name & Description \\
\hline REP-B-AB-THM.inp & REP Base Metal Only Level A \& B Composite Cycle Heat Transfer Analysis \\
\hline REP-W-AB-THM.inp & REP with Weldment Level A \& B Composite Cycle Heat Transfer Analysis \\
\hline REP-B-AB-EPP.inp & $\begin{array}{l}\text { REP Base Metal Only Level A \& B Composite Cycle Elastic-Perfectly Plastic } \\
\text { Model }\end{array}$ \\
\hline REP-W-AB-EPP.inp & $\begin{array}{l}\text { REP with Weldment Level A \& B Composite Cycle Elastic-Perfectly Plastic } \\
\text { Model }\end{array}$ \\
\hline REP-B-AB-EPP-RST.inp & $\begin{array}{l}\text { REP Base Metal Only Level A \& B Composite Cycle Restart File for multiple } \\
\text { pseudo-cycles }\end{array}$ \\
\hline REP-W-AB-EPP-RST.inp & $\begin{array}{l}\text { REP with Weldment Level A \& B Composite Cycle Restart File for multiple } \\
\text { pseudo-cycles }\end{array}$ \\
\hline REP-B-AB-EPP-SL-\#.\#-0.00.inp & $\begin{array}{l}\text { REP Base Metal Only Level A \& B Composite Cycle Strain Limit Analysis } \\
\text { for target base metal inelastic strain \#.\#\# }\end{array}$ \\
\hline REP-W-AB-EPP-SL-\#.\#\#-\#.\#.inp & $\begin{array}{l}\text { REP with Weldment Level A \& B Composite Cycle Strain Limit Analysis } \\
\text { for target base metal inelastic strain \#.\#\#\% and weldment inelastic strain } \\
\# . \# \#\end{array}$ \\
\hline REP-B-AB-EPP-CF-\#.\#\#.inp & $\begin{array}{l}\text { REP Base Metal Only Level A \& B Composite Cycle Creep-Fatigue Analysis } \\
\text { for target creep damage \#.\#\# }\end{array}$ \\
\hline REP-W-AB-EPP-CF-\#.\#\#.inp & $\begin{array}{l}\text { REP with Weldment Level A \& B Composite Cycle Creep-Fatigue Analysis } \\
\text { for target creep damage \#.\#\# }\end{array}$ \\
\hline REP-thermal-AC.inp & REP Level A \& C Composite Cycle Heat Transfer Analysis \\
\hline REP-EPP-AC.inp & REP Level A \& C Composite Cycle Elastic-Perfectly Plastic Model \\
\hline REP-EPP-AC-N.inp & REP Level A \& C Composite Cycle Restart File for multiple pseudo-cycles \\
\hline REP-EPP-AC-\#.\#\#.inp & $\begin{array}{l}\text { REP Level A \& C Composite Cycle Strain Limit Analysis } \\
\text { for target inelastic strain \#.\#\# }\end{array}$ \\
\hline REP-EPP-AC-Sctb-Dck=\#.\#\#.inp & $\begin{array}{l}\text { REP Level A \& C Composite Cycle Creep-Fatigue Analysis } \\
\text { for target creep damage \#.\#\# }\end{array}$ \\
\hline SxT-\#.\#\#.csv & $\begin{array}{l}\text { Strain Limit Pseudo Yield Stress } \\
\text { for target inelastic strain \#.\#\% from Appendix B }\end{array}$ \\
\hline Sctb-\#.\#\#.csv & $\begin{array}{l}\text { Creep-Fatigue Pseudo Yield Stress in base metal } \\
\text { for target creep damage \#.\#\# from Appendix C }\end{array}$ \\
\hline Sctw-\#.\#\#.csv & $\begin{array}{l}\text { Creep-Fatigue Pseudo Yield Stress in weldment } \\
\text { for target creep damage \#.\#\# from Appendix C }\end{array}$ \\
\hline
\end{tabular}


Output Files

\begin{tabular}{|c|c|}
\hline Output File Name & Description \\
\hline REP-B-AB-THM.odb & $\begin{array}{l}\text { REP Base Metal Only Level A \& B Composite Cycle Heat Transfer Analysis } \\
\text { Results }\end{array}$ \\
\hline REP-W-AB-THM.odb & $\begin{array}{l}\text { REP with Weldment Level A \& B Composite Cycle Heat Transfer Analysis } \\
\text { Results }\end{array}$ \\
\hline REP-B-AB-EPP-SL-\#.\#-0.00-*.odb & $\begin{array}{l}\text { REP Base Metal Only Level A \& B Composite Cycle Strain Limit Analysis } \\
\text { Results for target base metal inelastic strain \#.\#\# at pseudo cycle * }\end{array}$ \\
\hline REP-W-AB-EPP-SL-\#.\#\#-\#.\#-".odb & $\begin{array}{l}\text { REP with Weldment Level A \& B Composite Cycle Strain Limit Analysis } \\
\text { Results for target base metal inelastic strain \#.\#\#\% and weldment inelastic } \\
\text { strain \#.\#\% at pseudo cycle * }\end{array}$ \\
\hline REP-B-AB-EPP-CF-\#.\#\#.inp & $\begin{array}{l}\text { REP Base Metal Only Level A \& B Composite Cycle Creep-Fatigue Analysis } \\
\text { Results for target creep damage \#.\#\# at pseudo cycle * }\end{array}$ \\
\hline REP-WB-AB-EPP-CF-\#.\#.inp & $\begin{array}{l}\text { REP with Weldment Level A \& B Composite Cycle Creep-Fatigue Analysis } \\
\text { Results for target creep damage \#.\#\# at pseudo cycle * }\end{array}$ \\
\hline REP-thermal-AC.odb & REP Level A \& C Composite Cycle Heat Transfer Analysis Results \\
\hline REP-EPP-AC-\#.\#\#- ${ }^{*}$.odb & $\begin{array}{l}\text { REP Level A \& C Composite Cycle Strain Limit Analysis Results } \\
\text { for target inelastic strain \#.\#\% at pseudo-cycle * }\end{array}$ \\
\hline REP-EPP-AC-Sctb-Dck=\#.\#\#- ${ }^{*}$. odb & $\begin{array}{l}\text { REP Level A \& C Composite Cycle Creep-Fatigue Analysis Results } \\
\text { for target creep damage \#.\#\# at pseudo-cycle * }\end{array}$ \\
\hline
\end{tabular}




\section{Comprehensive Report -- Page 110 of 112}

The following computer files directory listing lists the input/output files used in the analyses.

Computer Files Directory Listing

\begin{tabular}{|c|c|c|}
\hline Date & Time & File Name \\
\hline $05 / 12 / 2014$ & $04: 02 \mathrm{PM}$ & 121 REP-B-AB-EPP-CF-0.90.inp \\
\hline 05/09/2014 & $11: 17 \mathrm{PM}$ & 121 REP-B-AB-EPP-CF-1.00.inp \\
\hline 05/09/2014 & $08: 54 \mathrm{PM}$ & 16,056 REP-B-AB-EPP-RST.inp \\
\hline $05 / 27 / 2014$ & $11: 19$ AM & 126 REP-B-AB-EPP-SL-1.00-0.00.inp \\
\hline 05/09/2014 & $11: 15 \mathrm{PM}$ & 6,672,158 REP-B-AB-EPP.inp \\
\hline $05 / 09 / 2014$ & $09: 53 \mathrm{PM}$ & $6,775,510$ REP-B-AB-THM.inp \\
\hline 02/07/2014 & $04: 46 \mathrm{PM}$ & 83 REP-EPP-AC-0.40.inp \\
\hline 02/07/2014 & $04: 46 \mathrm{PM}$ & 83 REP-EPP-AC-0.60.inp \\
\hline 02/07/2014 & $04: 46 \mathrm{PM}$ & 83 REP-EPP-AC-1.00.inp \\
\hline $01 / 30 / 2014$ & $04: 32 \mathrm{PM}$ & 13,501 REP-EPP-AC-N.inp \\
\hline $01 / 31 / 2014$ & $06: 40 \mathrm{PM}$ & 90 REP-EPP-AC-Sctb-Dck=1.00.inp \\
\hline $01 / 30 / 2014$ & $03: 56 \mathrm{PM}$ & 5, 784,459 REP-EPP-AC.inp \\
\hline $10 / 29 / 2013$ & $03: 42 \mathrm{PM}$ & 5,873,427 REP-thermal-AC.inp \\
\hline $05 / 15 / 2014$ & $08: 34 \mathrm{PM}$ & 121 REP-W-AB-EPP-CF-0.90.inp \\
\hline $05 / 15 / 2014$ & $02: 43 \mathrm{PM}$ & 121 REP-W-AB-EPP-CF-1.00.inp \\
\hline $05 / 09 / 2014$ & $08: 54 \mathrm{PM}$ & 16,056 REP-W-AB-EPP-RST.inp \\
\hline $05 / 27 / 2014$ & $01: 12 \mathrm{PM}$ & 126 REP-W-AB-EPP-SL-1.00-0.50.inp \\
\hline $05 / 10 / 2014$ & $07: 45 \mathrm{AM}$ & $11,177,192$ REP-W-AB-EPP.inp \\
\hline $05 / 09 / 2014$ & $09: 53 \mathrm{PM}$ & $11,351,188$ REP-W-AB-THM. inp \\
\hline $05 / 15 / 2014$ & $02: 02 \mathrm{PM}$ & 547 sctb-0.90.csv \\
\hline $05 / 15 / 2014$ & $02: 02 \mathrm{PM}$ & 550 Sctb-0.95.csv \\
\hline $05 / 15 / 2014$ & $02: 02 \mathrm{PM}$ & 548 sctb-1.00.csv \\
\hline $05 / 15 / 2014$ & $02: 02 \mathrm{PM}$ & 547 Sctw-0.90.csv \\
\hline $05 / 15 / 2014$ & $02: 02 \mathrm{PM}$ & 546 Sctw-0.95.csv \\
\hline $05 / 15 / 2014$ & $02: 02 \mathrm{PM}$ & 549 Sctw-1.00.csv \\
\hline $12 / 23 / 2013$ & $08: 43 \mathrm{AM}$ & 917 SxT-0.40.csv \\
\hline $05 / 27 / 2014$ & $10: 46 \mathrm{AM}$ & 868 SXT-0.50.CSV \\
\hline $12 / 23 / 2013$ & $08: 52 \mathrm{AM}$ & 823 SXT-0.60.CSV \\
\hline $05 / 27 / 2014$ & $10: 46 \mathrm{AM}$ & 748 SXT-1.00.CSV \\
\hline 06/02/2014 & $06: 55 \mathrm{PM}$ & $6,138,226,708$ REP-B-AB-EPP-CF-0.90-3.odb \\
\hline 06/02/2014 & $05: 13 \mathrm{PM}$ & $5,055,790,768$ REP-B-AB-EPP-SL-1.00-0.00-2. odb \\
\hline 05/09/2014 & $10: 37 \mathrm{PM}$ & $81,595,600$ REP-B-AB-THM. odb \\
\hline $06 / 03 / 2014$ & $02: 00 \mathrm{PM}$ & $9,357,198,168$ REP-W-AB-EPP-CF-0.95-3.odb \\
\hline $06 / 02 / 2014$ & $05: 13 \mathrm{PM}$ & $7,705,960,772$ REP-W-AB-EPP-SL-1.00-0.50-3.odb \\
\hline 05/09/2014 & $10: 49 \mathrm{PM}$ & $121,749,696$ REP-W-AB-THM.odb \\
\hline
\end{tabular}




\section{Calculation Verification}

Verifier: $\mathrm{n} / \mathrm{a}$

\begin{tabular}{|c|c|}
\hline Verification Method & Verification Scope \\
\hline$\square \quad$ Line-by-Line Review & Entire calculation. \\
\hline$\square \quad$ Alternate Calculations & \\
\hline
\end{tabular}

Line-by-Line Review Checklist

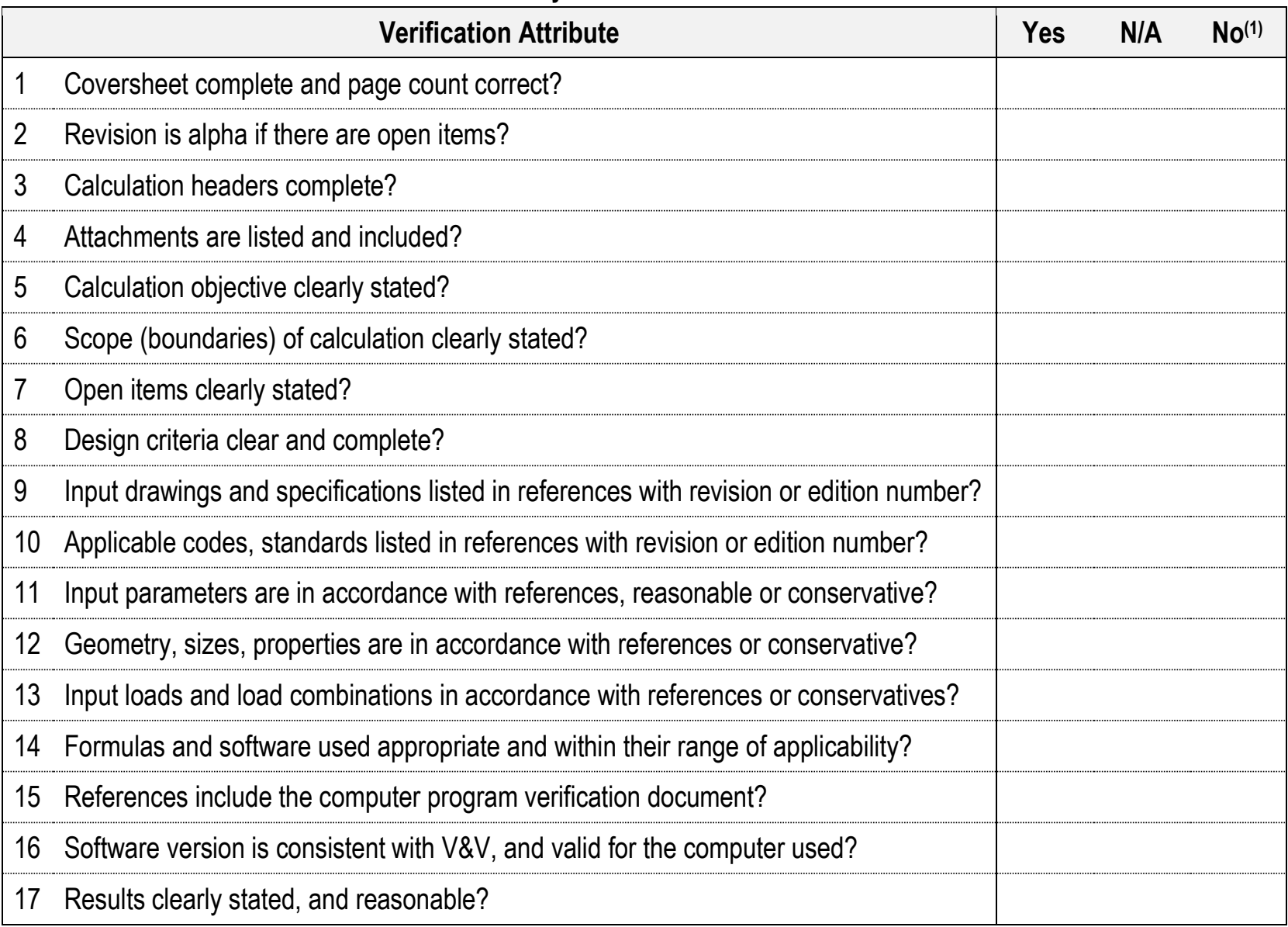
Notes:

(1) If "No" is selected then an explanation is provided in the following verifier comments.

Verifier Comments (If Necessary)

\begin{tabular}{|l|c|}
\hline$\# \quad$ Location Comment \\
\hline \\
\hline
\end{tabular}




\section{Record of Revisions}

\begin{tabular}{|c|c|c|}
\hline Revision & Date & Description of Changes \\
\hline 0 & $10 / 30 / 2013$ & Initial issue. \\
\hline 1 & $1 / 8 / 2014$ & $\begin{array}{l}\text { Updated section } 2 \text { Summary. } \\
\text { Added Strain Limit Pseudo Yield Stress to Section } 3.2 \text {. } \\
\text { Split pressure and mechanical load time history amplitudes into step-based amplitudes } \\
\text { in Section 3.6.3. } \\
\text { Added methodology for evaluating multiple cycles to Section 4.1. } \\
\text { Added Strain Limit Methodology to new Section } 4.1 .1 \\
\text { Added Strain Limit Evaluation to new Section 4.3.2 } \\
\text { Fixed time value typos in Table 3.6.3-1. } \\
\text { Added new Table 3.6.3-2 to determine total time duration of high temperature service. } \\
\text { Added step end time and maximum temperature change to Table 4.2-1 and 4.2-20 } \\
\text { Added state descriptions to Figure 4.3.1-1 and 4.3.1-2. } \\
\text { Added new Figures 4.3.2-1 through 4.3.2-4 } \\
\text { Added new Appendix B Pseudo Yield Stress for Strain Limit Analysis }\end{array}$ \\
\hline 2 & $6 / 5 / 2014$ & $\begin{array}{l}\text { Complete revision to include two models, one without a weldment including only base } \\
\text { metal and one with a weldment explicitly modeled. } \\
\text { Added Creep-Fatigue evaluation. } \\
\text { Updated for latest Code Cases in the Design Specification [Ref. 1]. }\end{array}$ \\
\hline 3 & $6 / 23 / 2014$ & $\begin{array}{l}\text { Updated fatigue evaluation. } \\
\text { Removed references to deliverable items. }\end{array}$ \\
\hline
\end{tabular}

